\title{
THE MIDWIFE OF TRUTH: THE NATURE OF IRONY AND A RATIONALE FOR ITS PREVALENCE IN THE GOSPEL OF JOHN.
}

\section{BY}

BRUCE W. BELL

\begin{abstract}
A thesis
submitted to the Victoria University of Wellington in fulfilment of the requirements for the degree of Doctor of Philosophy
\end{abstract}

Victoria University of Wellington (2014) 
ABSTRACT

The Gospel of John is renowned for its pervasive use of irony. While this phenomenon is widely recognized by scholars, there have been only a few attempts to explain the "how" of Johannine irony and no meaningful attempt to explain its "why." The last major treatment of the topic was by Paul Duke in his 1985 work, Irony in the Fourth Gospel, which provides an account of how Johannine irony works through an analysis of local and extended ironies. Other examinations, such as Gail O'Day's Revelation in the Fourth Gospel in 1986, explore irony as a corollary of some other thematic concern. The reticence of scholars to delve deeper into the nature of Johannine irony is understandable given that as Duke puts it, irony laughs at all pretensions, especially the pretension of claiming to have grasped irony.

This study undertakes the demanding but necessary task of describing irony to a level that allows meaningful engagement with ironic texts, while accepting that it remains ultimately indefinable. Particular attention is paid to historical shifts of understanding of the nature of irony and the implications this has for appreciating irony at a conceptual level. From a survey of the Johannine scholarship, a comprehensive but non-exhaustive overview of the Fourth Gospel's use of irony is derived. No previous work has attempted to approach the subject in this way. The main advantage of doing so is that it allows for the identification of broad patterns of irony and the way it functions in the narrative. This in turn provides a framework for proceeding to an examination of particular texts and the identification of a possible rationale.

The present study assesses several hypotheses to explain why the author of the Fourth Gospel makes such sustained use of irony. The preferred hypothesis is that it is intrinsically linked to a predominant Johannine theme of alètheia (truth). Drawing on the conceptual link between irony and truth, it argues that the truth theme is a deliberate literary strategy employed by the author to entice the reader to seek certain propositional truths within the narrative. This ultimately serves the author's desire to evoke revelation and response in line with the Gospel's purpose statement in 20:31.

The argument that irony serves the Johannine truth theme is tested with particular reference to the Prologue (1:1-18) and the Passion Narrative (chapters 18-19). The study establishes that irony serves as the link between appearance and reality in the narrative. Its subtle and engaging qualities make irony the most suitable vehicle to testify to the Gospel's propositional statements in a manner that fulfils the author's stated Christological (a revelation of Jesus' true identity) and soteriological (a response that leads to salvation) purposes. 


\section{ACKNOWLEDGEMENTS}

I wish to recognise the profound debt I owe Professor Chris Marshall for his wisdom and encouragement during the completion of this dissertation. Without his advice this study, which became a longer journey than originally anticipated, would have been a much lesser work and may not have been completed at all. His timely insights saved me on numerous occasions from my own over-ambition and passion for this topic, thereby keeping the project manageable. My thanks also go to Dr Geoff Troughton for his valuable input at a crucial juncture in the preparation of this manuscript. I am profoundly grateful for the support of initially The Rock Church and later The Olive Tree Church. Without their generosity in allowing me time off to work on this project, it would have been impossible. The Olive Tree in particular, demonstrated remarkable forbearance and kindness in tolerating my dual focus at times, particularly as this manuscript came closer to completion. I wish to acknowledge my parents, Bill and Annette Bell, who have always stood by me in all of my undertakings. I deeply regret that my father passed away shortly before he saw this one finished. My uncle, Dr Alan Roberts, provided sage advice on the process of thesis writing that made the exercise much more enjoyable and productive than it otherwise would have been. I thank my children, Rebecca, Erin and Matthew for their willingness to accept the constraints on my time as I frequently burned the candle at both ends. Above all, I want to recognise the sacrifice and unstinting support of my wife, Lee, to whom I dedicate this work. 


\section{Contents}

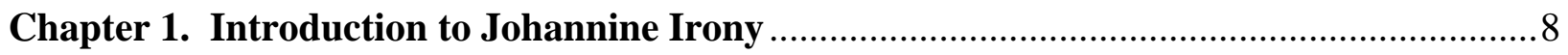

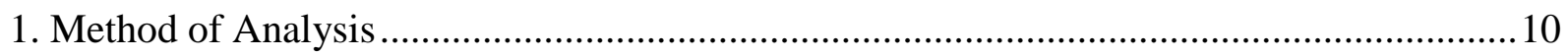

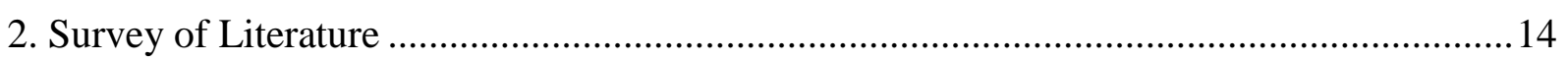

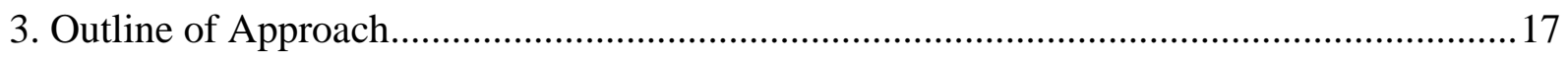

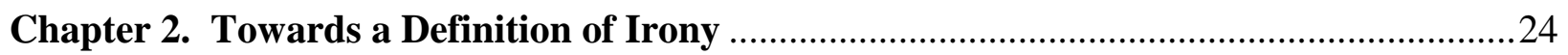

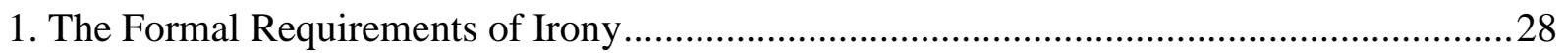

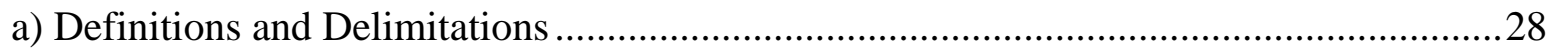

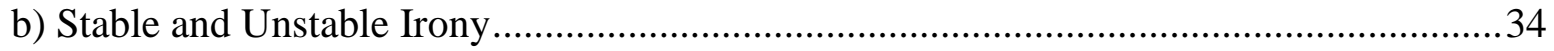

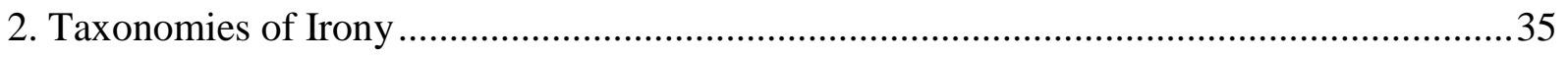

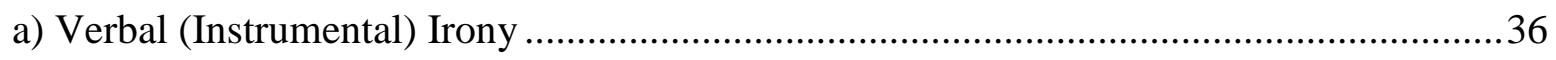

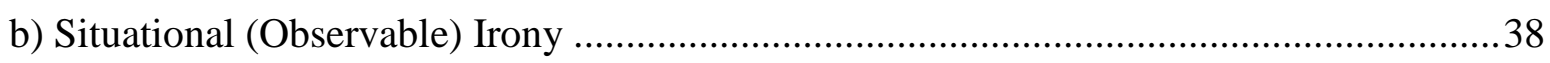

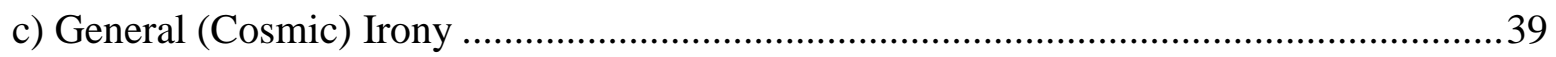

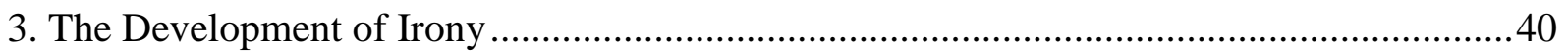

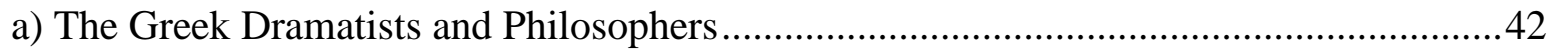

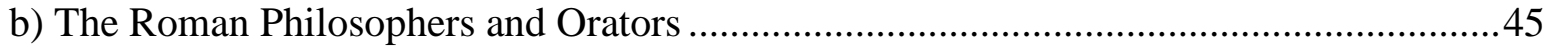

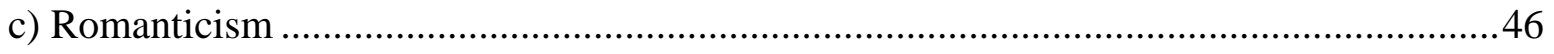

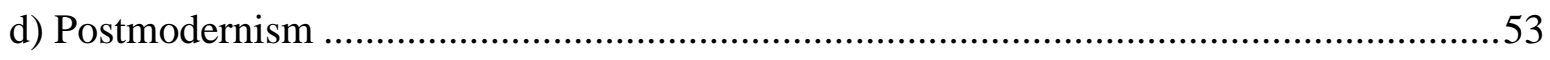

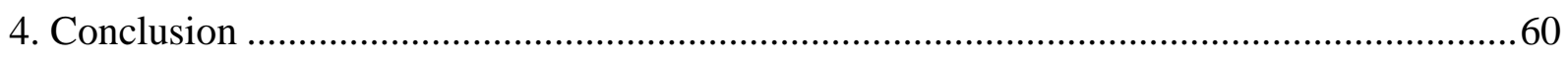

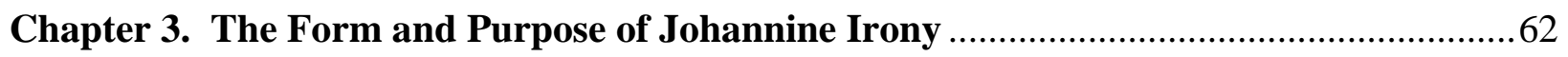

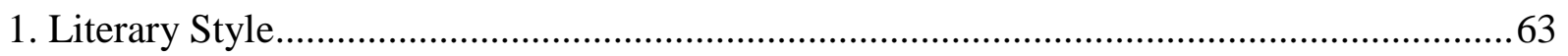

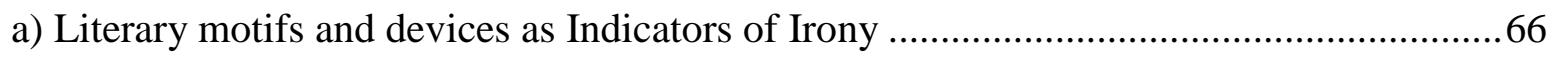

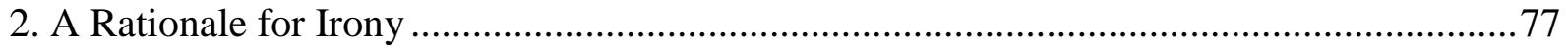

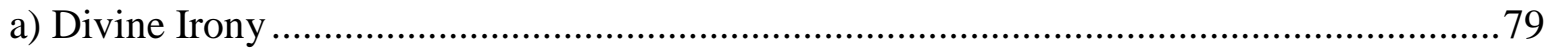

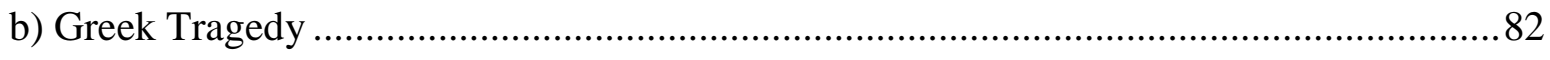

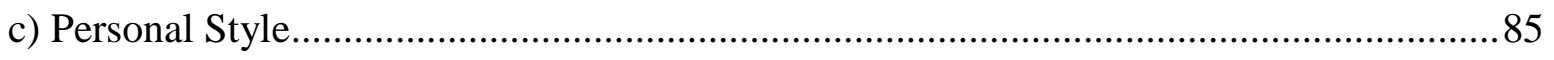

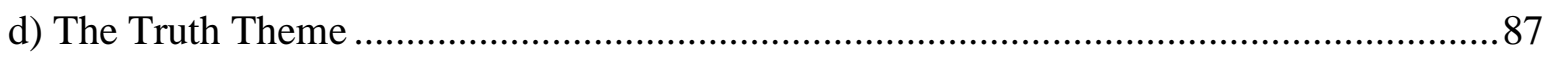

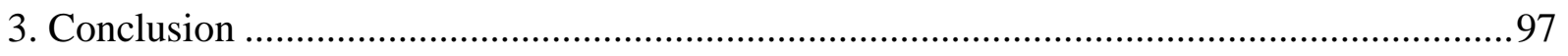

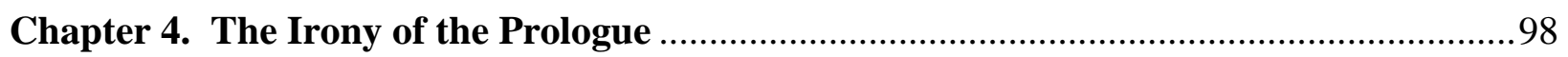

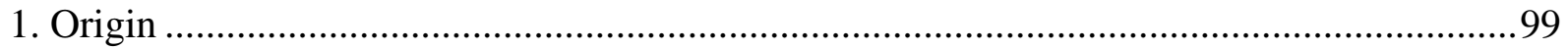

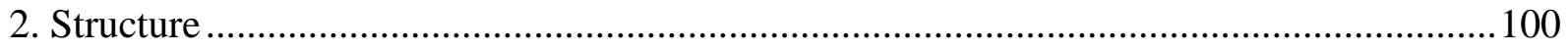

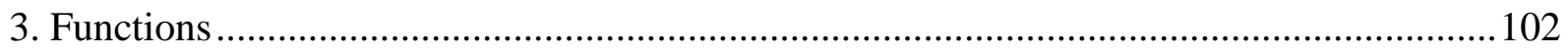

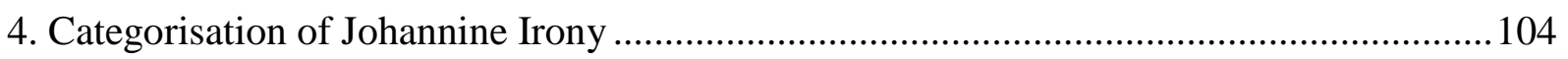


5. Implications for Johannine Irony and the Prologue ....................................................... 107

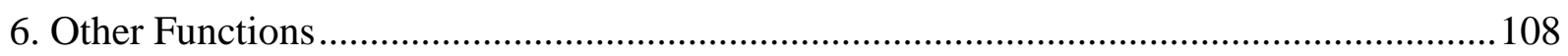

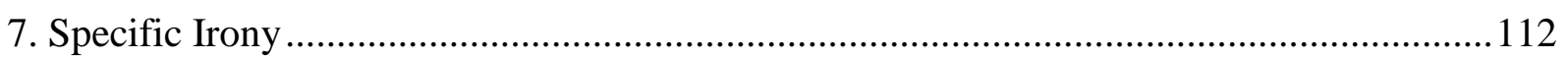

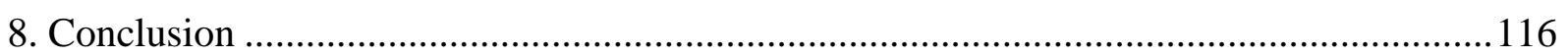

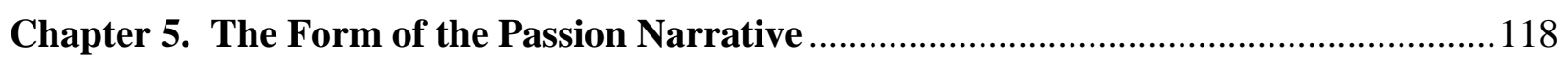

1. Relationship to Historicity and the Synoptic Gospels ....................................................121

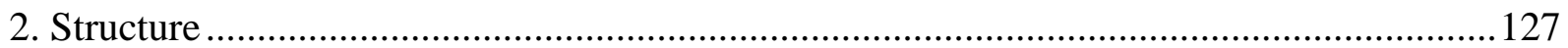

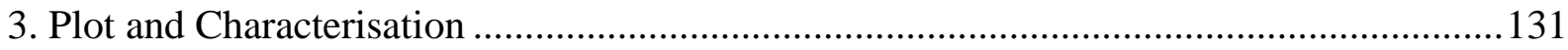

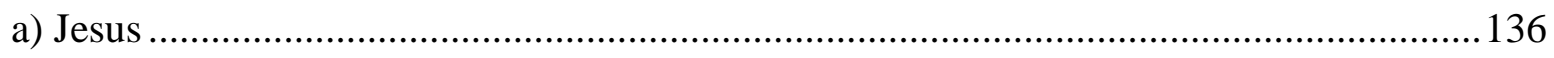

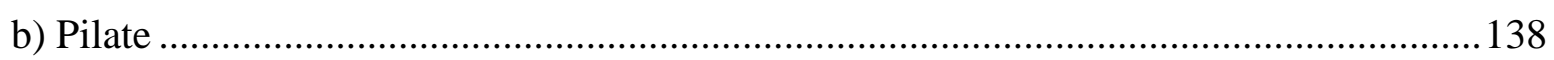

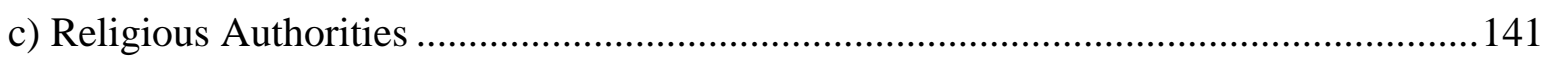

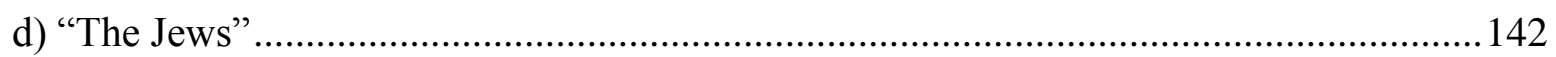

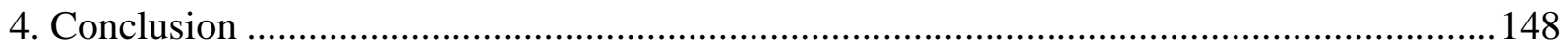

Chapter 6. The Irony of the Passion Narrative ............................................................... 150

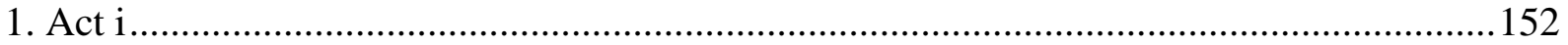

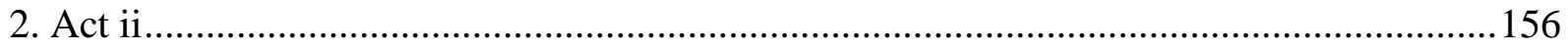

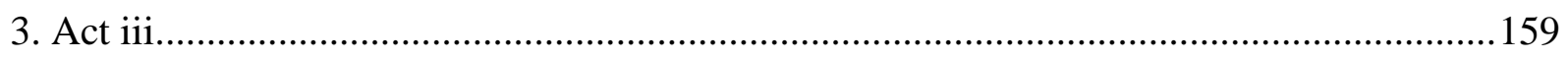

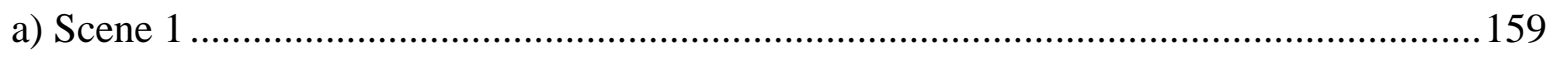

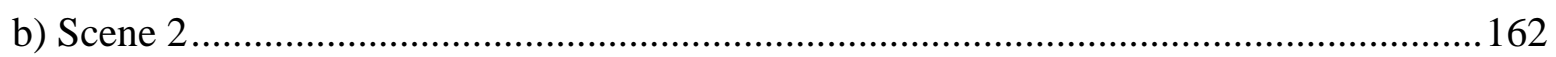

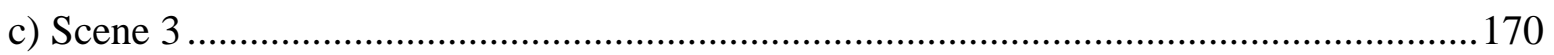

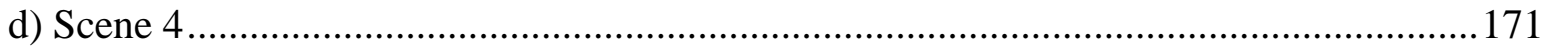

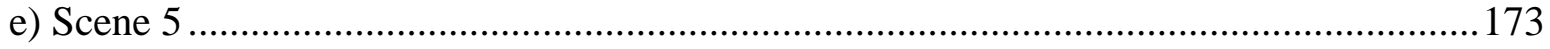

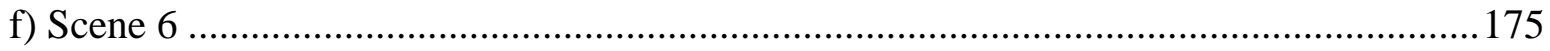

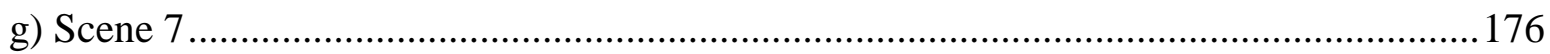

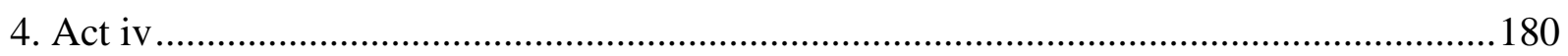

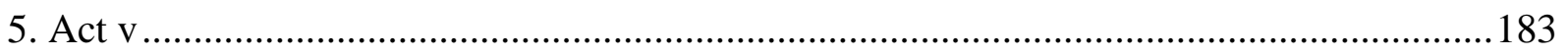

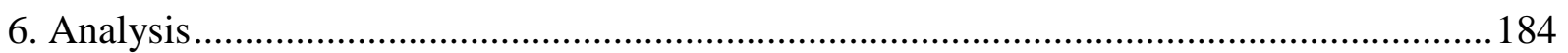

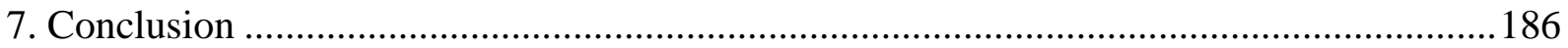

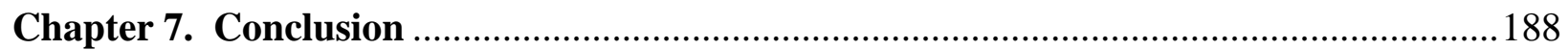

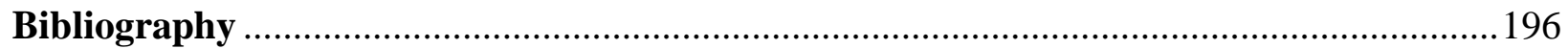




\section{Chapter 1}

\section{Introduction to Johannine Irony}

The Fourth Gospel well deserves its reputation as the most enigmatic of the Christian Gospels; by turns, it delights and perplexes. It possesses unique features and is notoriously dissimilar to its closest literary contemporaries, the Synoptic Gospels. The casual reader finds within its simple narrative spiritual insights conveyed with a verve and sagacity that has made it a perennial favourite with adherents of the Christian faith. Yet scholars discern within it a sophisticated narrative structure distinguished by double layers of meaning, vivid symbolism, profound prose and an impressive array of rhetorical devices used to potent effect.

One of the more engaging rhetorical devices, and a major contributor to the Gospel's enigmatic reputation, is its extensive use of irony. That the Fourth Gospel is replete with irony is an oft made but seldom explored observation. The Gospel's earliest readers would have been well attuned to its many ironies since irony was a common rhetorical and literary device in GrecoRoman culture. ${ }^{1}$ Scholarly commentators, as early as Martin Luther, have noted its prominence. ${ }^{2}$ Regrettably, albeit for understandable reasons to be explored in Chapter 2, "the standard commentaries on John all include entries for irony in their indices but make little or no effort to assess either the distinctiveness of Johannine irony or the theological significance of this literary technique.",3

The subtle and sophisticated nature of irony is one of the reasons why this Gospel has been especially beloved by readers. The author reaches out to the reader via the inherent inclusivity of irony. ${ }^{4}$ Through irony, the author creates a dual level narrative, which invites the attentive reader to step into the inner world of the narrative to share in the Gospel's deeper revelation of truth. This is with the express intention that the author's truth may ultimately become theirs:

\footnotetext{
${ }^{1}$ Craig S. Keener, The Gospel of John: A Commentary (Peabody: Hendrickson, 2003), 1.223.

2 “In seiner Übersetzung des Johannesevangeliums macht Luther zu der Frage des Pilatus 'was ist Wahrheit?' die Anmerkung: 'Ironia est. Wilt du von Wahrheit redden, so bist du verloren." Wilhelm Büchner "Über den Begriff der Eironeia” Hermes: Zeitschrift für klassische Philologie-einzelschriften 4 (1941), 358.

${ }^{3}$ Gail R. O’Day, Revelation in the Fourth Gospel (Philadelphia: Fortress, 1986), 3.

4 "Never is the reader the victim of irony. On the contrary, inclusion is the strongest effect of John's irony." Alan Culpepper, Anatomy of the Fourth Gospel: A Study in Literary Design (Philadelphia: Fortress, 1983), 179.
} 
"But these are written so that you may come to believe that Jesus is the Messiah, the Son of God, and that through believing you may have life in his name" (20:31). Accordingly, the author of the Fourth Gospel first and foremost invites the reader on a journey of faith - often by witnessing the successes and failures of the Gospel's characters on their journeys through the narrative.

The author's invitation is gentle and beguiling. It is itself clothed in sublime irony and delicious bursts of humour, amidst the tragedy of the truth rebuffed with murderous consequences. Indeed, given John's portrayal of the chief protagonist as the Logos (that is the personified expression $)^{5}$ of God, this rejection of Jesus assumes such catastrophic proportions that it can only be comfortably conveyed with the oblique approach irony affords. Thus the author regularly asks questions but does not pause for the answer; his overarching concern is not to reveal what the narrative's characters think but to provoke the reader to reflect. Accordingly, irony often coincides with these unanswered questions, or some other indirect signifier, as the author reveals a previously concealed truth in a manner readily discernible by the reader.

An understanding of Johannine irony is essential to fully comprehend the Gospel because of what O'Day calls "the intrinsic relationship of narrative mode and theological claim."6 However, Duke cautions against expecting a conclusive understanding of the device because: "The subject simply will not stop moving. Irony, it should be remembered, laughs at all pretensions, especially the pretension of claiming to have grasped irony."7 Culpepper proscribes any attempt at exhaustive analysis of the Gospel's ironies on the basis that it would constitute an act of vandalism. ${ }^{8}$ Thus, as will be progressively revealed during the course of this study, Johannine irony is similar to the Gospel itself; a journey of discovery that individuals must undertake for themselves. Nonetheless, while the concept of irony has inherent ambiguity there is sufficient common ground to permit worthwhile dialogue on its meaning. As with any rhetorical device, irony only exists to advance the author's literary objectives. ${ }^{9}$ These overarching purposes provide a window into the Gospel's theology, as “in the Fourth Gospel theology is irony." 10 In this study, I intend to engage not primarily with the functionality of

\footnotetext{
${ }^{5}$ Walter Bauer, A Greek-English Lexicon of the New Testament and Other Early Christian Literature (Chicago: Chicago University Press, 2000), 601.

${ }^{6}$ O'Day, Revelation, 114.

${ }^{7}$ Paul Duke, Irony in the Fourth Gospel (Atlanta: John Knox, 1985), 4.

${ }^{8}$ Culpepper, Anatomy, 151-152

9 “John's irony is employed only to serve a larger purpose." Duke, Irony, 3.

${ }^{10}$ George W. MacRae, "Theology and Irony in the Fourth Gospel," in The Gospel of John as Literature: An Anthology of Twentieth Century Perspectives, ed. Mark Stibbe (Leiden: Brill, 1993), 89.
} 
Johannine irony (the "how"), which has received previous consideration, but with the unexplored question of the rationale or purpose for Johannine irony (the "why").

\section{Method of Analysis}

This study will predominantly employ the tools of narrative criticism to investigate the Gospel and its attendant ironies. ${ }^{11}$ Until comparatively recently, historical-critical approaches dominated Johannine studies. ${ }^{12}$ The aim was to distil the various traditions, influences and sources behind the composition of the Gospel to rediscover "the world behind the text, so that there be no abuse of the world in the text."13 However, the result of such an approach was often to reduce the Gospel to a bricolage of other material, interpolation and aporia. The extant Johannine narrative was eclipsed by a focus on its perceived sources.

In the later decades of the twentieth century, scholars began to recognise that the burgeoning field of literary theory could assist in rediscovering the Gospel as a literary whole. Alan Culpepper's work in the early 1980s is universally regarded as pivotal in establishing narrative criticism within the broader milieu of Johannine studies. He did not deny the value of the historical-critical approach, which he described as "fruitful and exciting."14 However, he noted that it "neglects the essential unity of the most literary of the gospels, and overlooks the importance of the relationship between text and reader."15 Culpepper's compelling presentation of the Gospel as a narrative with a strong stylistic unity and a great deal of internal consistency demonstrated that the historical-critical method had consistently over-reached the text. As Carson explains, "However insightful some of these studies may be, at times it is necessary not only to question the source-critical methods, but to demonstrate the remarkable fragility of the

\footnotetext{
${ }^{11}$ Aune defines narrative criticism as "a type of formalist literary criticism which typically approaches the biblical texts as a unified whole (i.e., as a closed, internally consistent story-world), emphasizing plot, conflict, character, setting, event, narrator, point of view, standards of judgment, the implied author, ideal reader, style and rhetorical techniques." David E. Aune, The Westminster Dictionary of New Testament and Early Christian Literature and Rhetoric (Louisville: John Knox, 2003), 315.

${ }^{12}$ Such as those by C. K. Barrett, The Gospel According to St John 2nd ed. (Cambridge: University Press, 1978); Jürgen Becker, Das Evangelium Nach Johannes, Ökumenisscher Taschenbuch-Kommentar Zum Neuen Testament 4?1-2, 2 vols. (Wursburg: Gütersloher Verlagshaus Gerd Mohn, 1991); Raymond E. Brown, The Gospel According to St John, Anchor Bible Commentary 29/29A, 2 vols. (New York: Doubleday, 1966); Rudolf Bultmann, The Gospel of John: A Commentary (Philadelphia: Westminster, 1964); Ernst Haenchen, A Commentary on the Gospel of John, Hermeneia, eds. Robert W. Funk and Ulrich Busse 2 vols. (Philadelphia: Fortress, 1984); Rudolf Schnackenburg, The Gospel According to St John. 3 vols. (New York: Crossroad, 1968); et al.

${ }^{13}$ Francis J. Moloney, The Gospel of John, Sacra Pagina 4, (Collegeville: Liturgical Press, 1998), 13.

${ }^{14}$ Culpepper, Anatomy, 4.

15 Ibid.
} 
underlying assumptions... comprehensive source theories are unacceptably speculative, and too frequently end up contradicting the only textual evidence we actually have."16

Narrative criticism enables us to recover the unity of the text and appreciate its literary features, plot and characters without it being sectionalised according to speculative sources. It also brings differing perspectives to the exploration of Johannine discourse. This methodology allows for the reclaiming of biblical texts, as long as the approach taken integrates the literary and the theological. ${ }^{17}$ This is particularly true in examining specific rhetorical devices, which are marginalised when studied in isolation. By examining the narrative as a unified whole, rhetorical devices have the potential to reveal the author's broader literary intentions and their overarching theological aims.

Another contribution of narrative criticism is its capacity to elucidate the relationship between the author, the reader and the text. Authors invariably write with a purpose and with some conception of a likely audience. The author of the Fourth Gospel expressly relates his purpose to evoking a response from his audience: "But these are written so that you may come to believe" (20:31). A clear understanding of the dynamics of the relationship between reader and text is therefore imperative. Notwithstanding that literary critics use a "bewildering array of terms to describe the reader of a text and the relationship of the reader to the text: an implied reader, informed reader, ideal reader, flesh-and-blood reader, super-reader, mock reader, extrafictional reader, and resisting reader, to name a few." 18

There are three main approaches to identifying the reader's position in relation to the text. ${ }^{19}$ First, the reader is understood as a construct of the text. ${ }^{20}$ This reader is entirely the product of authorial intention, via the author's signals in the text. Second, the reader possesses total dominance over the meaning of text. ${ }^{21}$ This approach is routinely criticised for being overly

\footnotetext{
${ }^{16}$ Donald A. Carson, The Gospel According to John, Pillar New Testament Commentary, (Leicester: IVP, 1991), 44.

${ }^{17}$ O’Day, Revelation, 47-48. Klein suggests that narrative critics open themselves up to censure if they "depreciate the religious value of a text in favour of its aesthetics, even if sometimes this is done to correct a past imbalance in the other direction." William Klein, Craig Blomberg, and Robert Hubbard, Introduction to Biblical Interpretation (Nashville: Thomas Nelson, 2004), 71.

${ }^{18}$ James L. Resseguie, Narrative Criticism of the New Testament (Grand Rapids: Baker, 2005), 30.

${ }^{19}$ In keeping with the overall vagueness in terminology, all three may be designated individually or corporately as reader-response criticism. For this schema, cf. Resseguie, Narrative Criticism, 30-33.

${ }^{20}$ E.g. Gerald Prince, "Introduction to the Study of the Narratee," in Reader-Response Criticism: From Formalism to Post-Structuralism, ed. Jane Tompkins (Baltimore: John Hopkins University Press, 1980), 7-25.

${ }^{21}$ This approach is often paired with Post-modern and Post-Structuralist interpretations of texts.
} 
subjective to the point of dissociating authorial intent and even the text itself. $^{22}$ The third approach is that of the "implied" reader, who neither dominates nor is dominated by the text. This reader instead interacts with the text, attempting to fill the gaps left by the author in order to produce a consistent and coherent meaning. The author thereby creates expectations in the implied reader as the narrative journey unfolds which may be fulfilled or frustrated. This third approach strikes a constructive balance between the two previous approaches and is preferred in this study.

Although the terminology that accompanies this approach can become convoluted, the valuable distinction warrants the semantic intrusion. The original author and eventual reader (known as the "real author" and "real reader") are distinguished from the literary author and literary reader (known as the "implied author" and "implied reader"). The real author is the historical figure behind the text whereas the implied author is the sum of the literary choices made by the real author in the narrative. ${ }^{23}$ The implied author is therefore always discoverable from the text whereas the real author may not be. This allows a discussion of narrative elements such as the use of plot devices, characters, settings, time, and rhetorical devices without having to speculate as to the historical author or sources behind the document. ${ }^{24}$ For the purposes of this study, the term "author" will always refer to the implied author unless otherwise indicated. ${ }^{25}$

Similarly, the implied reader is one who realistically responds to the narrative strategies and conforms to the reasonable expectations of the author while still maintaining a degree of freedom. Accordingly in the Fourth Gospel, the implied reader is understood to comprehend Koine Greek (so that the double meaning of words are appreciated), Jewish messianic categories, religious customs and the geographical and political context of first century Palestine. $^{26}$ The term "reader" will always apply to the implied reader, unless a contrary intention is indicated.

\footnotetext{
${ }^{22}$ Later in this Chapter and in Chapter 3 two examples of this approach in a Johannine context will be briefly considered (Staley and Thatcher).

${ }^{23}$ For this reason sometimes the narrator can be almost indistinguishable from the implied author, as occurs in the Fourth Gospel.

${ }^{24}$ This is helpful in situations such as the Fourth Gospel were authorship is uncertain. The use of an implied author means that term "author" can be utilised in a meaningful way without entering into a tangential and time consuming consideration of whether the real author is John the Disciple, John the Elder, a Johannine community or any other proposed alternative.

25 This includes occasional references to the author as "John," which also reference the implied author unless a contrary intention is indicated. As Tovey notes traditionally the titles "John" and "the Evangelist" have been utilised in a manner similar to the implied author. Derek Tovey, Narrative Art and Act in the Fourth Gospel (Sheffield: Sheffield Academic, 1997), 36-37.

${ }^{26}$ Raymond E. Brown, An Introduction to the Gospel of John (New York: Doubleday, 2003), 36.
} 
It should be recognised that narrative criticism has limitations and has been critiqued on several counts. ${ }^{27}$ Overemphasis on the text as a purely literary work of art can be as problematic as an overemphasis on sources. For example, Carson takes Culpepper to task for the category error of treating a Gospel as a modern novel. He notes that if the Gospel's themes "are given force within some narrative framework other than the novel, the shape of the discussion inevitably swings to some consideration of the kind and quality of the history purportedly being told and therefore to truth claims - and not just the shape of the story being narrated." ${ }^{28}$ This observation is relevant to the central thesis of this study, which will focus on the relationship between the Gospel's approach to truth and its approach to irony.

Carson further observes that novels portray universal truth, which is depicted through characters representative of the human condition in general terms. Whereas, the Gospel presents specific truths and its characterisation of Jesus is unashamedly unique rather than representative. ${ }^{29}$ Consequently, even if the Gospel contains historical errors it is still historiography and should be treated as such. ${ }^{30}$ Increasingly, many narrative critics accept that it is important to acknowledge the Gospel's claims to historical reliability and eyewitness testimony $(19: 35 ; 20: 24)$; otherwise it will "open the door to excessive subjectivity." 31 Thus, Stibbe argues that the Fourth Gospel must be considered against its Hebraic and Greco-Roman background "and not against the background of the modern novel. As it stands, Culpeper's method is fundamentally anachronistic." 32 In addition, many scholars stress the need for narrative criticism to integrate the literary and theological elements of the Gospel. ${ }^{33}$

The need for an integrated approach explains why this study will employ predominantly, but not exclusively, a narrative critical methodology. Narrative criticism will be used to view the text as a whole, to facilitate a close reading of its complexities and nuances of meaning, and to examine

\footnotetext{
${ }^{27}$ As Resseguie notes, one of its earliest forms, known as new criticism, is "now discredited for its excesses and considered passé among literary critics.” Resseguie, Narrative Criticism, 21.

${ }^{28}$ Carson, John, 63-64. Notably Duke accepts this critique of his mentor in his introduction. Duke, Irony, 2.

29 "In short, the Fourth Evangelist is interested in presenting certain truths to certain people, and he exercises the preacher's prerogative of shaping his message accordingly." Carson, John, 47.

${ }^{30}$ Ibid., 66.

${ }^{31}$ Colin G. Kruse, John, Tyndale New Testament Commentaries 4, (Leicester: IVP, 2003$), 37$.

${ }^{32}$ Mark W. G. Stibbe, John as Storyteller: Narrative Criticism and the Fourth Gospel (Cambridge: Cambridge University Press, 1992), 11.

33 See O'Day, Revelation, 47; Furthermore, Stibbe notes that "One of the things which has been omitted by narrative critics is a careful consideration of the relationship between theological purpose and the narrative form." Stibbe, Storyteller, 12.
} 
the effects of the narrative on the reader. ${ }^{34}$ At the same time due cognisance will be taken of the text's historical, grammatical and theological elements. In short, narrative criticism will be combined with other complementary approaches required to do justice to its genre as "Gospel.",35 Brown observes that "when seen as complementary enrichment rather than rejection or cataclysmic replacement, [narrative critical] approaches have filled out Johannine study in a fascinating way." ${ }^{36}$ I will not engage with the narrative holistically, but rather through the sole perspective of the rhetorical device of irony. ${ }^{37}$ This means that I will only interact with other aspects of the narrative, such as plot, setting, composition (structure and form), characterisation, the narrator, theme, and other rhetorical devices to the extent that they impact on or illuminate the author's use of irony in the narrative.

\section{Survey of Literature}

In 1971 Lindars commented of the Johannine corpus, "The literature on it is immense, and even a scholar who devotes all his [sic] time to the study of the New Testament cannot hope to keep up with it." 38 Forty years later Moloney noted that "the situation has not eased." 39 The comparatively short but distinguished list of works on Johannine irony falls into three discernible periods. The first phase predated the rise of narrative criticism in the late 1970s and early 1980s. ${ }^{40}$ A handful of monographs on Johannine irony anticipated literary studies of the Fourth Gospel: Clavier; ${ }^{41}$ Leroy; $^{42}$ Wead; $^{43}$ and MacRae. ${ }^{44}$ Of these MacRae's work had the greatest impact. He connected Johannine irony with the author's theological purposes, noting in

\footnotetext{
${ }^{34}$ Resseguie, Narrative Criticism, 38-40.

35 Stibbe offers an example of an integrated narrative hermeneutic in which both synchronic and diachronic elements are present. Stibbe, Storyteller, 13. Likewise, De Jonge suggests, "Exegetes can never limit themselves to synchronic analysis. I remain convinced that only literary analysis combined with historical criticism will lead to a full picture of the state of affairs." Marinus De Jonge, "The Gospel and Epistles of John Read Against the Background of the History of the Johannine Communities," in What We Have Heard From the Beginning: The Past, Present, And Future of Johannine Studies, ed. Tom Thatcher (Waco: Baylor University Press, 2007), 144.

${ }^{36}$ Brown, Introduction, 31.

${ }^{37}$ Aune observes that there is a tendency away from a holistic treatment of Gospel narratives by narrative critics in favour of "focusing on a particular perspective or certain literary aspects of the Gospels." Aune, Literature and Rhetoric, 315-316.

${ }^{38}$ Barnabas Lindars, Behind the Fourth Gospel (Saffron Walden: Talbot, 1971), 11.

${ }^{39}$ Francis J. Moloney, "Recent Johannine Studies: Commentaries," The Expository Times 123, vol.7, (2012): 313.

${ }^{40}$ Isolated studies of Johannine irony had occurred previously and indeed very early e.g. George Salmon, $A$ Historical Introduction to the Study of the Books of the New Testament $7^{\text {th }}$ ed. (Dublin: University, 1894).

${ }^{41}$ Henri Clavier, "L’ironie dans L'enseignement de Jésus," Novum Testamentum 1, (Jan. 1956), 3-20.

${ }^{42}$ Herbert Leroy, Rätsel und Missverständnis: Ein Beitrag zur Formgeschichte des Johannesevangeliums (Bonn: Hanstein, 1968).

${ }^{43}$ David W. Wead, “Johannine Irony as a Key to the Author-Audience Relationship in John's Gospel,” in American Academy of Religion Biblical Literature: 1974, edited by Fred O. Francis (Missoula: Scholars Press, 1974), 33-50.

${ }^{44}$ MacRae, Theology and Irony.
} 
an oft-quoted statement that in the Fourth Gospel "theology is irony." "45 Irony is more than just a dramatic device for the author because "it is through this ironic vision that the contact with Johannine theology is made, for it is in irony that John expresses his own insight into the meaning of Christ for the world."46 Unfortunately MacRae's valuable albeit incompletely formed insights were not built upon. The rise of narrative criticism changed the focus from the theological "why" of Johannine irony to the "how" of its function as a rhetorical device. In many respects, this study takes the threads that MacRae first articulated and develops them more fully.

The second phase commenced with the paradigm altering work of Culpepper. ${ }^{47}$ His focus on the Fourth Gospel as a literary construct included an impressive and innovative section on irony. ${ }^{48}$ He provided the first systematic treatment of the theme and created a methodological framework in which further examination became virtually inevitable. It was a scant two years later that a full treatment arrived courtesy of one of Culpepper's students. Paul Duke's Irony in the Fourth Gospel is a magisterial work which provides a thoroughgoing analysis of John's use of irony. He provides a background to irony in general and then offers examples of both local and extended ironies. Duke's contribution to the study of Johannine irony cannot be overemphasised. The meticulousness of his work, together with the inherently challenging nature of the subject matter, may well have been twin disincentives to further exploration. It is notable that in the decades since Duke there have been few substantive works on Johannine irony. Most commentators mention Johannine irony, provide some representative examples and then footnote Duke for further consideration.

That said, Duke's ground-breaking work only addresses certain aspects of Johannine irony. His observation that analysis of local ironies "has yielded the discovery that in Johannine irony, form follows theme" begs further investigation. ${ }^{49}$ The obvious question is why is this so? What explicit thematic reasons are there for the author's use of irony? Duke concludes that irony serves the author as a weapon against his opponents and as a tool to serve his desire to bear witness, in as much as "the light that blinds also gives sight." 50 Duke considers the witness component to be predominant. However, as O`Day has observed, "his literary analysis leaves

\footnotetext{
${ }^{45}$ MacRae, Theology and Irony, 89.

${ }^{46}$ Ibid., 94.

${ }^{47}$ In Culpepper, Anatomy.

${ }^{48}$ Culpepper, Anatomy, 165-180.

${ }^{49}$ Duke, Irony, 92.

${ }^{50}$ Ibid., 149-151.
} 
many of the larger theological questions open, for his assessment of the 'why' of Johannine irony is more pragmatic than theological." "51 This study will examine the "why" of Johannine irony in light of the Gospel's wider theological themes.

Gail O'Day's Revelation in the Fourth Gospel also features Johannine irony strongly. Her primary focus on revelation means that her interaction with irony is more a development of MacRae's theological perspective than Duke's functional approach. Accordingly, she considers "the ways in which the Fourth Evangelist uses irony in the Gospel narrative to create and recreate the dynamics of revelation." 52 Her intention is not to examine either the "how" or "why" of Johannine irony but rather the mechanism of revelation in the Fourth Gospel. In particular, she demonstrates "the inseparability of narrative mode and theological claim." study will seek to marry Duke's functional concept of irony as witness with O'Day's theological focus on irony as revelation. I will consider whether what is being witnessed to and revealed provides a rationale for Johannine irony.

The third phase features a number of shorter articles published in the late 1980s and 1990s that variously intersect with Johannine irony. These works include: Johnston, ${ }^{54}$ Kotze, ${ }^{55}$ Myers, ${ }^{56}$ Botha, ${ }^{57}$ Dokka $^{58}$ and Anderson. ${ }^{59}$ While these studies have increased the breadth of understanding of Johannine irony they have predominantly focused on other topics, such as Christology, ecclesiology, linguistics (notably Speech-Act Theory), and narrative criticism itself. The fundamentals of Johannine irony as a literary device are still primarily predicated upon the work of Culpepper, Duke and O’Day.

One work from the third phase that deserves closer inspection is Thatcher's "The Sabbath Trick: Unstable Irony in the Fourth Gospel," published in 1999. Thatcher is representative of a reader

\footnotetext{
${ }^{51}$ O’Day, Revelation, 4.

52 Ibid., 10.

${ }^{53}$ Ibid., 112.

${ }^{54}$ George Johnston, "Ecce Homo! Irony in the Christology of the Fourth Evangelist." in The Glory of Christ in the New Testament: Studies in Christology eds. Hurst, L. D. and Wright N. T. (Eugene: Wipf and Stock, 1987).

${ }^{55}$ Pieter P. A. Kotze, “John and Reader's Response," Neotestamentica 19, (1987).

${ }^{56}$ Doris Myers, "Irony and Humor in the Gospel of John," Occasional Papers in Translation and Textlinguistics 2 , (1988).

57 Eugene Botha, "The Case of Johannine Irony Reopened I: The Problematic Current Situation," Neotestamentica 25 (1991), 209-220; "The Case of Johannine Irony Reopened II: Suggestions, Alternative Approaches." Neotestamentica 25 (1991), 221-232.

58 Trond Dokka, "Irony and Sectarianism in the Gospel of John," in New Readings in John: Literary and Theological Perspectives eds. Nissen, et al. (Sheffield: Sheffield Academic Press, 1999).

${ }^{59}$ Paul N. Anderson, "The Having-Sent-Me Father: Aspects of Agency, Encounter, and Irony in the Johannine Father-Son Relationship," Semeia 85 (1999).
} 
response approach in which the reader has dominance over the text. He alleges that the Fourth Gospel contains a number of unstable ironies and that the reader is frequently victimised by irony. However neither example he adduces of such victimisation $(3: 22 / 4: 2 ; 7: 1-10)$ is ironic. Furthermore, for the narrator to withhold information (e.g. that a healing occurred on the Sabbath), provide clarification of earlier information (3:22/4:2) or to show a change of mind in a character (7:1-10) does not necessarily, and indeed will rarely, constitute "a form of narrative "irony." "60 Instead, these may be legitimate narrative devices used by the author to create tension, moderate pace and achieve character development. Thatcher's post-structural reading of 5:1-10 is distorted by the use of multiple unfounded a priori assumptions, ${ }^{61}$ the misidentification of irony ${ }^{62}$ and selectivity in the use of text. ${ }^{63}$ Thatcher's work is heavily influenced by Staley, ${ }^{64}$ and both have been roundly criticized for their excessive subjectivity and most scholars have declined to build upon their post-structural foundations. ${ }^{65}$ Remarkably, there has been a scarcity of works on Johannine irony in the twenty-first century.

\section{Outline of Approach}

In order to answer the question of why the author of the Fourth Gospel makes such extensive use of irony, I will first attempt to delineate irony, consider its taxonomies and chart its development historically. Chapter 2 will therefore provide a foundational understanding of the nature and function of irony, to the extent this is possible. I will then consider in Chapter 3 the distinctiveness of the author as a storyteller, with special attention to how the literary characteristics of the narrative condition Johannine irony. A review of various potential

\footnotetext{
${ }^{60}$ Tom Thatcher, “The Sabbath Trick: Unstable Irony in the Fourth Gospel,” JSNT 76, (1999), 57.

${ }^{61}$ E.g. that the author is ignorant about Jesus (Thatcher, Sabbath Trick, 69) or that Jesus has ulterior motives for his healings (Ibid., 70-71).

${ }^{62}$ The lame man's lack of knowledge does not constitute irony of identity (Thatcher, Sabbath Trick, 69) as ignorance does not constitute irony unless there is an appropriate reversal of expectation (this requirement will be explained in Chapter 2). Irony occurs when "the spectator knows something the protagonist doesn't and should know." [Italics mine.] Robert Alter, The Art of Biblical Narrative (New York: Basic Books, 2011), 12.

${ }^{63}$ E.g. Thatcher maintains that Jesus "does not mourn for the suffering of his friend" Lazarus ignoring other relevant evidence in the text such as Jesus openly weeping for Lazarus (11:35). Thatcher, Sabbath Trick, 70.

${ }^{64}$ Jeffrey Staley, The Print's First Kiss: A Investigation of the Implied Reader in the Fourth Gospel (Atlanta: Scholars Press, 1988); Jeffery Staley, Reading with a Passion: Rhetoric, Autobiography, and the American West in the Gospel of John (New York: Continuum). Thatcher goes further than Staley in describing the Gospel's narrator as unreliable. Staley's views on the narrator will be critiqued in Chapter 3.

${ }^{65}$ E.g. "However, alternative explanations of the flow of the narrative are possible (if not more probable) and Thatcher's attempt at a poststructural reading of John 5 and 9 ultimately fails to convince." Andreas Köstenberger, John, Baker Exegetical Commentary on the New Testament, (Grand Rapids: Baker, 2004), 81. "Staley's generalized reader masks... the critic himself: Staley's reader reads the way Staley does." Mary Ann Tolbert, "A Response from a Literary Perspective," in Semeia 53: The Fourth Gospel from a Literary Perspective, eds. Alan Culpepper and Fernando Segovia (Atlanta; SBL, 1991), 206.
} 
explanations will identify a preferred rationale for why Johannine irony is so pervasive in the Fourth Gospel. I will advance the hypothesis that Johannine irony serves the Fourth Gospel's notion of truth (alètheia). In particular, that the Fourth Gospel exhibits a profound truth theme: described by explicit and implicit usages of truth terminology and conveyed by the author's propositional truth claims. I propose that the author employs irony as the preeminent vehicle for the expression of his truth theme because this is the most effectual and engaging manner in which he can achieve his purposes (cf. 20:31). I will then examine this hypothesis against the backdrop of the text in Chapters 4, 5 and 6. I have chosen the Prologue and the Passion Narrative to be representative of the text as this is where the Gospel's key themes respectively find their genesis and their dramatic denouement.

As we will see in Chapter 2, the identification of irony is a fraught undertaking. To assist in wrestling with the inherent ambiguity and subjectivity of irony I undertook a survey of the examples of irony I detected in the Gospel, together with a review of instances of irony proposed in the Johannine literature. This survey will provide corroboration for some of the key conclusions in this study. The Johannine corpus is too large to attempt to cover it all and as we have observed both Culpepper and Duke note that exhaustive lists of irony are not possible due to the idiosyncratic nature of irony itself. While I have endeavoured to be as comprehensive as possible in my coverage of the text, in light of wider Johannine scholarship, I readily concede that it is not exhaustive. It is intrinsically likely that others may detect ironies not included in the survey. However, even a partial survey can still allow for the identification of broad patterns in the way in which Johannine irony features in the narrative. The value of the survey is that it attempts, for the first time, a thoroughgoing assessment, which incorporates the wider scholarly consensus on irony in the Gospel. An abbreviated version of the survey is located at Figure 1. 
Figure 1 - Survey of Local Irony as Proposed by the Johannine Literature

\begin{tabular}{|c|c|c|c|}
\hline Chapter & Verse & Attestation & Strength \\
\hline \multirow{6}{*}{1} & $10-11$ & Robust & Strong \\
\hline & 14 & Moderate & Medium \\
\hline & 30 & Limited & Weak \\
\hline & 45 & Moderate & Disputed \\
\hline & 46 & Robust & Strong \\
\hline & 49 & Limited & Disputed \\
\hline \multirow{4}{*}{2} & 4 & Limited & Disputed \\
\hline & $9-10$ & Robust & Strong \\
\hline & 17 & Limited & Medium \\
\hline & $18-21$ & Robust & Strong \\
\hline \multirow{4}{*}{3} & 4 & Moderate & Strong \\
\hline & 10 & Robust & Strong \\
\hline & 12 & Limited & Medium \\
\hline & $13-21$ & Limited & Weak \\
\hline & 7 & Moderate & Medium \\
\hline & 9 & Limited & Weak \\
\hline & 10 & Moderate & Strong \\
\hline & 11 & Moderate & Medium \\
\hline & 12 & Robust & Strong \\
\hline & 13 & Limited & Weak \\
\hline & 15 & Limited & Weak \\
\hline & 16 & Limited & Weak \\
\hline & $17-18$ & Moderate & Weak \\
\hline 4 & 21 & Limited & Weak \\
\hline & 25 & Moderate & Strong \\
\hline & 27 & Limited & Disputed \\
\hline & $28-29$ & Moderate & Weak \\
\hline & 32 & Limited & Disputed \\
\hline & 33 & Moderate & Medium \\
\hline & 39 & Limited & Medium \\
\hline & $41-42$ & Moderate & Weak \\
\hline & 45 & Moderate & Medium \\
\hline & 3 & Limited & Medium \\
\hline & 7 & Limited & Weak \\
\hline & $9-10$ & Moderate & Strong \\
\hline 5 & 18 & Limited & Strong \\
\hline & $39-40$ & Limited & Weak \\
\hline & 45 & Moderate & Strong \\
\hline & 21 & Limited & Disputed \\
\hline & 30 & Robust & Medium \\
\hline & 34 & Limited & Medium \\
\hline 6 & 37 & Limited & Medium \\
\hline & 42 & Robust & Strong \\
\hline & 52 & Limited & Weak \\
\hline & 68 & Limited & Weak \\
\hline & $3-4$ & Robust & Strong \\
\hline & 13 & Limited & Medium \\
\hline & 14 & Limited & Medium \\
\hline & 15 & Moderate & Medium \\
\hline & 19 & Limited & Medium \\
\hline & 20 & Robust & Medium \\
\hline & $22-23$ & Robust & Strong \\
\hline & 26 & Limited & Weak \\
\hline 7 & $27-28$ & Robust & Strong \\
\hline & 35 & Robust & Strong \\
\hline & $36 a$ & Limited & Medium \\
\hline & $41-42$ & Robust & Strong \\
\hline & $45-46$ & Moderate & Medium \\
\hline & $47-48$ & Robust & Strong \\
\hline & 49 & Moderate & Strong \\
\hline & $50-51$ & Robust & Strong \\
\hline & 52 & Robust & Strong \\
\hline & 17 & Limited & Weak \\
\hline & 21 & Limited & Medium \\
\hline & 22 & Robust & Strong \\
\hline & 28 & Limited & Medium \\
\hline & $31-37$ & Limited & Medium \\
\hline 8 & 33 & Limited & Strong \\
\hline & $41 \mathrm{~b}$ & Robust & Medium \\
\hline & $48,52 \mathrm{a}$ & Moderate & Medium \\
\hline & 53 & Robust & Strong \\
\hline & 57 & Moderate & Strong \\
\hline & 59 & Moderate & Weak \\
\hline & 9 & Limited & Weak \\
\hline & 14 & Limited & Disputed \\
\hline & 16 & Moderate & Medium \\
\hline & $22 \mathrm{a}$ & Limited & Weak \\
\hline & 23 & Moderate & Medium \\
\hline & 24 & Robust & Strong \\
\hline 9 & 27 & Robust & Strong \\
\hline & 28 & Moderate & Medium \\
\hline & 29 & Robust & Strong \\
\hline & $30-34$ & Robust & Strong \\
\hline & 36 & Limited & Strong \\
\hline & 37 & Limited & Weak \\
\hline & $39-41$ & Robust & Strong \\
\hline 10 & 24 & Limited & Weak \\
\hline 10 & 25 & Limited & Weak \\
\hline
\end{tabular}

\begin{tabular}{|c|c|c|c|}
\hline Chapter & Verse & Attestation & Strength \\
\hline \multirow{4}{*}{10} & 31 & Limited & Weak \\
\hline & 32 & Robust & Strong \\
\hline & $33 \mathrm{~b}$ & Robust & Strong \\
\hline & $34-36$ & Limited & Weak \\
\hline \multirow{10}{*}{11} & 4 & Limited & Weak \\
\hline & 12 & Limited & Medium \\
\hline & 16 & Robust & Strong \\
\hline & 34 & Limited & Disputed \\
\hline & 36 & Limited & Disputed \\
\hline & 43 & Limited & Medium \\
\hline & $45-47$ & Moderate & Strong \\
\hline & $\begin{array}{ll}48 \\
\end{array}$ & $\begin{array}{l}\text { Robust } \\
\end{array}$ & Strong \\
\hline & $49-50$ & Robust & Strong \\
\hline & 55 & Limited & Medium \\
\hline \multirow{9}{*}{12} & $5-6$ & Limited & Medium \\
\hline & $10-11$ & Limited & Medium \\
\hline & 19 & Robust & Medium \\
\hline & $20-26$ & Limited & Disputed \\
\hline & 34 & Limited & Medium \\
\hline & 35 & Limited & Medium \\
\hline & $39-40$ & Limited & Strong \\
\hline & 42 & Limited & Medium \\
\hline & 48 & Limited & Medium \\
\hline & 8 & Limited & Weak \\
\hline & 23 & Limited & Weak \\
\hline & 29 & Moderate & Weak \\
\hline 13 & 30 & Limited & Weak \\
\hline & 37 & Robust & Strong \\
\hline & 38 & Moderate & Strong \\
\hline 14 & 8 & Limited & Medium \\
\hline 15 & 25 & Moderate & Medium \\
\hline 15 & $26-27$ & Limited & Medium \\
\hline & $2-3$ & Robust & Strong \\
\hline & $4 \mathrm{a}$ & Limited & Weak \\
\hline & $8-10$ & Limited & Weak \\
\hline 16 & 16 & Limited & Disputed \\
\hline & 25 & Limited & Disputed \\
\hline & $29-30$ & Robust & Strong \\
\hline & 31 & Robust & Strong \\
\hline 17 & 4 & Limited & Weak \\
\hline & 3 & Robust & Strong \\
\hline & 6 & Limited & Medium \\
\hline & 12 & Limited & Disputed \\
\hline & 14 & Moderate & Medium \\
\hline & 19 & Limited & Medium \\
\hline & 26 & Limited & Weak \\
\hline & $28-29 a$ & Robust & Strong \\
\hline & $29 \mathrm{~b}$ & Limited & Weak \\
\hline & 30 & Limited & Weak \\
\hline 18 & 31 & Robust & Medium \\
\hline & 32 & Moderate & Medium \\
\hline & 33 & Moderate & Strong \\
\hline & 34 & Moderate & Medium \\
\hline & $35 \mathrm{a}$ & Robust & Strong \\
\hline & 37 & Limited & Medium \\
\hline & 38 & Robust & Strong \\
\hline & 39 & Limited & Medium \\
\hline & 40 & Robust & Strong \\
\hline & $1-3$ & Robust & Strong \\
\hline & 5 & Robust & Strong \\
\hline & 6 & Moderate & Medium \\
\hline & 7 & Moderate & Weak \\
\hline & $8-9$ & Moderate & Medium \\
\hline & $10-11$ & Moderate & Strong \\
\hline & 12 & Robust & Strong \\
\hline & 13 & Robust & Medium \\
\hline & $14 a$ & Moderate & Strong \\
\hline 19 & $14 \mathrm{~b}$ & Robust & Strong \\
\hline & 15 & Robust & Strong \\
\hline & 16 & Limited & Strong \\
\hline & $19-20$ & Robust & Strong \\
\hline & $21-22$ & Moderate & Strong \\
\hline & $23-24$ & Limited & Weak \\
\hline & 28 & Moderate & Strong \\
\hline & 31 & Moderate & Medium \\
\hline & 38 & Limited & Medium \\
\hline & 41 & Limited & Medium \\
\hline & 2 & Limited & Weak \\
\hline & $11-13$ & Limited & Medium \\
\hline & 14 & Limited & Weak \\
\hline 20 & 15 & Robust & Strong \\
\hline 20 & 16 & Limited & Weak \\
\hline & $19 \mathrm{a}$ & Limited & Weak \\
\hline & 28 & Limited & Medium \\
\hline & 29 & Limited & Weak \\
\hline & 7,20 & Limited & Weak \\
\hline 21 & 22 & Limited & Weak \\
\hline & 24 & Limited & Weak \\
\hline
\end{tabular}


In the survey, I identify 176 instances of perceived localised Johannine irony. Classification can be problematic however, as the ironies are occasionally interrelated, ${ }^{66}$ or occur across multiple verses. ${ }^{67}$ Furthermore, commentators are adept at identifying surprisingly varied aspects of the same ironic utterance. A single ironic statement, in which various ironic aspects are identified, is only registered as a single instance of irony. Although the aspects may be entirely dissimilar, they are variations of the same ironic statement. In some instances, it is possible that the author intended multiple layers of irony but the uncertainty surrounding such interpretations and where boundaries could be safely drawn, precludes treating them as separate ironies. In any case, the value of the survey is not its exactitude but the broadly representative picture of Johannine irony it gives, from which overarching conclusions may be drawn.

The range and subtlety of irony means that not all ironies are equal. An irony that is almost universally recognised and clearly an integral part of the narrative warrants more attention than an obscure reference that is identified by one person. Consequently, I have applied two qualifications to the irony contained in the survey, while remaining mindful that if the identification of irony is a fraught undertaking its qualification is doubly so. However, the inherently subjective nature of irony means that readers are forced to make value judgments of some sort. It is common to hear ironies described in scholarly works in terms such as "weighty", "tragic", "formidable", "bitter", "great", "obvious", "terrible" and "sublime." As we will see in the next chapter, one of the formally recognised elements of irony is an emotional response. This means that irony by its nature invites a reader to render judgments as to its aptness and impact. I have codified my judgments into categories and attempted to employ as many objective criteria as the subject matter will permit.

The first qualification is an assessment of its support in Johannine scholarship. I rated each proposed irony for its degree of attestation in the secondary literature ("robust", "moderate", or "limited"). The extent of attestation derives from two factors: the number of scholars who

\footnotetext{
${ }^{66}$ E.g. the unknowing prophecy of Caiaphas at 11:49-50 is reintroduced at 18:14. While both relate to the same ironic utterance, its use in a different location in narrative causes a change in focus. Consequently, the first expression was classified under the "death" motif whereas the second better represented the "rejection" motif.

${ }^{67}$ E.g. 16:29-31 in which the Disciples ironically exhibit misplaced belief, which also Jesus remarks on ironically. Some place the irony in v.29, others in v.30 while some subsume the whole ironic interchange into Jesus' response in V.31. Care was taken not to double report, even though observers may perceive different aspects of the irony depending on where they place the locus (i.e. v.29 their continued misunderstanding of plain speech and v.30 the veracity of their belief). So in this case vv.29-30 was perceived as a single instance of irony, albeit often expressed slightly differently and v.31 (since it involves a different speaker) constitutes a separate irony whose meaning can be considered independently.
} 
reference the irony, and the manner in which they engage with irony and the text. ${ }^{68}$ The latter aspect is essential because scholars often incorporate without alteration representative lists of irony from previous works, creating the possibility of false corroboration. If a proponent bases his or her identification of irony on a detailed exegesis or explanation of the proposed ironic utterance, I attached greater weight to their identification. The various proponents fall into three groups: specialists in Johannine irony (such as Culpepper, Duke and O’Day), commentators who offer substantive exegesis and those who simply mention an irony without further explanation. Each assessment was undertaken on a case-by-case basis. It is important to note, however, that while a higher degree of attestation is indicative it does not definitively validate the existence of irony in the text. Equally, limited attestation does not necessarily mean that the irony is unreliable, just less recognised.

The second qualification is an assessment of the literary merits of the irony ("strong", "medium", "weak", or "disputed"). ${ }^{69}$ This is a more subjective judgment but necessary for two reasons. First, to avoid suggesting that wide consensus automatically equates to superior irony, since attestation does not speak to the quality of the irony only its level of recognition. Second, to help distinguish between ironies that are intended by the implied author and those that are perceived by readers other than the implied reader. ${ }^{70}$ As the implied author is a product of the text we can analyse the narrative to determine the likelihood that a particular irony is integral to the text and therefore reflective of the implied author's literary strategy. The criteria used to ascertain the literary merits of an irony in the Fourth Gospel are predicated on how well it conforms to the features of irony identified in Chapters 2 and 3. In particular, does it meet the initial requirements of a basic definition, formal elements, and/or a known classification? If not then it is unlikely to be ironic and could be another Johannine rhetorical device, such as dual meaning or misunderstanding. At the very least, this would warrant a disputed classification.

\footnotetext{
${ }^{68}$ For example, 20 scholars identify irony at 4:12 and so it is rated as "Robust", while in the next verse (4:13) only two scholars see irony and it is rated as "Limited". Only three scholars detect irony at 4:7 however, the exegesis is especially thorough; in particular, Duke's extended comparisons with the Old Testament's treatment of meetings between men and women at wells. Despite the low number of attesters, it receives a "Moderate" rating.

${ }^{69}$ Irony rated as "disputed" means that another scholar has criticised this postulation or that it is unlikely based on the criteria from Chapters 2 and 3 of this study.

${ }^{70}$ For example, at John 11:48 the chief priest and the Pharisees express the concern that if they do not do something about Jesus then the Romans will "come and destroy both our holy place and our nation." The situational irony that the Romans did exactly this in 70 C.E. due to Jewish rather than Christian actions would not have been lost on either author or reader since it is commonly held that the Gospel was written after this event. Nonetheless, a reader may also perceive a further ironic reversal of fortune in that several centuries later the Roman Empire was won over by Christianity. This is a valid ironic observation by a modern reader, however since it requires knowledge that the author could not possess we cannot ascribe it to the author or use it to assess the author's theological or literary purposes in utilising irony.
} 
If an instance meets the fundamental requirements then its relative merits can be qualified according to a number of factors. The primary criterion is how well it matches the formal elements, for example, how pronounced the ironic contrast is between appearance and reality? ${ }^{71}$ Further considerations are whether it matches a category or theme the author consistently uses; how well does it fit within the recognised literary, philosophical and/or theological milieu of the author; the extent to which it accords with the author's own literary style, especially in terms of similarities with other ironic utterances; whether it requires knowledge that the reader is unlikely to possess; and whether it contains an ironic indicator (a literary wink or nod) such as those described in Chapter 3? The answers to these questions will provide a sense of the likelihood that the irony is integral to the author's literary strategies.

I do not pretend this classification offers conclusive proof of an irony, as if such a thing were possible. Rather, its primary purpose is to allow a higher degree of confidence in the validity of the survey's contents. It also bears noting that from a reader's perspective weak irony is not necessarily bad irony. Indeed, the less obvious nature of weak irony may heighten the enjoyment of its eventual recognition, even more so than strong irony.

To commence our investigation into a rationale for Johannine irony, we turn first to the definition and classification of irony as a literary device. Waiting until the second part of Chapter 3 before broaching the study's central hypothesis may seem an undue delay. However, as will soon be demonstrated, the intricacies and idiosyncrasies of both irony and the Johannine narrative deserve respectful and circumspect consideration first. O'Day's critique of one scholar, that he "fell short because of his circumscribed understanding of irony" could regrettably be applied to many who have injudiciously tackled Johannine irony. ${ }^{72}$ Furthermore, the preferred hypothesis arises in part from the conceptual foundations laid in our examination of irony. The groundwork laid in Chapters 2 and 3 will pay valuable dividends, to assist us in determining how the most complex and ambiguous of rhetorical devices serves the most enigmatic of Gospels.

\footnotetext{
${ }^{71}$ This consideration will also draw strongly on Meucke's secondary elements described in Chapter 2. These are not part of the primary elements as they speak more to how successful an irony is than its initial existence.

${ }^{72}$ O'Day, Revelation, 116.
} 


\section{Chapter 2}

\section{Towards a Definition of Irony}

Irony's appeal is undeniable but so too is its ability to frustrate the casual observer and trip up the unwary practitioner. In 1995 Canadian songstress Alanis Morissette co-wrote and performed a song entitled "Ironic." The various ironic incidents it purports to recount turn out to be merely unfortunate, random or irksome coincidences. A song about irony that in reality contains no irony renders itself ironic for all the wrong reasons. However, it also serves as a salient warning about the inherent difficulties that surround the concept and use of irony. These difficulties extend beyond popular culture's tendency to equate irony with quirky happenstance; they even bedevil academic attempts to define and delimit irony in a critical sense.

Irony deserves its sobriquet of "the mother of confusions." A sophisticated device that delights both the perpetrator and the perceiver, as they are joined in a community of secret knowledge. Often the more abstruse the irony the more delightful its discovery proves. However, this brings the attendant risks of miscommunication, leading to confusion or offence. Furthermore, the thrill of the hunt for ironic utterances can become all-consuming and the original subject matter can all too quickly be eclipsed by the supposed means of transmission. In academic analysis, the destructive or distractive lure of irony can result in a reductive tendency to fragment texts into ever decreasing constituent parts. As more and more ironic utterances are ostensibly unearthed, credibility strains to breaking point.

The difficulties inherent in any attempt to define irony are legendary. Muecke captures the problem with characteristic verve in suggesting that "getting to grips with irony seems to have something in common with gathering the mist; there is plenty to take hold if only one could." 2 While this statement could be wrongly taken to imply that irony is somehow insubstantial, ${ }^{3}$ it does capture the nub of the problem. The elusiveness of irony is also a reminder that irony is not

\footnotetext{
${ }^{1}$ Alanis Morissette, "Ironic.” From the album “Jagged Little Pill” Maverick, 1995.

${ }^{2}$ Douglas C. Muecke, The Compass of Irony (London: Methuen, 1969), 3.

3 Holland makes this criticism; however, his attempt using sand at the seashore is only moderately better conceptually but lacks the same style. Glenn S. Holland, Divine Irony (London: Associated University Press, 2000), 19.
} 
the solitary domain of literary critics; people have enjoyed irony in everyday forms of speech and drama for thousands of years. There appears to be an irresistible urge in human beings to glance up at the torrential rain, turn to a companion and remark, "lovely weather." Irony appears to be an irrepressible part of the human condition, transcending time and culture and certainly not, as some have proposed, purely "a Greek thing." "The universality of irony serves to make identification easy but delineation difficult. Like good art, it may be difficult to describe exactly what it is but we know it when we see it.

Good's comment that "irony like love, is more readily recognized than defined" is correct, even if the comparison is overstated. ${ }^{5}$ Authors have waxed lyrical comparing irony to concepts such as love, religion, philosophy, beauty and so forth. Such comparisons however do little to help our understanding of irony as principally a rhetorical device. A more useful comparison would be with humour in its many forms, each different, each capable of carrying meaning, and the success of each utterance very much dependent on the hearer/observer. Ultimately, humour is, like irony, a form of communication and a means to an end. It is a way of making a point for either pleasure or a painful confronting of truth (or perhaps both).

One of the earliest and better-articulated attempts to move beyond mere recognition was Quintilian's description of irony, in utroque [the figure of irony or the trope of irony] enim contrarium ei quod dicitur intellegendum est. ${ }^{6}$ While succinct, this is unsatisfactory, for the same idea can embrace a gamut of other rhetorical devices. As Colebrook observes, "this definition is so simple that it covers everything from simple figures of speech to entire historical epochs."7 Other attempts to coin succinct definitions have been numerous and universally unsuccessful. Most scholars accept that no brief and simple definition exists, which will include all kinds of irony while excluding all that is not irony. Muecke adopts a different approach by seeking to classify the essential elements of irony and eschewing any attempt at a definition. ${ }^{8}$

\footnotetext{
${ }^{4}$ James A. K. Thomson, Irony: A Historical Introduction (London: George, Allen \& Unwin, 1926), 2.

${ }^{5}$ Edwin M. Good, Irony in the Old Testament 2nd ed. (Sheffield: Almond, 1981), 13.

${ }^{6}$ [9.2.44, see also 6.2.15, 8.6.54]. Marcus Fabius Quintilian, Quintilian: The Orator's Education ed. and trans. Donald A. Russell 5 vols. (Cambridge: Harvard University Press, 2001), 4.58. "Contrarium" is best translated as "opposite" but frequently translated as "contrary" by ironists. This is presumably because this is a more charitable reading, which would incorporate non-oppositional instances of irony (e.g. where irony is the result of understatement or overstatement). For examples of those who read "contrary," see Claire Colebrook, Irony: The New Critical Idiom (London: Routledge, 2004), 1; Joseph Dane, The Critical Mythology of Irony, (Athens: University of Georgia Press, 1991), 49; Ernst Behler, Irony and the Discourse of Modernity (Washington: University of Washington Press, 1990), 77.

${ }^{7}$ Colebrook, Irony, 1.

${ }^{8}$ Muecke, Compass, 14.
} 
This approach has many adherents and its appeal is understandable, as alternatively each new attempt to gather the mist leaves the intrepid ironist empty handed.

Duke's warning bears repeating: "Irony, it should be remembered, laughs at all pretensions, especially the pretension of claiming to have grasped irony." Ultimately, the classification of formal elements alone fails because irony refuses to be reduced to the sum of its constituent parts. Understanding the chemical composition of water vapour does not prepare one for encountering mist in its natural environment. The analogy with humour is again instructive for as soon as humour becomes formulaic it ceases to funny. To be fair to Muecke, in all probability he would concur. However "despite Muecke's provisos and demurrals, he also abstracts, perhaps necessarily, what is probably best grasped intuitively." ${ }^{\prime 10}$ Recognising that irony by the "very simplicity of its definition becomes curiously indefinable," propose a three-tiered approach to the subject.

The first approach is a deductive examination of the formal requirements for irony. This can either lead to an attempt at a definition or alternatively a systematic classification of formal elements. Although these constitute only one side of irony's multi-faceted personality, as Duke suggests, "certain elements do seem basic, and by coming to terms with these something at least resembling a definition might be reached."12 The second approach is an inductive survey of the taxonomies of irony that can lead to general principles that reveal further facets. Again this is a common strategy as an "attempt at a definition of irony is most often surrendered in favour of a listing of characteristic examples, usually classified into different types of irony." 13 Finally, there needs to be an understanding of the historical development of irony as a concept. This is particularly true in the consideration of ancient texts since what irony meant for the author and what it means for contemporary readers may be different. Therefore, an integration of the historical and topical approaches provides a proper context for the study of irony and its role in the Fourth Gospel as revelatory language. ${ }^{14}$ Comparatively recent developments in postmodern theory have intensified and enlarged the concept of irony, raising questions that have received scant attention in older studies of irony in the Fourth Gospel. ${ }^{15}$

\footnotetext{
${ }^{9}$ Duke, Irony, 4.

${ }^{10}$ Holland, Divine Irony, 22.

${ }^{11}$ Colebrook, Irony, 1.

${ }^{12}$ Duke, Irony, 13.

${ }^{13}$ Holland, Divine Irony, 21.

${ }^{14}$ O'Day, Revelation, 11-12.

${ }^{15}$ Notably Duke, O’Day and Culpepper, the most thoroughgoing studies to date.
} 
This three-stage approach will nonetheless still fall short of encapsulating all that is ironic and excluding all that is not. It is however, possible to overstate the problems around the articulation of the concept of irony and thereby create the impression that it is not possible to speak in a determinate manner about it. While irony eludes precise or concise delineation, it is not unknowable or unrecognisable. A thorough consideration of the three facets described above will provide a sufficient working knowledge of irony that allows us to approach ironic utterances with confidence. This allows for meaningful engagement with ironic intent, particularly within the fixed parameters of a text, but does not negate the subjectivity of the perception of irony. ${ }^{16}$ As we will see in Chapters 4-6 when considering the text of the Fourth Gospel, it is possible to discuss the existence, or otherwise, of irony in the text in a robust manner. Despite the idiosyncratic nature of irony, there is a surprisingly broad level of agreement over the incidences of ironies in the text of the Fourth Gospel. Comparatively few ironic utterances are in dispute. Nonetheless, there is considerable variation in the perception of the exact locus or meaning of the irony. This creates a rich ironic tapestry with different interlocutors pursuing various threads.

In our consideration of each of the three approaches, we will discover that they work together so that when one approach falters another provides clarity. For example, we will see in the next section that one of the formal requirements is that there is a "reversal of understanding."17 However, this does not occur in all ironic discourse. In ironies where a person speaks better than he or she knows, a reversal into a new reality does not supplant the ostensible appearance. Rather the patent insufficiency of the original appearance creates ironic understatement, which leads to a sense of heightened understanding in relation to reality. ${ }^{18}$ While this seemingly fails the test of formal elements, it is a recognised category of irony. ${ }^{19}$ Accordingly, while none of the three approaches are sufficient in themselves, they work together to provide a multi-layered methodology that produces a sufficient working knowledge of irony. We will therefore now proceed to examine each approach, cognisant of both their limitations and the valuable contribution they make to a wider practical and conceptual comprehension of irony.

\footnotetext{
16 "[W]hile we may legitimately question whether or not something has been said or done with ironical intent, we cannot question anyone's right to see something as ironic. We may question his sense or taste though." Douglas C. Muecke, Irony and the Ironic 2nd ed. (London: Methuen, 1982), 43-44.

${ }^{17}$ Ibid., 39.

${ }^{18}$ Caiaphas' statement that "it is better for you to have one man die for the people than to have the whole nation destroyed" (John 11:50b) exemplifies such irony. There is no reversal of the apparent meaning: it is not that no one will die; or that Jesus will not die; or that he will not die for the nation. Rather the reader by now is well aware that Jesus will die for much more than political expediency (John 1:29; 3:14-15, 16-17; 6:54; 8:28; 10:11, $17 ; 11: 25-26)$. He will die as the 'Son of Man' in order to procure eternal life for the entire world.

${ }^{19}$ This will be considered later in this chapter under the heading of "Situational Irony."
} 


\section{The Formal Requirements of Irony}

\section{a) Definitions and Delimitations}

As we have already observed, attempts to define and delimit irony all too often ignore Muecke's axiomatic observation that "the principal obstacle in the way of a simple definition of irony is the fact that irony is not a simple phenomenon." ${ }^{20}$ Accordingly, concise definitions of irony are seldom proffered and are seldom adequate. ${ }^{21}$ Duke proposes an impressively succinct definition: "Irony as a literary device is a double-levelled literary phenomenon in which two tiers of meaning stand in some opposition to each other and in which some degree of unawareness is expressed or implied." 22 A key problem with this definition is that the mere presence of Duke's components does not guarantee irony, since it is possible to envisage instances of satire, sarcasm or non-ironic over/under-statement that would fall within this definition. This leakage of meaning between overlapping rhetorical devices is extremely difficult to avoid and many proposed definitions are simply an attempt to distinguish irony from what it is not rather than a positive description of what it is. Moreover, in this definition a classification of good or successful irony is lost in a bland description of componentry.

When examined closely most definitions are actually attempts to categorise the types of irony (e.g. most dictionary definitions) or the classification of its elements (Duke's definition). ${ }^{23}$ It is hard not to agree with Muecke that "should anyone ever discover in himself the need to reduce another to mental and syntactic confusion, few things will be found so efficacious as asking him to write down on the spot a definition of irony." 24 Nonetheless, simple definitions can prove sufficient for many purposes. This is perhaps what Muecke had in mind when he stated in reference to the work of Erich Heller that since he "has already quite adequately not defined irony, there would be little point in not defining it all over again." ${ }^{, 25}$ Perhaps a more accurate description would be an 'adequate non-comprehensive defining of irony.' However, this does not reduce the force of Muecke's argument that attempts to go beyond this point are rapidly rendered quixotic.

\footnotetext{
${ }^{20}$ Douglas C. Muecke, Irony: The Critical Idiom (London: Methuen, 1970), 7.

${ }^{21}$ Glyndle M. Feagin, Irony and the Kingdom in Mark (Lewiston: Mellen Biblical, 1997), 11.

${ }^{22}$ Duke, Irony, 17.

${ }^{23}$ Duke's definition is really a systematised adoption of Muecke's early attempts at element classification.

${ }^{24}$ Muecke, Critical Idiom, 8.

${ }^{25}$ Muecke, Compass, 14.
} 
The problems entailed in defining irony have led many scholars instead to identify the formal elements of irony. In this respect, the work of Muecke remains unsurpassed. Over the years, he has refined a set of formal (as opposed to aesthetic) requirements for irony: ${ }^{26}$

1. A contrast between an appearance and a reality,

2. An unawareness that appearance is only appearance (pretended in the ironist and real in the victim),

3. A reversal of understanding through the recognition that the appearance is only appearance, and

4. The conscious pleasure of awareness of the contrast between appearance and reality. ${ }^{27}$

This approach, while not comprehensively encapsulating all that is ironic and excluding all that is not, offers a deeper understanding of the complexities of irony and assists in delimiting irony's fluid boundaries. Accordingly, I will adopt this description of irony as a high-level or working definition of irony for the purpose of this study. Although it will take the remainder of the Chapter to fill out an understanding of irony as both a rhetorical device and a concept, the above definition is sufficient for the identification of irony in the majority of cases. As this will frequently provide the start point for our consideration of irony in the text of the Fourth Gospel, it is beneficial to consider each element in further detail.

Irony's most foundational element is a contrast between what is believed to be and what is, be it real or pretended. This disjuncture forms the pivot upon which all irony turns. It is in all instances a double-layered or two-storey phenomenon. ${ }^{28}$ There is a necessary contrast (even conflict is not too strong a term) between these layers of meaning from which the irony arises. ${ }^{29}$ The lower level is the level of appearance, inhabited by victims, if any, of the irony. The upper level is the level of reality, ${ }^{30}$ inhabited by the author of the irony and potentially an informed audience to whom the irony is addressed.

In Sophocles' King Oedipus, Oedipus is painfully unaware of the situation in which he has, while attempting to thwart prophecy, actually fulfilled it by murdering his own father Laius and

\footnotetext{
${ }^{26}$ Ibid., 19.

${ }^{27}$ Muecke, Irony and the Ironic, 33-54.

${ }^{28}$ Muecke, Compass, 19.

29 "Irony, then, begins in conflict, a conflict marked by the perception of the distance between pretense and reality." Good, Irony, 14.

30 "'Reality', as the word is used here, is to be taken as meaning only what the ironist or the ironic observer sees as such.” Muecke, Irony, 34.
} 
marrying his mother Jocasta. ${ }^{31}$ Oedipus' earnest, but mistaken, statements invoke tragic irony to which the audience is attuned through full knowledge of the back-story. So when he exclaims “Thus, serving Laius, I serve myself" the audience is aware that Oedipus' efforts to bring the killer of Laius to justice will not, despite the natural appearance, serve Oedipus but in tragic irony bring ruin upon all that he holds dear. ${ }^{32}$

It is the element of conflict or incongruity between the layers of meaning that provides the most distinctive and identifiable aspect of irony. The necessity for opposition has led to perceptions of negativity in irony. Kierkegaard famously labelled irony as "infinite absolute negativity." 33 The discordant element in irony springs from overstatement, understatement or even simply tone against content. This discord only occurs however as a precursor to a change of perspective, in which "a new vision of things is gained, and the newness springs from the clash of opposition."34 Muecke sees the contrasting interplay between these layers as the determinative element in distinguishing irony from metaphor and analogy. In the latter instances, there are two levels present but the relationship is not one of negation but of one layer building upon another. ${ }^{35}$ O'Day also uses this to distinguish the more problematic concept of paradox as "the contradiction does not, as with irony, lie in the relationship between two levels of meaning but is stated quite clearly in the literal meaning." 36

Irony demands that the contrast between appearance and reality begins with an attitude of unawareness. This unawareness is intended to be transitory, even if this intention is not always realised, ${ }^{37}$ since the ironist "dissembles or rather pretends, not in order to be believed but... in order to be understood." 38 Irony intentionally uses misunderstanding and unawareness to point to a deeper truth than could have been grasped without the deployment of the rhetorical device. Thus, in King Oedipus the awful and ironic fate of Laius, Jocasta and Oedipus is never arbitrary. For Laius and Jocasta their fate is the result of their attempted infanticide. Oedipus appears to be

\footnotetext{
${ }^{31}$ Sophocles, "King Oedipus," in The Theban Plays (New York: Penguin, 1984).

32 Ibid., 29.

33 Søren Kierkegaard, The Concept of Irony with Continual Reference to Socrates, trans. Howard V. Hong. (Princeton: Princeton University Press, 1989), 196. However, this comment occurred in the context of Kierkegaard's attack on the prevailing ironic concepts of his day and not irony per se. This will be further examined under the rubric of German Romantic irony.

${ }^{34}$ Duke, Irony, 16.

${ }^{35}$ See also Feagin, Irony, 13.

${ }^{36}$ O’Day, Revelation, 25.

37 "The ironic criticism requires of its hearers and readers the burden of recognition, the discovery of the relation between the ironist's 'is' and his 'ought.' And to use the ironic method is to risk the failure of this recognition, the misunderstanding of the ironist's criticism." Good, Irony, 31

${ }^{38}$ Muecke, Irony, 35.
} 
an innocent victim but his transgression is revealed during the play, particularly in his exchanges with the blind prophet Teiresias. In response to Oedipus' boasts and allegations of wickedness against Teiresias, the prophet responds, "You are pleased to mock my blindness. Have you eyes, and do not see your own damnation." Oedipus is guilty of hubris and moral blindness. ${ }^{39}$ The force of the ironic exchanges is in the knowledge that the truth will inexorably bring his pride low.

Irony can also be distinguished from lies, hoaxes and equivocations because in deceptions the appearance is offered and the reality withheld, whereas "in irony the real meaning is meant to be inferred either from what the ironist says or from the context in which he says it." 40 Deception attempts to obscure the truth whilst irony seeks to enable the truth, although this may be in oblique or obscure ways that do little more than invite reflection upon the order or fitness of things. An ironic discourse involves either a substitution of information or a movement of perspective that replaces the multi-layered and incongruous meanings with a unified, transcendent position. There is recognition or re-interpretation of a previously held viewpoint that leads to reversal of understanding, vis-à-vis appearance and reality. Thus, all ironic statements require judgement on the reader's part to analyse both levels of meaning and to make the correct move from the literal to the intended meaning. ${ }^{41}$ This peripeteia is not always comfortable and "the incongruity can evoke reactions that are downright visceral."42 Accordingly, the interplay between text and subtext, appearance and meaning is usually complex or subtle (or both).

In King Oedipus the dramatic effect of the reversal is heightened by having different characters encounter it at different times. Jocasta learns before Oedipus and his dismissal of her warnings is intensely ironic as he lambasts her pride while being driven headlong to disaster by his own. "The woman, with more than woman's pride, is shamed by my low origin. I am the child of fortune, the giver of good, and I shall not be shamed." truth is telling, "Alas! All out! All known, no more concealment!"44 Irony seeks to reveal and illuminate, even when, and perhaps especially when, the outcome is not attractive.

\footnotetext{
${ }^{39}$ Moral blindness is a major theme in the Fourth Gospel (especially in chapter nine).

${ }^{40}$ Muecke, Irony, 35.

${ }^{41}$ O'Day, Revelation, 9.

42 Jerry Camery-Hoggatt, Irony in Mark's Gospel: Text and Subtext (Cambridge: Cambridge University Press, 1992), 1.

${ }^{43}$ Sophocles, Oedipus, 55.

${ }^{44}$ Ibid., 58.
} 
Muecke's final element is the least substantial but reveals the heart of ironic discourse. If irony is arguably the most enigmatic of rhetorical devices and laughs at those pretentious enough to claim to understand it, why is it so popular? Why does both ancient and modern literature, as well as everyday discourse teem with ironic utterances? Muecke finds the answer in a "feelingquality common to all instances of irony."45 Indisputably, an emotional payoff occurs when irony is experienced. Muecke's suggestions about the nature of this emotional component are wisely tentative. There is first, a sense of pleasure derived from the recognition of the irony itself, a sense of discovery. If this sense is not present because the contrast between appearance and reality is too pronounced, such as in a sarcastic comment that has no underlying plausibility then the comment cannot be ironic. Conversely if not enough clues are given to allow the victim of the irony to navigate the ambiguity, then the contrast between appearance and reality is too light and irony is not possible, leaving only deception or hoax. In either case, while there is an overt contradiction there is no covert element to be discovered. Booth describes this as the recognition of "acceptable covert connections" that lead to "acceptable covert conclusions." 46

The second emotional component is the sense of pleasure derived from the liberation from being a slave to appearance only. ${ }^{47}$ This can be brief and comedic as occurs when the author of the irony plays the pseudo-victim of their own irony. Or, at the other end of the continuum, it can be drawn out and tragic as a deeper, darker truth is revealed. The often complex and subtle nature of irony makes this a satisfying and liberating discovery nonetheless. The distance created by the use of a rhetorical device allows this feeling to be expunged of the guilt or dismay that might otherwise entail. There is a third emotional element in irony, which Muecke does not identify, which involves the sense of community the irony constructs as the author invites attentive readers to come and dwell on their higher plane of revelation. ${ }^{48}$ Ironic discourse while often subtle and sophisticated is never an attempt to prevaricate or dissimulate; rather it is an invitation by the author to come to the truth. This creates a satisfying bond between the author and the recipient of the irony as a community of the informed is created.

Muecke cites King Oedipus and Othello as examples of tragic stories in which the use of irony can hardly be said to be pleasurable on the usual levels. He comments, "they are however,

\footnotetext{
${ }^{45}$ Muecke, Irony, 44.

${ }^{46}$ Wayne C. Booth, A Rhetoric of Irony (Chicago: University of Chicago Press, 1974), 37.

47 "I am not at all sure that 'liberation' is the right or the only word for this second feeling. Perhaps what we need is a constellation of psychologically related terms any one of which may be the best suited in a particular case." Muecke, Irony, 46.

${ }^{48}$ Booth, Rhetoric, 37.
} 
spectacles of blindness, and calling them tragedies cannot take away from them what they have in common with blind-man's buff: comic pleasure with overtones of sadism and voyeurism." 49 Aristotle sees a subtler and kinder form of pleasure in that tragedies effect "through pity and fear [what we call] the catharsis of such emotions." ${ }^{50}$ If a person were to read in a newspaper of a man who killed his father and married his mother it would only evoke repulsion. However, in Oedipus the irony renders the plot engaging rather than repulsive. It creates the necessary distance for the underlying morality of the tale to be absorbed and catharsis achieved. In the case of dramatic irony, "the "punch' of irony depends in part upon someone failing to see it.",51 On an emotional level, the reader enjoys the pleasure of feeling superior to the victim of the irony because of the additional knowledge possessed. ${ }^{52}$ Furthermore, when the ironic contradiction is resolved, even if the results are tragic, the world returns to rights because the truth is revealed and established.

Muecke tentatively lists other elements: ${ }^{53}$

1. A principle of economy in which "the accomplished ironist will use as few signals as he can,",54

2. A principle of high contrast which notes that the higher the disparity between appearance and reality the greater the sense of irony, ${ }^{55}$

3. The position of the audience can affect the quality of the irony, especially if they possess knowledge unknown to key participants, ${ }^{56}$

4. The topic itself can also be important in that "ironies will be more or less forceful in proportion to the amount of emotional capital the reader or observer has invested in the victim or the topic of the irony."

He admits that they "seem to be aspects of a more general principle that I cannot identify.",57

Duke adds to this list the clash of the painful with the ironic and a sense of detachment between the author and audience. ${ }^{58}$ All of these extra elements, however, do not constitute the core elements of irony so much as explain why some ironic utterances are more successful than

\footnotetext{
${ }^{49}$ Muecke, Irony, 47.

${ }^{50}$ Aristotle, Poetics (New York: Norton, 1982), 50.

${ }^{51}$ Duke, Irony, 16.

${ }^{52}$ Feagin, Irony, 16

${ }^{53}$ Muecke, Irony, 52-55.

${ }^{54}$ Ibid.

${ }^{55}$ Hence it is ironic for a robber to be robbed or a swimming instructor to drown precisely because of the increased unlikelihood.

${ }^{56}$ Although this observation is more appropriate for literary, and especially theatrical, usages of irony.

${ }^{57}$ Muecke, Irony, 52.

${ }^{58}$ Duke, Irony, 17.
} 
others. They are elements of good irony but not necessarily elements of all irony. Thus, they are affective elements but not formal elements. Alternatively, as Duke notes they tend to describe the participants and not the device itself. ${ }^{59}$

b) Stable and Unstable Irony

Another approach to classification is the work of Booth who seeks to distinguish between stable and unstable irony. Duke includes a discussion of Booth's classification in his examination of taxonomies. However, Booth's distinction is not between types of irony but between its affective elements. When Booth speaks of "stable irony," he means irony that possesses "a specific kind of literary fixity... that does in fact present us with a limited number of reading tasks - regardless of the breadth or narrowness of our conception of irony in general."60 As Duke observes it is stable irony that pervades the Fourth Gospel rendering the distinction between stable and unstable irony essentially moot for the purposes of this study. However, Booth's work is still worthy of consideration because it raises a number of issues that impact upon contemporary studies into irony.

The first element of stable irony is that it must have an intentional component. Booth uses the example of the words "Arbeit Macht Frei," carved over the entrance to German concentration camps. The dreadful events of the Holocaust render the use of these words tragically ironic. Nonetheless, the original architect of the camp had no advance knowledge of the Final Solution and so we may not infer authorial irony. ${ }^{61}$ Intention is crucial, though certainty concerning the intentionality behind an irony may not always be possible. ${ }^{62}$

The second element of stable irony is that it is covert, "intended to be reconstructed with meanings different from those on the surface." 63 Irony can approach overtness however this is naive irony and moves unacceptably "from dance to assertion."64 Muecke operates with a less trammelled and preferable view of semi-overt irony in which both the "the victim and reader or both are meant to see the ironist's real meaning at once." 65 The very blatancy of the incongruity that makes it obvious and the immediacy of its effect are the redeeming features of this type of

\footnotetext{
${ }^{59}$ Duke, Irony, 17.

${ }^{60}$ Booth, Rhetoric, 3.

${ }^{61}$ Ibid., 4.

${ }^{62}$ Duke, Irony, 19.

${ }^{63}$ Booth, Rhetoric, 6.

${ }^{64}$ Ibid., 206.

${ }^{65}$ Muecke, Compass, 54.
} 
irony, which often encroaches into the area of sarcasm. Muecke perceives an important place in literature for obvious irony, not excluding sarcasm. ${ }^{66}$

The third element of stable irony is that it is fixed. Once a reconstruction of meaning has taken place, it is not open to further reconstructions. This is a natural corollary of the aspect of intentionality. If however the element of intention is rejected, as some recent ironists do, the third element is also debatable. The final element of stable irony is that it is finite in application. Booth means by this, "it delimits a world of discourse in which we can say with great certainty certain things that are violated by the overt words of the discourse."67 This again is a function of intentionality and brings Booth into direct conflict with poststructuralists like Derrida. For Derrida "deconstruction insists on looking at the way in which any text has a force to disrupt what we take to be stable and decided. All meaning is potentially ironic." 68

Booth's views are increasingly out of step with recent trends in the study of irony, such as postmodern interpretations. Fish in particular has taken Booth to task by suggesting that "irony is risky business because one cannot at all be certain that readers will be directed to the ironic meanings one intends." 69 Fish's critique is all the more telling because while he "emphasizes the role of the reader/interpreter in the communication of irony, he still argues on the basis of authorial intention."70 It is significant that Muecke has not adopted Booth's categories of stable and unstable irony. ${ }^{71}$ Nevertheless, Booth's terms are widely used and awareness of their meaning is necessary to navigate many discussions of irony.

\section{Taxonomies of Irony}

Irony, as previously stated, is more readily recognised than defined and consequently the attempt at a definition of irony is usually abandoned "in favour of a listing of characteristic examples, usually classified into different types of irony." 72 For this reason, Duke's assertion that "if

\footnotetext{
${ }^{66}$ Muecke, Compass, 55.

${ }^{67}$ Booth, Rhetoric, 6.

${ }^{68}$ Colebrook, Irony, 107.

${ }^{69}$ Stanley Fish, Doing What Comes Naturally: Change, Rhetoric, and the Practice of Theory in Literary and Legal Studies (Durham: Duke University Press, 1989), 181.

${ }^{70}$ Holland, Divine Irony, 29.

71 "In fact, his categories of classification for irony bear almost no resemblance to those of Booth." Feagin, Irony, 19.

${ }^{72}$ Holland, Divine Irony, 21.
} 
definitions are difficult, taxonomies of irony are impossible"73 appears erroneous. A single, simple definition appears impossible, while a catalogue of taxonomies is the easiest approach to such a polyvalent rhetorical device. Nonetheless, Duke is correct in stating that it would be absurd to attempt an exhaustive catalogue of taxonomies "not only because the types and shades of irony are countless, but because they fade in and out of each other like colours of a spectrum."74

Muecke offers an array of types or shades of irony: irony as rhetorical enforcement; selfdisparaging irony; ironic mockery; irony by analogy; non-verbal irony; ironic naivety; dramatic irony; unconscious irony; irony of events; cosmic irony; ironic incongruity; double irony; Catch22 irony; and romantic irony. ${ }^{75}$ Scholars have a habit of using the same terms to mean slightly, or occasionally vastly, different things about irony and so the descriptions themselves are not as important as the illustrations provided. Muecke then greatly simplifies the process by reducing all of these sub-types to two basic forms of irony: "verbal" and "situational" irony. ${ }^{76} \mathrm{He}$ relabels these, "instrumental" and "observable" irony respectively. ${ }^{77}$ Another form of irony, general irony, has become more prominent in the years since 1982 when Muecke published his last edition, and is included here as a third major form.

\section{a) Verbal (Instrumental) Irony}

In verbal irony, the author of the irony is the originator of the words that deliver the ironic meaning, which emanate from a position of superior knowledge. The verbal ironist says one thing but in such a way that something else is clearly meant. This is done in a manner that explores the tension between two or more meanings "so as to create an unanticipated result, that is, the sudden awareness of what had not been realized before."78 The key to verbal irony is an element of pretence, which distinguishes irony form other rhetorical devices used in a similar fashion, and the appeal is often found in the subtlety of the pretence. It is usually possible therefore to infer the intended meaning solely from the words of the ironist or from the context. ${ }^{79}$

\footnotetext{
${ }^{73}$ Duke, Irony, 18.

${ }^{74}$ Ibid.

${ }^{75}$ Muecke, Irony, 8-13.

${ }^{76}$ Ibid., 13.

${ }^{77}$ Although Muecke's point about the names is well made, more so in relation to verbal irony, the traditional names are still so widely accepted and used that to change now would only court unnecessary confusion and so for the purposes of this study the original terms are retained.

${ }^{78}$ Mark D Nanos, The Irony of Galatians: Paul's Letter in First-Century Context (Minneapolis: Augsburg, 2002), 34.

${ }^{79}$ Feagin, Irony, 14. [italics mine]
} 
The context can be as nuanced as a tone of voice or a subtle use of body language. This is why Muecke favours the term "instrumental irony"; it better captures the sense that the author sets out to create words that their interlocutor is intended to reject as false.

The creation of verbal irony requires a dissimulating device of some nature, to create the initial contradiction that will be resolved ironically. The historic link with Socrates means that understatement is a common form of irony. Muecke identifies two varieties of understatement: litotes, a denial of the contrary, and meiosis, the substitution of a minimum statement for a maximum one. ${ }^{80}$ Understatement is devastatingly effective when the perpetrator of the irony is "feigning ignorance or lack of capability in order to undermine the confidence or expose the naïveté or incompetence of the victim." 81 Overstatement is also widely employed in the service of irony. The Angel of the Lord's description of Gideon of "you mighty warrior" as he cowered in fear of the Midianites in a wine press (Judges 6:12) is an often cited example of this. Duke catalogues other devices used to create verbal irony: praise to blame, blame to praise, ambiguity, analogy, parody, insinuation, incongruity, pretended error and pretended doubt. ${ }^{82}$ These dissimulating devices allow for the detachment and distance that are needed to create a duality of meaning and enable it to be recognised.

O'Day proposes that all Johannine irony is verbal because "it is an irony deliberately created with words." 83 But this is to go too far. Not all written irony need be verbal even where an artist and medium are presupposed. For example, when the author of the Fourth Gospel places ironic statements in his character's mouths (e.g. 7:42) he creates dramatic irony. The Prologue includes situational irony (e.g. 1:10), where the author is merely pointing to an ironic situation rather than using prose to create the irony. O'Day fails to see that an author may utilise forms of irony other than purely verbal irony and still have an element of intentionality. ${ }^{84}$ The genre of the Gospel as variously polemical, didactic, dialectic, theological, and historical allows the author to employ a variety of ironic styles.

\footnotetext{
${ }^{80}$ Muecke, Compass, 80.

${ }^{81}$ Nanos, Galatians, 34.

${ }^{82}$ Duke, Irony, 22-23.

${ }^{83}$ O’Day, Revelation, 22.

${ }^{84}$ O'Day seems overly reliant here on Booth's concept of stable and finite irony.
} 
In situational irony, the irony originates from an unexpected outcome rather than the provision of superior knowledge. There may still be a participant with superior knowledge but that person is not the one who utters the irony. For example, in 2 Samuel 12:5-6, King David utters an ironic denouncement of the villain of Nathan's story unaware, unlike both Nathan and the reader, that he is the subject of the story. Thus, situational irony can occur where there is a situation in which there is an unanticipated outcome or a situation that is capable of an interpretation that not all parties appreciate in the moment. For example, the cases of King David or Oedipus when they fail to realise it is their own fate they foretell but the audience or reader is aware of the naïveté of the character's statement or action in view of a more informed view or expectation. ${ }^{85}$

Situational irony requires additional development and a deeper sense of shared context than verbal irony. Verbal irony is often "local irony" (meaning that it occurs at given points in the text) while situational irony is often "extended irony" (meaning that it works through structural elements in the narrative and extraneous detail to achieve ironic effect). ${ }^{86}$ Easy classification is hazardous but as Feagin advises a situational irony can be confined to a single ironic episode "but more often situational irony is achieved through a series of episodes which when taken together create an ironic theme or motif." 87

Many sub-categories of situational irony exist but the three most common are irony of events, irony of self-betrayal and dramatic irony. "Irony of events" exploits the incongruity arising from where events bring an unforeseen result, especially where the means sought to avoid the result turns out to be the very means of bringing it about. ${ }^{88}$ An example is found in Amos 5:18-19 where fleeing from mortal danger in the form of a lion leads to an encounter with a bear, as an illustration of the inexorable nature of God's judgement. "Irony of self-betrayal" occurs where the words or actions of an individual betray the fact that the person is not who or what they claim to be. This is unlike the situation of ironic understatement because here $\alpha \lambda \alpha \zeta o v \varepsilon i \dot{\alpha} \alpha$ (false pretence) is active so that the person who utters the irony is the victim and not the perpetrator.

\footnotetext{
${ }^{85}$ Nanos, Galatians, 34. For an extended treatment of both ironic narratives see Anthony Esolen, Ironies of Faith: The Laughter at the Heart of Christian Literature (Wilmington: ISI Books, 2007), 19-29.

${ }^{86}$ Duke, Irony, 43.

${ }^{87}$ Feagin, Irony, 24.

${ }^{88}$ Duke, Irony, 26.
} 
"Dramatic irony" is not so much a separate category of irony as a subsuming of all the aspects of situational irony into a literary format. "Simply put, dramatic irony occurs when the story-line itself plays upon the reader's own repertoire of knowledge and convictions to create a distinctive subtext." ${ }^{\text {}}$ The key difference is the authorial intent to place specific words in the mouth of a character, or to propel them to certain actions knowing that this will create an ironic contrast. Accordingly, an author can make a character speak better than they know - a tactic used effectively by the author of the Fourth Gospel. ${ }^{90}$ This can be an ostensibly innocent statement or be in the form of an irony of self-betrayal. There is a certain degree of crossover here with verbal (instrumental) irony but the instrumentality is removed from the speaker and shared between an author and an audience who sit "on high" above the action.

To sit in a privileged position the audience requires superior knowledge, which is achievable in a number of ways. In King Oedipus the audience knows the story as a Theban myth and are therefore already apprised of all the pertinent facts, allowing Sophocles to present only as much as he needs to build the dramatic irony. For example, there is no need to show Oedipus' mistaken murder of his father as the audience already knows it has occurred. This serves two purposes: it keeps Oedipus as a more sympathetic character by not reliving his worst moment and it allows Sophocles to move directly to the ironic undertones that occur as a result. Other means of providing the requisite knowledge to the audience can involve a prologue, a narrator, prophecies, oracles, soliloquies, a chorus or, in film and television, the use of flashbacks.

\section{c) General (Cosmic) Irony}

General irony predates postmodernism but it has received added impetus from postmodernism's philosophical underpinnings. Put simply, general irony is the understanding that all life is ironic. Irony is viewed as metaphysical and general, with the ironist seeing all humanity as victims of an irony inherent in the human condition. ${ }^{91}$ Rather than being a single or distinct concept general irony is more a broad philosophical milieu that has been influenced by writers, psychologists, sociologists, literary critics, philosophers and ironists. Such as: Samuel Butler, Franz Kafka, Samuel Beckett, Sigmund Freud, Carl Jung, Harold Bloom, Georges Palante, Stanely Fish, Jacques Derrida, Jürgen Habermas, Richard Rorty, Ernst Behler, Frederick Nietzsche, Paul de Man, Michael Foucault, Linda Hutcheon and Claire Colebrook.

\footnotetext{
${ }^{89}$ Camery-Hoggatt, Irony, 2.

${ }^{90}$ E.g. John 2:9-10; 4:12, 25; 5:7; 7:3-4, 7:48; 9:33; 11;12, , 48, 50; 12:19; 18:33; 19:1-3, 5, 14, 19-20.

${ }^{91}$ Muecke, Critical Idiom, 67.
} 
Muecke provides a representative list of aspects of life that may generate general irony, though he is deeply ambivalent about the concept: ${ }^{92}$

1. Irony based on the certainty of death, the essential unpredictability of life and the unbreakable chain of cause and effect.

2. Irony in the concept of technological progress, in that solving one problem invariably spawns more.

3. Irony derived from life's intrinsic determinism through; genetic makeup, environment (climatic, national and sociological), childhood experiences (as per Freudian psychology), biological drives and emotional states.

4. Irony arising from doubts about the purpose of life and the existence and nature of God.

5. Irony in the inherent contradiction between the desire to know everything and the impossibility of knowing everything.

6. Irony deriving generically from "other fundamental and unresolvable oppositions," which life presents.

Consideration of general irony has been largely ignored in works examining irony and the Bible. Duke devotes only two sentences to it. Feagin writing as late as 1997 makes no reference at all to general irony. This may be indicative of a suspicion or antipathy by biblical scholars towards postmodernism, particularly in its more extreme forms.

\section{The Development of Irony}

Returning to the caveats made at the beginning of this chapter. The pertinent question is not has irony been adequately defined but rather, to borrow Muecke's phraseology, has an adequate nondefinition of irony been arrived at? One which will allow sufficient interaction with the Gospel's text? So far, we have adopted the widely accepted approaches to irony of examining attempts at definitions and formal elements, then proceeding to classify irony by type. However, one piece of the puzzle remains to be considered: how irony has developed and changed over

\footnotetext{
${ }^{92}$ Muecke, Critical Idiom, 72-77. In reference to general irony's view of the world, "One has to add here that this picture of the world may be quite wrong." Muecke, Critical Idiom, 68; Muecke, Irony, 50, 101. Noticeably consideration of this topic is missing from the first edition (1970) and second edition (1982) of his later work, Irony and the Ironic.
} 
time. As has already been noted, the term irony is used today to describe phenomena that the author of the Fourth Gospel would never have anticipated. To avoid anachronistic interpretations it is important to understand the literary and philosophical cargo the term carries today. This is also significant because it bears upon a key Johannine concept central to this study - the notion of truth. This threefold approach will allow us to approach the Johannine text with as much confidence as the elusive nature of irony will permit.

Irony is a device equally suited to predominantly oral as well as written cultures and so it is not surprising that its origins predate any enduring record of them. Irony was in use far before it was ever labelled as such and so "the use of irony in antiquity far outstripped any conscious concept of it." 93 Most studies start with its use by the Greeks. They were the first to label a person who utilises irony as an eirōn (cip $\omega v)$ and they raised its use to sublime heights. ${ }^{94}$ However, this does not make it theirs alone. As the Old Testament examples cited earlier in this chapter indicate, irony was also well established in Semitic speech and literature. ${ }^{95} \mathrm{We}$ see ironic understatement in Genesis 3:9, for example, as God cries out to Adam "Where are you?" Omniscient and omnipresent God has not misplaced his wayward creation but utilising the resulting ironic contradiction He asks a much deeper question: not "where are you" physically but "where are you" spiritually.

Consideration of the evidence shows that in addition to historical references to irony and its use in classical literature, there has also been a historical shift in the status and in perceptions of irony. ${ }^{96}$ Irony has never been an inert concept. Few rhetorical devices can match its versatility and its ability to reinvent itself in new guises, both literary and philosophical. Today we "employ the word irony in ways the Greeks never did - to describe broad or subtle contrasts between appearance and reality." 97 In fact, within the pantheon of Greek philosophers and writers, the word came to mean different things and to convey diametrically opposed ethical postures. The historically changeable nature of irony is important to reckon with when we come to biblical exegesis. The real author of the Fourth Gospel would have had access to both Semitic

\footnotetext{
${ }^{93}$ Duke, Irony, 10.

94 "The ancient Greek saw the same patterns but with marvellously meticulous art proceeded to expose every though, word and action that might heighten the inevitable irony." Duke, Irony, 11.

95 See Good, Irony, 33-38: Carolyn J. Sharp, Irony and Meaning in the Hebrew Bible (Bloomington: Indiana University Press, 2009), 9, 240-243.

${ }^{96}$ Colebrook, Irony, 8.

${ }^{97}$ Duke, Irony, 10.
} 
and Greek usage within his immediate cultural and literary context of Hellenistic Judaism. ${ }^{98}$ However, modern approaches to irony are increasingly used to impute ironic meanings of which the real author would never have conceived. Authorial intent is marginalised or rejected outright, either deliberately or unconsciously. Accordingly, it is essential to grasp irony's historical development in order to identify irony in ways consistent with its classical use and differentiate it from its contemporary expressions.

a) The Greek Dramatists and Philosophers

Examples of irony are as old as literature itself. Homer employed dramatic irony in The Odyssey. Odysseus returns to Ithaca in disguise and listens to the boastful and unknowing suitors fall into the irony of self-betrayal. Nevertheless, there is good reason for using the later Greek dramatists as a historical starting point. The first extant usage of the word eirōn occurs in The Clouds penned by Aristophanes in 423 BCE. The etymology of the word is problematic, "though it seems related to eirein (to say or speak) or perhaps more closely to the Ionic eiromai

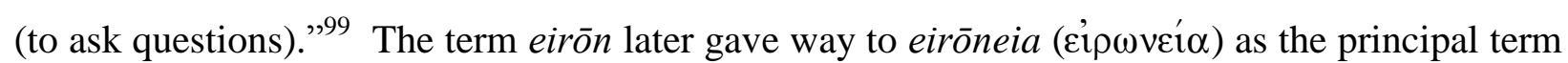
to denote the use of irony.

The Clouds is a comedic play in which Aristophanes lampoons the sophists of fifth-century Athens and produces a stinging satirical portrayal of Socrates. The most noticeable feature of Aristophanes' usage of eirōn is that it is included in a list of words imputing cunning deception. Aristophanes was the first of many to attribute negative associations to the term. As Behler explains, "originally... the words eirōneia and eirōn had a low and vulgar connotation, even to the extent of being an invective." 100 The Clouds, and the work of other Greek dramatists, give rise to two major themes that will return to influence later ironic theory. The first is the idea that irony can be both a rhetorical device and a mode of behaviour. The second is the role of Socrates in determining both the use and purpose or irony. Socrates is a cause célèbre in relation to irony and every school of ironic thought seemingly adopts him as their patron saint, citing his words and conduct as justification for their views.

\footnotetext{
${ }^{98}$ As Stibbe observes "[the Gospels] are narratives composed according to Hebrew and Greco-Roman storytelling conventions." Stibbe, Storyteller, 67. Duke asserts, "So similar is the dramatic style of John to the classic drama of the Greeks, and so unlike the restrained economy of other biblical writers, that the author's acquaintance with the tradition of classical Greek drama in some form must be postulated." [Italics mine.] Duke, Irony, 141.

${ }^{99}$ Duke, Irony, 8.

${ }^{100}$ Behler, Irony and Discourse, 78.
} 
The Greek dramatists rarely used the concept of the eirōn in isolation. The eirōn as a character was a dissimulator who proffered a view of himself as less than he was. The alter ego of the eirōn was the alazōn ( $\alpha \lambda \alpha \zeta \omega$ v) who held himself out to be more than he was, ${ }^{101}$ or "as the classic distinction has it, the eirōn dissimulates, the alazōn simulates." ${ }^{102}$ The alazōn tended to utter ironic statements of self-betrayal before being humbled, often at the hands of the eirōn. This did not necessarily make the eirōn a heroic figure as he or she was portrayed as "a grinning fox, a scoundrel not to be trusted."103 Curiously, Aristophanes' caricature of Socrates depicts him as the alazōn whereas it is otherwise universally accepted that Socrates was the master eirōn. ${ }^{104}$ There was a consistency of approach across the Greek dramatists, including luminaries such as Euripides and Sophocles, both in terms of the eirōn and alazōn dichotomy and the broadly negative connotations of irony. Demosthenes, the Greek orator, took up the latter point and considered the idiomatic use of eirōneia to be a term of pure abuse. ${ }^{105}$

Plato's account of the life of Socrates started the process of rehabilitating the concept of irony and the first use of the term eirōneia is found in his work The Republic. Socrates' dialogues, as captured by Plato, retain the negative connotation of irony. Many of Socrates' contemporaries viewed his feigned ignorance as chicanery, scorn, or deceptive escapism. ${ }^{106}$ However, there was a subtle alteration in the paradigm, which began to emphasise the power of irony to act as "both assassin of pretension and midwife of truth."107 Accordingly as Jean-Pol Madou states, "l'ironie est devenue avec Socrate la compagne du philosophe dans sa quête de la vérité. C'est en effet l'ironie socratique qui, à l'aube de la pensée, ouvre le champ de la dialectique, lui fournissant d'entrée de jeu toute les armes de la ruse et de la seduction."108

While the Platonic dialogues helped elevate eirōneia from a term of pure abuse to one with vaguely positive connotations, Aristotle's Nicomachean Ethics delivered a major reversal of

\footnotetext{
101 "Charlie Chaplain was the very image of the eirōn, the little man, the flat-footed nobody, apparently at the mercy of any power that sought control over him but in the end, the unaccountable victor over everyone. Donald Duck is surely the alazōn, thoroughly impressed with himself, usually defeated, humiliated, but ready to puff himself up again and again." Good, Irony, 14.

102 Duke, Irony, 9.

${ }^{103}$ Ibid., 8. Although it is beneficial to remember that this is referring to irony as a mode not as a rhetorical device per se.

${ }^{104}$ Good pauses to consider this anomaly and muses whether Aristophanes portrayal of Socrates was not in fact double irony or perhaps merely satirical and shorn of irony. He prevaricates and perhaps wisely concludes "we cannot easily slide Aristophanes into a pigeonhole. Perhaps it is well; he is too mercurial a genius for that." Good, Irony, 31.

105 O'Day, Revelation, 12.

${ }^{106}$ Behler, Irony and Discourse, 79.

${ }^{107}$ Duke, Irony, 9.

108 Jean-Pol Madou, "Ironie Socratique, Ironie Romanesque, Ironie Poetique," in Irony and Satire in French Literature, ed. A. M. Hardee, vol. 16 (New York: Rodopi, 1987), 62.
} 
fortune. Aristotle's concept of the ethical golden mean meant that he never completely approved of either the over- or underplaying of truth. However, he went on to note that "a moderate use of self-depreciation [eirōneia] in matters not too commonplace and obvious has not an ungraceful air," ${ }^{109}$ thereby indicating that he was not adverse to a little irony and distinctly preferred eirōneia to alazōneia. ${ }^{110}$ His justification for this view was that "ironical people who employ understatement appear more attractive in character, because their object is felt to be not profit but the avoidance of ostentation. They also especially disclaim qualities that are held in general regard, just as Socrates used to do."111

Demosthenes and Theophrastus viewed irony as a "social vice by which dissimulating people shirk responsibility"112 and Greek philosophers, dramatists and rhetoricians persisted in approaching irony with reservation. This notwithstanding, it is essential to remember that at this time irony was primarily conceived of as a mode of behaviour and not as a rhetorical device. Thus Demosthenes and Theophrastus could denounce irony while still enjoying the heavily ironic works of Sophocles, Euripides and Aristophanes. Likewise, Aristotle's begrudging support for irony was predicated not on its use as a rhetorical device but because when it was used by someone like Socrates it led to the truth. It was Aristotle's association of irony with a motive of truth seeking that sowed the seeds of change. In making this truth-irony correlation, O’Day rightly sees that "Aristotle's taxonomical genius is evident in this classification."113

Socrates' impact on the theory and practice of irony cannot be over-emphasised. Holland describes Socrates as "the ironist par excellence, whose reputation has determined the critical estimation of irony from the time of Aristotle."114 Modern theories still attempt to answer the challenge of Socrates' approach to irony and truth, and seek to prove themselves worthy interlocutors. Aristotle's student, Anaximenes of Lampsacus, started to build a rhetorical sense of the word and even attempted an early definition: "Irony is saying something while pretending not to say it, or calling things by the opposite of their real names." 115

\footnotetext{
${ }_{109}$ Aristotle, The Nicomachean Ethics (New York: Penguin, 1976), 167.

${ }^{110}$ He still consider both to be "deceivers." Aristotle, Ethics, 165.

${ }^{111}$ Ibid., 166-167.

${ }^{112}$ Duke, Irony, 10.

${ }^{113}$ O'Day, Revelation, 13.

${ }^{114}$ Holland, Divine Irony, 15.

115 Anaximenes, Rhetoric to Alexander 1434'.17, quoted in Dane, Mythology of Irony, 46.
} 
The rehabilitation of irony that began under the Greek philosophers and the transition away from irony as a mode of behaviour to a rhetorical device both find their denouement in the Roman philosophers and orators. This in turn set the tone for the consideration of irony through the Middle Ages and the Renaissance. Many modern views of irony have consciously rejected the rigid formulations of irony that are perceived in the works of Cicero and Quintilian. These criticisms are often based, however, on misunderstanding or oversimplification of these author's works.

Cicero greatly admired Socrates and for the first time ironia, as it was now rendered in the Latin, was completely divorced from its prior negative connotations. Irony, in Cicero's words, is “an elegant kind of humour, satirical with a mixture of gravity, and adapted to oratory as well as to polite conversation." ${ }^{116}$ Cicero incorporated both the ethical and rhetorical lines of Aristotle's thought and came to view irony increasingly, but not exclusively, in terms of its value as a rhetorical apparatus. He not only stripped away the negative connotations but correspondingly added positive associations. One of his major contributions to irony was to look to Socrates' ultimate aim. As Colebrook explains, "Cicero argued, Socrates believed that rhetoric was ultimately unimportant and ought to be subordinated to the truth of ideas."117 Cicero saw the value of the Socratic pursuit of truth and sought to incorporate this in the oratorical use of irony.

Quintilian considered irony in a purely rhetorical sense. His approach was more technical, as evidenced by his attempted definition. In the Institutio Oratoria he examines irony among the tropes and figures, describing irony as either: "in both we are asked to understand the opposite/contrary of what is said" (in utroque enim contrarium ei quod dicitur intellegendium est). ${ }^{118}$ In his general discussion of figures, he describes it as "the term employed when we give our language a conformation other than the obvious and the ordinary."119 This latter usage is broadly similar to the concept of irony as espoused by Cicero. Quintilian was equally enamoured of the Socratic approach to irony. Unfortunately a narrow view of his work later

\footnotetext{
${ }^{116}$ Marcus Tullius Cicero, On Oratory and Orators trans. J. S. Watson (Carbondale: Southern Illinois University Press, 1986), 162.

${ }_{117}$ Colebrook, Irony, 38.

${ }^{118}$ Quintilian, Orator's Education, 9.2.44.

${ }^{119}$ Ibid., 9.1.4.
} 
developed, primarily because most post-Quintilian rhetoricians did not pursue this aspect of his work. $^{120}$

Quintilian's influence on the study of irony was momentous and set the tone for well over a millennium. His observations are surprisingly pertinent to contemporary discussions of irony, although this is rarely acknowledged. For this reason, O'Day is correct in her bold assertion that:

His observations nevertheless foreshadow three concerns that are central to modern studies of irony and that will be important in the analysis of Johannine irony. First, his emphasis on delivery, speaker and subject reflects an integrated approach to identifying and interpreting irony, one in which internal and external factors play a role. Second, Quintilian highlights the question of the speaker's ironic intention, and third, he draws attention to the importance of taking the context seriously, noting that any ironic statement could be literally true in another context. ${ }^{121}$

Quintilian represents a base line that later ironic movements returned to or reacted against.

\section{c) Romanticism}

The technical form of irony that Cicero and Quintilian developed became heavily formalised during the Medieval and Renaissance periods. Behler goes too far in stating that "Socratic irony had been extinguished in the classicist tradition of the ars poetica by a glossy and formal device of rhetorical irony that followed established rules and, in its firm strictures of truth-orientated relations, constituted almost the opposite of what Socratic irony once had been." ${ }^{122}$ Nonetheless, this overly formulaic mode was rejected and irony reinvigorated, initially by the English Romantics. Therefore, writers such as Jonathan Swift, Alexander Pope, Daniel Defoe, and Henry Fielding, began to recognize irony as an important literary mode and expanded the limited ironic techniques outlined by Quintilian into comprehensive literary techniques. ${ }^{123}$

This movement was a precursor to the German Romantics who were to have a major impact on the theory and practice of irony. They built on the use of irony by their English counterparts and extrapolated from specific instances of irony an ironic representation of the human condition, in

\footnotetext{
${ }^{120}$ O’Day, Revelation, 18.

${ }^{121}$ O'Day, Revelation, 17.

122 Behler, Irony and Discourse, 81.

${ }^{123}$ O’Day, Revelation, 19.
} 
the vein of general irony. ${ }^{124}$ The German Romantics rapidly outgrew the foundations laid by their English brethren as they explored notions of life's ability to thwart language and understanding. ${ }^{125}$ Additionally, and of profound importance for this study, they redefined irony's relationship with truth. Instead of irony revealing a concealed truth, irony became an expression of truth, which in turn was used to destabilise notions of objective truth.

The term "romantic irony" defies easy classification and even Strohschneider-Kohrs in her definitive treatment of the topic does not attempt a definition. Instead she offers symptomatically vague statements by the preeminent Romanticist Friedrich Schlegel, such as: "Ironie ist klares bewusstsein der ewigen agilität, des unendlich vollen chaos," "126 or his description of irony as "logischer schönheit."127 Thus irony's attendant ambiguity reaches new heights in the Romantic tradition. Strohschneider-Kohrs captures this essence as she seeks to describe how romantic irony is much more than a singular event, "sondern als den "steten wechsel von selbsterschöpfung und selbstvernichtung', in dem als 'absolute synthesis absoluter antithesen.",128 Behler wisely cautions "we should be careful, however, not to construe this movement in dialectical or Hegelian manners a goal oriented, teleological process, but to consider instead a bottomless sliding as its main feature."129

The terms romantic irony and general irony are often used erroneously as synonyms; however, romantic irony is a sub-variety of general irony. It was grounded in the literary creative process, especially poetry, and as such romantic irony emphasised "the incongruities of both the artist in relation to his or her art and human beings in relation to their world." ${ }^{130}$ Irony became central to an artist's attempt to describe the world because while life may not be knowable, for knowledge and theory are conceptual, it could be experienced through irony. ${ }^{131}$

Romantic irony posited that all life is ironic; consequently, irony is commensurate with the human condition and its attendant absurdities. This was predicated on antipathy towards the strictures created by the Enlightenment preoccupation with reason as a universal human norm.

\footnotetext{
${ }^{124}$ These thought forms are commonly associated with the work of the Jena Romantics: the Schlegel brothers (Friedrich and August Wilhelm), Ludwig Tieck, Adam Müller, Novalis, and Karl Solger.

${ }^{125}$ Colebrook, Irony, 22.

${ }^{126}$ Ingrid Strohschneider-Kohrs, Die Romantische Ironie in Theorie und Gestaltung (Tübingen: Niemeyer, 2002), 59.

${ }^{127}$ Strohschneider-Kohrs, Romantische Ironie, 51.

${ }^{128}$ Ibid., 50.

${ }^{129}$ Behler, Irony and Discourse, 83.

${ }^{130}$ O’Day, Revelation, 19.

${ }^{131}$ Colebrook, Irony, 64.
} 
The Romantics were aware that their approach contained an internal inconsistency as "in order to argue against or challenge reason one needed to speak, but such speech would seem to demand understanding and would therefore rely on the very norms of reason it set out to delimit." "132 This necessitated the elevation of irony from either a rhetorical device or a mode of behaviour to a way of describing life itself. They reasoned that the perfect response to this internal inconsistency was irony: which could speak but simultaneously declare its own limitations and incomprehension.

This was a fundamental change in the nature of irony itself. For the German Romantics irony was not just a way of saying the opposite of what one intended, it became a way to say both opposites at once and label the contradiction ironic. ${ }^{133}$ They therefore went far beyond Socrates' irony as a mode of behaviour. Instead, the Romantics proclaimed irony, not as a mode of behaviour, but as the only true mode of life. Erroneously but predictably, the Romantics saw themselves as the true heirs of Socrates. Madou describes how Schlegel "se réfère explicitment à l'ironie socratique pour définer l'ironique romantique comme l'exercice d'une liberté qui se découvre infinite." 134

The precarious rationale behind this position did not escape the attention of prominent thinkers of the day and romantic irony was roundly criticised. Hegel offered this stinging rebuke: "This type of subjectivism not merely substitutes a void for the whole content of ethics, right, duties and laws - and so is evil, in fact evil through and through and universally - but in addition its form is a subjective void, i.e. it knows itself as this contentless void and in this knowledge knows itself as absolute."135 This form of irony occasioned Kierkegaard's famous description of it as "infinite absolute negativity." 136 Irony did not prove to be the ontological panacea the German Romantics had hoped for and, put delicately, "romanticism is often attacked for a certain incoherence." 137

\footnotetext{
132 Ibid., 47.

133 "Die echte ironie setzt das höchste bewusstsein voraus, vermöge dessen der menschliche geist sich über den gegensatz und die einheit der idee und wirklichkeit vollkommen klar ist." Strohschneider-Kohrs, Romantische Ironie, 195.

134 Madou, Ironie Socratique, 65.

${ }^{135}$ Georg Wilhelm Friedrich Hegel, Hegel's Philosophy of Right ed. T. M. Knox (London: Oxford University Press, 1967), 102-103.

${ }^{136}$ Kierkegaard, Concept of Irony, 261.

${ }^{137}$ Colebrook, Irony, 61.
} 
The internal inconsistency present in romantic irony gives rise to what Colebrook calls "the problem of irony," 138 by which, she really means the problem of general irony. In essence, the problem is how we can know the meaning or sense behind words. The traditional answer has been Platonic in nature - there are transcendent ideals that exist beyond or behind language. In referring to something as being "just," for example, the word itself has no intrinsic meaning other than pointing to an ideal that transcends our ability to describe it with language. Accordingly, when language is unreliable, inadequate or unstable appeal can be made to the idea behind the word. Alternatively, if the existence of objective and timeless ideas is considered unacceptably mystical, an explanation must be offered for meaning from within human language. The German Romantics therefore embraced the work of Kant. He posited the sensus communis, in which meanings are generated from within a communal framework. ${ }^{139}$ The way a word is used is not an appeal to a transcendent standard but rather to a communal standard; something is "just" because common usage determines it to be so.

In this sense, the romantic assertion that we can only speak ironically - that the subject can never turn back and know its own world-forming activity - has been affirmed as "a harbinger of postmodernism, as one of the first attempts to think beyond a totalising and all-consuming subjectivity." 140 This is problematic because in refusing to see any transcendence beyond subjectivity and therefore the need to interpret all ironically, irony itself becomes transcendent. Thus, the Romantics ambitiously proposed that "ironie sei das über die geheimen widersprüche."141 However, as we have observed in earlier in this chapter, the contradiction inherent in irony exists in order that it may be resolved and new meaning found. The contradictions raised by the German Romantics could not be resolved by merely labelling them as ironic; this does not rectify the paradoxical nature of their epistemology. Rejecting the tyranny of language as the arbiter of meaning, they replaced it with another equally problematic hierarchy. For this reason, romantic irony has been criticised as "the abandonment of a public and critical assessment of the social forces of language." $" 142$

As an overarching philosophy, romantic irony is woefully deficient. However, the German Romantics were not making philosophical claims. They were more interested in the artistic

\footnotetext{
138 Ibid.

${ }^{139}$ Immanuel Kant, Critique of the Power of Judgment trans. P. Guyer and E. Matthews. (Cambridge: Cambridge University Press, 2000), 173-176.

${ }^{140}$ Colebrook, Irony, 70.

${ }^{141}$ Strohschneider-Kohrs, Romantische Ironie, 81.

${ }^{142}$ Colebrook, Irony, 71.
} 
process of describing the world and accordingly they deliberately supplanted philosophy with poetry. ${ }^{143}$ They argued that poetry does not try to define humanity in transcendent terms, which they saw as an illusory exercise. The main thrust of romantic irony and its lasting contribution was the desire to "keep open the place of art in an open world... and ironically express within itself the general ironies of art and of the human predicament at large." ${ }^{144}$ Thus the Romantics encapsulated not only the creatively articulated contradictions of life within the rubric of irony but also the inherent contradictions of their own thought forms.

As in classical times, the artistic use of irony invigorated a philosophical debate, as noted above in relation to Hegel and Kierkegaard, but also among other intellectuals of the day. A generation after the death of the Schlegel brothers, Friedrich Nietzsche in exploring the limits of language investigated irony as a means of solving the ostensible contradictions in his epistemological theories. Nietzsche's work on irony is intriguing for two reasons. First, he is widely considered a forerunner of postmodernism, a bridge between romantics and postmodern irony. Second, while the intervention of a philosophical heavyweight like Nietzsche might be hoped to bring clarity to the discussion of irony, his work is interpreted in vastly different and sometimes diametrically opposed ways. Nietzsche's thought is at times inscrutable and those who follow different threads reach different conclusions.

A good example of the difficulty in getting to grips with Nietzsche's eclectic approach to irony is found in the works of Colebridge and Behler. Colebridge sees Nietzsche in the vein of a proto-postmodernist who embraced irony in a positive sense as an attempt to show through contradiction that language was not its own master. She notes, "Nietzsche's irony attempted to affirm the forces of life and will that extend beyond any creative self." ${ }^{145}$ Behler takes a contrary view. He maintains Nietzsche usually "avoided the term irony, which for his taste has too much romanticism in it, and preferred the classical notion of dissimulation which he translated as 'mask'.... In the few instances where we come across the term in Nietzsche's writings, irony has mostly a negative connotation."146 Nietzsche's' reliance on brief and sometimes obtuse aphorisms renders it difficult to draw definitive conclusions.

\footnotetext{
143 "Ironie ist ein Mittel der Selbstpräsentation von der Kunst." Strohschneider-Kohrs, Romantische Ironie, 70. Thus Strohschneider-Kohrs can quote Solger: "Ohne Ironie gibt es überhaupt keine Kunst." StrohschneiderKohrs, Romantische Ironie, 195.

${ }^{144}$ Muecke, Compass, 215.

${ }^{145}$ Colebrook, Irony, 99.

${ }^{146}$ Behler, Irony and Discourse, 93.
} 
While Colebridge and Behler disagree on how Nietzsche used irony, they agree on the outcome. Nietzsche embraced the principles of general irony but never transcended the inherent contradiction of the "problem of irony." As Colebrook explains,

Nietzsche, however, was caught in a paradoxical position. To say that language is not the thing itself, or is not literal - even to say that language can never be truth still allows for some ultimate truth or presence which language fails to grasp. Indeed, Nietzsche's explanation of the emergence of the fiction of truth both presents itself as true and gives a highly physical and literal explanation - just the sort of final scientific authority Nietzsche is criticising. ${ }^{147}$

Behler concurs that Nietzsche used all the rhetorical forms he so vehemently denounced in others. He condemned the use of irony as decadence, disassociation and "arrogant disdain," but as always when Nietzsche touches upon subjects of decadence "his straightforward evaluations begin to shift and soon let us notice his predilection for such phenomenon." 149 Nietzsche's contribution is hard to evaluate. What is certain is that he moved the discussion of irony away from the creative process and gave it a philosophical connotation that has predominated ever since. However, like the romantics, Nietzsche used irony selectively as a convenient means of dealing with the incongruity of his own hypothesis and perpetuated the romantic definition of irony that equated it solely with contradiction. However, while irony naturally contains contradiction it then necessarily transcends and resolves it, something Nietzsche and the Romantics never managed to do.

Søren Kierkegaard, the prolific Danish philosopher and theologian, was another who profoundly affected the debate on irony. His elucidation of the negative aspects of irony is as masterful as it is frequently ignored. His oft-quoted aphorism that irony is "infinite absolute negativity" clearly delimits the boundaries but is not, as sometimes cited, a denunciation of irony per se. Instead, it is a salient warning of the dangers inherent in ironic discourse:

It is negativity, because it only negates; it is infinite, because it does not negate this or that phenomenon; it is absolute, because that by virtue of which it negates is a higher something that still is not. The irony established nothing, because that which is to be established lies behind it.... Irony is a qualification of subjectivity. In irony, the subject is negatively free, since the actuality that is supposed to give the subject

\footnotetext{
${ }^{147}$ Colebrook, Irony, 98-99.

${ }^{148}$ Friedrich Wilhelm Nietzsche, Beyond Good and Evil trans. R. J. Hollingdale, (London: Penguin, 1990$), 122$.

${ }^{149}$ Behler, Irony and Discourse, 95.
} 
content is not there. He is free from the constraint in which the given actuality holds the subject, but he is negatively free and as such is suspended, because there is nothing that holds him. But this very freedom, this suspension, gives the ironist a certain enthusiasm, because he becomes intoxicated, so to speak, in the infinity of possibilities. $^{150}$

Kierkegaard's characteristically dense prose belies a refreshing coherence that eludes most who venture into literary and philosophical examinations of irony. His comments here are a thinly veiled attack on romantic irony delivered from an ethical standpoint. As Søltof notes, Kierkegaard accuses the romantic ironists of spurning both context and circumstance, in that "if he feels that they do not suit him, he simply recreates them to suit himself."151 Kierkegaard's warning not to use the subjective qualities of irony to avoid objective constraints is highly pertinent to recent developments in the study of irony. Although he had strong misgivings about the way in which irony was used within the romantic milieu of his day, his overall appreciation of irony was positive. Indeed the very subjective qualities he cautioned against over indulging, he himself used sparingly to great advantage. Thus, "irony was a form of indirection Kierkegaard employed, irony based on the mental detachment fundamental to symbolic communication."152 Within clearly defined constraints, Kierkegaard found irony to be an effective vehicle for delivering uncomfortable truth circuitously.

Many of Kierkegaard's examples draw on the negative aspects of irony. For example, he describes Socrates and John the Baptist as ironic destroyers of Greek culture and Judaism respectively. ${ }^{153}$ However, this is predicated on his notion of "justified irony." While Socrates and John the Baptist created havoc with irony, this was justified due to the corrupt and unsound natures of the societies that could not recognise nor accept their irony. ${ }^{154}$ Duke is therefore wrong in suggesting that Kierkegaard was "not altogether correct, for not every ironist is without positive purpose."155 This assessment does not recognise the full nuances of Kierkegaard's view of irony as beginning in negation but eventually being positive, even necessary. Kierkegaard's critique was not a rejection of irony but an attempt to restore the balance he found lacking in the

${ }^{150}$ Kierkegaard, Concept of Irony, 261-262.

151 Pia Søltof, "Ethics and Irony," in The Concept of Irony, International Kierkegaard Commentary 2, ed. R. L. Perkins, (Macon: Mercer University Press, 2001), 278-279.

${ }^{152}$ Holland, Divine Irony, 14.

${ }^{153}$ Kierkegaard, Concept of Irony, 263-265.

${ }^{154}$ Kierkegaard is quick to warn that "only history can judge whether the irony is justified or not." Ibid., 264.

155 Duke, Irony, 15. Although Duke accepts that "nonetheless there is more than a measure of truth in Kierkegaard's analysis. Even, when irony seeks to create new meaning or new community, it begins in negation." Ibid. 
prevailing romantic view of irony. Accordingly, he writes "Irony limits, finitizes, and circumscribes and thereby yields truth, actuality, content; it disciplines and punishes and thereby yields balance and consistency. Irony is a disciplinarian feared by those who do not know it but loved by those who do." 156

His explication of the link between irony and truth was another valuable contribution to the ongoing debate. For Kierkegaard, like Socrates and Aristotle, irony was fundamentally a means of yielding truth: truth too difficult or unpalatable to be addressed directly. The use of irony brings clarity by saying that which is not, hence his description of it as a negation. Nonetheless, irony's eventual elucidation of the actual is ultimately positive and desirable. This aspect of Kierkegaard's work is often neglected or misrepresented. His enthusiasm for irony's truth deriving qualities, as epitomised by Socrates, is frequently subverted by a contemporary enthusiasm for irony as a means of circumventing objective truth claims. Kierkegaard's critique of romantic irony, and the overarching problem of general irony, is surprisingly pertinent in contemporary discussion of irony.

\section{d) Postmodernism}

Postmodernism is a term with a frustration quotient for would-be definers almost equal to that of irony. Both its proponents and opponents have employed the term so diversely that it is rendered virtually meaningless. ${ }^{157}$ The term was first used in the 1950s for movements in architecture and literary criticism that broke modern conventions, but it later came to be used to describe almost anything that overturns traditional standards. In the 1980s the term was utilised by philosophers such as Jacques Derrida, Emmanuel Levinas, Michel Foucault, Hans-Georg Gadamer, Jean-Francois Lyotard and Richard Rorty. If there is a unifying thread to postmodern philosophy, it is a rejection of Enlightenment rationalism, although the form and degree of rejection are often radically dissimilar. It both engages with and against the principal architects

\footnotetext{
${ }^{156}$ Kierkegaard, Concept of Irony, 326.

${ }^{157}$ Some argue that the term postmodernism is inappropriate because the suffix "-ism" implies a unified or cohesive belief structure. Thus the term postmodernity is often used. While accepting the validity of this criticism, the expression postmodernism will be used here as it is the conventional and most widely accepted term. For the purposes of this study I make no differentiation between postmodernism and post-structuralism as the distinction is fraught and the general conclusions of this section apply equally to both.
} 
of modern thought such as Rene Descartes, Immanuel Kant, Johann Fichte, Georg Wilhelm, Friedrich Hegel, Wilhelm Dilthey and Edmund Husserl. ${ }^{158}$

Due to the inherent complexity of postmodernism an exhaustive treatment is not possible here. But a brief consideration is necessary because it potentially shapes the assumptions contemporary readers bring to the interpretation of the Fourth Gospel. In postmodernism general irony finds its culmination. Rather than being a literary device to describe life, it now becomes life itself. Moreover, life and all its component parts are absurd. ${ }^{159}$ In this sense, "irony is inseparable from the evolution of the modern consciousness."160

Irony's ability to offer a duality of meaning, which allowed the Romantics to have their semantic cake and eat it too, also appeals to the postmodern thinker who wants to retain the ability to assert meaning at the same time rejecting any overarching explanation. Irony becomes the means by which meta-narratives are subverted while still thinking it is possible to make substantial statements. Irony, in this sense, transcends expression and becomes its own reality. It evinces the huge problems of postmodernity, in that the context of contemporary life is ironic because nothing really means what it says. Accordingly, "we live in a world of quotation, pastiche, simulation and cynicism: a general and all-encompassing irony." ${ }^{161}$ Irony becomes the mechanism that simultaneously challenges and ultimately expresses the truth. Postmodern irony is therefore not merely a mode of questioning and expressing life but of ultimately existence itself. $^{162}$

This leads to a very different approach to literary studies. The Romantics, utilising irony as a mode, focused on the creative process and sought to create truly ironic viewpoints. For postmodern critics, however, irony is not just a view on the world but an expression of the world itself. Therefore, it is possible to re-examine the meaning of any text ironically. Texts not traditionally conceived to be "ironic texts" can be re-read ironically. This can result in literature

\footnotetext{
${ }^{158}$ Distinctions rapidly become blurred however as many postmodern thinkers retain elements of modernity, albeit often held with suspicion, and many so-called modern thinkers have what could only be termed thoroughgoing postmodern aspects to their thought.

${ }^{159}$ O’Day, Revelation, 20.

${ }^{160}$ Behler, Irony and Discourse, 73.

${ }^{161}$ Colebrook, Irony, 1.

162 "For postmodernism, the problem of inside/outside relations is not confined to the question of literature but extends rather across the whole field of culture and society. What was once the romantic space of the literary becomes, for postmodernism, a general plane of human existence." Lucy Niall, Postmodern Literary Theory (Oxford: Blackwell, 1997), ix.
} 
being "characterised by its potential for irony, its capacity to mean something other than a common-sense or everyday use of language." 163

Postmodern irony and the literary responses it enables are therefore rightly called deconstructionist. They embrace Kierkegaard's “infinite absolute negativity" with a vigour hitherto unimagined. Previously irony was grounded in, but simultaneously detached from, a context or a reality, with the irony being located in the difference between them. Therefore, irony was "always contextual; it is an attack on determinate, non-contextual meaning.",164 Postmodern irony, however, widens that attack to include the context itself, since the epistemological context of irony is life itself. Thus, Colebrook asserts, "irony destroys the immediacy and sincerity of life; through irony we do not just live the meaning of our world, we can ask what these meanings are really saying." "165 For postmodernism critics, irony shares the fluidity and context-dependency of all general concepts, while simultaneously it allows for competing and discontinuous contexts.

Irony is removed from the hands of the author and is now wielded solely, in a reinvented and expanded form, by the reader. Critics differ on where the boundaries between the author, text and reader, if any, may lie. As early as 1956 Jorge Luis Borges proposed that all texts could benefit from an ironic reinterpretation. ${ }^{166}$ Colebrook concurs, noting that Mary Shelley could not have anticipated that in a world afflicted with AIDS her novel The Last Man (1826) would resonate so profoundly. Nor that Shakespeare's Romeo and Juliet would equally speak to urban gang warfare as much as its original historical and cultural context. She concludes that "one cannot determine in advance how the potentials of a text might be realised or actualised; one cannot reduce force to its manifest and present effects." ${ }^{167}$ The postmodern suggestion that meaning is never autonomous of the reader places epistemological considerations of the nature of truth to the fore. Accordingly, there is a sharp dividing line between those who see irony as functioning from a shared recognition of common truths (the consensus view) and those who see it as emanating from diverse viewpoints that are incommensurable (the divergence view).

\footnotetext{
${ }^{163}$ Colebrook, Irony, 5. Moreover, "Once we have the concept and theory of irony it is possible to discern ironic strands in literature that did not, itself, use or theorise the concept of irony." Ibid., 6.

${ }^{164}$ Holland, Divine Irony, 15.

165 Colebrook, Irony, 3-4.

166 "This technique would fill the dullest books with adventure. Would not the attributing of The Imitation of Christ to Louis Ferdinand Celiné or James Joyce be sufficient renovation of its tenuous spiritual counsels?" Jorge Luis Borge, Ficciones (New York: Grove, 1962), 55.

${ }^{167}$ Colebrook, Irony, 123.
} 
The first group sees irony as a rhetorical figure that is ultimately recognisable because of a common human understanding. This is epitomised by Socrates for whom irony was a "rhetorical move in order to reinforce truth and consensus."168 Philosopher John Searle and literary critics Booth and Muecke are examples of those who espouse the consensus view. The second group include those who see irony as a way of life, exemplified by Socrates for whom irony was the "rejection, consternation or disruption of shared norms."169 Literary critics Candace Lang and Linda Hutcheon are proponents of the divergence view. Inexplicably Colebrook includes Kierkegaard alongside Lang and Hutcheon. However, this misreads Kierkegaard's view of the negativity of irony. Kierkegaard rightly belongs in the consensus camp, as evidenced by his comments that; "Irony limits, finitizes, and circumscribes and thereby yields truth, actuality, content." 170 Kierkegaard saw irony as a negative road to a positive outcome, capable of revealing unpalatable truths through indirect communication.

Notably both groups appeal to the legacy of Socrates and accordingly the groups are divided as to whether Socrates is the beginning or the end of general irony. For Colebrook herself, he is the exemplar of postmodernity. She concedes the historical perspective of Socratic irony as a play with language that invariably moves from the instability of irony to the fixity of absolute moral truths. ${ }^{171}$ However, she accepts the view of postmodernists such as Lang and Nehamas that "Socrates is then unfortunately represented in the latter Platonic dialogues, and later Western thought, as one who use irony, rhetoric and play only to reveal some ultimate truth." ${ }^{172}$ How Plato's contemporaneous exposition of his own mentor and teacher became "unfortunate" is hard to see. Nor does it take into account that many modern perceptions of irony would be foreign to those whose understanding of irony was formed by Greco-Roman or Semitic literature. ${ }^{173}$

In examining Socrates' use of irony in Plato's Symposium, Colebrook demonstrates how the postmodern radical reinterpretation of Socrates leads to a degree of incoherence. She concludes, "this position described by Socrates is remarkably anti-ironic: there simply is a truth that we can arrive at, and discern beyond all particular points of view. I say this is anti-ironic because, unlike the enigma, suggestiveness and allusion of Socratic irony, this positing of essence and

\footnotetext{
168 Ibid., 44.

${ }^{169}$ Ibid., 44-45.

${ }^{170}$ Kierkegaard, Concept of Irony, 326.

${ }^{171}$ Colebrook, Irony, 40.

${ }^{172}$ Ibid. [Italics mine]

${ }^{173}$ Duke, Irony, 10.
} 
truth is literal.", Socrates' position is now anti-ironic and is somehow different from "Socratic irony" because he uses irony to reveal literal truth. This conclusion is patently absurd unless there is an a priori presupposition that irony cannot reveal literal truth. ${ }^{175}$ The postmodern appropriation of Socratic irony appears centred on an admiration for his enigmatic and disruptive style, which suits postmodern sensibilities as the purported meaning of texts are deconstructed. Meanwhile, Socrates' ultimate aim, the pursuit of truth, is marginalised as an unfortunate inconvenience. ${ }^{176}$ This question of Socratic intentionality is potentially significant for our present purposes because the author of the Fourth Gospel would likely have been influenced, to some degree, by classical Greek thought forms, either directly or indirectly through the wider legacy of Socratic thought and style in Hellenistic culture. ${ }^{177}$

Two other seminal voices in the consideration of postmodern irony are Richard Rorty and Jacques Derrida. Their approaches are dissimilar but both have the same outcome. Rortian irony is often termed "liberal irony" but it is indistinguishable from postmodern irony just described. It is grounded in a radical distrust of language to describe the world. No one individual's vocabulary is any closer to reality (or some transcendent power) than any other individual's. ${ }^{178}$ This distrust of final vocabularies leads to a belief in redescription. That is, that "anything can be made to look good or bad by being redescribed." 179 Since everything is capable of redescription, then a Rortian ironist must accept the contingency of their most central beliefs and desires.

Rorty's provocative approach to irony has been heavily criticised. His critics observe that Rorty's commitments to both contingency and moral ideals are incompatible. ${ }^{180}$ Furthermore, he

\footnotetext{
${ }^{174}$ Colebrook, Irony, 32.

175 Vasiliou warns, "Socratic irony is potentially fertile ground for exegetical abuse. It can seem to offer an interpreter the chance to dismiss any claim which conflicts with his account of Socratic philosophy merely by crying 'irony'. If abused in this way, Socratic irony can quickly become a convenient receptacle for everything inimical to an interpretation. Much recent scholarship rightly reacts against this and devotes itself to explaining how Socrates actually means everything he says..." Iakovos Vasiliou, "Conditional Irony in the Socratic Dialogues," The Classical Quarterly, vol.49 no.2 (1999), 456.

176 "Socrates clearly believes ethical propositions are truth functional." David Wolfsdorf, "The Irony of Socrates," The Journal of Aesthetics and Art Criticism 65.2 (2007), 185. Wolsdorf characterises Socrates as ultimately sincere and earnest. Ibid., 176.

177 Parsenios observes, "It is misleading, of course, to suggest that the terms 'Judaism' and 'Greco-Roman' correspond to utterly distinct realities in the study of 1st century Christianity or Judaism." Parsenios, Departure and Consolation: The Johannine Farewell Discourses in Light of Greco-Roman Literature (Leiden: Brill, 2005), 2. Brant, following Riley, proposes, given that the writers of the Gospels were literate in Greek, their education would have included consideration, and memorisation of Greek literature. Jo-Ann Brant, Dialogue and Drama: Elements of Greek Tragedy in the Fourth Gospel (Peabody: Hendrickson, 2004), 14.

${ }^{178}$ Richard Rorty, Contingency, Irony and Solidarity (Cambridge: Cambridge University Press, 1989), 73.

179 Ibid.

${ }^{180}$ Brad Frazier, Rorty and Kierkegaard on Irony and Moral Commitment, (New York: MacMillan, 2006$), 35$.
} 
defines autonomy as getting out from under a vocabulary without any regard for the content of that vocabulary, resulting in the outcome that the vast majority of persons that compose Rorty's audience (i.e. committed liberals) "cannot coherently adopt his position."181 Likewise his strident antirealism and complete rejection of objectivity have led others to describe his thought as "incoherent, inconsistent, or relativistic (or some combination thereof)."182

Rorty's liberal irony and his use of redescription in particular, have been denounced as morally dubious and devoid of meaningful notions of truth. Moody-Adams suggests that "for most surviving victims of Hitler or Stalin the notion that to them 'anything' might be made to 'look good' would be sheer anathema." 183 Likewise, Dane refers to "Rorty's nightmarish utopian vision of 'liberal ironists." 184 Rorty insists that the value of postmodern irony lies in its ability to refrain from making substantive truth claims, but this does not account for Rorty's own position. As Colebrook points out, postmodern irony - such as Rorty's - would irreconcilably "allow us to speak and not really mean what we say and that would happily allow us to say and not-say at one and the same time."

According to Derrida Western metaphysics has too long been under the sway of logocentrism. That is, all literature, speech, science and philosophy are grounded in systems or structures in which the "word" or "act of speech" is considered epistemologically superior. Derrida employs his trademark deconstructionism to disrupt these hierarchies while staying grounded in the recognition that while truth or concepts such as presence may be created rhetorically and intentionally they can take on an extra-rhetorical ethical force or power. ${ }^{186}$ Critics charge that this distinction is more semantic than real. Even Derrida accepts that his position is contradictory in that he is maintaining the laws of language are necessary yet impossible. ${ }^{187}$ This means that Derridean irony arrives at the same impasse as romantic and Rortian irony albeit accepting the validity of quandary. Accordingly, Derrida concedes: "we can pronounce not a single deconstructive proposition which has not already had to slip into the form, the logic, and the implicit postulations of precisely what it seeks to contest." 188

\footnotetext{
${ }^{181}$ Frazier, Moral Commitment, 35.

${ }^{182}$ Lloyd Gerson, "Philosophy, Literature and Truth," University of Toronto Quarterly 59 (1990), 449-451.

${ }^{183}$ Michele Moody-Adams, "Theory, Practice, and the Contingency of Rorty's Irony," Journal of Social Philosophy 25 (1994), 209-227.

${ }^{184}$ Dane, Mythology of Irony, 134.

${ }^{185}$ Colebrook, Irony, 169.

${ }^{186}$ Contra Nietzsche, Colebrook, Irony, 102.

187 Ibid., 98.

${ }^{188}$ Jacques Derrida, Writing and Difference trans. A. Bass (Chicago: The University of Chicago Press, 1978 ), 280.
} 
Since for Derrida all speech is potentially ironic, because nonsensical forces are at work in the articulation of all concepts, the concept of deconstructionism itself would be potentially ironic and open to deconstruction. However, unsurprisingly and unsustainably, Derrida demurs: "justice in itself, if such a thing exists, outside or beyond law, is not deconstructible. No more than deconstruction itself, if such a thing exists. Deconstruction is justice."189 This creates in deconstructionism an unchallengeable, ultimate ethical platform or philosophy for forming judgement (or meta-narrative) thereby resulting in logocentrism, the very evil deconstructionism seeks to vanquish. Thus, postmodernism does not lead to the deconstruction of metaphysics but rather to an exchange of metaphysical frameworks.

Inevitably, Colebrook's "problem of irony" that bedevilled the Romantics returns to haunt postmodern perspectives of irony. ${ }^{190}$ Irony is redefined until it is no longer recognisable, either as a rhetorical tool or as a mode of behaviour. Irony is stretched from the overly simplistic "saying one thing and meaning another" to an equally simplistic and ultimately untenable "saying two conflicting things and meaning both."191 Postmodern irony proves to be a philosophical cul de sac because if everything is ironic then nothing is. ${ }^{192}$

The turn of the century has witnessed a pronounced reaction against postmodern irony and its perceived destruction of the immediacy and sincerity of life. ${ }^{193}$ In 2000 Purdy published an erudite and heartfelt appeal against ubiquitous ironic detachment. ${ }^{194}$ This touched off a debate that polarised views. Many sympathised with his judgment that "the ironic stance invites us to be self-absorbed... its sophistication is sapping, a way of cultivating suspicion of ourselves and others. Refusing to place its trust in the world, irony helps to make a world that is more likely to be worthy of despair."195 Purdy's work gained added impetus in the wake of the terrorist attacks on the World Trade Centre on September $11^{\text {th }}, 2001$. Winokur penned a chapter in his The Big Book of Irony ${ }^{196}$ dedicated to the declaration by various cultural commentators that in the wake

\footnotetext{
${ }^{189}$ Jacques Derrida, "Force of Law: The Mystical Foundation of Authority," in Deconstruction and the Possibility of Justice eds. D. Cornell, et al. (New York: Routledge, 1992), 14-15.

${ }^{190}$ Colebrook, Irony, 61.

${ }^{191}$ Or as Muecke suggest this form of irony can potentially produce "not one but an endless series of subversive interpretations." Muecke, Critical Idiom, 31.

192 Duke notes that such a broad description of irony "robs us of a meaningful term with which to describe the particular literary phenomenon." Duke, Irony, 13. Muecke contends that deconstructionism is inimical to irony and will render the term decreasingly useful to literary criticism. Muecke, Critical Idiom, 101.

${ }^{193}$ Colebrook, Irony, 3-4.

194 Jedediah Purdy, For Common Things: Irony, Trust, and Commitment in America Today (New York: Vintage Books, 2000). Frazier notes that "Purdy's critique of a morally enervating sort of irony also closely parallels Kierkegaard's position." Frazier, Moral Commitment, 3.

${ }^{195}$ Purdy, Common Things, 19-20.

${ }^{196}$ Which naturally is a small tome.
} 
of September 11, "irony is dead."197 Noting their subsequent prevarications, he wryly suggested that irony was not dead but merely on a holiday.

Searle, who specialises in the philosophy of language, has attacked the propensity to treat all texts ironically, to deny they are grounded in stable and recognisable contexts and to see them as distanced or divorced from their original intention. ${ }^{198}$ Searle contends that language is a shared and conventional system that renders texts capable of stability. He builds on the earlier work of Muecke and Booth and convincingly asserts that irony, rather than epitomising linguistic instability, evinces the fundamental coherence of language and literature.

\section{Conclusion}

This overview of the history and development of irony demonstrates three significant points that are pertinent to a consideration of irony in the Fourth Gospel. The first and most significant contribution of the historical overview is that it demonstrates the intrinsic relationship between irony and truth. In every era, irony has been related to notions of truth, whether positively or negatively. The early antipathy towards irony was based on its perception as an obfuscation of the truth. Aristotle's reassessment of Socratic irony as truth seeking and truth revealing, favourably informed perceptions of irony until recent times. Romanticism started the assault on the notion of presence behind meaning and postmodernism developed this into a denial of absolute truth. The ironic rapier using wit to skewer opponents on the truth has become a nondiscriminating bludgeon that pummels every viewpoint with the audacity to claim to be true (except of course its own). Despite labelling the contradiction ironic, the inability to resolve this incongruity led to widespread rejection of these viewpoints. ${ }^{199}$ Likewise modern concepts of general irony have been found wanting. ${ }^{200}$ The salient point, however, is that the concept of truth is indispensable to any consideration of irony.

\footnotetext{
197 The comment is usually attributed to Graydon Carter the editor of Vanity Fair, while Time magazine essayist Roger Rosenblatt announced the "end of the age of irony." Jon Winokur, The Big Book of Irony (New York: St. Martin's, 2007), 75.

198 John Searle, “Literary Theory and its Discontents," New Literary History 25 (1994), 637-667.

199 "We probably have been too influenced in our hermeneutics by the modern ideals of detached truth... The postmodern reaction has gone too far in denying any 'presence' behind a meaning, in dissolving meaning simply into a strategy for coping, and hence making all utterances equally valid." Loren Wilkinson, "Hermeneutics and the Postmodern Reaction Against 'Truth'," in The Act of Bible Reading: A Multi-disciplinary Approach to Biblical Interpretation ed. Elmer Dyck (Downers Grove: IVP, 1996), 135.

200 "General irony is not primarily corrective or normative; we are all in the same hole and there is no way of getting out of it." Muecke, Compass, 120-121.
} 
Secondly, it is beyond dispute that irony as used in the first century was something quite different from recent views of irony. Accordingly, an understanding of modern theories is important to avoid anachronistic readings of Johannine irony. Furthermore, our primary question concerns the rationale for Johannine irony, which means that authorial intention will be of importance. The proper historical context for the authorial intent of Johannine irony will be that of the Greek tragedians, Socratic irony, the Old Testament and possibly the early Roman rhetoricians. In particular, the use of irony as a mode of behaviour and a rhetorical device, both of which are predominately used by authors of this milieu to convey underlying truths.

Finally, the overview has revealed that both the form and function of irony varies between practitioners. There is no settled interpretation, and even within one particular historical or philosophical context, there is remarkable fluidity in irony's expression. It is quite proper to speak of Socratic irony, Sophoclean irony, Euripidean irony, Rortian irony, Kierkegaardian irony and so on. Therefore, "Johannine irony" is not merely the irony found in the Gospel of John. It includes the context, literary features and style that the author of the Fourth Gospel brings to bear in creating irony within the narrative. Just as oral expressions of irony are often attended by a physical shrug, a wink or a perceptible change of tone, so too authors provide literary signals of their ironic intentions. These subtle clues create an ironic style specific to both text and author. Therefore, in order to comprehend fully Johannine irony, as well as an appreciation of the historical context, it is also important to have a working knowledge of Johannine literary style in general and of ironic devices and motifs in particular. 


\section{Chapter 3}

\section{The Form and Purpose of Johannine Irony}

The Fourth Gospel is a work of literary virtuosity, both stylistically complex and theologically percipient. Its influence on the Christian faith can scarcely be overestimated. It was decisive in shaping numerous doctrinal pronouncements of the early church. ${ }^{1}$ Thus, the Fourth Gospel "has exercised a remarkable influence commensurate with the profundity of its message." ${ }^{2}$ The Gospel's profoundness derives primarily from its content but also from the author's literary choices. For example, the decision to eschew a Synoptic-like genealogy in favour of a Prologue dramatically changes the reading experience. ${ }^{3}$ The Prologue provides privileged information that elevates the position of the reader from the start, simultaneously imbuing the text with upper and lower levels that facilitate irony. ${ }^{4}$

A circumscribed understanding of irony, as we noted at the end of Chapter 1, constrains the ability to meaningfully engage with the Johannine narrative. Conversely, a circumscribed understanding of the unique Johannine style will impoverish attempts to comprehend specific instances of irony. If ironic utterances are dissociated from the sweeping grandeur of the narrative arc, they will either go unnoticed, as the reader ceases to be an informed reader, or their theological import will be lost.

Irony is only one of many devices utilised by the author to facilitate the Gospel's theological purposes. The author repeatedly overlays literary techniques meaning that they cannot be properly understood in isolation. Culpepper notes that the devices of misunderstanding, irony

\footnotetext{
${ }^{1}$ Previously doubts have lingered over the Gospel's acceptance in the second century. Sanders and Bauer in particular, argued that a Gnostic predilection for the Fourth Gospel generated reservations among many orthodox Christians in the early church. These doubts have been convincingly challenged: Nagel refutes the notion of orthodox rejection and widespread acceptance by the heterodox; Hill persuasively argues that both Gnostic taint and orthodox rejection are a scholarly myth. Joseph N. Sanders, The Fourth Gospel in the Early Church: Its Origin and Influence on Christian Theology Up to Irenaeus (Cambridge: Cambridge University Press, 1943); Walter Bauer, Orthodoxy and Heresy in Earliest Christianity Edited by Robert A. Kraft and Gerhard Krodel (Philadelphia: Fortress, 1971); Titus Nagel, Die Rezeption des Johannesevangeliums im 2. Jahrhundert (Leipzig: Evangelische Verlagsanstalt, 2000); Charles E. Hill, The Johannine Corpus in the Early Church (Oxford; Oxford University Press, 2004).

${ }^{2}$ Köstenberger, John, 1.

${ }^{3}$ As found in Matthew chapter one and Luke chapter three.

${ }^{4}$ The role of the Prologue in facilitating Johannine irony will be fully examined in Chapter 4.
} 
and symbolism are closely interrelated and that misunderstanding and irony in particular play important roles in teaching the reader how to read the narrative. ${ }^{5}$ The theological themes these devices serve are in turn interrelated so that "any attempt to itemize his theology and present it in neat compartments is bound to misrepresent it." ${ }^{\prime \prime} \mathrm{He}$ adds that eschatology is bound up with Christology, salvation with faith and knowledge, miracles with sacraments, such that if any of these themes is discussed in isolation from the others, distortion becomes inevitable. Considering literary devices in isolation from the theological message is equally hazardous because of the inseparability of narrative mode and theological claim. ${ }^{7}$ Consequently, attention must now be given to the Gospel's literary features and how irony plays a part in the wider narrative.

\section{Literary Style}

A distinctive feature of the Fourth Gospel is the author's overt statement of purpose in 20:31: "But these are written so that you may come to believe that Jesus is the Messiah, the Son of God, and that through believing you may have life in his name." However, this statement is not as unequivocal as it first appears. ${ }^{8}$ Ironically, the only Gospel, which has an explicit statement of purpose, is also the Gospel for which there has been such little agreement within scholarship as to its purpose. ${ }^{9}$ The primary reason for a plurality of views is a textual variant that has implications for determining the intended audience. If "iv $\alpha \_\sigma \tau \varepsilon v ́ \eta \tau \varepsilon$ (present subjunctive) is preferred, then the meaning of "in order that you may continue to believe" implies an audience of Christian believers. ${ }^{10}$ Conversely, if "iv $\pi \imath \sigma \tau \varepsilon v ́ \sigma \eta \tau \varepsilon$ (aorist subjunctive) is favoured, the meaning suggests an evangelistic purpose. ${ }^{11}$ Both variants have notable early support, although the present subjunctive appears to have gained a measure of ascendency in the works of recent

\footnotetext{
${ }^{5}$ Culpepper, Anatomy, xi.

${ }^{6}$ Barrett, St. John, 67.

${ }^{7}$ O'Day, Revelation, 112; "Moreover, at times analyses of Johannine 'style' include features that have more to do with content than style strictly so called and are more properly considered 'theology." Urban C. Von Wahlde, The Gospel and Letters of John, Eerdmans Critical Commentary, 3 vols. (Grand Rapids: Eerdmans, 2010), 1.19.

8 "It is not always observed that this verse, important as it is, raises more questions than it answers, and provides no more than a starting point for a discussion of the purpose of the gospel." Barrett, St. John, 134.

${ }^{9}$ Gordon Fee, "On the Text and Meaning of John 20:30-31," in To What End Exegesis: Essays; Textual, Exegetical and Theological (Grand Rapids: Eerdmans, 2001), 29.

${ }^{10}$ Proponents of this view are: Brown (1970); Schnackenburg (1975); Barrett (1978); Fee (1992); Brodie (1993); Moloney (1998); Keener (2003); Lincoln (2005); Osborne (2007).

${ }^{11}$ Proponents of this view are: Robinson (1962); Carson (1987); Morris (1995); Köstenberger (2004).
} 
commentators. ${ }^{12}$ Arguably, the textual evidence is so evenly balanced because the narrative offers examples of events that would serve both proselytising and encouraging continuation of belief, so that both purposes are not only possible but also probable. ${ }^{13}$ Furthermore, "it is hazardous to build anything on such a fine point of detail, as John does not use tenses with absolute precision." ${ }^{\prime 14}$

The purpose statement does however illustrate that the author's intention went beyond the mere narration of events, to the advancement of certain propositional truths with the motivation of both provoking and reinforcing faith. O'Day notes that there are two basic dimensions of the statement of purpose: the first is Christological ("Jesus is the Christ, the Son of God") and the second soteriological ("that believing you may have life in his name"). Accordingly, the author addresses a community grounded in, and empowered by the name and identity of Jesus. She concludes that these dimensions "transcend the debate about audience."15 Consequently, most commentators accept that neither option is precluded and that the salient features of 20:30-31 are the interrelated identity of Jesus and its commensurate theological implications for the reader. These related aspects will affect many of the literary decisions the author makes, including in the use of irony.

Vouga proposes that the informed position required of the reader presupposes a Christian audience and accordingly, the question of audience is organically connected with Johannine irony:

l'ironie johannique n'a de sens dans son ensemble que si l'évangéliste sait que ses destinataires admettent a priori sa doctrine... En effet, si Jn employait son ironie dans une intention missionaire, il y aurait de fortes chances que paraisse ridicule non plus celui qui ne comprehend pas ou refuse d'admettre que le Jésus crucifié est le Fils de Dieu, mais celui qui admet contre toutes les évidences que derrière la simple apparence humaine de Jésus se cache une autre réalité. ${ }^{16}$

12 Bruce M. Metzger, A Textual Commentary on the Greek New Testament $2^{\text {nd }}$ ed. (Stuttgart: Deutsche

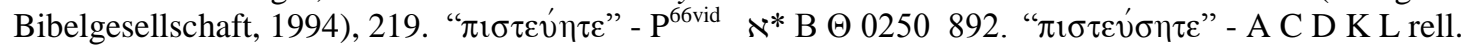

${ }^{13}$ E.g. for new believers: 4:1-39; 10:16; 12:20-26; 17:20. E.g. for extant believers: 3:1-21; 7:1-9; 8:31-32; 16:1-4.

${ }^{14}$ Barnabas Lindars, The Gospel of John, The New Century Bible Commentary, (Grand Rapids: Eerdmans, 1972), 617. "In fact, it can easily be shown that both expressions are used for both initial faith and continuing faith... so that nothing can be resolved by the appeal to one textual variant or the other." Carson, John, 90.

${ }^{15}$ O’Day, Revelation, 93.

${ }^{16}$ Francois Vouga, Le Cadre Historique et L'intention Théologique de Jean (Paris: Éditions Beauchese, 1977$), 35$. 
However, prior Christian knowledge is not necessary to understand the Gospel. The Prologue supplies all the requisite information to enable conclusions about the other reality of Jesus' identity and to avoid ridicule (i.e. victimisation by the irony). Furthermore, Johannine irony "in a post-Easter context, could have functioned as an effective evangelistic tool in beckoning the reader not to follow the path of disbelief but to read deeper, and as such, it would draw the reader into the experience of revelation." ${ }^{17}$ Accordingly, Johannine irony could serve to support an evangelistic, not just a catechetical, purpose. ${ }^{18}$

The Fourth Gospel's demarcated structure is also characteristic. Traditionally it is divided into two parts: the Book of Signs (1:19-12:50), ${ }^{19}$ and the Book of Passion/Glory (13:1-20:31). ${ }^{20}$ These are bookended by the Prologue (1:1-18) and the Epilogue (21:1-21:25). The Book of Signs features seven miracles attributed to Jesus as well as most of the interaction with persons other than the disciples (especially antagonists). The Book of Glory comprises three main sections. Chapters 13 to 17 deal with the Last Supper, Jesus' farewell discourse to his disciples and his farewell prayer. Chapters 18-19 cover the trial and Passion of Jesus and chapter 20 postresurrection interactions with his disciples. When considering Johannine irony I will examine the Book of Glory under the rubrics of the Farewell Discourses (chapters 13-17), the Passion Narrative (chapters 18-19) and the Resurrection (chapter 20).

The structure demonstrates an interesting relationship between subject matter and narrative mode. While irony is found throughout the Gospel, it decreases dramatically in the Farewell Discourses. This is significant because where a rhetorical device is not used can be potentially as instructive as where it is. The survey of identified instances of irony in the Gospel (see Figure 1) shows that the Book of Signs features on average 9.2 incidences of irony per chapter. This leaps to 15 per chapter in the Passion Narrative and the Resurrection. However, during the Farwell Discourses the average drops to 3.4. Not only are ironic utterances less common but

\footnotetext{
${ }^{17}$ Saeed Hamid-Khani, Revelation and Concealment of Christ: A Theological Inquiry into the Elusive Language of the Fourth Gospel (Tübingen: Mohrs Siebeck, 2000), 211.

${ }^{18}$ For a fulsome discussion of the topics pertaining to the audience and origins of the Gospels, especially the question of a universal or specific audience, see Edward Klink III, ed. The Audience of the Gospels (London: T\&T Clark, 2010).

${ }^{19}$ Although as Beasley-Murray observes, in light of "the passage that describes the purpose of the book, 20:30-31, the whole work is viewed as a book of signs." George R. Beasley-Murray, John, Word Biblical Commentary 36, $2^{\text {nd }}$ ed. (Nashville: Thomas Nelson, 1999), xc.

${ }^{20}$ Dodd prefers "Book of the Passion." C. H. Dodd, The Interpretation of the Fourth Gospel (Cambridge: Cambridge University Press, 1953), 289. However Brown has popularised "Book of Glory." Brown, St. John, cxxxviii.
} 
they are qualitatively inferior. ${ }^{21}$

For the author the predominantly didactic nature of the Farewell Discourses clearly does not lend itself to the use of irony. This is illustrated in Figure 2.

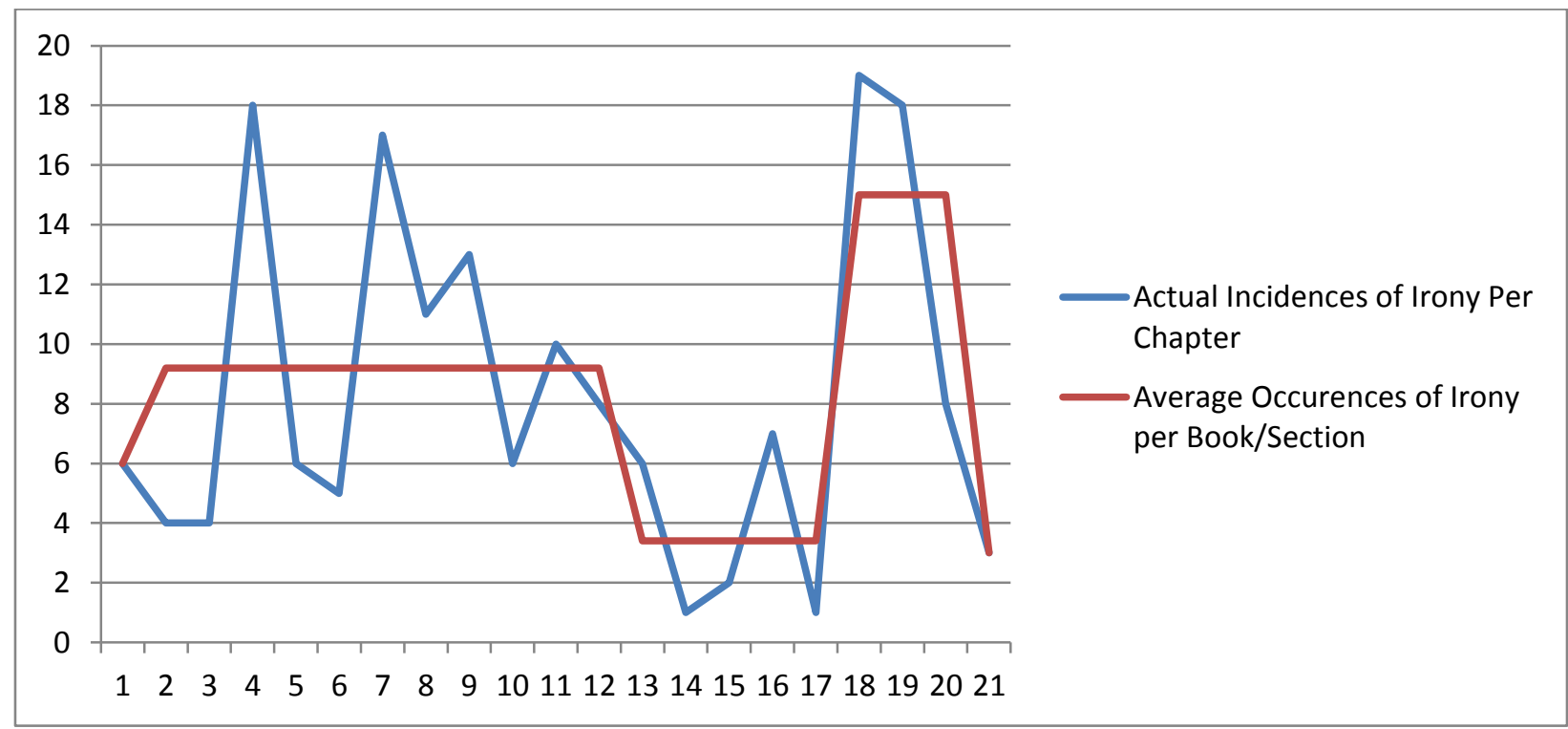

Figure 2.

a) Literary motifs and devices as Indicators of Irony

The manner in which literary devices and motifs frequently overlap and flow into each other renders any attempt to distinguish them difficult. For example, Jesus' statement at 2:19 (“Jesus answered them, 'Destroy this temple, and in three days I will raise it up.'”) can be categorised under symbolism, dual level meaning, misunderstanding and irony. This also occurs at the linguistic level. As Malina and Rohrbaugh note, the author does not simply relexicalize, that is use new words/phrases to convey a reality not usually associated with those words. He also overlexicalizes by using a plethora of different and interchangeable words/phrases to convey primary concerns. ${ }^{22}$ The fluidity and transposability of the author's rhetorical style and vocabulary makes delineation and exposition difficult. However, there are certain key elements of Johannine style that require consideration because they routinely intersect with irony.

\footnotetext{
${ }^{21}$ Three of the five chapters featuring no strong instances of irony and a further three out of the five do not even boast medium examples.

22 "With very little appreciable difference in meaning, John speaks of believing into Jesus, following him, abiding in him, loving him, keeping his word, receiving him, having him, or seeing him. This kind of redundancy is what we mean by overlexicalization." Bruce J.Malina and Richard L. Rohrbaugh, Social-Science Commentary on the Gospel of John (Minneapolis: Fortress, 1998), 5.
} 
(i) The existence of dual levels of meaning or reference is one of the most recognised features of Johannine style. $^{23}$ Many commentators commence with the adage that "the Gospel of John is deep enough for an elephant to swim and shallow enough for a child not to drown." 24 The duality of meaning allows a casual reader to leave the text satiated while concurrently it is "one of the most perplexing of texts among serious interpreters. ${ }^{~} 25$ Significantly, irony itself is also a dual-level phenomenon. The duality of meanings is incongruous or incompatible and accordingly only readers who perceive and incorporate the author's hermeneutical key resolve them. $^{26}$

Duality can occur as higher and lower levels of language or meanings that exist simultaneously, with one level clearly superior to the other. The author addresses the need to access the superior level in 7:24: "Do not judge by appearances, but judge with right judgment." From the Prologue, it is made apparent to the reader that there is a lower level of appearance that conceals a higher level of reality. Duality can also occur with one aspect contrasting another. This may be structural where similar situations end with contrasting reactions, e.g. the healing of the lame man (5:2-15) and man born blind (9:1-34). On the other hand, it may be rhetorical where symbolic meaning is generated through the use of dualistic language: e.g. light and dark, life and death, sight and blindness.

Duality of meaning does not automatically generate irony. As Culpepper observes the "implicit commentary" 27 that these layers create in the Gospel can be due to a range of rhetorical devices. $^{28}$ When it is the result of irony, however, the purpose is not obfuscation but the stripping away of the appearance. The contradiction in ironic discourse compels the reader to attempt a resolution of the double meaning. Thus John's irony, "in fact intensifies meaning and comprehension. It does not contribute to dualism, but points beyond the clues and glimpses to the inexplicable reality." 29 Irony is not an attempt by the author to perpetuate the duality but to assist the reader to make the transition to a shared superior knowledge. Both Duke and Culpepper have systematically examined the connection between stylistic and structural duality

\footnotetext{
${ }^{23}$ Ernest Saunders suggests that the author "reflects the mental and artistic qualities of a theological poet... (who) delights in the use of antitheses." As quoted by Robert Kysar, Voyages with John: Charting the Fourth Gospel (Waco: Baylor University Press, 2005), 43.

${ }^{24}$ This quote is variously attributed to either Augustine or Chrysostom.

${ }^{25}$ Paul Anderson, The Riddles of the Fourth Gospel (Minneapolis: Fortress, 2011), 1.

${ }^{26}$ Andreas Köstenberger ed., A Theology of John's Gospel and Letters (Grand Rapids: Zondervan, 2009$), 151$.

27 "The narrator's use of implicit commentary is one of the most engaging aspects of the Fourth Gospel, which is nothing if not subtle. Culpepper, Anatomy, xi.

${ }^{28}$ Such as paradox, sarcasm, misunderstanding, symbolism etc.

${ }^{29}$ Jey J. Kanagaraj and Ian S. Kemp, The Gospel According to John: Asia Bible Commentary Series (Singapore: Asia Theological Association, 2002), 24.
} 
in the Gospel and Johannine irony. ${ }^{30}$ Culpepper's observation that the multiple layers create a surplus of meaning thereby giving Jesus' pronouncements an oracular quality is particularly insightful. $^{31}$

(ii) Another important device is misunderstanding. ${ }^{32}$ Johannine misunderstanding often occurs when, "A saying of deep import is uttered by Jesus; His hearers misunderstand it, after a fashion that appears stupid; and then $\mathrm{He}$ repeats the saying in a slightly different form before $\mathrm{He}$ explains it and draws out its lesson." 33 The first example of such misunderstanding is 2:19-21, where tellingly the narrator intrudes into the narrative to demonstrate how to decode this rhetorical device so that the reader will be suitably equipped to handle further occurrences. Culpepper identifies 18 passages involving misunderstanding and all but four are ironic (8:5153 ; $8: 56-58 ; 11: 23-25 ; 14: 4-6)$, demonstrating the close relationship between these devices. ${ }^{34}$ There can sometimes be multiple ironies within a single misunderstanding (e.g. 4:10-15 contains four ironies).

The nature and function of misunderstandings has been the subject of debate. ${ }^{35}$ Bultmann contends that Johannine misunderstandings do not "consist in one word having two meanings... rather that there are concepts and statements which at first sight refer to earthly matters, but properly refer to divine matters." 36 Leroy used form criticism to identify 11 misunderstandings. ${ }^{37}$ He defined misunderstandings, contra Bultmann, as "Stellen also, die eine Fehlinterpretation des Jesus wortes durch die Gesprächspaertner wiedergeben," 38 which function as riddles that separate outsiders from the insiders of the Johannine community. Leroy's 1968

\footnotetext{
${ }^{30}$ O'Day notes the valuable work of Duke and Culpepper but adds the gentle critique: "Yet Duke and Culpepper put too much emphasis on polar opposition in the dualities that they identify (e.g. 'below' and 'above') and not enough emphasis on the ways in which John presents these dualities as simultaneously operative in the Gospel. John does not present a simple either/or situation. Through his use of irony, the Fourth Evangelist asks the reader to see the real meaning in and through the expressed meaning, not as independent or removed from it." O'Day, Revelation, 8.

${ }^{31}$ Culpepper, Anatomy, 199.

${ }^{32}$ Misunderstanding is frequently considered under the general heading of duality. However, given its prevalence in the Fourth Gospel and its interrelationship with irony it is worthy of separate treatment.

33 J. H. Bernard, A Critical and Exegetical Commentary on the Gospel According to St. John 2 vols. (Edinburgh: T\&T Clark, 1929), 1.cxi.

34 2:19-21; 3:3-5; 4:10-15; 4:31-34; 6:32-35; 6:51-53; 7:33-36; 8:21-22; 8:31-35; 8:51-53; 8:56-58; 11:11-15; $11: 23-25 ; 12: 32-34 ; 13: 36-38 ; 14: 4-6 ; 14: 7-9 ; 16: 16-19$.

${ }^{35}$ Bultmann and Dodd see parallels, stylistically but not in terms of content, between Johannine misunderstanding and passages in the Shepherd of Hermas and other Hermetic literature. Bultmann, John, 127; Dodd, Interpretation, 321. Brown sees misunderstandings as "the Johannine equivalent to the parabolic language of the Synoptics, this misunderstanding... represents the world's inability to see the truth.” Brown, St. John, cxxxvi.

${ }^{36}$ Bultmann, John, 135.

${ }^{37} 2: 19-22 ; 3: 3-5 ; 4: 10-15 ; 4: 31-24 ; 6: 32-35,41 ; 6: 51-53 ; 7: 33-36 ; 8: 21-22 ; 8: 31-33 ; 8: 51-53 ; 8: 56-58$.

${ }^{38}$ Leroy, Rätsel und Missverständnis, 1.
} 
work is still considered the most thoroughgoing. ${ }^{39}$ However, Carson demonstrates that Leroy's categories are too narrow to deal adequately with all misunderstandings in the narrative. ${ }^{40} \mathrm{He}$ places too much emphasis on literary form and a well-defined sitze im Leben, thereby undervaluing the importance and pervasiveness of misunderstanding. ${ }^{41}$ Vouga summarises the problem as follows, "On comprend maintenant que les malentendus johanniques ne soient ni des énigmes pour la pédagogie catéchétique (Leroy), ni seulement des expressions à double sens que l'interlocuteur comprend ou mécomprend selon qu'il sait ou non qui Jésus (Bultmann...)., 42

A broader view of misunderstanding clarifies its close correlation with irony. Leroy is correct to note that misunderstandings create insiders/outsiders; however, the intention is not to separate but to include. ${ }^{43}$ Culpepper observes the effect on the reader: "The readers who resolve the gospel's misunderstandings, as they must for a successful reading of the gospel, find themselves drawn again toward a fuller comprehension of the narrator's ideological point of view."44 The reader is drawn to the community of insiders in the same way that irony functions. The author uses both rhetorical devices to alert the reader to multiple levels of meaning. Misunderstanding is therefore often a clue to the presence of irony and its role in fulfilling the author's revelatory purposes.

(iii) A further prominent literary feature is the use of questions. ${ }^{45}$ There are approximately 170 questions in the Gospel, with an average 8.1 per chapter. ${ }^{46}$ Two types of questions are of particular interest: rhetorical and unanswered questions. Rhetorical questions were a common literary and oratorical device in the ancient world. They appear in all four Gospels. Rhetorical questions are an excellent vehicle for pointing out situational ironies. ${ }^{47}$ For example, 3:10: "Jesus answered him, 'Are you a teacher of Israel, and yet you do not understand these things?"”

\footnotetext{
${ }^{39}$ For a summary see Tom Thatcher, and Stephen Moore, eds. Anatomies of Narrative Criticism: The Past, Present, and Future of the Fourth Gospel as Literature (Atlanta: SBL, 2008), 9.

${ }^{40}$ Carson, "Understanding Misunderstandings in the Fourth Gospel," TynB. 33 (1982), 64.

${ }^{41}$ Ibid., 63, 74-78; Culpepper, Anatomy, 154.

${ }^{42}$ Vouga, Théologique de Jean, 36.

${ }^{43}$ For a summary of the flaws in Leroy's proposal that the insiders are the disciples (Jewish catechumens in the Johannine community) and the outsiders are "the Jews" (the Synagogue) see Carson, Misunderstandings, 75-78.

${ }^{44}$ Culpepper, Anatomy, 164. Furthermore "John does not use misunderstanding as a 'technique' which is applied in the same manner in every instance.” Ibid., 154. Thus Culpepper avoids Carson's rebuke of Leroy for overemphasis on misunderstanding as a rhetorical device only. Carson, Misunderstandings, 59, 89-90.

${ }^{45}$ For a full-length treatment see Douglas Estes, The Questions of Jesus in John: Logic, Rhetoric and Persuasive Discourse (Leiden: Brill, 2013).

${ }^{46}$ Jackson Painter, The Gospel of John: A Thematic Approach (Eugene: Wipf and Stock, 2011), 1.

${ }^{47}$ Feagin points out that rhetorical questions are especially useful in communicating irony by praising in order to blame or blaming in order to praise e.g. Mark 7:9. Feagin, Irony, 23.
} 
They are less likely to be carriers of verbal irony because the question implies the answer, which means there is usually no contradiction for the irony to inhabit.

Rhetorical questions are not without risk for the author, as questions with strong rhetorical qualities can increase reader uncertainty and, for better or worse, make a reader "more argumentative."48 They remain popular, however, because they have more persuasive power than a direct statement. ${ }^{49}$ In the Fourth Gospel, over sixty percent of Jesus' questions have noticeable rhetorical qualities. In a rare commonality, both the Synoptic and Johannine Jesus demonstrates a predilection for them. However, Duke notes two key differences: the Synoptic questions, while equally compatible with irony, contain little. In addition, where they do employ irony, it is "spoken with fire in his eyes. The heavenly revealer of John's Gospel speaks irony too, but his eyebrow is raised, and there is the trace of a smile on his lips."

While rhetorical questions expect no reply, unanswered questions warrant an answer yet the author provides none. The Gospel contains an abundance of unanswered questions in which the question, and in many cases the questioner, is left hanging. ${ }^{51}$ The resultant pregnant pause reveals a false assumption, in which the character unwittingly and usually ironically offers the truth. ${ }^{52}$ However, the lack of an answer does not perturb the reader as it would the interlocutor in the narrative. The reader possesses superior knowledge, which, if not providing the answer outright, at least provides a framework for deliberation rather than confusion. This reinforces the community of shared knowledge between author and reader. Unanswered questions are almost invariably a pointer to the existence of irony in the text. Intriguingly unanswered questions occur only in the Book of Signs and the Passion Narrative, somewhat mirroring the pattern of Johannine irony seen in Figure 2.

(iv) An additional and frequently used literary feature is symbolism, which is employed to comprehend the transcendent significance of an image, action, or person. ${ }^{53}$ This feature also

\footnotetext{
${ }^{48}$ Estes, Questions, 55.

${ }^{49}$ Resseguie, Narrative Criticism, 60. "Since questions with a rhetorical quality look to give as much or more than to receive, a rhetorical quality is, as a whole, more useful for persuading listeners than an informational quality." Estes, Questions, 55.

${ }^{50}$ Duke, Irony, 53.

${ }^{51} 1: 46,2: 20,4: 12,6: 42,7: 26,7: 35,7: 42,7: 48,8: 22,12: 34,18: 35,18: 38,19: 9$. However, the obscure nature of Jesus' responses makes classification difficult. Culpepper would add 6:52, 7:20, 8:53, and 9:40 presumably because although Jesus responds to the questions his response is oblique and typically provides more questions than answers. The distinction between rhetorical and unanswered questions is often also blurred.

${ }_{52}$ Culpepper, Anatomy, 176.

${ }^{53}$ See Craig Koester, Symbolism in the Fourth Gospel 2nd ed. (Minneapolis: Fortress, 2003); Dorothy Lee, The Symbolic Narratives of the Fourth Gospel (Sheffield: JSOT Press, 1994).
} 
derives from the author's fondness for duality. Culpepper proposes three "core" forms of symbolism: Light, Water and Bread. ${ }^{54}$ Koester provides a more detailed classification: representative figures, symbolic actions, light and darkness, water, and crucifixion and death. These categories culminate in a symbolic revelation of Johannine theology. ${ }^{55}$

Lee proposes that the symbolic narratives prompt the reader to embrace alternate perspectives, in particular the author's perception of the incarnation and human existence. ${ }^{56}$ She takes exception to O'Day's conclusion that irony is characteristic of the revelatory mode and proposes that "symbol, being more than a literary device, is better able to bear the weight of John's theological worldview." $" 57$ However, the potent imagery of symbolism often enriches irony and the thoughtprovoking qualities of irony likewise enhance symbolism. There is no need to choose between them. It is equally true that fully understanding the Gospel is not possible without an appreciation of symbolism ${ }^{58}$ and that irony is central to John's dynamic of revelation. ${ }^{59}$ They both "work together to draw readers beyond the realm of the senses to divine realities, without permitting truth to be equated with sense perception or to be so divorced from sense perception that communication is no longer possible." 60 Irony and symbolism therefore exhibit a symbiotic relationship.

(v) Repetition is another prominent stylistic device. ${ }^{61}$ The repetition can be verbatim or with a pivotal modification. Jesus frequently repeats the comments of his interlocutors in a way that

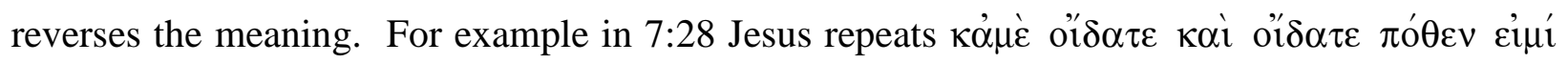
by which he underscores their original unintentional irony. ${ }^{62}$ Jesus echoes their claims of knowing twice and in the Greek the repetition forms a little chiasm "which almost carries the rhythm of a taunt." 63 Jesus uses the same device to gentler effect with the disciples in 16:31 $\not{\alpha} \rho \tau \imath \pi \imath \sigma \tau \varepsilon \dot{\varepsilon} \varepsilon \tau \varepsilon$. Repeating their claim to believe Jesus adds the emphatic $\alpha_{\rho} \tau \tau$ stressing that

\footnotetext{
${ }^{54} \mathrm{He}$ also provides an "other" category, which includes inter alia, weddings, the temple, festivals, the cross, meals, doves, lambs, sheep, tombs, grave wrappings, garments, anatomy, and horticulture. Culpepper, Anatomy, 190-198.

${ }^{55}$ Which Koester separates into "community" (unity, patterns of discipleship and the world) and "the knowledge of God" (God the Father, human estrangement and Jesus as the way). Koester, Symbolism, 287-299.

${ }_{56}^{56}$ Lee, Symbolic Narratives, 232-235. Her approach is an insightful use of Reader Response Criticism.

${ }^{57}$ Ibid., 17-18.

${ }^{58}$ George MacGregor, The Gospel of John: Moffatt New Testament Commentary (London: Hodder and Stoughton, 1953), xxv.

${ }^{59}$ O'Day, Revelation, 48.

${ }^{60}$ Koester, Symbolism, 31-32.

${ }^{61}$ E.g. $3: 4,10 ; 4: 10,17 ; 6: 42,52 ; 7: 20,28,35-36 ; 8: 22,58 ; 11: 16 ; 1234 ; 13: 38 ; 14: 8-9 ; 16: 17-18,29-30 ; 18: 37$; 19:21-22; 20:15.

${ }^{62}$ This irony is also emphasised by the double $\kappa \alpha 1$, which accentuates each of their bold assertions both of which the reader knows to be untrue.

${ }^{63}$ Duke, Irony, 48.
} 
"now you believe." This irony functions in two ways. At last, the disciples are coming to belief after all they have experienced. However, the reader knows that while now they believe, "in the sweet glow of supper, cleansed feet and gorgeous discourse," the soldiers, swords, and great darkness that will shortly surround them will soon crowd out all belief. ${ }^{64}$

Repetition is not confined to Jesus. For example, the disciples uncomprehendingly repeat Jesus'

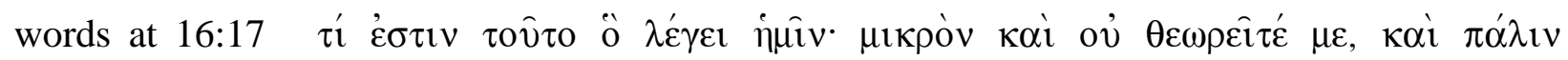

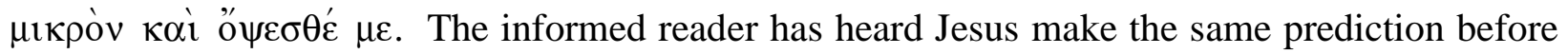
$(7: 33 ; 12: 35 ; 13: 33 ; 14: 19 ; 16: 10)$ rendering the disciples' obtuseness ironic self-betrayal. The disciples' ongoing inability to comprehend impresses on the reader that they indeed possess privileged and crucial knowledge. Jesus' opponents also engage in repetition. For example, at

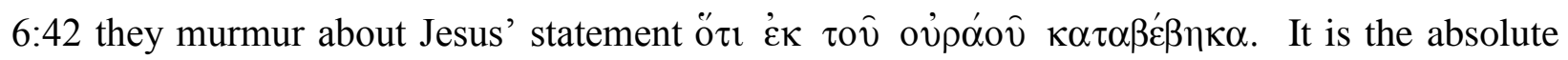
certainty of their assertion $\eta \mu \varepsilon i \varsigma$ o' $\delta \alpha \mu \varepsilon v$, which the reader knows betrays their real ignorance and creates the irony. Additionally, irony is particularly prevalent in the repetition of hina clauses, substituting an opposing verb. ${ }^{65}$

Ironic repetition also occurs in extended ironies, usually based on the repetition of key words rather than clauses. A word may be repeated in relation to the same character but with a different significance. Duke offers the examples of $\pi \tau \omega \chi 0 \hat{\iota} \varsigma$ for Judas and $\alpha \nu \theta \rho \alpha \kappa i \alpha$ ' for Peter. ${ }^{66}$ In the latter, the dual description of $\alpha v \theta \rho \alpha \kappa i \alpha \nu$ signals the author's intention to link the two scenes. However, contra Duke, while Peter's restoration over the same type of fire that he denied Jesus is poignant it is not ironic. A better example of an ironic repetition is found in 3:10: "Jesus answered him, 'Are you a teacher of Israel, and yet you do not understand these

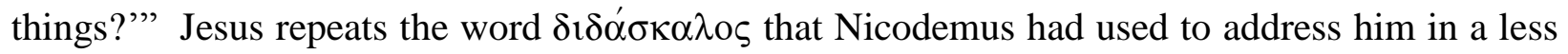
than convincing manner and on a level that the informed reader knows is much less than the reality. Jesus then turns the dubious honour of the title back on Nicodemus in an ironic reversal. The emphatic use of the $\sigma v$ expresses both exasperation and feigned surprise. The use of the definite article o distances Nicodemus from Jesus and grants him a representative role as one of many who misconstrue what Jesus is saying and who he really is.

\footnotetext{
${ }^{64}$ Duke, Irony, 49.

${ }^{65}$ Ibid., 60.

${ }^{66}$ Ibid., 114-115.
} 
(vi) Strong claims to knowledge or the lack of knowledge in others is another device that is indicative of irony. ${ }^{67}$ Over-confident assertions are classic pointers to the ironic presence of an alazōn. For example, in 11:49-50 Caiaphas ironically prophesies the death of Jesus. At one level, he offers insights derived from political expediency (11:48); however, the narrator intrudes to make sure that the reader does not miss its prophetic significance in 11:51. As CameryHoggard observes, "What makes the double entendre particularly pointed is that Caiaphas

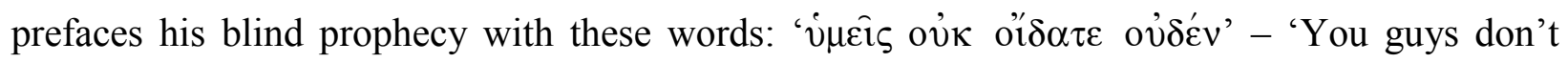
know nothin!' It is often pointed out that John's entire Gospel fairly resounds with this sort of unintended irony." 68 Similarly, "the Jews" assert knowledge about Jesus' parentage and provenance in 6:42: "They were saying, 'Is not this Jesus, the son of Joseph, whose father and mother we know? How can he now say, 'I have come down from heaven'?'” The misplaced fervency of their belief is demonstrated by the use of the emphatic pronoun with the verb: in $\mu \varepsilon i \varsigma$ o' $\delta \alpha \mu \varepsilon v$. The result of this recurring knowledge/lack of knowledge motif for the reader is to bring to mind the Prologue's ironic pronouncement at 1:10: “...yet the world did not know him."

(vii) A further distinctive feature of John's style is the author's use of vocabulary, grammar and syntax. In this regard, the only other documents in the New Testament that even remotely resemble the Fourth Gospel are the Epistles of John. The author's use of language resists classification: according to classical standards, it is not good Greek but neither is it bad. ${ }^{69}$ Despite relying on a limited vocabulary, the text is sophisticated and complex. Abbot describes the author as "one of the simplest writers yet one of the most ambiguous; with a style, in parts, apparently careless, parenthetic, irregular, abrupt, inartistic - an utterer of after-thoughts and bythoughts putting down words just as they came into his mind... but, in general effect, an inspired artist endowed with an art of the most varied kind." ${ }^{70}$ Although John's vocabulary and syntax are simpler than other New Testament writings, professional translators frequently have difficulty articulating exactly what the author meant. ${ }^{71}$

Barrett offers a detailed analysis of the syntax of the Fourth Gospel. ${ }^{72}$ One of its most salient features is the eschewing of the usual hypotactic style of Greek, whereby subordinating participles or connecting particles connect sentences. Instead, the Fourth Gospel uses parataxis,

\footnotetext{
${ }^{67}$ E.g. $4: 25 ; 6: 42 ; 7: 27-28,49 ; 8: 48,52 ; 9: 24,29 ; 11: 49 ; 12: 19 ; 16: 30 ; 19: 10-11$.

${ }^{68}$ Camery-Hoggatt, Irony, 66.

${ }^{69}$ Barrett, St John, 5.

${ }^{70}$ Edwin Abbott, Johannine Vocabulary: A Comparison of the Words of the Fourth Gospel with Those of the Three (London: Adam and Charles Black, 1905), vii.

${ }^{71}$ Malina, Social-Science, 4.

${ }^{72}$ Barrett, St John, 5-11.
} 
which the author often achieves by linking sentences with $\alpha \alpha$ i. This allows the sentences to retain independence rather than subordination and is sometimes used in an adversative form (e.g. $1: 5 ; 8: 52,55 ; 17.11)$. This often creates an ambiguous relationship between the sentences with the reader needing to look for a thematic link, potentially through the repetition of a word, phrase, verb, subject or an intensification of an earlier thought. ${ }^{73}$ This preference for coordination rather than subordination can amplify the two levels of meaning necessary for irony. An example is 1:10-11: "He was in the world, and the world came into being through him; yet the world did not know him. He came to what was his own, and his own people did not accept him." Here $\kappa \alpha i$ is used 3 times to pronounced ironic effect. Notably many translate the second $\kappa \alpha i$ in v.10 as "yet" or drop it altogether in recognition of its unusual use. ${ }^{74}$

Along with parataxis, the author makes frequent use of asyndeton, where no coordinating or subordinating conjunctions are used at all. The sentences lie side by side and context infers coordination. This arrangement "is preferred before forms of the anaphoric pronoun houtos and for cases of repetition or simple restatement (the prepositional relation of the positive-positive, e.g. 14:27)." "75 In Greek, asyndeton is often the default option used whenever definite connection is not required; e.g. where an agent has changed, a reply is being given, an interruption in causal sequence has occurred $(2: 17 ; 4: 31 ; 8: 27)$ or an interruption that is sequential but motivationally distinct from what precedes $(8: 42,52 ; 11: 25){ }^{76}$ Asyndeton may also create the tension required for irony, but though it is less effective due to its higher degree of ambiguity.

Another characteristic Johannine conjunction is oun (ov̂v). The author uses this particle frequently and unconventionally. It loses its argumentative force and becomes a simple narrative link. It is used this way 110 times in the Fourth Gospel compared to four times in the rest of the $\mathrm{NT}^{77}$ Poythress suggests that oun is used by John to suggest a quasi-causal relationship. Accordingly, "Oun occurs at just those points in the narrative where, without such a suggestion, the narrative would be in some danger of falling into pieces."

\footnotetext{
${ }^{73}$ Vern Poythress, "The Use of the Intersentence Conjunctions De, Oun, Kai, and Asyndeton in the Gospel of John," Novum Testamentum 26/4 (1984), 323-324.

${ }^{74}$ NRSV, ESV, HCS, use "yet"; NIV, TNIV, NLT, drop the "and" altogether; NCV opts for "but"; KJV, NKJV, NASB retain the "and."

${ }^{75}$ Poythress, Conjunctions and Asyndeton, 323-325.

${ }^{76}$ Ibid., 332-333.

${ }^{77}$ Barrett, St John, 7.

${ }^{78}$ Poythress, Conjunctions and Asyndeton, 329.
} 
combines thoughts and holds disparate narrative threads together. The resultant duality can therefore also serve as a pointer to irony (e.g. 18:3, 6, 19, 28, 31, 33, 37, 39, and 40). ${ }^{79}$

The use of the emphatic personal pronoun and the derogatory use of demonstrative pronouns routinely signal irony. ${ }^{80}$ Both forms of pronouns are displayed in 6:42a: "They were saying, 'Is not this [demonstrative] Jesus, the son of Joseph, whose father and mother we [emphatic] know?" 81 The demonstrative pronoun houtos is used to refer dismissively to Jesus as this person. Since his name is also used, the pleonastic use of the pronoun is "contemptuous," 82 and contains "an element of disparagement." allows speakers to place distance between the person they are referring to and themselves. Duke observes, "On the lips of Jesus' opponents [houtos] will almost always signal irony (cf. 7:15, 26, 27, 35; 9:16, 24; 18:30)." ${ }^{\circledR 84}$ The emphatic personal pronoun we (i் $\mu \mathrm{i} \varsigma$ ) amplifies the overconfident assertion.

Moreover, Culpepper suggests that references to Jesus as "a man" constitutes an unintentional depreciation of Jesus by which the "author winks at the reader," signalling irony (e.g. 4:29; 5:7, $18 ; 7: 46 ; 9: 16 ; 10: 33 ; 11: 47,50 ; 18: 17,29 ; 19: 5) .{ }^{85}$ For example, when the sick man at the pool

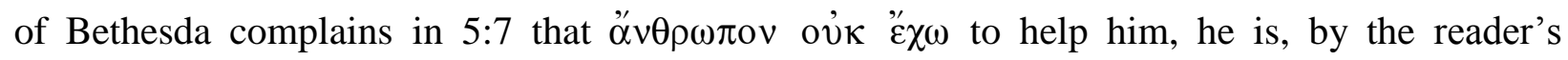
estimation, painfully ignorant that he has infinitely more available than that in Jesus. The resulting irony is not strong. However, the reader's pleasure is heightened by the anticipation of the man's imminent incorporation into the community of those who know Jesus' identity. The complaint of the Chief priests and Pharisees at 11:47 that ơं $\sigma \eta \mu \varepsilon i \alpha$ contains greater irony. They miss the incongruity in their own statement that if "this man" were just a man how could he be "performing many signs." Yet they obdurately refuse to consider the obvious explanation. This "man or more" motif finds its denouement in Pilate's proclamation at 19:5: "Here is the man." This climactic statement reveals the ironic disparity in that "all they beheld was a man, but others beheld his glory." 86

\footnotetext{
${ }^{79}$ This is so common that I only chose examples from one chapter. NB. In these cases the word is not translated and serves only as a narrative link. The ironic elements of these verses will be discussed in Chapter 6.

${ }^{80}$ E.g. emphatic personal pronoun: 3:10; 4:12; 6:42; 7:47, 52a; 8:41, 48, 53; 9:24, 27, 29; 10:33; 11:49. E.g. derogatory demonstrative pronouns: $6: 42 ; 7: 15,26,27,35,36,9: 16,24 ; 18: 30$.

${ }^{81}$ Previously also cited as an example in relation to strong claims to knowledge.

${ }^{82}$ B. F. Westcott, The Gospel According to St John (London: John Murray, 1882), 104.

${ }^{83}$ Brown, St John, 270.

${ }^{84}$ Duke, Irony, 172.

${ }^{85}$ Culpepper, Anatomy, 171.

${ }^{86}$ Ibid., 172.
} 
A further construct that regularly signals irony is the prefacing of a question with the negative particle $m \bar{e}\left(\mu \eta^{\prime}\right){ }^{87}$ The implication of a negative response places the questioner's cards on the table and permits the reader to discern any attendant irony. In 18:35 Pilate asks Mń $\tau \imath$

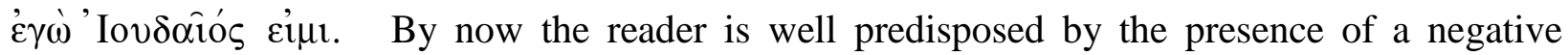
particle to pause and consider if Pilate could indeed be a Jew, in some ironic sense. ${ }^{88}$ Correspondingly, "insofar as 'the Jews' represents the world's rejection of Jesus, Pilate is already in the process, even while despising them, of joining them." 89 This also interplays ironically with Pilate's repeated proclamations of Jesus as "The King of the Jews" $(18: 39 ; 19: 14-$ $15,19-21)$.

Finally, irony may be indicated by a variety of lexical intensifiers, such as "indeed," "hardly," "behold" or "truly." 90 This is not always the case as the author does uses intensifiers in nonironic instances. However, the intensifier alēthōs ( $\alpha \lambda \eta \theta \hat{\omega} \varsigma$, variously translated as "truly," "indeed," "really" or "in truth") almost always accompanies irony (in five of seven usages). It is either present with the irony $(4: 42 ; 7: 26 ; 8: 31-37)$ or immediately follows an ironic utterance $(1: 47 ; 7: 40)$. Likewise, ide (íc, "behold") is one of the author's authors favourite dramatic words and is often associated with irony $(7: 52 ; 12: 19 ; 16: 29 ; 19: 5,14) .{ }^{91}$ The intensifier amēn

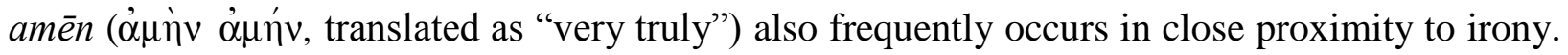
The only character who gets to speak "very truly" is Jesus. These statements do not exhibit direct irony but they often correct or precipitate an ironic utterance. ${ }^{92}$

This survey of some of the chief characteristic features of the Fourth Gospel's literary style is not exhaustive but is enough to attune us to the various ways the author signals irony in the narrative. Although some literary features have been noted as almost always accompanying irony they are not used with a frequency that would make the ironic utterance explicit. Johannine irony is never formulaic and such a lack of subtlety would diminish the efficacy and appeal of the irony. Just as it is impossible to define irony conclusively, it is impossible to provide a comprehensive list of literary features, which will allow identification of all examples of Johannine irony. The author uses irony extensively and we take this to be purposeful.

\footnotetext{
${ }^{87}$ E.g. 4:12; 7:26, 35-36, 41b, 47, 48, 52a; 8:22, 53.

${ }^{88}$ The term "the Jews" and its ironic aspects will be explained further in Chapter 5 .

${ }^{89}$ Duke, Irony, 129.

${ }^{90}$ Köstenberger, Theology, 152.

${ }^{91}$ See Duke, Irony, 57, 86.

92 This phrase follows irony in $1: 51 ; 3: 5,11 ; 6: 53 ; 8: 34,58 ; 13: 38$ and precedes it in $3: 3,11$. In $3: 11$ the phrase follows on from Jesus' pointing out of a situational irony relating to Nicodemus and then precedes his development of a much wider situational irony in v.12.
} 
Accordingly, he leaves deliberate clues of its presence, a trail of literary breadcrumbs to be followed. In subsequent chapters, we will observe these clues in several key passages, catching the author's subtle winks and nods that accompany his use of irony. First, more needs to be said about the author's reasons for using irony so pervasively in his narrative.

\section{A Rationale for Irony}

Before turning to key examples of irony in the Gospel, it is worth considering the reason for the Fourth Gospel's pervasive use of irony. Here we are navigating unchartered waters as there are no thoroughgoing explanations for the raison d'être of Johannine irony in the literature. Nonetheless, intimations exist in some of the works previously considered. MacRae forewarns us to expect a connection to the author's theological purposes since in the Fourth Gospel "theology is irony."93 Likewise, O'Day has demonstrated that there is an "intrinsic relationship of narrative mode and theological claim." 94 The author's theological strategies fully integrate Johannine irony to the point that it transcends its character as a rhetorical device. As Duke puts it, "Irony is a device; and irony is the truth." 95

Scholars have offered various descriptions of the functions and uses of irony from which we might potentially deduce a rationale. Duke dedicates a chapter to the functions of irony. However, in a continuation of his emphasis on the "how" of Johannine irony, he does not address function in a purposive sense. He recounts the qualities required to create a community of superior knowledge between the author and audience, reliability, voice, detachment, clues and reconstruction. $^{96}$ He then distinguishes between positive and a negative use of irony. The positive is the use of "irony as appeal." This is pleasurable even to its putative victim. It is grounded in common convictions and offers new levels of insight. The negative is the use of “irony as a weapon." This form scorns culpable ignorance and victimises an alazōn for hubris.

The distinction, however, is one of outcome rather than function, as it is dependent on its ultimate reception. How irony is received can vary markedly from reader to reader, to a degree

\footnotetext{
${ }^{93}$ MacRae, Theology and Irony, 89.

${ }^{94}$ O'Day, Revelation, 113.

${ }^{95}$ Duke, Irony, 41.

96 Ibid., 29-35.
} 
uncommon with most other literary devices. ${ }^{97}$ The distinction is also not absolute. Ironic mockery may reach a victim of hubris in a way that brings insight and consequently becomes pleasurable. Alternatively, the unanticipated obtuseness of a recipient, who thereby is unintentionally victimised, may undermine a supposedly pleasurable irony. Contrary to Duke's categories these examples are, respectively, a positive use of irony that was initially negative and a negative use of irony that began positively.

When Duke returns to functions in his conclusion, he suggests that Johannine irony fulfils a dual role. First, it is a negative weapon used in a polemic. While this occurs against the backdrop of controversy with the Synagogue, it is primarily against unbelief in a universal sense. ${ }^{98}$ Second, it functions as a positive witness, which he sees as its predominant use. ${ }^{99}$ This is a valuable insight, although Duke fails to recognise that irony can be weapon and appeal simultaneously. His focus is still firmly on the manner of its use rather than the reasons for its use. ${ }^{100}$ However, Duke also explicates irony's relationship to the text, "So crucial is this irony to the Johannine message that it may fairly be said, if we do not grasp the irony we do not grasp the Gospel."101 Significantly, for this study, this implies that any rationale for Johannine irony will be located within the message; i.e. grounded in the content of the narrative itself and not just in the rhetorical context. ${ }^{102}$

O'Day also examines the functions of irony. She follows Duke in considering the practical functionality of irony, with particular reference to the author/audience relationship. When she turns to irony as a revelatory mode, she offers insights that potentially point towards a rationale. She stresses that "irony is a mode of revelatory language. It reveals by asking the reader to make judgements and decisions about the relative value of stated and intended meanings, drawing the reader into its vision of the truth."103 This reinforces the notion that the ultimate

\footnotetext{
97 "There simply is no irony in any statement until it is done - by someone. Hence, the irony cannot properly be said to be 'in' the statements at all, it resides in their reception." Dokka, Irony and Sectarianism, 94. This is an overstatement. While the success of an ironic utterance is entirely dependent upon its reception this does not invalidate an author's original intention to place an irony within a text or statement. Thus, contra Dokka ironic intentionality can exist in a statement beyond its polysemy.

98 O'Day misses the subtlety of Duke's point and describes him as proposing a "polemic against 'the Jews." O'Day, Revelation, 4.

${ }^{99}$ Duke, Irony, 149-155.

${ }^{100}$ Duke's final sentence demonstrates that the rationale for Johannine irony remains firmly outside his purview: "If John punctuates his witness to Jesus with an occasional wink or grin or tear, if he now and then falls into awesome silence, it is ultimately because there is no better way to tell this story." Ibid., 156.

101 Ibid.

102 Since Duke limits himself to the rhetorical context this explains why he does not address the question of rationale.

${ }^{103}$ O’Day, Revelation, 31.
} 
purpose of Johannine irony is to intensify meaning and comprehension. O'Day clarifies the content of the author's ironically expressed vision of truth: "The locus of revealed truth lies in Jesus, a Jesus that the Fourth Gospel has been at pains to make available to the reader." 104 Consequently, the intrinsic relationship between ironic mode and theological claim is grounded within the narrative in the revelation of Jesus. O'Day states directly what Duke implied, "rather than looking for the locus of revelation behind or in front of the literary text, the operation of irony as revelatory language suggests that the locus of revelation lies in the text itself."105

I will assess four hypotheses for explaining why Johannine irony is so prevalent. Three are inadequate to explain the phenomenon, though all have important insights to offer. None of the first three hypotheses have been specifically advanced as a rationale for Johannine irony. They make relevant, general observations, about irony, the Fourth Gospel or both, and thus have been identified as potential candidates. They are not, however, simply straw men. I argue that due to their limitations, these first three hypotheses cannot constitute an overarching rationale for the prevalence of Johannine irony. Nevertheless, I also believe that each may contribute, in varying degrees, to explanations for isolated instances of irony in the Gospel. On the other hand, the fourth hypothesis, that there is a link between Johannine irony and the Fourth Gospel's notions of truth, does offer a compelling explanation that draws on many of the features identified in Chapter 2. In particular, it posits a link with the subject matter of the text that corresponds to Duke and O'Day's predictions.

\section{a) Divine Irony}

The first possible rationale is Glenn Holland's concept of 'Divine Irony.' Holland observes, "Irony is pre-eminently a product and expression of distance, specifically the intellectual distance between the detached observer and the continual flux of human thought and experience." 106 He notes that only the gods see things as they really are. In contrast with the circumscribed nature of human knowledge, this creates the ultimate detachment or distance. Therefore, human attempts to speak of the divine will invariably generate irony, particularly in light of humanity's fallen nature. ${ }^{107}$ Conversely, divine attempts to cross the distance will appear oracular and enigmatic.

\footnotetext{
${ }^{104}$ O’Day, Revelation, 112.

105 Ibid., 31-32.

${ }^{106}$ Holland, Divine Irony, 59.

107 "If original sin is perceived only through salvation, then it must be classed not as pessimism but as irony, involving the awareness of a crucial incongruity between the 'is' and the 'ought' of human existence, between the
} 
Holland illustrates divine irony by using Socrates and Paul as examples of revelators who speak of divine truth and consequently generate irony. Socrates' dissembling and claims to knowing nothing are therefore a wise man's acknowledgement of divine irony. Socratic irony "is in the fullest sense divine irony, with both its origins and its consummation in an awareness of the divine." ${ }^{108}$ Likewise, Paul consistently employs an irony that is drawn from an experience of the divine. ${ }^{109}$ He attempts to build solidarity through irony. In 1 Corinthians 1:18-25 Paul ironically contrasts the "foolishness of God" and the "wisdom of the world."110 In 2 Corinthians 11:30, in a very Socratic way, he positively boasts of his weaknesses not strengths. Holland concludes that "Paul and Socrates are alike in their use of irony as an indirect means of communicating the insights they gained from a revelation of the divine perspective. In both cases their irony was meant to educate, to be recognised as irony, and appropriated by their audiences as a means for discovering divine truth."111

Does the author of the Fourth Gospel seek to convey truth in a similar manner? Undoubtedly. Holland's thesis that communication of the divine is more likely to generate irony is correct. But does this explain the prevalence and form of Johannine irony? Such a hypothesis is unconvincing for several reasons.

The first problem is that if humanity's attempts at divine discourse inevitably produce irony, then all theological dialogue would be inescapably ironic. If irony is a product of humanity's fallen condition, since it depends on the distance between what is and what should be, then humanity's universally fallen state should yield ubiquitous irony. Yet this is not supported by sacred writings. In the New Testament, irony varies from author to author, genre to genre, book to book and even within the same literary work. In the Fourth Gospel, irony declines significantly during the Farewell Discourse just as Jesus is at his most didactic and articulating the deepest concepts around the divine. ${ }^{112}$ This is the opposite of what we would expect according to Holland's proposition.

\footnotetext{
human self-perception and the human reality. But the incongruity is stated not in order to damn the reality but in order to redeem it." Good, Irony, 30.

${ }^{108}$ Holland, Divine Irony, 116.

${ }^{109}$ Ibid., 120.

110 This is developed through three linked modes of ironic contrast: wisdom/foolishness; strength/weakness; honour/disrepute (1 Corinthians 4:10).

${ }^{111}$ Holland, Divine Irony, 156.

${ }^{112}$ For example, this section contains all of Jesus' teaching on the Holy Spirit.
} 
Holland anticipates this objection. He asks, "if distance and irony are basic to biblical religion, why is irony so rarely in evidence among the biblical documents?"113 His response is two-fold. First, some biblical works are for insiders and because of the shared values contain less irony. Others are for outsiders whose follies are open to contention; accordingly, irony appears more frequently in adversarial books like Job, the Prophets and the Gospels. However, this explanation fails to account for the variation between the Fourth Gospel and the Synoptics or the variation between the Prophetic books. Conversely, one of the most ironic books in the OT is Ecclesiastes, which is written for insiders. His second reason is that when the values of the faith community move closer to the surrounding culture recognition of the ironies become more difficult. This is equally unpersuasive. It does not explain why Paul's epistles to the Corinthians contain robust irony whilst his epistle to the Romans does not. Both cultures are equally foreign to Paul's own background. ${ }^{114}$ Neither of these explanations can adequately explain the wide variance in Biblical irony.

Secondly, if the distance between divinity and humanity creates the irony, this is problematic because only the divine would be able to appreciate it. Unless there is superior knowledge equating to divine perception, it is impossible to know if the ironic incongruity even exists. Moreover, without a divine perspective it could not be resolved in the manner that irony requires to function. Thus, if Holland's theory were true it would be unknowable from a human perspective. Human authors, through the use of the narrator, a prologue or a dramatic device such as the Greek chorus, can mimic the divine perspective but can never truly possess it. Holland does not address this problem of divine-referentiality. This lacuna would mean that divine irony would actually be harder to detect and less prevalent than non-divine irony. It also fails to explain why some divine discourse appears more ironic than others.

The third problem is linked to the second, in that Holland over-aggrandises the role of the author. Since a divine viewpoint is required Holland promotes the author to this role; "the author who employs literary irony is generally perceived as a benevolent deity by the reader." 115 The author, who creates his or her own world and populates it with characters of their own devising, does act in an unrestrained and god-like way. However, this is not an adequate description of the author's relationship to the Gospel narrative. In the Fourth Gospel, the author

\footnotetext{
${ }^{113}$ Holland, Divine Irony, 149.

${ }^{114}$ In fact, due to widespread Hellenistic influences, the Greek culture of Corinth would have been more familiar to Paul than the Latin culture of Rome.

${ }^{115}$ Holland, Divine Irony, 160.
} 
claims that the real author personally testifies to the truthfulness of the account $(21: 24)$. This severely limits the author's options in terms of characters, plot and dialogue. Holland's thesis only applies to situations where the author has the creative license to fashion a divine perspective within their work. Divine irony is accordingly better categorised as a subset of dramatic irony.

Holland's hypothesis is intriguing but insufficient to provide a comprehensive explanation of Johannine irony. It describes some aspects of the Gospel's irony, especially in the Prologue where the narrator briefly provides the reader with a god-like overview. However, it cannot account for the prevalence of Johannine irony in comparison to similar literary works, especially the Synoptic Gospels. Nor can it provide an explanation for the variance of irony within the Gospel.

b) Greek Tragedy

A second hypothesis locates the rationale for irony in the literary form of the Gospel. It is often observed that the Fourth Gospel shares many similarities with Greek drama, especially Greek tragedies. Origen first drew attention to the parallels between the arrest of Jesus in John 18 and Euripides' story of Dionysus in the Bacchae. ${ }^{116}$ Carson observes how, "The narrative unfolds like a Greek tragedy, there is triumph, there is glorification: the supreme irony is that in the ignominy and defeat of the cross the plan of God achieved its greatest conquest, a conquest planned before the world began." 117 Most who comment on the resemblances are careful to clarify that they are not equating the Fourth Gospel with Greek tragedies but noting certain convergences. $^{118}$

Jo-Ann Brant discusses the influence that Greek tragedians may have had on the text and how it contains distinctly performative elements. Parallels to Greek drama are evident in the Prologue and Epilogue, in the episodic nature of the narrative and the transitions between episodes, in the unity of the plot, and in dramatic plot features such as - reversal (peripeteia), recognition (anagnōrisis) and suffering (pathos). Similarly, she finds parallels in the Gospel's dialogue and

\footnotetext{
${ }^{116}$ Stibbe, Storyteller, 131.

${ }^{117}$ Carson, John, 56-57.

${ }^{118}$ E.g. "The purpose of this article is, not to prove that the Gospel of John is a Greek drama, consciously modelled and artificially arranged with reference to the dramatic unities, but to present evidence that there is a close parallelism of form and method between it and the great Greek tragedies." Butler Pratt, "The Gospel of John from the Standpoint of Greek Tragedy," The Biblical World, Vol. 30, No. 6 (Dec., 1907), 448.
} 
direct speech. The author makes extensive use of deictic language, that is, language that presents subjectivity, temporality, spatiality and modality. In particular, the author uses the demonstrative pronouns ekeinos and houtos "to trace a path from the verbal gesture to the thing indicated." "119 There are numerous examples where the deictic language functions as an ordering schema, at times bordering on stage directions.

Of particular interest is Brant's suggestion that the verbal sparring of the Gospel is a dramatic device known as "flyting" in which ad hominem barbs or insults are traded. ${ }^{120}$ She adds that "A key component of literary flyting is irony, for it is the audience who determines whether a point has been scored."121 Brant notes that the central pivot of much of the dramatic action is the identity of Jesus; "the more that Jesus clarifies his identity, the more he makes himself the subject and the object of all action." 122

Brant has been criticised for rejecting forensic rhetoric and instead assigning the Fourth Gospel to epideictic rhetoric. ${ }^{123}$ Parsenios notes the overlap between tragedy and legal rhetoric in that "both tragedies and court cases involved juries and were competitive performances." to allow for both dramatic and forensic elements instead of seeing the two modes of discourse as mutually exclusive polarities. ${ }^{125}$ This has implications for our investigation as both elements are centred on determining the truth of key propositional claims. ${ }^{126}$ Parsenios concludes that the literary tensions of the Fourth Gospel are an attempt to express the "inexpressible reality" of Jesus' incarnation and thus "the blending of rhetoric and drama."127

The similarities of the Gospel with Greek tragedy and rhetoric offer a potential explanation for Johannine irony - the author incorporates the dramatic form and inherits the tragedian predilection for irony. There is historical precedent for the mingling of drama and theology, for

\footnotetext{
${ }^{119}$ Brant, Dialogue and Drama, 81.

${ }^{120}$ Jesus' exchange with Nicodemus $(3: 1-21)$ is a gentle example, whereas the exchanges with "the Jews" in 8:39-59 and 10:24-39 are openly hostile flyting.

${ }^{121}$ Brant, Dialogue and Drama, 124. Using chapter 10 as an example, Brant maintains that many of the proposed seams and aporia or allegorical interpretations can be better explained as twists and turns in the verbal battle. However, flyting is typical of epic rather than tragedy as evidenced by Brant's use of Homer to make her points.

122 Ibid., 170.

${ }^{123}$ George Parsenios, Rhetoric and Drama in the Johannine Lawsuit Motif (Tubingen: Mohrs Siebeck, 2010 ), 13. Epideictic rhetoric is one of Aristotle's three forms of rhetoric and is concerned with the present and whether something is honourable; as opposed to deliberative (of the future and concerned with expediency) and forensic (of the past and concerned with justice).

${ }^{124}$ Parsenios, Rhetoric and Drama, 15.

125 Ibid., 43.

${ }^{126}$ E.g. in a tragedy such as King Oedipus the true identity of the titular protagonist and in court cases the identity of the guilty party.

${ }^{127}$ Parsenios, Rhetoric and Drama, 129-130.
} 
as Pratt observes, "the dramatists were the higher critics of the Greek religion." 128 The similarities observed between the Gospel and tragedies, such as the importance of reversal, recognition, the use of demonstrative pronouns, the polemic element of flyting and the centrality of identity issues, have all also been identified as key elements of Johannine irony. Duke notes that "the ironic techniques of the Fourth Gospel are far more akin to the techniques of Greek drama" than the Hebraic irony of the Old Testament. ${ }^{129}$ The likelihood of a cross-pollination of ideas and forms appears compelling. However, is it strong enough to provide a substantive rationale?

One reason to think not, is that while there are many similarities the dissimilarities with tragedy are equally numerous. Parsenios warns that "some scholars define John as a tragedy based on how Aristotle defines tragedy in book 12 of Poetics. But this goes too far. The Fourth Gospel does not follow a metrical scheme. There is no shift from speech to song." ${ }^{130}$ Another drawback to considering the Fourth Gospel as a Greek Tragedy is the presence of the narrator. Brant acknowledges that since the narrator provides most of the references to objects, time and place in the Fourth Gospel this places it in the genre of narrative rather than play. ${ }^{131}$ Moreover, the large didactic sections of the Gospel are entirely unsuited to a dramatic performance. ${ }^{132}$

Furthermore, considering the author of the Fourth Gospel akin to a playwright fails to account for the direct claims to historicity and witness. The author is not constructing characters and dialogue. The narrator claims that the author is providing truthful testimony, in 21:24: "This is the disciple who is testifying to these things and has written them, and we know that his testimony is true." 133 Brant accepts that "as the author of a historical narrative, the gospel writer does not create characters." ${ }^{\prime 134}$ Moreover, the author is not pointing to a general truth by telling a story as the Greek dramatists do, but rather intends to convince the reader of the veracity of specific truths (20:31). For the author, the failure of Jesus' interlocutors to perceive him as the

\footnotetext{
${ }^{128}$ Pratt, Greek Tragedy, 453.

${ }^{129}$ Duke, Irony, 140.

${ }^{130}$ Parsenios, Rhetoric and Drama, 10.

${ }^{131}$ Brant, Dialogue and Drama, 109. Also "the presence of (and dependence upon) a narrator is perhaps the single efficient datum that undermines an argument that the genre of the Fourth Gospel is more like a play than a history or a biography or a Hellenistic novella." Ibid., 202.

${ }^{132}$ John 13 to 17 is, almost without exception, dialogue and extended monologue.

${ }^{133}$ For a fulsome treatment of the Fourth Gospel's claims to eyewitness testimony see, Richard Bauckham, Jesus and the Eyewitnesses: The Gospels as Eyewitness Testimony (Grand Rapids: Eerdmans, 2006), 358-411. Bauckham proposes based on the internal evidence, developments in the study of oral tradition and the study of memory (cognitive psychology) that the Gospel is the product of an eyewitness.

${ }^{134}$ Brant, Dialogue and Drama, 164. However, she also notes that literary techniques can still be applied to historical figures and that therefore they may still function, to some lesser degree, as characters.
} 
Messiah is not tragic because it demonstrates the human capacity for hubris/folly (as the failure to identify does in King Oedipus). Rather it is tragic because Jesus is in reality the Messiah and this has real spiritual implications for the characters in the narrative and the reader. Keener warns that neither aspect of the Gospel can be overly elevated or disassociated since "the Fourth Gospel is both historical and literary/theological."135

While the stylistic similarities with Greek tragedies are another contributory influence for Johannine irony, they again fall short as a primary rationale. The convergences represent a literary form that the author ingeniously incorporates where it suits his purposes but equally, and more frequently, eschews when it does not. Thus, while the author makes use of dramatic and theatrical conventions, he does not make consistent use of them. The dramatic conventions "seem to serve more as tools to tell the sort of story he wants to tell rather than the constitutive parts of a genre he seeks to realise." 136 These techniques undoubtedly heighten the irony on occasion but irony also pervades the non-dramatic and non-theatrical parts of the Gospel. A more pervasive and systemic framework is required to explain Johannine irony. As Duke and O'Day have anticipated, the rationale for irony should have a correlation with the content of the narrative and not just its literary form or context. This is especially true when the Gospel only occasionally makes use of that form.

\section{c) Personal Style}

Another possible explanation for the prevalence of Johannine irony is that it is indicative of the author's own style. It is not the nature, form or text of the Gospel that provides an answer but rather the ironic proficiency of the author. The real author is a Socratic-like figure for whom irony is a natural and characteristic form of expression and this conditions the implied author's literary choices. Accordingly, irony is the author's mode of seeing the world and not just a rhetorical device. He does not consciously employ it for any particular reason; it is simply his natural way of thinking and speaking.

This hypothesis, however, presents a number of difficulties. First, there is the matter of internal consistency. If irony was the author's idiosyncratic form of expression it would be conveyed more-or-less uniformly throughout the Gospel. Conversely, there is considerable variance. Ironic discourse tends to proliferate when there is a contending over propositional truths and is

\footnotetext{
135 Keener, John, 17.

${ }^{136}$ Brant, Dialogue and Drama, 158.
} 
less frequent during didactic passages. When Jesus' claims are subjected to the greatest challenge, during the Passion Narrative, irony reaches its apex. As shall be seen in the next Chapter, Johannine irony has an observable thematic focus. Certain themes predominate when ironic utterances are present, suggesting irony is specifically targeted rather than uniform. This corroborates Duke's finding that "in Johannine irony, form follows theme."137

Second, there is an external consistency issue. It is generally, although not unanimously, held that the author of the Fourth Gospel also penned the Epistles of John. ${ }^{138}$ There are extensive similarities in key themes (e.g. the centrality of truth, the contrast of opposites, clear categories of belief/unbelief, the author's role as an eyewitness, and spiritual blindness), vocabulary (e.g. truth, love, light and darkness, life and death) and grammar (e.g. use of conjunctions and asyndeton, the use of few particles). The parallels are so striking that as Brown suggests, "the burden of proof lies with the person who would deny their common authorship." 139 Yet the Epistles exhibit little irony. If the author had a general predilection for irony, it should be present in his other literature at a commensurate rate.

Third, how the author could inject such an extensive, personal ironic emphasis and retain the integrity of the account, if, as we have identified, the Gospel is historical as well as literary/theological? Moreover, does the irony originate with the real author or Jesus? Our narrative critical focus on the implied author as a product of the text means that we do not need to distinguish ironic sources. For our purposes, Johannine irony is entirely a product of the literary choices of the implied author. ${ }^{140}$ Notwithstanding, some scholars, have conjectured that the "irony of the Gospel originates in Jesus himself, who is the master ironist." consider the presence of irony in the Synoptic Gospels as corroborating evidence. If true, this would further militate against Johannine irony being entirely an attribute of the real author.

\footnotetext{
${ }^{137}$ Duke, Irony, 92.

${ }^{138}$ See Keener, John, 122-126; Robert Yarbrough 1-3 John, Baker Exegetical Commentary on the New Testament, (Grand Rapids: Baker, 2008), 5-11; John Stott, The Letters of John (Grand Rapids: Eerdmans, 1988), 17-28; Colin Kruse, The Letters of John, Pillar New Testament Commentary, (Grand Rapids: Eerdmans, 2000), 9-14, 36-37, 42; I. Howard Marshall, The Epistles of John: The New International Commentary on the New Testament (Grand Rapids: Eerdmans, 1978), 42-48; Raymond Brown, The Epistles of John, Anchor Bible Commentary 30 (New York: Doubleday, 1982), 19-30; Stephen Smalley, 1, 2, 3 John, Word Biblical Commentary 51, (Nashville, Thomas Nelson, 2007), xx-xxi; Gary Burge, Letters of John, The NIV Application Commentary, (Grand Rapids: Zondervan, 1996), 22-24.

${ }^{139}$ Brown, Epistles, 20.

${ }^{140}$ In any case, most of the verbal ironies are placed in the mouths of Jesus' opponents, the disciples or, in the case of situational ironies, noted by the narrator.

141 Hamid-Khani, Revelation, 76. MacComb portrayed Jesus as a master ironist as early as 1904: Samuel MacComb, "The Irony of Christ," The Biblical World vol.23, no.2 (1904), 104-109.
} 
Nonetheless, even if the essential irony originates with Jesus this does not preclude the author framing their narrative in a manner conducive to further ironies.

Finally, the concept of irony as a way of perceiving the world is a recent phenomenon. For the author to infuse the entire Gospel with irony solely as an expression of a general ironic detachment or a love of irony would be to go beyond even Socratic irony. Irony was not an expression of Socrates' personality but rather a methodology "to bring his interlocutors to ethical knowledge."142 Divorcing Johannine irony from an expression of propositional truths is attributing to the author a sense of general irony that is anachronistic. Duke observes that while some do use irony to express their fundamental detachment from life, their permanent bemusement, or their love of irony for irony's sake, this type of ironist "is a creature of the modern era and bears no resemblance to the author of the Fourth Gospel."143

This hypothesis is another contributing factor to the final form of the Gospel's irony. The author clearly has an appreciation for and skill in handling irony but this alone cannot serve as a rationale for its carefully plotted use.

d) The Truth Theme

Three of the most influential voices on Johannine irony - MacRae, Duke and O'Day - have intimated that any clues for John's rationale are likely to be found within the text itself. There cannot be a direct correlation between irony and a singular topic in the text because otherwise the resultant overtness would negate the irony. Accordingly, the subject matter of Johannine irony is as varied as the characters who utter it and the circumstances in which they utter it. Consequently, if an answer lies within the content of the text it will be some large, integrating concept or theme that operates at the highest levels of the Gospel. One such concept stands out as an obvious candidate.

We saw in Chapter 2 that there is an integral connection at a conceptual level between irony and truth. The literal meaning destabilises perceptions, while the intended meaning resides in a previously unseen truth the author wishes to highlight. Thus, the essential conflicts and incongruities within irony draw the reader into the author's vision of truth, enabling the reader to

\footnotetext{
${ }^{142}$ Colebrook, Irony, 23.

${ }^{143}$ Duke, Irony, 3.
} 
perceive reality and "judge with right judgment" (7:24). ${ }^{144}$ Accordingly without Kierkegaard's "truth, actuality, content" $" 145$ irony would remain ineffable and ultimately unresolvable. Without two levels of meaning (the literal but untrue, and the non-literal but true) irony cannot exist. Irony inhabits the space between deception (where the contrast between appearance and reality is so ambiguous it conceals the truth) and sarcasm (where the contrast is so obvious that truth is used as a bludgeon so that commonality is lost). Thus, Duke's description of Socrates as "both assassin of pretension and midwife of truth" ${ }^{146}$ is an apt description of irony itself.

The inherent relationship between truth and irony is pertinent because the Fourth Gospel possesses a profound truth theme. ${ }^{147}$ John's concern for truth is expressed in two main ways: first, via statements that make explicit use of truth terminology, by utilising the alètheia word group (hereinafter referred to as "truth statements"). These explicit truth statements also form a semantic field with a number of statements that use terms that implicitly relate to the truth. The second way John expresses his concern for truth is by statements that assert propositional truths, while not expressly using truth terminology (hereinafter referred to as "propositional statements"). ${ }^{148}$ This establishes a discernible pattern in the narrative, whereby the author uses the truth statements to alert the reader to the existence of the truth theme and, as will soon be demonstrated, he uses the propositional statements to convey the content of the truth theme.

Most religious literary works employ truth terminology; however, the author of the Fourth Gospel turns truth statements into a leitmotif. The word alètheia (and other forms alèthēs, alèthinos) appear twice in Matthew and four times each in Mark and Luke. They appear a remarkable 48 times in John! ${ }^{149}$ Of the total uses of the word alètheia in the entire New Testament, $43 \%$ are in the Johannine literature. For alēthēs and alēthinos the usages are $65 \%$ and $82 \%$ respectively.

\footnotetext{
${ }^{144}$ Feagin, Irony, 27.

${ }^{145}$ Kierkegaard, Concept of Irony, 326.

${ }^{146}$ Duke, Irony, 9.

${ }^{147}$ In relation to the New Testament notion of truth, "the summit of this development is reached in the Fourth Gospel. Truth for John is a very important concept." Leon Morris, The Gospel According to John, The New International Commentary on the New Testament, (Grand Rapids: Eerdmans, 1995), 260. See also, Merril C. Tenney, "Literary Keys to the Fourth Gospel: The Imagery of John" in Bibliotheca Sacra 121 (Jan 1964$), 13$.

148 "The type of speech-act most commonly found in the Fourth Gospel is the assertive as the implied author is concerned to present the implied reader with propositions about Jesus." Tovery, Narrative Art, 73.

${ }^{149}$ Schnackenburg also notes that in relation the term "truth" its usages in "the synoptic texts have no theological significance.”Schnackenburg, St. John, 2.225.
} 
In the Fourth Gospel, these truth statements often have Jesus as their focal point. Jesus is

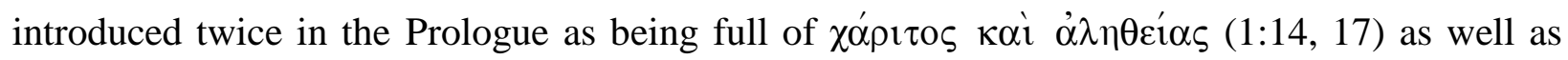

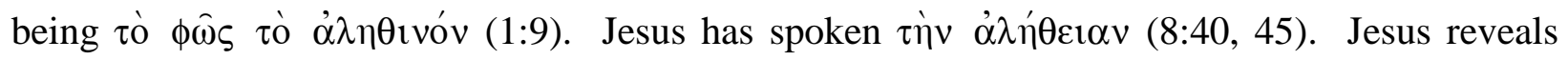

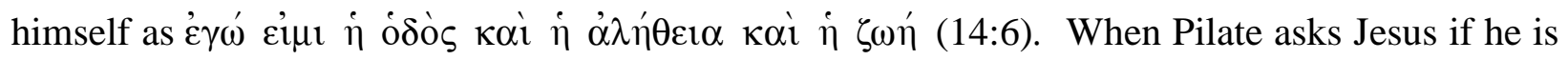
a king Jesus responds in the affirmative but immediately refocuses the question in terms of the

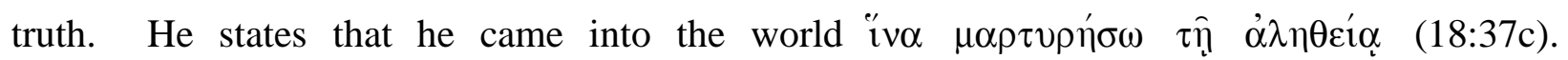

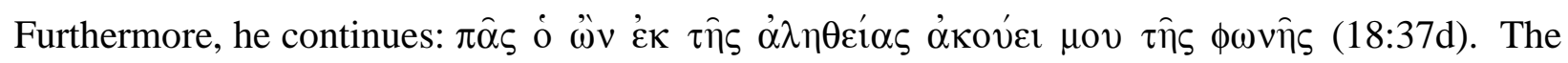
direct usages of aletheia connect the notion of truth with the person of Jesus to the point that "Jesus is both the truth and the revealer of the truth." 150

Other usages of the word relate to the worship of the Father by $\alpha \lambda \eta \theta$ ivoi $\pi \rho 0 \sigma \kappa v v \eta \tau \alpha$ '

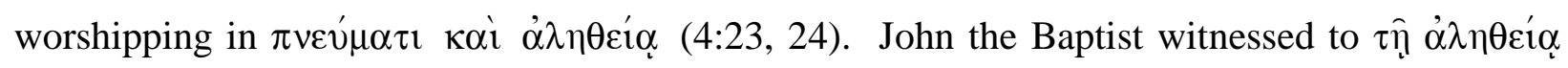

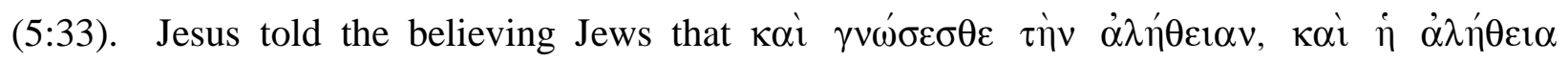

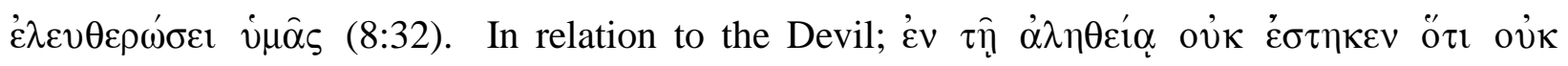

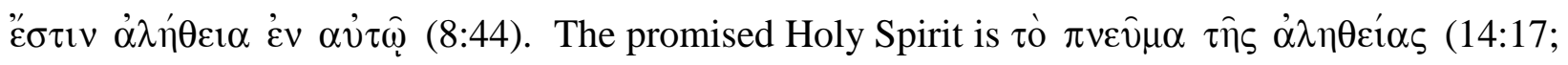

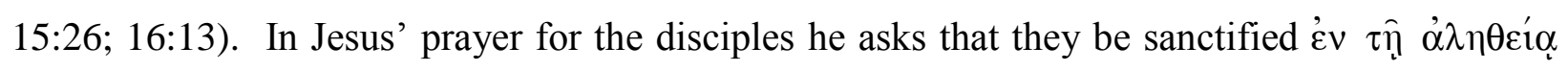

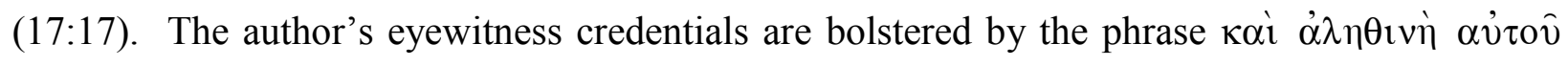

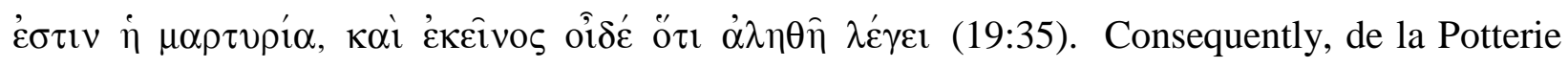
observes "all New Testament scholars will readily concede that the idea of truth is one of the central theological concepts in the thought of John."

Commentators have differed, however, on the conceptual background of John's notion of truth. Bultmann and Dodd favour a Greek background in which truth hovers between the meanings of "reality," or "ultimate reality," and "knowledge of the real."152 Kupyer, on the other hand, influenced by discoveries at Qumran, posits a Hebraic background for the term. ${ }^{153}$ He suggests that the phrase "grace and truth" in 1:14 and 1:17 occurs as a hendiadys. This gives alètheia the meaning of faithful loyalty or dependability in covenantal fellowships, as opposed to "something abstract, a concept of the mind." 154 Morris, Barrett, Brown and Witherington similarly emphasise the Hebrew meaning but are more accommodating of lesser Greek influences. De la

\footnotetext{
${ }^{150}$ Hamid-Khani, Revelation, 341.

${ }^{151}$ Ignace De La Potterie, "The Truth in Saint John," in The Interpretation of John ed. John Ashton (Edinburgh: T\&T Clark, 1997), 67.

${ }^{152}$ Dodd, Interpretation, 177.

${ }^{153}$ Lester Kuyper, "Grace and Truth: An Old Testament Description of God, and Its Use in the Johannine Gospel," Interpretation 18 (1) January 1964, 6-7.

${ }^{154}$ Kupyer, Grace and Truth, 15.
} 
Potterie rejects both options as too restrictive and argues that it is a comprehension of a double tradition "que s'explique le mieux l'emploi johannique de la notion de vérité."155

There is an increasing recognition that the use of the term alètheia in the Fourth Gospel is more distinctively Johannine than either Greek or Hebrew. ${ }^{156}$ As Schnackenburg proposes, “"truth' in the Johannine writings turns out to be a concept taken from the language of the time and flexibly used to sustain and illuminate the Johannine theology of the saving revelation in Jesus Christ." 157 There is a consensus that "ce soit le mot alêtheia qui exprime avec le plus de plenitude le thème johannique fundamental de la révélation." 158 Truth is not an abstract notion for the author rather Jesus personally reveals truth. ${ }^{159}$ Furthermore, since truth is interrelated with revelation and Johannine irony creates the revelation experience for the reader, ${ }^{160}$ there is already an inherent relationship between John's theme of truth and irony.

A further component of John's truth statements is the presence of similar terminology that generates a semantic field, which augments the truth theme implicitly. ${ }^{161}$ An example is the Fourth Gospel's concept of "believing." It uses the word pisteuō ( $\pi 1 \sigma \tau \varepsilon v$ w, "believe") 98 times, in comparison to Mark (14), Matthew (11), and Luke (9). Belief requires an object and so there is a clear correspondence between the act of believing and the truth that is believed in. While the Gospel uses the verb pisteuo liberally, the corresponding noun pistis ( $\pi \dot{i} \sigma \tau \iota \varsigma$ ) is entirely absent. This means that John's concept of faith is active; it is, "not something one has. Faith is something one does." 162 The verb is also regularly and unusually paired with the preposition eis $(\varepsilon ı \varsigma)$ in the accusative. ${ }^{163}$ This construction places the emphasis on the object of the belief. For the author "to believe" is to be subsumed into the thing revealed, it "is an activity that takes

\footnotetext{
${ }^{155}$ Ignace De la Potterie, La Vérité dans Saint John 2 Vols. (Rome: Biblical Institute Press, 1977), 278.

156 "J. Barr and A. Thiselton have shown that the common distinction made between Greek and Hebrew meanings for truth simply does not work linguistically. John's usage is not 'Greek,' it is 'Johannine,' and as we shall see it is not incompatible with an OT/Hebrew background." David Crump, "Truth," in Dictionary of Jesus and the Gospels eds. Joel Green, et al. (Downers Grove: IVP, 1992), 861. See also Anthony Thiselton, "Truth," in The New International Dictionary of New Testament Theology ed. Colin Brown, (Grand Rapids: Zondervan, 1978), 3.889-894.

${ }^{157}$ Schnackenburg, St John, 2.237.

${ }^{158}$ Ignace de la Potterie, La Vérité, 1.3.

159 "And that revelation is Jesus himself and his career - he is both revealer and revelation... While in early Judaism it was the Torah that was the truth, and studying it made a person free, here the claim is that believing in Jesus and his story has this effect." Ben Witherington, John's Wisdom: A Commentary on the Fourth Gospel (Louisville: John Knox, 1995), 177.

${ }^{160}$ O’Day, Revelation, 95.

${ }^{161}$ We have already noted the linked terms of alēthōs and amēn amēn earlier in this Chapter.

${ }^{162}$ Robert Kysar, John: The Maverick Gospel (Louisville: John Knox, 1993), 94.

${ }^{163}$ Dodd observes that there is no precedence for this use in profane Greek or the LXX. Dodd, Interpretation, 183.
} 
people right out of themselves and makes them one with Christ."164 This close correlation between belief and revelation enables the author to use irony to challenge existing beliefs and beckon the reader to active belief in his truth claims.

Scholars have identified a trial motif in the Fourth Gospel. ${ }^{165}$ They observe a covenant lawsuit in John's use of "forensic language to describe a cosmic lawsuit between God and the world." 166 Two elements that feature predominantly in the trial motif also implicitly relate to John's notion of truth. The first are the linked concepts of "witness" and "testimony." A witness formally provides testimony to the veracity of a matter. ${ }^{167}$ Accordingly, in the Fourth Gospel "the Witness theme is concerned with Truth and various forms of testimony to the Truth." 168 Within the narrative a number of characters witness or testify to the truth $(1: 7,8,19 ; 3: 11 ; 4: 39 ; 5: 33$ $34 ; 7: 7 ; 8: 17 ; 12: 17 ; 15: 26,27 ; 21: 24)$ and testimony is sometimes disputed $(3: 11,32-33 ; 8: 13$; 18:23). The scriptures testify (5:39), the works of Jesus testify $(5: 36 ; 10: 25)$, and Jesus' role is depicted in witness language: "For this I was born, and for this I came into the world, to testify

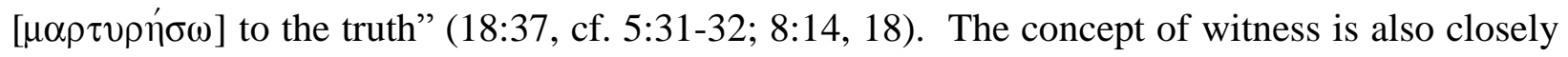
related to the progressive presentation of the person of Jesus. ${ }^{169}$ Witness statements provide an interpretive framework through which the reader perceives irony in latter statements or situations.

The second prominent element in the trial motif is the concept of "judgment." Through the trial motif, the Gospel narrative "is judgement in action, judgement as story or drama."170 This occurs within the narrative and during the reading experience, as propositional statements come under forensic analysis. The extended trial narratives ${ }^{171}$ are a brilliant literary strategy, by which the author places the reader in a position of judgement over others, even as they ostensibly pass judgement. The author vindicates the reader's position by noting that those who presume to judge Jesus are ironically opening themselves up to judgement $(1: 19 ; 5: 22,27,30 ; 8: 15-16$; $9: 39 ; 12: 48 ; 16: 8,11)$. Consequently, it is incumbent on the characters in the story, and by extension the reader, to "judge with right judgement" (7:24).

\footnotetext{
${ }^{164}$ Morris, John, 296-297.

${ }^{165}$ Lincoln provides the most thoroughgoing treatment of the topic: Andrew Lincoln, Truth on Trial: The Lawsuit Motif in the Fourth Gospel (Peabody: Hendrickson, 2000).

${ }^{166}$ Alison Trites, The New Testament Concept of Witness (Cambridge: Cambridge University Press, 1977 ), 112.

${ }^{167}$ In ancient texts "eyewitness evidence (autopsia), was thought the most reliable historical source." David Aune, The New Testament in Its Literary Environment (Philadelphia: Westminster, 1987), 81.

${ }^{168}$ Painter, John, 61.

${ }^{169}$ Merrill Tenney, “The Meaning of 'Witness' in John,” Bibliotheca Sacra 132 (July 1975), 230.

${ }^{170}$ Francis Moloney, "Who is 'The Reader' in/of the Fourth Gospel?" Australian Biblical Review 40 (1992), 226.

${ }^{171}$ I.e. chapters 5-10 and 18-19.
} 
The distinction between truth statements and propositional statements is important because explicit truth statements and irony only infrequently exhibit direct correlation. Since the narrative must initially disguise truth for irony to function, overt truth statements are not conducive to irony. Accordingly, only four of the 176 ironic statements proposed in the survey contain any of the alētheia word group. In only one of these, Pilate's $\tau^{\prime} \dot{\varepsilon} \sigma \tau \imath \nu \alpha^{\prime} \lambda \eta^{\prime} \theta \varepsilon \iota \alpha$ (18:38), is the notion of truth directly related to the point of the irony. However, the term aletheia is pivotal, not because the statement is true but rather the opposite. The irony is located in Pilate's reckless indifference to the truth. Thus, irony is more likely to occur when a previously established truth faces subsequent challenge. ${ }^{172}$ The link between truth statements and irony is in the author's prior use of alêtheia to induce the reader to identify and prioritise key propositional truths. This creates a truth framework, which will subsequently be challenged ironically.

The truth theme must consist of more than just the use of truth statements because while they describe the importance and locus of the truth theme they do not describe its content. Truth statements fall into five categories. The first and most predominant are the affirmations that Jesus is the Gospel's focal point for truth because he exemplifies and personifies truth. In the second category, in a manner similar to the Gospel's portrayal of Jesus, God the Father (3:33; $7: 28 ; 8: 26 ; 17: 3)$ and the Holy Spirit $(14: 17 ; 15: 26 ; 16: 13)$ are also described as truth or being true. Conversely, there is no truth in the Devil $(8: 44)$. The third are statements that indicate that truth is an important function of discipleship. ${ }^{173}$ The fourth group describe the witnesses who testify to the truth: John the Baptist $(5: 33 ; 10: 41)$ and the author $(19: 35 ; 21: 24) .{ }^{174}$ Finally, there are texts that speak of the positive and negative consequences of responding to the truth. The truth will set those who know it free (8:32). On the other hand, ambivalence towards the truth will result in being restricted to acting incongruently (18:38). The Gospel's truth statements are only infrequently also direct propositional statements. ${ }^{175}$ The truth statements talk generically about the truth, why it is important (because it will set you free or is essential for discipleship) or

\footnotetext{
${ }^{172}$ Accordingly, a truth presented polemically rather than didactically is more likely to provoke irony at a later juncture.

${ }^{173}$ E.g. True worship must be in spirit and truth $(4: 23,24)$, the disciples know Jesus came from God in truth (17:8), they need sanctification in truth $(17: 17,19)$, and if they continue in Jesus' word then they are true disciples (8:31)

${ }^{174}$ It is plausible that this is not a separate category but rather John the Baptist and the author functioning as true disciples. However, the specific reference to testifying fits with a wider testimony theme that also relates to truth statements $(3: 33 ; 5: 31-32 ; 18: 37)$ and so I have retained the possibility that this is another category.

${ }^{175}$ E.g. $1: 9 ; 3: 33 ; 4: 42 ; 6: 32,55 ; 15: 1$.
} 
in whom it is found (Jesus, God, the Holy Spirit and certain witnesses), but they do not specifically elucidate what is the substance of the truth.

Uncovering the substance of the Johannine truth theme is the journey of discovery the author wants the reader to undertake. Accordingly, the Gospel's propositional statements convey the content of the truth theme. Propositional statements are the wide-ranging assertions in the narrative that while lacking explicit truth phraseology, the author presents as truthful. ${ }^{176}$ However, not all propositional statements carry the truth theme. The author avers in the narrative that amongst other things, Jesus attended a wedding at Cana (2:1-2), healed on the Sabbath at the pool of Bethzatha (5:9), was a friend of Lazarus $(11: 3,36)$, and taught the disciples about persecution $(15: 18,20 ; 16: 32)$. These are propositional statements, in that the author maintains that the event, action, timing, relationship or teachings occurred; however, these truths will not set a person free or reveal why Jesus is the truth. The truth theme consists of certain truths that function in accordance with the description of the truth statements.

Hence, the existence of a truth theme in the Fourth Gospel does not imply that the Synoptics are not equally interested in truth. The Synoptics also contain many propositional statements, as does most sacred literature. The Johannine truth theme is distinguished by the author's distinctive use of truth terminology to signal the existence of key but unspecified truths that express the author's primary theological concerns and are discoverable by the reader. The truth theme is a strategy employed by the author to engage the reader in the identification and prioritisation of the Gospel's truths. An understanding of this feature of the truth theme is important for our consideration of Johannine irony, because we need to remain cognisant that we are attempting to identify a connection between the indefinable and the unspecified. As already noted, we would not expect a direct correspondence between rhetorical device and a single topic; not all irony will serve the truth theme and not all aspects of the truth theme will be conveyed with irony. Notwithstanding, if this hypothesis is correct, we would still expect to see a sufficiently identifiable correlation between the narrative's ironies and the truth theme's key propositional statements. Since the success of irony in the Gospel will depend on the reader's ability to recognise and apply the relevant propositional statement to the incongruity ironically presented.

\footnotetext{
${ }^{176}$ Noting that "a claim to truth is specific to whatever genre is under discussion: there is the truth of a poem, the truth of historiography, the truth of a novel." Andrew Lincoln, "'We Know That His Testimony is True': Johannine Truth Claims and Historicity," in John, Jesus and History: Volume 1 Eds. Paul Anderson, et al. (Atlanta: SBL, 2007), 1.183.
} 
The most salient examples of propositional statements in the narrative are Jesus' paradigmatic "I am" statements. He claims to be "the bread of life" $(6: 35,41,48,51)$, "the light of the world" $(8: 12)$, "the gate of the sheep" $(10: 7,9)$, "the good shepherd $(10: 11,14)$, "the resurrection and the life (11:25), "the way, the truth and the life" $(14: 6)$, and "the true vine" $(15: 1,5)$. Only two of these contain truth terminology but all are substantial propositional truths. Furthermore, all but one generates strong irony later in the narrative. ${ }^{177}$ Moreover, unlike the Synoptic Gospels, the miraculous works of Jesus are not miraculous acts of "power" ( $\delta v v \alpha \dot{\mu} \mu \varsigma)$ but "signs" ( $\sigma \eta$ घiov). Accordingly, not just Jesus' words but also his deeds are pointers to the Gospel's key truths.

The presence of propositional statements invariably produces themes, which propagate the author's theology. Painter identifies six major themes: Identity, Life, Festival, Witness, Believing, Signs, and Destiny. ${ }^{178}$ Other scholars suggest their own lists of theological themes. ${ }^{179}$ For our purposes, Painter's themes are suitably representative. We also need to recognise that an over-emphasis on thematic categorisation can become unproductive, since the author's "theology is so wonderfully integrated, however, that attempts to compartmentalize his thought by itemizing its components are destined in some measure to misrepresent it."180 Significantly, Painter also identifies two meta-themes: Revelation and Response. ${ }^{181}$ These mirror John's purpose statement: "But these are written so that you may come to believe that Jesus is the Messiah, the Son of God" (Revelation); "and that through believing you may have life in his name" (Response). Whereas response is the prerogative of the reader, revelation is the responsibility of the author. The propositional statements convey the underlying revelation that allows the reader to perceive the contrast between appearance and reality necessary for irony.

The hypothesis that the Johannine truth theme can provide a rationale for the nature and pervasiveness of irony in the Fourth Gospel is predicated on a number of concepts established in our preliminary chapters. We noted in Chapter 1 that Johannine irony is prevalent in a manner

\footnotetext{
177 Only "the true vine" does not result in later irony. This occurs didactically in the Farewell Discourse where the author de-emphasises irony.

${ }^{178} \mathrm{He}$ cautions that these are not the only themes and that the author "creates the narrative with a synchronic theological structuring where all of the themes enter and exit again and again throughout the Gospel." Painter, John, 4.

${ }^{179}$ Dodd presents 12, (Dodd, Interpretation, 133-285); Carson 9 (Carson, John, 95-100); Keener 6 (Keener, John, 280-330); Schnackenburg 8 - divided into theological and topical interests (Schnackenburg, St John, 153-172); Barrett 9 (Barrett, St John, 67-99).

${ }^{180}$ Carson, John, 95.

${ }^{181}$ Painter, John, 3.
} 
uncommon to the Synoptic Gospels and other biblical literature. In Chapter 2, we observed that at a philosophical level there is an intrinsic relationship between truth and irony. The same chapter also demonstrated that irony is efficacious in producing revelation and delivering difficult truths in an inclusive and appealing manner. In this chapter we have observed that the author of the Fourth Gospel desires, and accordingly makes literary choices, to achieve certain outcomes (cf. 20:31). These outcomes require revelation and response. We have noted that any rationale is likely to be found in the content of the text, in some integrating or overarching theme. We also observed that the Gospel's truth statements evidence the existence of a distinctly Johannine truth theme and the Gospel's propositional statements provide its substance.

The cumulative effect of these points leads to the compelling explanation that the author chooses to use the distinguishing features of irony (especially the indirect revelation of difficult truths and the elicitation of positive responses) to serve his truth theme (an integrating theme) in a way that would achieve his stated aims. As Duke notes, "irony is language shaped for both judgment and invitation." 182 Thus, through the ironic revelation of truth readers are expected to judge "that Jesus is the Messiah, the Son of God" (20:31a) and then invited to respond in order "that through believing you might have life in his name" (31b). Indeed, irony proves so effective in facilitating the author's purposes that many scholars have noted that irony is both a literary device and an integral part of the author's stance in truth. As Good explains, "Irony is a way of expressing ideas, but, more than that irony is also an idea that is expressed, a perception with a content of and assumptions about truth."183 This integration of rhetorical device and truth theme explains why John's use of irony in the Fourth Gospel differs from all other books of the New Testament, including his own Epistles. Furthermore, because the pervasiveness of the truth theme surpasses even that of the Gospel's irony, unlike the previous hypotheses, it offers the key to a comprehensive rationale.

The truth theme's ebb and flow explains why ironic utterances are not uniformly spread throughout the Gospel. As noted, the Johannine truth theme is not conveyed by every propositional statement the author makes but rather through an expression of certain truths that the author wishes to underscore in order to fulfil his objectives. These truths are varied but share a broadly polemical quality as the author is using them to attack perceived false assumptions about Jesus. This is why irony is sparse in the Farewell Discourse. As Jesus authoritatively teaches his disciples irony diminishes; the didactic setting simply does not generate the requisite

\footnotetext{
${ }^{182}$ Duke, Irony, 5.

${ }^{183}$ Good, Irony, 241.
} 
conflict or duality of meaning. When the truth is overt and uncontested, irony abates. When irony does feature in the Farewell Discourse, it is either a situational irony brought on by a lack of comprehension by the disciples $(13: 8,29,37-38 ; 14: 8 ; 16: 29-30,31)$, a continuation of existing symbolic irony (13:30), or because the opponents of Jesus have indirectly re-entered the narrative $(15: 25 ; 16: 2-3)$. This is in stark contrast to the cut and thrust of Jesus' earlier ironic exchanges with his opponents. There the author establishes the truth theme by placing its opposite in the mouth of Jesus' opponents, who take on the role of the alazōn.

The interaction between irony and truth also explains why Johannine irony itself is thematically discriminate. The truth theme provides a number of substantive claims that set off ironic exchanges. In these instances, the irony is thematically discriminating because it is serving the author's wider theological purposes. ${ }^{184}$ Accordingly, the truth theme is an integrating concept that draws together topics that share the ability to advance the author's key purposes. For example, the identity of Jesus is an integral part of the truth theme due to its connection with the author's purposes (cf. 20:31). However, the identity and nature of the Holy Spirit (14:15-31; 15:26-27; 16:7-14) is not. Tellingly, the sections on the Holy Spirit feature no significant irony. The next Chapter will take up this point and explore its implications further.

This rationale does not force anachronistic interpretations of irony upon the author. Irony as an instrument of truth, "an alluring and effective weapon that turns on its head superficial judgements," $" 185$ is compatible with the real author's first-century milieu - both Hellenistic and Hebraic. It is also consistent with the timeless appeal of irony as a way of communicating truth. $^{186}$ An author whose overarching purpose is to draw readers into a community of faith predicated on certain truths about Jesus (cf. 20:31a) would find the inclusive nature of irony attractive. Irony's indirect method of exposing erroneous beliefs and drawing readers into a community of like-mindedness would complement direct propositional statements that the author desires will result in personal actualisation (cf. 20:31b). Irony "typically has a corrective function, serving to unmask the fallacious beliefs, hypocritical actions, or transparent bias of a character or group of characters in the narrative and thus draw the reader to the side of the author, guiding him or her to the conclusions about the truth of a given matter intended by the

\footnotetext{
184 “John's irony is employed only to serve a larger purpose. This point may seem overly obvious but many recent discussions about ironists do not seem to recognize such a distinction." Duke, Irony, 3.

${ }^{185}$ James Resseguie, The Strange Gospel: Narrative Design and Point of View in John (Leiden: Brill, 2001$), 30$.

186 "In general, and independent of any specification according to historical time, the most crucial issues of irony reside in the area of self-conscious saying and writing and concern the problems of linguistic articulation, communication, and understanding in regard to truth." Behler, Irony and Discourse, 111.
} 
narrator."187 In light of the author's avowed purposes, irony makes the perfect "midwife of truth" for the Fourth Gospel.

\section{Conclusion}

In this chapter, we have reviewed several possible explanations for the widespread presence and deliberate use of irony in the Fourth Gospel. The fourth hypothesis - that the author's articulation of a truth theme has a causative connection with Johannine irony - is the most compelling. It is consistent with the well-documented relationship between irony and truth; it is expansive enough to encompass the breadth of Johannine irony; it explains the variation within the narrative; and it is ideally suited to the author's overarching purpose of facilitating revelation and response. It is the qualities derived from irony's complementary relationship with truth that explain why the author has chosen irony, instead of any other rhetorical device, to be the main form of expression for his central themes. The prevalence of the Johannine truth theme therefore provides the primary explanation for the prevalence of Johannine irony. However, we will find the most convincing evidence in an exegesis of the text itself. Accordingly, I will now turn to the Prologue and Passion Narrative to demonstrate a quantitative ${ }^{188}$ and qualitative ${ }^{189}$ connection between Johannine irony and the truth theme.

\footnotetext{
${ }^{187}$ Köstenberger, Theology, 152-153.

${ }^{188}$ I.e. there is a commensurate proportion of Johannine irony in the text that serves the author's key truth themes.

${ }^{189}$ I.e. there are significant instances of Johannine irony in the text that robustly express the truth theme.
} 


\section{Chapter 4}

\section{The Irony of the Prologue}

The Prologue, whilst comprising just eighteen verses, fulfils an array of functions in the Gospel, many of which are important to the consideration of Johannine irony. Scholars often described it as "the foyer" to the rest of the Gospel or "a key" that will enable the Gospel's decryption. ${ }^{1}$ Accordingly, "the secret to unlocking the meaning of the Gospel of John is to accept what the author says in the Prologue." ${ }^{2}$ There are many substantive and structural parallels between the Prologue and the wider Gospel, such that the Prologue also functions as a summary. ${ }^{3}$ Although scholars disagree on many things about the Prologue, they all accept that it is "a work of immense assurance and literary power."4

The importance of the Prologue for our purposes lies in the fact that it introduces the Gospel's central themes, including the truth theme. Notably it contains truth statements (v.9 $\tau$ ò $\phi \hat{\omega} \varsigma$ iò $\dot{\alpha} \lambda \eta \theta \mathrm{v} v$ óv $^{5}$ and v.14 $\left.\dot{\alpha} \lambda \eta \theta \varepsilon^{\prime} \alpha_{\varsigma}\right)$ and multiple propositional statements (particularly concerning Jesus' true identity). ${ }^{6}$ The Prologue provides the reader with the superior knowledge that allows a correct interpretation of the subsequent narrative, or in the case of irony to detect and resolve its contradictions between appearance and reality. Therefore, if my hypothesis about the rationale for Johannine irony is correct, we will expect the Prologue to anticipate the themes expressed ironically in the body of the Gospel. Irony in the Prologue itself will be limited, since it is not the adducing of the truth but its subsequent contradiction that is conducive to ironic discourse. Accordingly, any irony present in the Prologue will be significant, especially if it interacts directly with the truth theme. The form and function of the Prologue is also likely to be critical for Johannine irony since "the omniscient prologue was almost indispensable in plays which exploited dramatic irony based on hidden identities."7

\footnotetext{
${ }^{1}$ Carson, John, 111, and Witherington, John's Wisdom, 47, respectively.

${ }^{2}$ Francis Moloney, The Resurrection of the Messiah (Mahwah: Paulist Press, 2013), 101.

${ }^{3}$ Edwyn Hoskyns, The Fourth Gospel 2 vols. (London: Faber, 1940), 1.130.

${ }^{4}$ Lindars, John, 77.

${ }^{5}$ Further developed in $3: 19-21 ; 8: 12 ; 9: 15 ; 12: 35-36,46$.

${ }^{6}$ I.e. that Jesus is the incarnate Word of God, pre-existent, the true light, the glory and revelation of the Father, full of grace and truth (the latter phrase repeated in vv.14 and 17).

${ }^{7}$ Culpepper, Anatomy, 168.
} 


\section{Origin}

For a time it was fashionable to consider the Prologue a later interpolation. Some scholars find evidence for this in the uniqueness of the personal logos concept in the Prologue, which the Gospel does not reflect or recapitulate. ${ }^{8}$ Bultmann saw this as evidence of a Gnostic origin. ${ }^{9}$ However, John's logos theology more likely has a Jewish provenance: Ronning argues for an anchoring of the Prologue's logos theology in the Jewish Targums, ${ }^{10}$ while Keener proposes that it represents the embodiment of the Torah. ${ }^{11}$ While the narrative does not repeat the logos terminology, most increasingly accept that Christology of the Prologue accurately reflects the exalted Christology that pervades the whole Gospel.

Moreover, Tovey demonstrates how the author creates a strong association between the Logos and the story's chief protagonist. ${ }^{12}$ He proposes that the use of the arthrous noun-phrase creates "a nonsequential sequence-signal."13 This, together with a character substitute in v.2 (houtos), invites the reader to begin immediately the task of identification. The structure of the Prologue means that the reader cannot resolve the identity question until the first mention of the name of Jesus in v.17. ${ }^{14}$ The non-repetition of logos terminology in the subsequent account is therefore indicative of a narrative strategy to emphasise identification and revelation, rather than interpolation. ${ }^{15}$ This analysis provides insight into a central element of the truth theme and Johannine irony: the identity of Jesus. Additionally, the Prologue is interwoven with the rest of the Gospel on a literary level to such a degree that "stylistically, John's prologue is most naturally read from the same hand that produced the rest of the Gospel."16 Consideration of Johannine irony, as will be seen, is supportive of this conclusion.

\footnotetext{
${ }^{8}$ Schnackenburg, St. John, 222.

${ }^{9}$ He sees "Gnostic dualism" and "the language of Gnostic mythology" in the Prologue. Bultmann, John, 28.

${ }^{10}$ John Ronning, The Jewish Targums and John's Logos Theology (Peabody: Hendrickson, 2010). Ronning's work is hailed as an impressive and valuable contribution but has not found universal acceptance, many noting the need for further development.

${ }^{11}$ Keener, John, 334.

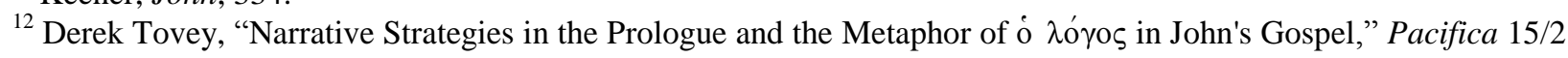
(2002), 139. Tovey evidences this by citing 6 examples of this strong association from the text: 6:60; 7:36; 8:37; $10: 35 ; 12: 48 ; 17: 17$ b. Ibid., 141-142.

${ }^{13}$ That is a noun-phrase that is lacking an immediate referent. Authors intentionally use this technique to pique a reader's curiosity since the referent is mysteriously missing.

${ }^{14}$ Verse 8 specifically excludes John the Baptist.

15 Tovey warns "one cannot, of course, wholly ignore nor abandon attempts to find the literary origins of the term in the philosophical and cultural milieu outside the Gospel. But there is a danger that all this industry diverts attention from its ironic use within the narrative." Tovey, Strategies, 153.

${ }^{16}$ Keener, John, 333. Notably Ronning continues his intertextual analysis into the wider body of the Gospel to make his point.
} 
Another interpolation theory suggests the Prologue was a pre-existing hymn that the author redactionally incorporates, thereby accounting for the stylistic parallels. The primary evidence for this is the rhythmic nature of the text or its components. Scholars have spilt oceans of ink trying to determine the exact parameters of the purported hymn. Schnackenburg suggests four strophes, ${ }^{17}$ O'Neill three, ${ }^{18}$ Rissi eight, ${ }^{19}$ Green two, ${ }^{20}$ and Gordley seven. ${ }^{21}$ Even when authors agree on the number, they vary on where to divide them. Coloe proposes bipartite sections with three strophes each, a reflection of Genesis $1 .^{22}$ There is an obvious appeal to this structure as both documents begin with the portentous phrase: "In the beginning.... ${ }^{23}$ Coloe's proposal also has the virtue of relying on an extant structural framework, unlike many of the speculative alternate theories.

Others dispute the existence of the purported hymn suggesting there are internal consistency issues and that the elusive hymnal structure is overly speculative and ultimately superfluous. ${ }^{24}$ Keener notes that in Greek rhetoric, even prose was expected to be rhythmic, though not metrical and therefore in the absence of specifically hymnic elements (such as the explicit iambic trimeter in the Sibylline Oracles or Hebrew parallelism in the Psalms) there is no meaningful way to differentiate a hymn and exalted prose. ${ }^{25}$ Notwithstanding that the Prologue does have a pacing and dignity that evokes poetic/hymnal qualities, it is apparent that the descriptor " "poem' can be applied to the Prologue only with hesitation." 26

\section{Structure}

For our purposes, only a brief review of the many structural theories about the Prologue is required. The structure of the Prologue is significant because it can assist in clarifying the author's purposes. In particular, the manner in which the Prologue incorporates the truth

\footnotetext{
${ }^{17}$ Schnackenburg, St. John, 1:226.

18 J. O’Neil, “The Prologue to St. John's Gospel,” JTS NS 20 (1969), 48-49.

${ }^{19}$ Mathias Rissi, “Jn 1:1-18 (the Eternal Word)," Interpretation 31 (1977), 395.

${ }^{20}$ Humphrey Green, “The Composition of St. John's Prologue," Expository Times 66 (1954-1955), 292.

${ }^{21}$ Matthew Gordley, "The Johannine Prologue and Jewish Didactic Hymn Traditions," JBL 128 no.4 (2009), 786.

${ }^{22}$ Mary Coloe, "The Structure of the Johannine Prologue and Genesis 1," Australian Bible Review 45 (1997), 41-55.

${ }^{23}$ Barrett argues "that John's opening verse is intended to recall the opening verse of Genesis is certain." Barrett, St John, 151.

${ }^{24}$ See Eugen Ruckstuhl, Die Literarische Einheit des Johannesevangeliums: der Gegenwärtige Stand der Einschlägigen Forschung (Freiburg: Paulus, 1951); Herman Ridderbos, The Gospel of John: A Theological Commentary (Grand Rapids: Eerdmans, 1997), 19-21; Barrett, St John, 150-151; Keener, John, 334-337.

${ }^{25}$ Keener, John, 337. Even Schnackenburg admits that "the rhythm of the hymn is, indeed, debatable." Schnackenburg, St. John, 1:225.

${ }^{26}$ Carson, John, 112.
} 
statements and the propositional statements will demonstrate their importance to the overall narrative and establish the relationship with the irony in the body of the Gospel. Furthermore, identifying the narrative threads that connect the Prologue to the Gospel's irony evinces literary unity, thereby contributing to an understanding of the structure, origins and insertions in the Prologue.

Proposed structures of the Prologue fall into three general categories. ${ }^{27}$ The first includes models based on a linear progression of thought. This approach suggests that the Prologue contains sequential units, which present their ideas in a consecutive or chronological manner. Coloe provides a helpful visual summary of how Brown, Barrett and Beasley-Murray understand this progression. ${ }^{28}$ The primary problem with this approach is the double witness of John the Baptist. Proponents of this structure are required to propose various explanations for this double handling of the prophet.

The second group utilises rhetorical devices such as chiasms and parallelisms. Chiasm-hunting in the Prologue is a well frequented sport. Both Bailey and Culpepper discern in vv.1-2 a double chiastic structure ${ }^{29}$ although only one of the chiastic arrangements is common to both creating three separate chiasms for two verses! Larger chiastic structures, some extending to the entire Prologue, also proliferate. ${ }^{30}$ Some of these larger chiasms are particularly compelling and we examine these in relation to a specific example of irony shortly. Bultmann appeals to parallelism. He perceives the Prologue as composed of couplets that support or stand in opposition to each other, in a form "not foreign to Semitic poetry." 31 Again, we will consider a specific example of this in due course.

The third group comprises 'other structures.' Staley proffers a concentric structure in the Prologue that he bases not on literary devices but on the concentric structure of the Gospel itself. $^{32}$ This structure ingeniously corresponds to Jesus' five ministry tours. Each iteration expands markedly, so that the while the first is 18 verses long the last is 10 chapters. De La Potterie suggests that there are "trois mouvements... en spirale." 33 Michaels radically proposes

\footnotetext{
${ }^{27}$ Contra Coloe who posits two categories (although she would presumably conflate the latter two).

${ }^{28}$ Coloe, Prologue, 41.

${ }^{29}$ Kenneth Bailey, Poet and Peasant (Grand Rapids: Eerdmans, 1976), 59; Alan Culpepper, “The Pivot of John's Prologue," NTS 27 (1980), 9.

${ }^{30}$ E.g. Köstenberger, John, 21.

${ }^{31}$ Bultmann, John, 15.

${ }^{32}$ Staley, Print's First Kiss, 50-73.

${ }^{33}$ Ignace De La Potterie. "Structure du Prologue de Saint Jean,” NTS vol.30 03, (July 1984), 354-381.
} 
a five-verse "preamble." 34 Others take Giblin's lead and suggest two or more complementary structures. $^{35}$

An examination of the ironic threads that weave through the Prologue and the wider narrative supports the prevailing view that the Prologue was written by the same hand as the Gospel. Whatever its origin and shape, "the form of the Prologue is not loose or haphazard but rigid and even minor details are governed by strict rules." 36 A cogency and internal consistency suggest that rather than an afterthought, "the opening phrases of the gospel are among the most carefully constructed in the entire gospel." ${ }^{37}$ Even if the Prologue is a redacted hymn, it has been "thoroughly reworked" $" 38$ by the author to suit his own theological and literary purposes. These overarching purposes and rules give sufficient ground to explore the presence of Johannine irony in the Prologue irrespective of its origin and structure. Moreover, some of the structural features of the Prologue, in particular the chiastic structures, offer potentially intriguing insights into the author's ironical perspective.

\section{Functions}

The Prologue fulfils a range of purposes, many of which relate directly to an examination of Johannine irony. They include an introduction to Jesus and his mission, to the narrator as an interlocutor and guide and to John the Baptist as an initial and trustworthy witness. Other purposes fulfil key literary functions, like introducing major propositional statements, key narrative themes, symbolic concepts and imagery for later development, antithetical norms which will be in conflict in the narrative, ${ }^{39}$ and privileged information that allows the reader a superior position to assess the narrative.

The Prologue displays features common to Greek rhetoric, where it was customary to start speeches with an introduction (prooimion) and statement of facts (diēgēma). ${ }^{40}$ Brevity was crucial. Accordingly, the introduction would present key points in a proto-form to be

\footnotetext{
${ }^{34}$ Ramsey Michaels, The Gospel of John, The New International Commentary on the New Testament, (Grand Rapids: Eerdmans, 2010), 45.

${ }^{35}$ Charles Giblin, “Two Complimentary Literary Structures in John 1:1-18,” JBL 104/1, (1985), 87-88.

${ }^{36}$ Bultmann, John, 15.

${ }^{37}$ Staley, Print's First Kiss, 50.

${ }^{38}$ Haenchen, John, 101.

${ }^{39}$ Culpepper, Anatomy, 89.

${ }^{40}$ Keener, John, 338
} 
subsequently developed. Likewise, Greco-Roman biographies commonly started with accounts of ancestry, birth or predictions of greatness. ${ }^{41}$ The Fourth Gospel here shares a rare similarity with the Synoptic Gospels, each of which starts with a reference to origins or beginnings:

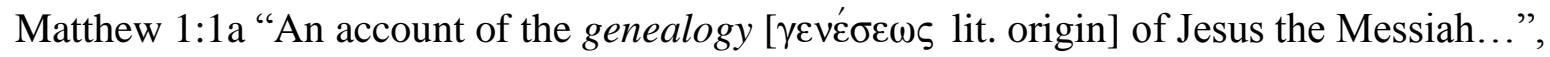

Mark 1:1 "The beginning of the good news of Jesus Christ, the Son of God",

Luke 1:2-3a “...just as they were handed on to us by those who from the beginning were eyewitnesses and servants of the word, I too decided, after investigating everything carefully from the very first."

John radically locates the Gospel's beginning in eternal pre-existence, an approach not without precedent in classical literature.

It is here we find the most important function of the Prologue - the introduction of Jesus as the Word of God. ${ }^{43}$ By placing primary focus on the identity of Jesus, the author sets up the Prologue as a "gateway to Christological truth." 44 Since the purpose of the whole Gospel is that "you may come to believe that Jesus is the Messiah, the Son of God, and that through believing you may have life in his name" (20:31) the true provenance of Jesus is of paramount importance for both Christological and soteriological reasons. As Kostenberger observes, "As a comprehensive Christological designation, the expression 'the Word' encompasses Jesus' entire ministry, placing all of Jesus' works and words within the framework of both his eternal being and existence and God's self-revelation in salvation history." 45 The author therefore arms the reader with the single most important piece of information at the very outset. The rest of the narrative comprises an elaboration and a validation of this initial disclosure.

The dynamic revelation of vv.1-2 forms an inclusio with v.18 ("No one has ever seen God. It is God the only Son, who is close to the Father's heart, who has made him known"), which marks the transition from the Prologue to the main narrative. Thus, the Prologue moves from "a programmatic statement about the logos, the Word, to the concrete narrative embodiment and demonstration in the gospel narrative of how the word is manifested and functions. John 1:18

\footnotetext{
${ }^{41}$ Aune, Literary Environment, 32.

${ }^{42}$ Luke also contains a genealogy in chapter three.

${ }^{43}$ Theodore of Mopsuestia (ca. 350-428) suggested in his commentary on John that the author's description of Jesus in vv.1-3 speaks "about the inscrutable essence of God the Word so concisely that another would not have been able to show what he understood even if he had used six hundred words." Theodore of Mopsuestia. Ancient Christian Text: Commentary on the Gospel of John trans. Marco Conti, eds. Thomas Oden and Gerald Bray, (Downers Grove: IVP, 2010), 5.

${ }^{44}$ Martin Hengel, "The Prologue of the Gospel of John as the Gateway to Christological Truth," in The Gospel of John and Christian Theology. eds. Richard Bauckman and Carl Mosser, (Grand Rapids: Eerdmans, 2008), 265.

${ }^{45}$ Köstenberger, John, 25.
} 
provides the key... pointing to the purpose of the incarnation: to make God known."46 Accordingly the Fourth Gospel's Christology is predicated upon an issue of identity - that Jesus the Messiah and Son of God is to be identified with God, the pre-existent Word personified and the only true revelator of God (1:18).

The centrality of the identity of Jesus in the Prologue allows the first opportunity to test the hypothesis that Fourth Gospel's truth theme is the rationale for Johannine irony. Since the identity of Jesus is a key component in establishing the Christological aspect of the author's purpose statement (his central and overarching propositional claim), it forms an integral part of the truth theme. If my hypothesis is correct, the author should direct a commensurate proportion of ironic utterances to propositional statements evincing Jesus' identity. It will be even more persuasive if the Prologue also expresses this truth claim ironically. The survey of identified Johannine irony (see Figure 1) provides an opportunity to test this hypothesis by seeing if a direct correlation between this central theme of the identity of Jesus and irony exists. Before we can make such a comparison, we must consider how Johannine irony should be categorised.

\section{Categorisation of Johannine Irony}

The categorisation of Johannine irony into themes is challenging. The Gospel's integrated theology that means that attempts to compartmentalise it risks oversimplification at best, and misrepresentation at worst. Culpepper categorises Johannine irony under six themes: the rejection of Jesus, the origin of Jesus, the identity of Jesus, the ministry of Jesus, Jesus' death and discipleship. These categories are problematic on a number of counts. First, how does one differentiate between the rejection of Jesus, his origins and his identity? Culpepper notes that "the foundational irony is that the Jews rejected the Messiah they eagerly expected."47 Yet the truth of Jesus' status as Messiah is inherently tied to his origins (both heavenly e.g. 1:1-2 and earthly e.g. 7:41-43) and therefore, by extension to his real identity. Tellingly, when Jesus is asked "Who are you?" he responds, "What have I been saying to you from the beginning?" (8:25), which causes the reader to nod knowingly from a position of superior knowledge about the real beginning (cf. 1:1-2). Likewise, the rejection or acceptance of Jesus is intrinsically a

\footnotetext{
${ }^{46}$ O’Day, Revelation, 34.

${ }^{47}$ Culpepper, Anatomy, 169.
} 
function of his real identity. ${ }^{48}$ Jesus' origin and his rejection pertain directly to his identity. Accordingly, Culpepper's first three categories really belong together under the broader rubric of "the identity of Jesus."

Culpepper's category "discipleship" is also insufficiently overarching to warrant its own category. Even Culpepper observes that "most of the ironic passages which fall into this category concern Peter." 49 Likewise, the category of "Jesus" ministry" is too vague to be meaningful; indeed the principal example Culpepper advances under this category is better considered under "signs." 50 In fairness to Culpepper, his work was the first attempt at categorisation and irony is notoriously difficult to delimit. One reader may see irony, or perceive a theme as predominating, where another does not. For example, when Jesus speaks of rebuilding the temple in three days (2:19-21), is the predominant theme: signs (involving the body/temple), Jesus' death (and resurrection) or a misplaced belief (i.e. that he is speaking literally)? These broad ironic themes frequently overlay each other in this manner.

Duke approaches Johannine irony under the rubric of "local" or "extended irony" and effectively eschews thematic categorisation. His primary focus is on form of expression, such as false assumption, misunderstanding, superficial confession, false promise, false claims to knowledge, accusations, suggestions of belief and unconscious prophecy. He only partially mentions themes when he considers extended irony. There he examines ironic characterization, irony of identity, ironic imagery, and the very broadly titled "irony of the gospel" (which predominantly focuses on the identification and subsequent rejection of Jesus, cf. 1:11). ${ }^{51}$ At this point Duke abandons the implied author and offers speculative insights into his putative real author, the Johannine community. ${ }^{52}$ It is regrettable that Duke should forsake Narrative Criticism for Source Criticism at this crucial juncture. If he had continued his consideration of the implied author his observations in relation to the interplay between form and theme may have yielded interesting conclusions about the author's literary purposes.

In order to be able to test the validity of the claim that irony is tied to certain fundamental truths presaged in the Prologue, I have undertaken an examination of the instances of Johannine irony

\footnotetext{
${ }^{48}$ E.g. 4:42; 6:29, 42, 69; 7:27, 41-43; 10:26-30, 37-38; 12:44, 48-49; 14:9-11, 16:27-28, 19:7-8, 15; in 16:2-3 the impending rejection of the disciples is also linked to the identity of Jesus.

${ }^{49}$ Culpepper, Anatomy, 174.

${ }^{50}$ The turning of the water to wine (2:1-12).

${ }^{51}$ Unfortunately this list conflates themes (identity, "irony of the Gospel") and devices (characterisation, imagery).

52 This leads him to offer the uncharacteristically dismissive suggestion that the existence of ironic themes is simply indicative of "stock' ironic responses" of the Johannine community to the synagogue. Duke, Irony, 94.
} 
identified in the survey. I classified them according to their subject matter and overarching themes. $^{53}$ They fall into five primary categories: Jesus' identity, ${ }^{54}$ misunderstanding and misplaced belief, signs, Jesus' death and finally a miscellaneous category (which includes diverse themes such as time, witness, worship, roles, Old Testament allusions, ${ }^{55}$ the Sabbath). When I applied the instances of irony in the survey to these categories, the results were decisive:

$\begin{array}{ll}\text { Identity } & 56 \% \\ \text { Misunderstanding } & 22 \% \\ \text { Signs } & 9 \% \\ \text { Death } & 8 \% \\ \text { Miscellaneous } & 5 \%\end{array}$

I also applied the survey results to Painter's six major themes. I had to create a seventh category of "Other" since these are general themes and not specifically ironic themes and, accordingly, some of the Gospel's ironies do not match any of Painter's categories. The results broadly corroborate the more accurate analysis:

$\begin{array}{ll}\text { Identity } & 50.5 \% \\ \text { Signs } & 9 \% \\ \text { Life } & 5.5 \%^{56} \\ \text { Believing } & 4 \% \\ \text { Festival } & 3 \% \\ \text { Witness } & 2 \% \\ \text { Other } & 26 \%\end{array}$

\footnotetext{
${ }^{53}$ As previously noted a single ironic utterance can touch on two or even more themes. This necessitates a degree of selectivity and subjectivism in the selection of the predominant theme. However, the sample size was large enough and the results sufficiently self-evident that occasional equivocations over categorisation would not meaningfully affect the outcome.

${ }^{54}$ Which includes his origins and the rejection of his identity since this is simply the negating of the positive truth. In other circumstances it may be desirable to split this theme into its constituent parts since these ironies are so prolific. The overall "Identity" theme breaks down into Identity 55\%, Rejection 35\% and Origins $10 \%$.

${ }^{55}$ E.g. 7:14 which is linked by some to Malachi $3: 1 ; 12: 39$ linked to Isaiah 6:9-10.

${ }^{56} \mathrm{I}$ included some references to death in this category, if only life were considered this figure would drop to $0.5 \%$.
} 


\section{Implications for Johannine Irony and the Prologue}

The survey provides evidence that there is congruence between the author's principal truth claim in the Prologue and Johannine irony. Just as the true identity of Jesus is central to the Prologue, so it is also to John's use of irony in the wider narrative. As we will soon see, this conclusion is also reinforced by a specific and significant irony in the Prologue, which develops the same theme. Furthermore, identity is the central propositional claim in the truth theme and so this demonstrates that the majority of the Gospel's ironies advance the truth theme. The survey validates what many scholars of Johannine irony have recognised. Culpepper predicted this conclusion by noting that the identity of Jesus "lies at the core of most of the ironic passages in the gospel." 57 These findings verify and quantify Duke's assertion that "that in Johannine irony form follows theme."58 Likewise, MacRae suggests that in the strongest examples of irony, "the irony arises from the reader's faith-understanding of who Jesus really is, and the issue is less that of Jesus' guilt or innocence than that of his true identity."

Furthermore, the strong correlation between irony and Jesus's identity supports O'Day's conclusion that "the Fourth Evangelist's use of irony enables the reader to participate in the Gospel narrative and to experience Jesus as revealer."60 The author could have used other rhetorical devices to reveal the Gospel's central propositional statements, however irony is the primary vehicle chosen. Just as the purpose statement in 20:31 reveals the author's key claim (that "Jesus is the Messiah, the Son of God") it also implies why irony is the rhetorical device deemed most suitable to make this claim and evoke a response to it ("so that you may come to believe"). No other rhetorical device is more effective than irony in agreeably engaging with a reader while simultaneously challenging their presuppositions. Irony not only serves to reveal Jesus' true identity, it also invites the reader to actively respond. ${ }^{61}$ Thereby the reader participates heuristically in a journey of discovery, parlaying their initial superior knowledge into full membership of the author's community of the informed.

It could be countered, however, that the correlation is explicable as a passive function of probability rather than an active integration between irony and the truth theme. If an author has

\footnotetext{
${ }_{58}^{57}$ Culpepper, Anatomy, 171.

${ }^{58}$ Duke, Irony, 92

${ }^{59}$ MacRae, Theology and Irony, 111.

${ }^{60}$ O’Day, Revelation, 94-95

61 "Irony speaks to people in a liminal state, to those in the process of changing." Alan R. Culpepper, "Reading Johannine Irony," in Exploring the Gospel of John edited by Alan R. Culpepper, Clifton C. Black, (Louisville: John Knox, 1996), 205.
} 
a predilection for a particular rhetorical device and writes predominantly on a topic, naturally there will be overlap between theme and device. While there is an element of truth to this observation, it is a highly improbable explanation for such robust findings. The Gospel traverses many other subjects and while the identity of Jesus is clearly the central claim of the truth theme, it does not comprise over $50 \%$ of the narrative. The author presents Jesus as spending considerable time, especially in his Farewell Discourses, teaching on topics like servant-hood and love (chapter 13), the Holy Spirit (chapters 14 and 16), discipleship (chapters 15 and 17) yet they contain few instances of irony. The substantial correlation between irony and select topics, notably those that form the core of the truth theme, strongly suggests that this is not an accidental distribution.

Notwithstanding the cogency of these findings, they are only preliminary. The Prologue paints the truth theme in only the broadest of brush strokes. It is the unpacking and developing of the themes in the wider narrative that provides the Gospel with its literary and theological potency. The correlation between the truth theme in the Prologue and the focus of Johannine irony needs to be explored in the larger narrative. If as Zumstein proposes, "il convient alors d'envisager l'évangile comme la médiation qui essaie de susciter le croire des croyants," ${ }^{, 62}$ then it is to be expected that ironic utterances will be to the fore in provoking such belief. This will require a careful examination of ironic utterances in the text to see if such a correlation exists. Therefore much will be determined by where and how irony is used in the wider narrative, without forgetting that it may be equally instructive where it is not used. ${ }^{63}$

\section{Other Functions}

The Prologue serves others functions that are also relevant to a consideration of Johannine irony. It provides the reader with "the Olympian vantage point" that will allow the decoding the author's ironic intent. ${ }^{64}$ The superior information provided is predominantly positive. This sets an optimistic tone for the entire first chapter: "Jesus is majestically introduced, John fulfils his role as a witness, and immediately various individuals, most notably an Israelite begin to follow him. Revelation is taking place, and there is the promise of even greater things to come

\footnotetext{
62 Jean Zumstein, L'évangile Selon Saint Jean (13-21) (Geneva: Labor et Fides, 2007), 296.

${ }^{63}$ No other portion of the Gospel reveals more about the author's key themes than the Passion Narrative, where these themes are brought to a dramatic denouement. Accordingly, the connection between the truth theme as expressed in the Passion Narrative and Johannine irony will be explored in Chapters 5 and 6.

${ }^{64}$ Alan Culpepper and Clifton Black, eds. Exploring the Gospel of John (Louisville: John Knox, 1996), 194.
} 
(1:50)." ${ }^{, 65}$ This creates fertile ground for irony and imparts an even keener tragic edge to its later appearance. In contrast to tragedies like King Oedipus where the superior knowledge is initially negative producing a painful journey from darkness to light, here the journey for many will be from supposed light into darkness (9:39-41). This will culminate in erstwhile good people committing premeditated murder thinking they are doing service to God (16:2). However, such responses are not predetermined. Some will receive him (1:12) thereby creating a tension for the reader who is conditioned to hope for an appropriate response.

The Prologue also identifies 'light/darkness' (1:4-5, 7-9) as one of the major symbolic devices that permeates the Gospel and provides a rich source for situational irony. ${ }^{66}$ Throughout the narrative "ironic imagery is the author's implied commentary whispering to the reader: all is not as it appears." ${ }^{~}$ Consequentially small asides can take on added meaning, often providing insight into an individual's personal level of illumination. Jesus speaks to Nicodemus at night $(3: 2 ; 19: 39)$ and he goes away both literally and figuratively 'in the dark.' The woman at the well speaks to Jesus in the full light of day (4:6) and receives the revelation (4:26) that Nicodemus sought in vain. This foreshadowing in the Prologue allows the reader to become conditioned to "judge with right judgment" (7:24) the symbolic language so as to extract the full meaning and any irony.

Another pivotal function of the Prologue is to establish the narrator as trustworthy. The narrator's dependability is crucial because the narrator makes numerous explanatory remarks in the narrative, ${ }^{68}$ and "serves as the voice of the implied author." 69 This is also pertinent for Johannine irony as the constant ironic challenging of appearance and reality can undermine the reader's confidence in the narrative. A reliable narrator can adequately counterbalance this. Accordingly, the Prologue establishes the narrator as an authoritative voice. He speaks from an omniscient position, ${ }^{70}$ he sees inside Jesus mind, ${ }^{71}$ authoritatively interprets Jesus' words, ${ }^{72}$ and possesses a pre-incarnational and post-resurrection perspective. ${ }^{73}$ As Culpepper explains, "The Johannine narrator is neither unreliable nor deliberately suppressive, but rather begins the

\footnotetext{
${ }^{65}$ Culpepper, Anatomy, 90.

${ }^{66}$ See $3: 2,19-21 ; 5: 35 ; 6: 17 ; 8: 12 ; 9: 4-5 ; 11: 9-10 ; 12: 35-46 ; 19: 39 ; 20: 1,3,19$.

${ }^{67}$ Duke, Irony, 107-108.

${ }^{68}$ The exact number is debated as it is often unclear when narration ends and direct speech commences (and vice versa) however the range appears to be between 59 (Tenney) and 91-109 (O'Rourke), for a summary see Culpepper, Anatomy, 18.

${ }^{69}$ Culpepper, Anatomy, 16.

${ }^{70}$ Stibbe, Storyteller, 20.

${ }^{71} 4: 1 ; 5: 6 ; 6: 6,15,61,64 ; 11: 5,33,38 ; 13: 1,11,21 ; 16: 19 ; 18: 4,19: 28$.

$722: 21 ; 6: 6,71 ; 7: 39 ; 8: 27 ; 12: 33 ; 13: 11 ; 18: 32 ; 21: 19,23$.

${ }^{73} 1: 1-3,18$ and $2: 21-22 ; 12: 16$ respectively.
} 
narrative with an overview of the identity of the central figure and the course of action to follow (John 1:1-18). From the beginning the narrator shares his omniscient vantage point with the reader, so that the reader is given all that is needed to understand the story."

Staley and Thatcher question the narrator's dependability, proposing instead that he engages in a "covert entrapment strategy."75 Staley alleges that the narrator misdirects and withholds information from the reader leading to the reader being victimised by irony. For example, the narrator informs the reader that Jesus and the disciples were baptising (3:22) only to later state that Jesus himself was not baptising (4:2). He speaks of Jesus deciding to go up to Jerusalem (7:10) after telling his brothers that he did not intend to (7:8-9). However, to suggest that such minor incongruities ironically victimise the reader is unsustainable in view of the narrator's fulsome sharing of profoundly important information in the Prologue.

Moreover, there are explanations for the narrator's alleged misdirection. The statement in 3:22 likely implies the disciples were baptising at the behest of Jesus, not that Jesus was personally involved. ${ }^{76}$ Whereas in $4: 2$, the author continues the strategy of differentiating John the Baptist and Jesus (cf. 1:8, 15, 27, 30). Moreover, in 7:10 the author is demonstrating elements of Jesus' character, namely that he could be unpredictable, ${ }^{77}$ and unbounded by other's expectations. ${ }^{78}$ These are scarcely new revelations for the reader much less victimisation. A narrator is permitted strategies to encourage drama and suspense in the narrative without becoming undependable. Consequentially Thatcher and Staley's assertion that Johannine irony is at times "radically unstable"79 is demonstrably false. Accordingly, scholars almost universally prefer Culpepper's work on the narrator. ${ }^{80}$

The narrator's role is also to provide markers that irony is present. This is achieved by three main mechanisms. The first is the way that the narrator's parenthetical comments often come to resonate with greater symbolic meaning. Comments such as "and it was night" (13:30) are delivered with an implied nod and a wink, whereby the reader understands that the darkness that

\footnotetext{
${ }^{74}$ Culpepper, Anatomy, 19.

${ }^{75}$ Staley, Reading, 94. I will focus on Staley as Thatcher is dependent on his work in relation to the narrator and we have already considered Thatcher in the review of literature.

${ }^{76}$ That they would baptise without the express approval of their Rabbi is inconceivable.

${ }^{77}$ E.g. 2:4 where Jesus acted even though stating, as he did here, that his time had not yet come.

${ }^{78}$ See also $2: 15 ; 4: 7,31,40 ; 5: 9 ; 6: 6,19,66$.

${ }^{79}$ Thatcher, Sabbath Trick, 54.

80 "Never is the reader the victim of irony. Nor is the reliable narrator ever the victim of John's irony. On the contrary, its strongest effect is inclusion. Irony draws the reader and the narrator together in a community of faith, a whole new (and higher) plane of existence.” Culpepper, Exploring, 195.
} 
Judas moves into is as much spiritual as physical. The second mechanism is festival markers, which condition the reader to anticipate irony. The narrator makes such a reference in 7:2 "Now the Jewish festival of Booths was near." The subsequent refusal of Jesus to go up at his brother's bidding only to go in secret the middle of the festival, Morris describes as "characteristic Johannine irony." 81 Jesus refuses to go on his brother's terms - a rustic preacher seeking metropolitan acclaim - but rather comes on his own terms. Consequentially, "the words

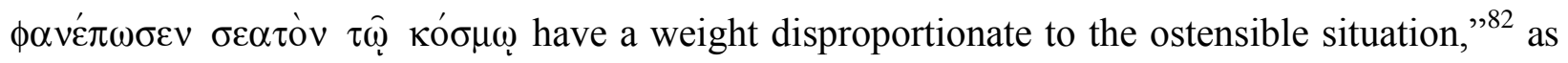
the Messiah manifesting himself to Israel.

Morris sees yet a further level of meaning as we now have the manifestation of the eternal logos who, at Sukkot when Israel celebrates God's provision, protection and faithfulness, is about to be rejected by his own. Significantly, chapter seven closes with division among the people 7:4044 and rejection by the authorities 7:45-52. The irony of $1: 11$ is played out fully as "God, the only Son" (1:18) comes to his own temple and is rejected. In a similar vein, another festival marker at 11:55 provides an excellent example of Johannine irony. The same people who have just plotted murder against the blameless Son of God for entirely self-serving reasons are now concerned that they not be found ceremonially unclean at the Passover, ${ }^{83}$ betraying a remarkably ironic double standard.

The third, less frequent, mechanism for signalling ironic intent is the narrator's commentary on Old Testament references. For example, in 12:39-40 the narrator identifies the quote as coming from Isaiah (Isaiah 53:1), connects this with another Isaianic quote (Isaiah 6:39-40), then offers a brief explanation (12:41). This passage is notoriously problematic, particularly in its suggestion that God may have caused the rejection of Jesus (12.40 "hardened their heart") and a hint that Isaiah may have seen the pre-incarnate Jesus. Hollenbach solves the first difficulty by proposing that Isaiah 6 is being used ironically. ${ }^{84}$ His argument is cogent and given the author's recognised predilection for irony, highly feasible. If this is true, then the author's simultaneous use of Old Testament scriptures as authoritative truth and irony bolsters the view that Johannine irony is thematically related to the Gospel's propositional statements. Additionally Carson tentatively proffers that "the last clause, and I would heal them, approximates the wording of the LXX, and

\footnotetext{
${ }^{81}$ Morris, John, 358.

${ }^{82}$ Ibid.

${ }^{83}$ Numbers 9:6; 2 Chronicles 30:17-18.

${ }^{84}$ Bruce Hollenbach, "Lest They Should Turn and Be Forgiven: Irony,” Bible Translator 34.3 (July 1983), 313.
} 
probably includes an ironic reference to the inner meaning of the healing miracles." ${ }^{\prime 25}$ The narrator's explanatory comments again invite the reader to look for the layers of meaning that produce fertile ground for Johannine irony. The establishing of the narrator as authoritative and the provider of privileged information beneficial to the reader by the Prologue endows these later comments with greater significance. The narrator's role in the Prologue is therefore crucial in setting the ironic tone for the rest of the narrative.

\section{Specific Irony}

Irony also occurs directly in the Prologue, providing further evidence of a linkage between the truth theme and irony. The introduction of irony is unexpectedly early and clearly deliberate. The categorisation mentioned above has indicated that there is a quantitative correlation between the central claim of the truth theme (Jesus' identity) and Johannine irony. Now a profound situational irony located in the Prologue at vv.10-11 establishes a qualitative correlation.

The irony is best understood in the wider context of the Prologue. The irregular construction of the initial verses of the Prologue, as Tovey notes, 'prompts the reader to ask, 'What Word?', and to wonder as to the identity of this mysterious figure." 86 As the Prologue progresses, it describes this unidentified personage as the creator of all (1:3), the life and light of all people (1:4-5), the object of John the Baptist's witness (1:6-8) and one who has now come into the world (1:9). ${ }^{87}$ The prose is exalted, creating an upward and optimistic movement. However, the reader's expectations suddenly encounter a reversal. In a dramatic situational irony, the very people this remarkable person created and came to enlighten spurn him. ${ }^{88}$ If the foundational truth claim of the Gospel is the divine identity of Jesus then "the foundational irony of the gospel is that the Jews rejected the Messiah they eagerly expected." ${ }^{\prime 29}$ Likewise, as Duke observes, "inasmuch as the Fourth Gospel is eminently concerned with the identity of the Revealer from God, through

\footnotetext{
${ }^{85}$ Carson, John, 449

86 Tovey, Prologue, 141.

${ }^{87}$ Since the masculine or neuter singular participle is grammatically neutral the NIV and NKJV attach the phrase

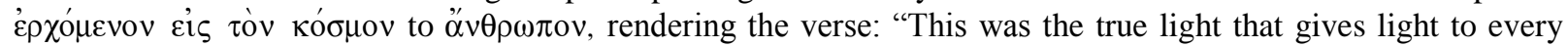
man who comes into the world." This approach is not preferred here as although this interpretation is based on a common Rabbinic expression, that is always plural while this instance is singular. Furthermore coming into the world thematically makes more sense of the $\phi \hat{\omega} \varsigma$ ¿ò $\alpha \lambda \eta \theta$ ıvóv. As per the NRSV, NASB. NLT, ESV, NCV.

88 "An oft-used device of situational irony, particularly of ancient dramatic irony, is the situation of unknown or mistaken identity." Duke, Irony, 100

${ }^{89}$ Culpepper, Anatomy, 169.
} 
whom the world was made, 'yet the world knew him not' $(1: 10)$, such irony is inevitable."90 Once Jesus' true identity is established, and it is as glorious and lofty as can be humanly imagined, anything other than a full response of belief is going to be woefully inadequate and invariably exposes the responder to the role of the eironn. The stage thus set, it is the conflict between belief and unbelief as responses to Jesus that propels the plot of the gospel. ${ }^{91}$

Just as the Prologue establishes meta-themes that pervade the Gospel, it also establishes in vv.10-11 a meta-irony that sets the ironic tone for the Gospel. The importance of this meta-irony is shown by how it mirrors the purpose statement in 20:31. Verses 10-12 are a virtual paraphrase of the purpose statement, which is that the reader would accept the identity of Jesus and therefore not reject him as the world has done (1:10-11), but instead come to a place of active faith leading to eternal consequences (1:12). Without v.12, the incongruity ironically expressed in vv.10-11 would be universal and hope forlorn. Verse 12 places an essential qualification on the tragic irony; some will respond appropriately and reap a reward commensurate with the magnitude of the reality of Jesus' true identity. This creates a dramatic tension that the reader carries into the narrative. What will each character believe and how will they respond? Some characters are disposed to believe (right revelation) but struggle to cross over to active faith (right response). The early depictions of Nicodemus and Pilate are good examples of this, albeit with differing outcomes. Such characters straddle this incongruity uncomfortably and are accordingly often the source of rich irony until they resolve it correctly.

The meta-irony of the rejection of Jesus' true identity works on two levels. In v.10 the rejection is by the world. The term ov' "' ${ }^{\prime} \gamma \omega \omega$ is used for the first time here but recurs throughout the Gospel. Notably, in the other usages it is almost invariably refers to groups representing generic unbelief. The first group are "the Jews," a term the author uses ironically to describe a type of the unbelieving world $(8: 27,43,55 ; 10: 6,38 ; 16: 3) .^{92}$ The second are "the world" $(17: 23,25)$. The final usage is the only individual, Nicodemus (3:10), who nonetheless at this juncture of the narrative epitomises the wider unbelieving group. Each subsequent use, ov ${ }^{\prime}{ }^{\prime} \gamma \nu \omega$ denotes a stubborn refusal to accept the truth of the revelation brought by Jesus. ${ }^{93}$ Since the unbelieving owe their very existence to him (1:3) their lack of recognition and belief is both ironic and

\footnotetext{
${ }^{90}$ Duke, Irony, 100-101. See also Andrew Lincoln, The Gospel According to Saint John, Black's New Testament Commentary, (New York: Hendrickson, 2005), 102; Culpepper, Anatomy, 169, 177; Kruse, John, 66; Köstenberger, John, 36; Keener, John, 399; Cynthia Briggs Kittredge, The Gospel of John (New York: Morehouse, 2007), 22.

${ }^{91}$ Culpepper, Anatomy, 97.

92 Keener, John, 223-228. This will be considered further in a section on characterisation in Chapter 5.

${ }^{93}$ Moloney, John, 44.
} 
inexcusable. 94 "Even in 1.10 the world made through the Word is a world capable of knowing, or of reprehensibly not knowing, it's maker." 95 For the author this demonstrates how far the world has become estranged from the truth.

The irony deepens and becomes more tragic when in v.11 the focus moves from the unbelieving world to God's own people. The expression, $\varepsilon \dot{i} \sigma \tau \dot{\alpha}$ ' $\delta 1 \alpha$, is found in two other places in the Gospel where it means "to one's own place/home" $(16: 32 ; 19: 27) .{ }^{96}$ The domestic nature of the reference is in stark contrast to the exalted language of the Christ descriptors and the global references to humanity, thereby accentuating the personal element of the rejection. It is one thing to be rejected by an unbelieving world, quite another to be rejected by your own people, in your own home. Arguably, there is no situational irony more profound or affecting in the Gospel than this statement.

Remarkably many commentators overlook the centrality of this irony and its pivotal location in the Prologue. On the other hand, those who do recognise its presence, use superlatives such as, "massive irony,"97 "great irony,"98 "foundational irony,"99 "inevitable" irony, ${ }^{100}$ and "the most obvious" irony. ${ }^{101}$ Its significance in the Prologue is reinforced by its position in the chiastic macrostructure outlined by Köstenberger and others: ${ }^{102}$

A. The Word's activity in creation (1:1-5)

B. John's witness concerning the light (1:6-9)

C. The incarnation of the Word (1:10-14)

$\mathrm{B}^{1}$. John's witness concerning the Word's pre-eminence (1:15)

$A^{1}$. The final revelation brought by Jesus Christ (1:16-18)

The irony in v.10-11 is located at the chiasm's crux, the fulcrum upon which the chiasm's main point turns. Thus the rejection (1:10-11) or acceptance (1:12-14) of Jesus' true identity is

\footnotetext{
${ }^{94}$ This point is reminiscent of, and may potentially reflect, the Pauline theology found in Romans 1:20 "Ever since the creation of the world his eternal power and divine nature, invisible though they are, have been understood and seen through the things he has made. So they are without excuse;"

${ }^{95}$ Barrett, St John, 161

${ }^{96}$ Kruse, John, 66.

${ }^{97}$ Lincoln, Saint John, 102.

${ }^{98}$ Kruse, John, 66

${ }^{99}$ Culpepper, Anatomy, 169.

${ }^{100}$ Duke, Irony, 101.

${ }^{101}$ Ibid., 111.

102 Andreas Köstenberger, Encountering John: The Gospel in Historical, Literary and Theological Perspective (Grand Rapids: Baker, 1999), 57.
} 
enshrined as the central theme of the Prologue, and by extension the Gospel as a whole. As well as mirroring the Christological and soteriological aspects of 20:31, these verses also anticipate the Gospel's meta-themes. ${ }^{103}$ This is expressed negatively in vv.10-11 - the world "did not know him" (lack of revelation) and his own "did not accept him" (lack of response) - then positively in 1:12: "to all who received him" (response) and "believed in in his name" (revelation).

This forms an antithetical ${ }^{104}$ parallelism common in Hebrew poetry. ${ }^{105}$

a

A Negative revelation (v.10)

$b^{2}$

B Positive response (v.12a) b

Negative response (v.11)

$a^{1}$

Positive revelation (v.12b)

The use of both Greek and Hebrew rhetorical structures illustrate the creative genius of the author. The care taken to create multiple structures to highlight these verses further emphasises their importance. They deliver an irony of remarkable quality.

The superlatives and description of the irony at vv.10-11 as a meta-irony appear justified. The author has used irony at a time when it is uncommon and difficult to achieve well, linked it to the Gospel's primary truth claim (Jesus' identity), juxtaposed it with the prevailing optimism of the earlier verses, used dual structures to emphasise it and make it the central pivot upon which the Prologue turns. The reader is duly put on notice as to the author's preferred manner of truth exposition, and this superbly prepares them for the many ironies to come.

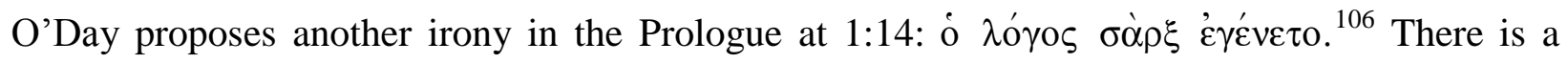
contrast between appearance ( $\sigma \alpha \dot{\alpha} \rho \xi$, Jesus' humanity) and reality (o $\lambda \hat{o} \gamma o \zeta$, Jesus' divinity) but without some form of reversal this is insufficient to create irony. Bultmann perceives only paradox here. ${ }^{107}$ Nonetheless, the Greek perceptions of soul/essence (psukē) and body (sōma) in most schools of philosophy, particularly Aristotelian, as wholly antithetical could make ò $\lambda o ́$ o $\varsigma$ $\sigma \grave{\rho} \rho \xi \dot{\varepsilon}^{\prime} \gamma^{\prime} \dot{\varepsilon} \varepsilon \tau \tau_{0}$ a viscerally shocking reversal of expectations. ${ }^{108}$ Whether this reversal is

\footnotetext{
${ }^{103}$ I.e. Painter's revelation and response. Painter, John, 3.

104 The three forms of Hebrew parallelism are - synonymous, antithetical and synthetic. Klein, Biblical Interpretation, 286.

${ }^{105}$ Bultmann proposes a number of similar poetic parallels, although not the one I have adduced. Bultmann, John, 14-16.

${ }^{106}$ O’Day, Revelation, 6.

${ }^{107}$ Bultmann, John, 63.

${ }^{108}$ Conceptual problems around this distinction led to the monophysite/diphysite debates of the early church.
} 
sufficient to create irony would remain doubtful if it did not follow on from the logos pronouncements of vv.1-2 and the meta-irony of vv.10-11. These link the logos/sarx dichotomy to the identity/rejection theme. ${ }^{109}$ Consequently, O'Day is correct in concluding, "The irony of the Logos is essential to the dynamics of revelation in John, because the source of conflicts and misunderstanding in the Gospel narrative is frequently the inability of those with whom Jesus speaks to comprehend both levels of Jesus' identity at once." ${ }^{110}$ However, the resultant irony is of medium strength. It is not strong because it assumes a degree of philosophical knowledge on the part of the reader, the author does not use any signals to indicate irony's presence, ${ }^{111}$ and the primary emphasis of the sentence is on the following explication of Jesus' identity.

\section{Conclusion}

Our exploration of the role of the Prologue has demonstrated that the presentation of Jesus' identity lies at the heart of all that is distinctive in the Fourth Gospel. ${ }^{112}$ The central component of the Johannine truth theme is therefore formed from propositional truths relating to the identity of Jesus. ${ }^{113}$ Accordingly, we have observed that a categorisation of the Gospel's ironies by theme establishes an emphatic quantitative correlation between the truth theme and irony. Furthermore, we have seen that a meta-irony in vv.10-11 demonstrates a qualitative connection with the truth theme. It also serves as an archetype for how the author will express truth ironically in the ensuing narrative. These results bode well for our hypothesis. The rationale for Johannine irony does indeed appear to be located within, and to be revealed by, the content (i.e. certain propositional claims) of the text. It now remains to be seen if the more numerous ironies of the Passion Narrative, where the themes inaugurated in the Prologue are brought to their dramatic conclusion, will provide similar confirmation.

\footnotetext{
109 "In a word, the heart of the Johannine theology is itself the irony of the Logos becoming flesh and dwelling amongst men." MacRae, Theology and Irony, 113

${ }^{110}$ O'Day, Revelation, 6-7.

${ }^{111}$ Such indicators would be doubly important at this early stage of the narrative as the reader is not yet attuned to the author's ironic style.

112 Carson, John, 95.

113 These propositional statements will include direct expressions of Jesus' identity, doubts over his origins, misunderstanding of Jesus' statements (especially the earthly/heavenly dichotomy), the implications of Jesus' signs, and the outright rejection of Jesus' identity.
} 


\section{Chapter 5}

\section{The Form of the Passion Narrative}

John's Passion Narrative deftly takes the themes of the Fourth Gospel, which debut in the Prologue and are developed in the wider narrative, and brings them to dramatic denouement. However, rather than a satisfying conclusion, the Passion Narrative confronts the reader with the failure of key characters to adequately perceive and act on the truth. The resultant drama imbues the trial narrative with a violent intensity, which, in a uniquely Johannine postulation, is contrasted with a preternaturally serene Jesus. The author achieves the narrative's literary and theological climax with a theatrical flair unrivalled in the Synoptic Gospels. ${ }^{1}$ The theatrical nature of the drama, juxtaposed with the inability of the characters to resolve correctly Jesus' identity, combines to elicit an emotional response from the reader. The pertinent question becomes not who do the characters in the drama believe Jesus to be but who does the reader believe Jesus to be?

The Passion Narrative contains levels of irony higher than any other part of the Gospel. At this crucial juncture no other rhetorical device comes as predominantly to the fore. Accordingly, as Senior notes, in the "passion narrative, "irony' becomes a favourite Johannine device." 2 The primarily didactic tone of the Farewell Discourse gives way to the irony-friendly polemical approach, as Jesus' opponents forcefully return. The irony comes thick and fast, often in consecutive verses or with multiple ironies in a single verse. By this point in the narrative, the author has so attuned the reader to his key themes and predilection for irony that the ironic utterances, while never overt, are hard to miss.

The author employs irony to reveal truth in two predominant ways. First, Jesus, the narrative's most authoritative voice, speaks truthfully. For most of the narrative, he speaks to his interlocutors in questions, which, as we have seen, usually coincide with irony. He replies with

\footnotetext{
1 "The trial before Pilate is the centrepiece and dramatic climax of the story of Jesus' hour. There is nothing to parallel to it in scope or literary artistry in the trial narratives of the Synoptic Gospels." Gail O'Day and Susan Hylen, John, Westminster Bible Companion, (Louisville: John Knox, 2006), 174. The Johannine Passion narrative has "a dramatic power and psychological subtlety, far beyond anything in the other Gospels." Charles Dodd, Historical Tradition in the Fourth Gospel (Cambridge: Cambridge University Press, 1963), 96.

${ }^{2}$ Donald Senior, The Passion of Jesus in the Gospel of John (Collegeville: Liturgical Press, 1991), 19.
} 
questions to those arresting him $(18: 4,7)$, to Peter $(18: 11)$, to Annas $(18: 21,23)$ and to Pilate $(18: 34) .^{3}$ But on the few occasions when Jesus replies with neither a question nor silence, he reasserts the central propositional statements introduced in the Prologue. Such as, his true provenance as an other-worldly king (18:36 cf. 1:1-4, 14, 18), his mission to proclaim the truth $(18: 37$ cf. $1: 9,14,17)$ and the ability of only some to receive that truth $(18: 37$, cf. 1:10-11). These proclamations of truth prompt from his interlocutors rhetorical and often deeply ironic questions $(18: 22,37,38)$. The second and more prominent vehicle for the truth theme is unwitting statements by third parties, again another fertile source of irony. Frequently, these are remarkably blatant statements on either Jesus' true identity or the true position of his opponents, ${ }^{4}$ but also they sometimes contain symbolic references to pre-existing motifs. ${ }^{5}$ Accordingly, most of the expressions of the truth theme in the Passion Narrative are ironic in nature or produce ironic rejoinders.

This corroborates my hypothesis that the Johannine truth theme is the principal reason for the pervasive and variegated nature of Johannine irony. The nascent irony we examined in the Prologue only hinted at the author's direction. It required statistical analysis to demonstrate that the emerging ironic themes would evolve, not only into major themes but also into the Gospel's key truth themes. By contrast, the ironies of the Passion Narrative are fully developed and convey the full weight of the author's literary intent. It is therefore significant that at the climax of the narrative, irony advances the truth theme almost exclusively.

My hypothesis explains this close correlation between irony and the truth theme in the Passion Narrative. Furthermore, as we will see these ironies function as a heuristic appeal to the reader. ${ }^{6}$ Earlier we had reason to question the universality of Duke's description of positive irony as "irony as appeal,"7 but such a description is appropriate here. Irony becomes so central to the author's message (revelation 20:31a) and his desire to provoke active faith in the reader (response 20:31b) that if we do not grasp the irony we miss the author's point. ${ }^{8}$ A close reading will reveal that the author piles question (rhetorical, direct and implied) upon question, appealing to the reader to discern and, more importantly, embrace his core truths about Jesus.

\footnotetext{
${ }^{3}$ I.e. to everyone that he speaks to during the crucial arrest and trial phase, without exception.

${ }^{4}$ E.g. 18:6, 14, 33, 35a, 37, 39, 40: 19:3, 5, 7, 14b, 15, 19-20, 21-22.

${ }^{5}$ E.g. 18:3, 40; 19:13, 14a, 23-24, 28.

6 "John's purpose is not academic. He writes in order that men and women may believe certain propositional truth, the truth that the Christ, the Son of God, is Jesus, the Jesus whose portrait is drawn in this Gospel." Carson, John, 663.

${ }^{7}$ Duke, Irony, 36-39.

${ }^{8}$ Ibid., 156.
} 
A drawback to direct presentations of propositional truths is that they inevitably invite immediate acceptance or rejection, often predicated on a person's preconceived views. Conversely, the use of irony acts as a distancing tool, obliging the reader to pause and ponder the deeper meaning of words and phrases. It often has the potential to bypass presuppositions and deter a premature rejection of their proffered truths. As Collins explains, "the use of irony heightens the drama but also leads the reader to find a deeper significance in the drama. In other words it is appropriate for the reader of the Fourth Gospel to distinguish between the Johannine drama and its theological significance, between the event and the meaning." compelled to suspend judgment until they can make the distinction between event and meaning, especially if the author indicates significance beyond the narrative. For example, 20:31 makes questions concerning Jesus' identity as pertinent for the reader as it has been for the narrative's characters. The sustained discovery of irony makes the passion story an experiential event, in which the reader learns truth heuristically. Accordingly, the Passion Narrative is "less concerned with the fate of Jesus than with the significance of that fate for his followers." 10

Irony is an effective literary device for someone encountering the Passion story for the first time, since the Prologue has enabled the reader to detect the ironic twists and turns in the narrative. However, it is particularly efficacious for those already familiar with the Synoptic account, which many of the author's later readers would have been. ${ }^{11}$ Those who already know the story are compelled to pause and ponder the reason for the differences between the accounts. Whether or not the real author was aware of the Synoptic tradition, the literary choices that produce the differences are open to narrative critical interpretation. For example, in contrast to the Synoptic account, in the Johannine narrative "there is no cry of dereliction, no mocking, no ironic request that he come down from the cross." $" 12$ The author has already displayed a predilection for irony, so why would he forgo this opportunity to relish yet another irony? The answer is theological. It would take away from the Johannine presentation of Jesus as sovereign ${ }^{13}$ and of the cross as a means of lifting up and glorification, not degradation. ${ }^{14}$

\footnotetext{
${ }^{9}$ Raymond Collins, These Things Have Been Written: Studies in the Fourth Gospel (Louvain: Peeters, 1990$), 98$.

${ }^{10}$ Brown, St John, 912.

${ }^{11}$ The issue of whether the real author and his original audience were aware of the Synoptics has been much debated.

${ }^{12}$ Francis Moloney, Love in the Gospel of John (Grand Rapids: Baker, 2013), 141.

$131: 49 ; 2: 19 ; 12: 13,15 ; 18: 6,33,37,39: 19: 3,14,15,19,30$.

${ }^{14} 3: 14 ; 7: 39 ; 8: 28 ; 12: 16,23-26,32-34$.
} 


\section{Relationship to Historicity and the Synoptic Gospels}

In the Fourth Gospel, the account of the Passion events has been "boldly reimagined."15 This gives rise to two interrelated questions. First, what is the relationship between historical fact and theological assertions in the narrative? Does the author prioritise theological meaning over historicity? The second question is why are there such major divergences between the Passion accounts of the Fourth Gospel and the Synoptics? Both of these questions have implications for understanding the relationship between irony and the Johannine truth theme.

The traditional presumption has been that the Synoptics are historical and the Fourth Gospel is theological. If the Gospel events are interpreted as symbolic or theological, then any truths that are generated by those events will be symbolic or theological abstractions. This interpretation conflicts with the Gospel's assertion that the author is testifying to real historical events and that this "testimony is true" $(19: 35 ; 21: 24) .{ }^{16}$ Furthermore, the author affirms in the Gospel's purpose statement (20:31) the historical reality of Jesus' claim to be the Messiah, which consequently necessitates an appropriate response of belief from the reader. A primarily theological interpretation of the Gospel would weaken the epistemological basis of the truth theme and require a partial redefinition to exclude appeals to literal truth. This would not be fatal to my hypothesis but any reduction in the correlation with the Socratic, truth-telling properties of classical irony would render it less probable.

Views on the Gospel's date of composition have shaped scholarly debate on these questions of John's historicity. The prevailing consensus until the later decades of the twentieth century was that the Fourth Gospel was composed at the earliest around the end of the 2 nd century C.E. By comparison, the Synoptics were believed to have been written sometime between 60 and 90 C.E. This rendered the Fourth Gospel vulnerable to claims that any factual data about the life of Jesus was inauthentic and historically unreliable. Accordingly, scholars frequently described it as symbolic, "by which they meant without factual content but primarily concerned with theological reflection by a writer who had no direct contact with the earthly Jesus."

\footnotetext{
${ }^{15}$ Moloney, Resurrection, 103.

${ }^{16}$ Bauckham concludes that "It is in the Jesus of testimony that history and theology meet." Bauckham, Eyewitnesses, 508.

17 Sandra Schneiders, Written That You May Believe: Encountering Jesus in the Fourth Gospel (New York: Crossroad, 2003), 63.
} 
Consequently, Dodd (1953) and Bultmann (1964) asserted that large sections of the Gospel contain only figurative meaning. Dodd claims that inter alia, the feeding of the multitude, the healing at Siloam, and the raising of Lazarus can only be understood symbolically. ${ }^{18}$ Likewise, Bultmann offers a creative reading of 19:27: "Doubtless this scene, which in the face of the Synoptic tradition can make no claim to historicity, has a symbolic meaning. The mother of Jesus, who tarries by the cross, represents Jewish Christianity...the beloved disciple represents Gentile Christianity."19 Anderson rightly takes Bultmann's interpretation to task and enquires how is it known that symbolic meaning automatically excludes any claim to historicity? ${ }^{20}$

Recent developments have made such interpretations even less credible. Scholars now date the Fourth Gospel much earlier. Rylands Papyrus P52 and Papyrus Egerton 2 are evidence that the Fourth Gospel was already in circulation by $125 \mathrm{CE}$. Therefore, a date of composition almost anytime between 55 and 95 C.E. is now thought possible. ${ }^{21}$ If the Gospel were composed in a period when Jesus' first disciples, or at least their disciples, were still alive, the author's ability to take symbolic liberties would not have been as great as previously thought. ${ }^{22}$ Furthermore, a number of archaeological discoveries have demonstrated that the author's grasp of the minutiae of daily life, customs and locations in Israel and Jerusalem, are much better than hitherto believed. ${ }^{23}$ Many supposed inconsistencies with Jewish traditions have simply evaporated in the face of new information and a re-evaluation of the old. ${ }^{24}$

The Fourth Gospel's claims to be based on eyewitness testimony, including of some of the events in the passion story (19:35), cannot be summarily dismissed. The real author is writing a narrative with a historical context, to real readers cognisant of that context. Therefore, as Coloe observes, "the author will use the words, faith expressions, geography, religious and cultural customs of his time. Even the symbolic world he creates in and through the narrative will be

\footnotetext{
${ }^{18}$ Dodd, Interpretation, 134.

${ }^{19}$ Bultmann, John, 673.

${ }^{20}$ Paul Anderson, "Graduations of Symbolization in the Johannine Passion Narrative," in Imagery in the Gospel of John, eds. Jörg Frey et al, (Tübingen: Mohr Siebeck, 2006), 161.

${ }^{21}$ Carson, John, 82. O'Day argues for a smaller range 75-85 CE i.e. around the same time as proposed for Matthew and Luke. O’Day, John, 5. Von Wahlde proposes three stages of composition over a wider timeframe.

${ }^{22}$ Schneiders, Written, 64.

${ }^{23}$ Anderson gives a salient example involving the five porticoes in 5:2 which were routinely deemed to be symbolic since pentagonal shapes were rare in antiquity. However, archaeological excavations of the Pool of Bēthzatha revealed five porticos (two groups of two placed vertically and one horizontal). Hence; "the number deserves a reading that is innocent of inferred symbolization." Anderson, Graduations, 162.

24 "Scholars have laboured endlessly over the trial scene because it does not agree with Mishnah Sanhedrin. The gospel accounts do present problems, but disagreement with the Mishnah is not one of them. For the present purpose it is not necessary to examine these stories critically. The system as the gospels describe corresponds to the system that we see in Josephus. The trial of Jesus agrees very well with his stories of how things happened." Edward Sanders, Judaism: Practice and Belief 63 BCE-66 CE (London: SCM Press, 1992), 487.
} 
bounded necessarily by the limitations of a particular time and place." 25 He can use historical events selectively for symbolic or representative value or theologically reinterpret them without sacrificing historical reliability. ${ }^{26}$ Readers can detect symbolism in the text, ${ }^{27}$ but it is dubious to assume its presence implies non-historicity.

Another factor contributing to the tendency to attribute purely symbolic value to the Passion Narrative is the difficulty of categorising the Gospel's genre in the literature of its time. Scholars have advanced a number of proposals. Brant and others note the striking parallels between John's narrative and Greek drama; should we then read the Passion Narrative as fiction? Burridge argues that the Gospel is a biography (bioi), albeit of a distinctive kind, the bios Iesou. ${ }^{28}$ Should we then read the Passion Narrative as biographical reportage? Keener has observed, "Martyr stories may explain the form in which some cohesive passion narrative or narratives circulated, but would not indicate their composition as fiction." 29 Neyrey argues for classification as an Encomium, a rhetorical formula for praising a person according to fixed categories. $^{30}$ In relation to the last two categories, should we read the Passion Narrative as nonfiction with intentional elements of aggrandisement?

No attempt at establishing a genre for the Fourth Gospel, or the Gospels generically, has received broad acceptance. Each option identifies similarities with its putative source but cannot explain important differences. What most readily distinguishes the Gospels from other genres is their kerygmatic element, which is not found in most other literary forms. The view that the Gospel in general and the Passion Narrative in particular, are sui generis and not explicable by any single category of Greco-Roman or Semitic literature remains the most plausible explanation. While some scholars go as far as describing the Passion Narrative as unique among

\footnotetext{
${ }^{25}$ Mary Coloe, Dwelling in the Household of God: Johannine Ecclesiology and Spirituality (Collegeville: Liturgical Press, 2007), 5.

26 "Something can both be symbolic and historical. We can discern symbolic significance in images, events, or persons without undercutting their claims to historicity, and we can recognize that certain images, events, and people are historical without diminishing their symbolic value." Craig Koester, Symbolism in the Fourth Gospel (Minneapolis: Fortress, 2003), 7-8. Tovey describes "the Fourth Gospel as an historically based theological display text" in which "theological discourse may also be historical discourse." Tovey, Narrative Art, 264-269.

${ }^{27}$ On occasion, by direct invitation of the author e.g. 2.21 .

${ }^{28}$ He notes that while the Gospels differ in key aspects from the pattern of ßior "but not to any greater degree than other Bior; in other words, they have at least as much in common with Graeco-Roman ßíor as the ßíor have with each other." Richard Burridge, What Are the Gospels?: A Comparison with Graeco-Roman Biography (Cambridge: Cambridge University Press, 1992), 258.

${ }^{29}$ Keener, John, 1069.

${ }^{30}$ Jerome Neyrey, "Encomium versus Vituperation: Contrasting Portraits of Jesus in the Fourth Gospel," JBL 126 (2007), 529.
} 
ancient literature, ${ }^{31}$ it is likely that the Gospel authors, either consciously or unconsciously, incorporated features of Greco-Roman popular literature. ${ }^{32}$ This explains the presence of the formal elements of drama, biography, martyr stories and encomia, while not demanding that any provide a comprehensive model.

This reinforces the likelihood that an informed reader will read the Passion Narrative as interplay between event and significance, historical truth and theological truth. ${ }^{33}$ The extent to which the author reinterprets or reimagines a factual event to suit a theological purpose is always open for conjecture. $^{34}$ This intertwining of historical and symbolic truth creates a fertile atmosphere for irony to flourish. Thus, "the Passion narrative becomes the metonymic core as a concrete event that the rest of John's Gospel interprets through metaphor." 35 An understanding of this integrated approach means that for example, it is possible to remain cognisant of the multi-layered irony of the depiction of Jesus' kingship in John 18-19, “without dismissing either its spiritual or sociopolitical implications." 36

Since a Gospel is best considered as sui generis the contrast between the Gospels will be more informative than comparisons with other forms of literature. The tendency to consider the Synoptic version of the Passion Narrative to be more historically grounded than John's version meant that John's divergences from the Synoptic tradition were assumed to be merely theological and discounted. The literary prowess and creative flair of the narrative, together with the more theological focus of the Gospel as a whole, seemed to substantiate this conclusion. The view predominated that John was a consummate storyteller, who for purely literary and theological purposes amended and embellished the historical story. However, scholars have recently come to reassess the relative credibility of the John's account. ${ }^{37}$ Even to the point, that

${ }^{31}$ Gerd Theissen, The Gospels in Context (London: T\&T Clark, 1992), 123.

${ }^{32}$ Larry Hurtado, "Gospel (Genre)," in Dictionary of Jesus and the Gospels, 282.

${ }^{33}$ Sloyan's approach to "proceed neither on the principle that the Gospel evidence on the trial is historically true unless proven false nor false unless proven true" is convoluted, unnecessary, and seemingly motivated by other concerns (primarily a desire "to improve the climate of Christian-Jewish discourse"). Gerard Sloyan, Jesus on Trial: A Study of the Gospels (Minneapolis: Fortress, 2006), 14-15.

${ }^{34}$ For example, in 19:13 the author leaves the text, at the very least, ambiguous. The author's point is not to delineate historically who sat where but rather to leave open a possible, albeit unlikely, interpretation together with its attendant symbolic irony.

${ }^{35}$ Beth Stovell, Mapping Metaphorical Discourse in the Fourth Gospel (Leiden: Brill, 2012), 296.

${ }^{36}$ Ibid.

${ }^{37}$ Even Dodd who considers John's passion account as primarily symbolic acknowledges that: "This narrative is far from being a second-hand rechauffé of the Synoptics ... the most probable conclusion is that in substance it represents an independent strain of tradition, which must have been formed in a period much nearer the events than the period when the Fourth Gospel was written, and in some respects seems to be better informed than the tradition behind the Synoptics, whose confused account it clarifies.” Dodd, Historical Tradition, 120. 
Schneiders can offer the previously inconceivable suggestion "that the Fourth Gospel might be even more historically reliable than the Synoptics." 38

Moreover, the differences between the Johannine and Synoptic Passion Narratives have been overstated and the similarities understated. Many scholars now conclude that overall the Johannine passion account coheres closely with that of the Synoptics, but at times manifests different emphases. ${ }^{39}$ There are details, especially chronological details, that are difficult, if not impossible, to correlate. Nonetheless, the major differences are predominantly in emphasis rather than substance. In Carson's judgment, "John's portrait of Jesus' arrest, interrogation, trials and death focuses on a different part of the spectrum than do the accounts by the Synoptics, but it is the same spectrum, and the portraits...prove mutually enriching and mutually explanatory." account is necessarily less historical than the Synoptics. Indeed, many would now argue that if claims to historicity are in contest - John's might prevail. ${ }^{41}$

Many of the differences in John's Passion Narrative stem from the inclusion of additional, seemingly first-hand information. ${ }^{42}$ These include the name of the servant whose ear was cut off and Peter as the culprit, the informal hearing before Annas, the identity of the person who afforded Peter access to the courtyard of the high priest, the forging of the link between Jesus' mother and beloved disciple, the cry from the cross "it is finished", the spear in the side, and Nicodemus accompanying Joseph of Arimatheia to claim the body. Likewise, the Johannine account of the Roman trial is more comprehensive than the Synoptics. Brown observes that with all its drama John's account of the trial is the most consistent and intelligible we have. He adds that "only John makes it clear why Jesus was brought to Pilate in the first place and why Pilate gave in and had Jesus crucified. John's chronology, where the judicial process takes place on the 14th of Nisan, is more credible than that of the Synoptics."43

\footnotetext{
${ }^{38}$ Schneiders, Written, 63-64.

${ }^{39}$ Köstenberger, John, 502.

${ }^{40}$ Carson, John, 573.

41 "Where John's Passion Narrative diverges from the Synoptics, it sometimes displays special Johannine interests. At the same time, D. Moody Smith argues that some of its divergences, such as Jesus carrying his own cross or the legs of the crucified men being broken, appear more historically likely than the Synoptics. Thus one should not rule out historical tradition in John's Passion Narrative.” Keener, John, 1072.

${ }^{42}$ Adding credence to the claim in 19:35 of eyewitness testimony.

${ }^{43}$ Brown, St John, 861.
} 
Of the differences between the narratives, the most salient is "the careful and impressive elimination of descriptions of insult and excruciating suffering from the passion tradition." 44 Most of the omissions in John fall under this rubric. For example, there is no mention of the agony in Gethsemane, the betrayal by Judas' kiss, Pilate's hand washing, Simon of Cyrene's carrying of the cross, the mocking at the cross, the criminal backgrounds of the others crucified at the same time, or Jesus' forsaken cry. The absence of these features is often ascribed to the overarching Johannine theme of the kingship of Jesus. ${ }^{45}$ The narrative portrays a sovereign Jesus who maintains a remarkable degree of kingly composure throughout the proceedings. It also accentuates the fact that he gave up his life willingly; his opponents did not take it from him. The author chooses to remain silent on details that may detract from this emphasis.

A substantive difference is the day and hour the trial and crucifixion took place. There have been many attempts to harmonise John's chronology with that of the Synoptics, though problems remain. $^{46}$ Significantly, the Johannine timeframe means that at the same time Jesus was crucified the Paschal Lambs were being sacrificed, with all the attendant symbolic and ironic meaning. $^{47}$ For this reason, on this point some interpreters are more inclined to read John symbolically than the Synoptics. ${ }^{48}$ Brown agrees that harmonisation is implausible but stops short of considering one account theological and the other chronological since both may be theological, even if the Johannine chronology prima facie makes the most sense. ${ }^{49}$

A further difference is that in John the Romans play a far greater role in the trial and execution of Jesus. This corresponds with the author's theological concern to show that rejection of Jesus was by an unbelieving world (1:10), even if the rejection started with his own people (1:11). There is a concomitant irony here, for, as Carson notes, "John is also frequently charged with anti-Semitism, and if that were his bias it is strange that Pilate should play so large a role. In any case, so far as Jesus' execution is concerned there is, as we shall see, more than enough guilt to go around." 50 The author's treatment of "the Jews" and claims of anti-Semitism in the Fourth Gospel will be discussed later in this Chapter.

\footnotetext{
${ }^{44}$ Moloney, Resurrection, 102.

45 "The major theme of John's passion narrative is the otherworldly kingship of Jesus." Köstenberger, John, 502.

${ }^{46}$ E.g. Theodore of Mopsuestia, John, 239; Westcott, St John, 282, 324-326; Morris, John, 801; Köstenberger, John, 538; Barrett, St John, 545.

${ }^{47}$ For a useful summary see Schnackenburg, St. John, 1:299-300.

${ }^{48}$ Keener, John, 1130.

${ }^{49}$ Raymond Brown, The Death of the Messiah: A Commentary on the Passion Narratives in the Four Gospels 2 vols. (New York: Doubleday, 1994), 2.959.

${ }^{50}$ Carson, John, 573.
} 
A consideration of the differences between the Synoptic and Johannine traditions of the Passion Narrative thus reveals no basis for assuming a purely non-historical symbolic or theological reading of the text. Any event or dialogue may be theological, historical or, more likely, both. A correct interpretation will require consideration of the text on a case-by-case basis. Nonetheless, whenever the Johannine Passion Narrative diverges from the Synoptics or offers additional details it is appropriate to consider if the author's change in emphasis is signifying that further layers of meaning are present. ${ }^{51}$ Accordingly, an appreciation of the synergetic relationship between history and symbolism, event and significance assists the reader in identifying the ironic contradictions. Likewise, it reinforces how the Johannine truth theme contains the author's propositional truths (both literal and theological).

\section{Structure}

The structure of John's Passion Narrative makes apparent both the intricacy and sweeping grandeur of the account. Like the Prologue the Passion Narrative has attracted numerous proposed structures, many of them chiastic. However, two main structural proposals predominate. Most commentators choose one or the other as a frame for their exegesis. It is my intention to use them both, as they are complementary. The first provides an outer framework while the second provides an inner. Both are required for a comprehensive literary reading of the text. Notably, Duke chose to use only the inner structure (comprising 18:28-19:16), but he recognised that this was insufficient and added a further passage as an epilogue (19:19-22). However, this unbalances the symmetry of the inner structure and couples it with a noncontiguous pericope. A better approach is to utilise both structures in the form of concentric circles. This works well as they both radiate from the same central point and the outer circle can provide the requisite context for the inner.

Moloney's schema for the outer structure is most helpful for exploring the ironies in the text. ${ }^{52}$ He divides chapters 18 and 19 into five distinct scenes and emphasises the theatrical quality of the narrative as it progresses from scene to scene. Each has an introduction that again highlights its dramatic attributes.

\footnotetext{
51 "Where John diverges from the traditions reported in the Synoptics, we do think likely that John adapts rather than contradicts the passion sequence on which they are based, probably at least sometimes on the basis of other traditions and probably at least sometimes for a measure of theological symbolism." Keener, John, 1067.

${ }^{52}$ Moloney, John, 482.
} 
i. "18:1-11: Jesus and his enemies in a garden (cf. vv.1-3 for the introduction).

ii. 18:12-27: Jesus' appearance before "the Jews" (cf. vv. 12-16 for the introduction).

iii. 18:28-19:16a: Jesus before Pilate (cf. v. 28 for the introduction).

iv. 19:16b-37: The crucifixion of Jesus (cf. vv. 16b-18 for the introduction).

v. 19:38-42: The burial of Jesus in a garden with his newly-found friends (cf. vv. 38-39 for the introduction)."

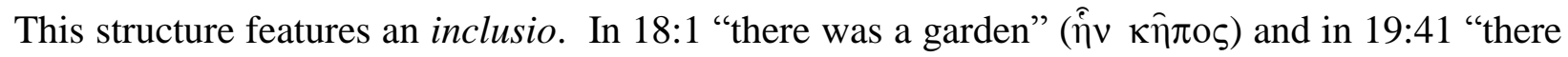
was a garden" (iं as a coherent literary unit. As will be seen, this device also signifies irony.

Ellis arranges the scenes into a chiastic structure:

"Section A (18:1-12) Arrested in a garden, Jesus is bound and led to trial

Section B (18:13-27) Jesus, the true high priest is put on trial before [Annas]. ${ }^{53}$ The beloved disciple is present.

Section C (18:28-19:16) Jesus, King of Israel, is judged by Pilate and rejected by his people

Section $\mathrm{B}^{1}$ (19:17-30) As true high priest, Jesus, like Isaac, carries the wood of his own sacrifice. beloved disciple is present.

Section $A^{1}$ (19:31-42) Bound with burial cloths, Jesus is buried in a garden."

Ellis' breaks between sections are marginally but inconsequentially different to Moloney's. While Keener notes that the suggested chiasmus does "evidence some patterns that point to the narrative artistry of their designer," he concludes that it is ultimately less than persuasive because it depends on too many secondary features. ${ }^{55}$ For this reason, Moloney's overall structure is to be preferred. However, Ellis' analysis is helpful in showing how, "Section C is the climactic centre of the whole passion account. It shows Jesus, the true judge of all the world, judged by Pilate and rejected as king by his own people in favour of Caesar."56 It is a further breakdown of this chiastic heart of the Passion Narrative (scene iii/section C) that provides our

\footnotetext{
${ }^{53}$ Inexplicably Ellis uses Caiaphas' name here. This may be in error or an attempt to contrast Jesus with the formal, as opposed to functional, high priest. Either way I have rectified this to avoid any confusion.

${ }^{54}$ Peter Ellis, The Genius of John: A Composition-Critical Commentary on the Fourth Gospel (Collegeville: Liturgical Press, 1984), 247. Italics his, indentations mine.

${ }^{55}$ Keener, John, 1067. Keener's criticisms are correct but harsh. With a little reworking the chiastic structure appears solid and Keener's concerns can be readily alleviated.

${ }^{56}$ Ellis, Genius, 247.
} 
second structure, which is often described as the trial proper. ${ }^{57}$ To avoid confusion between scenes in the outer and inner structure, henceforth I will refer to the sections in the outer structure as "Acts." 58 A visual presentation best illustrates the relationship between these structures. Figure 3 shows the structures as progressive scenes; Figure 4 shows the concentric nature of the chiastic forms.

\section{Structure One (Outer)}

\section{Structure Two (Inner)}

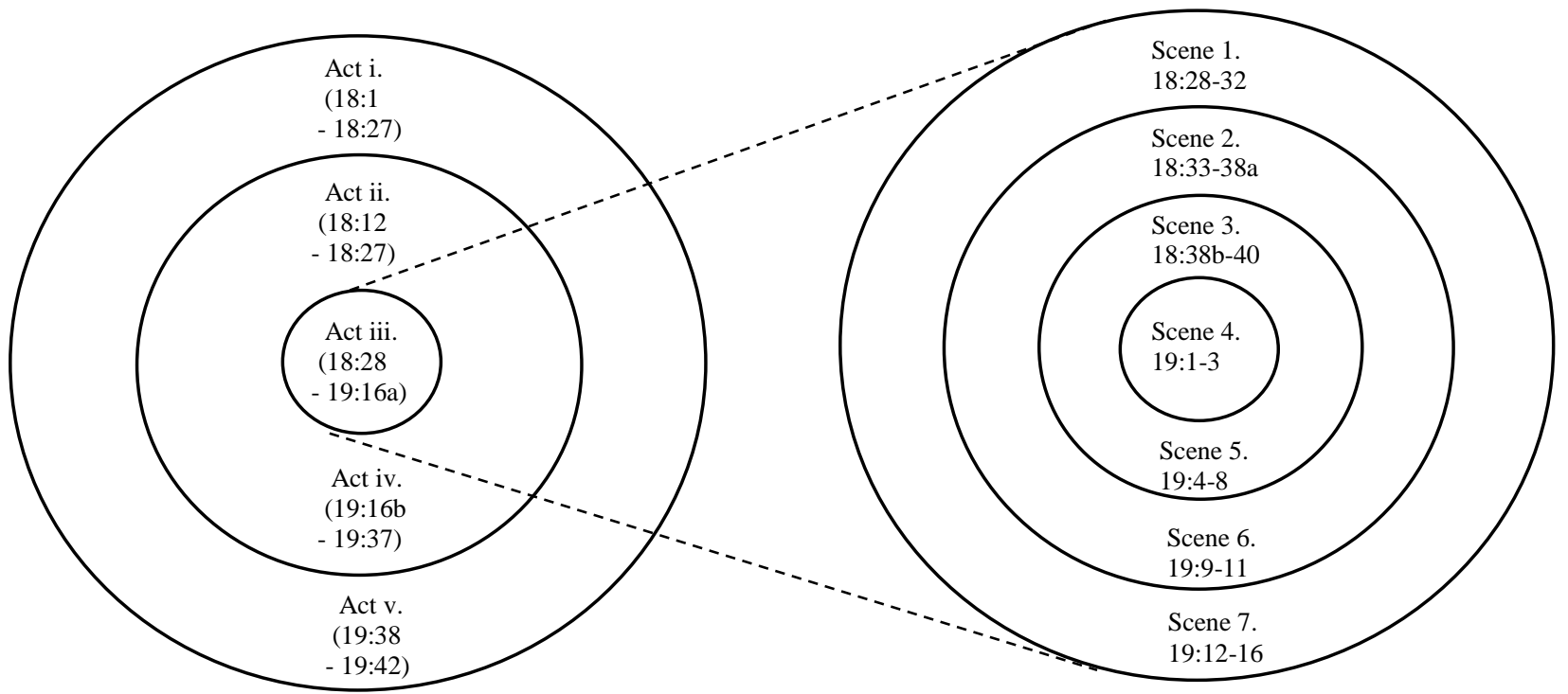

Figure 3.

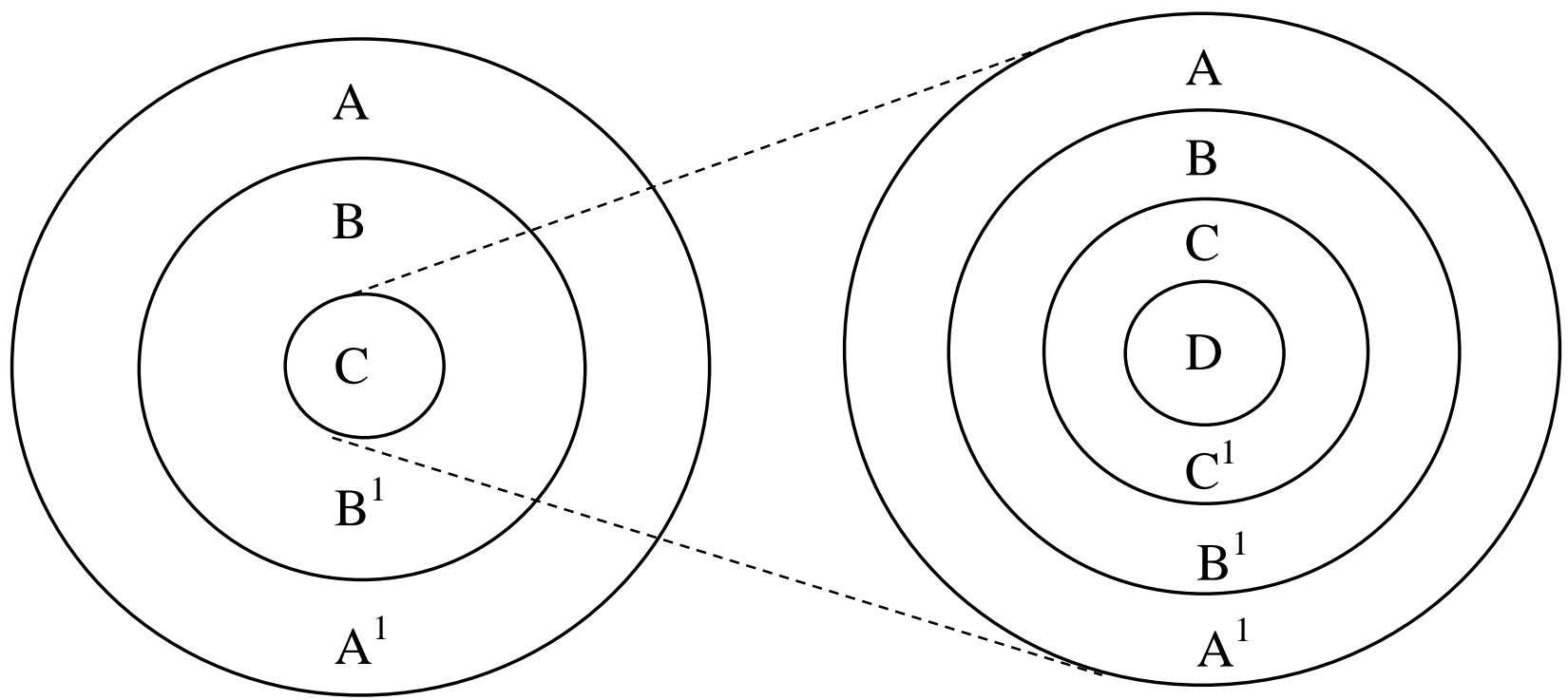

Figure 4.

\footnotetext{
57 The re-occurring presence and active engagement of the Jewish religious leaders means that the common description of this part of the narrative as "the Roman trial" is misleading.

${ }^{58}$ An advantage to this approach is that each of the Acts can also be broken down further into scenes.
} 
The inner structure of the trial before Pilate is broken down into seven scenes. Again, there are subtle variations between scholars, but Duke's version is to be preferred: ${ }^{59}$

Scene 1: $\quad 18: 28-32$.

Scene 2: $\quad 18: 33-38$ a.

Scene 3: $\quad 18: 38 b-40$.

Scene 4: $\quad$ 19:1-3.

Scene 5: $\quad$ 19:4-8.

Scene 6: $\quad$ 19:9-11.

Scene 7: $\quad$ 19:12-16.

The divisions between the sections in Structure Two are based on movement, almost like stage directions and which makes the term "scene" apt. The organising principle is the shifting of scenes from outside the praetorium to the inside and back again. The author is "deliberate in repeating that Pilate 'went out to the Jews' $(18: 29,38 ; 19: 4,13)$ and 'entered the praetorium' to converse with Jesus $(18: 33 ; 19: 9) . " 60$ This creates the effect of a front and back stage, with Pilate moving between them. ${ }^{61}$ The sense of movement is also of theological significance as Pilate's movement between the world outside and Jesus inside expresses and accentuates the Gospel's emphasis on the choice between the world and Jesus. Significantly, this structure also features an inclusio in that the trial starts and finishes with all the characters present in the courtyard of Pilate's headquarters. This again demarcates this section as a literary unit and validates seeing the two structures as distinct entities arrayed concentrically.

Like the outer structure, the inner one can also be displayed as a chiasm, one with broad support. ${ }^{62}$ Osborne describes it as "a dramatic seven scene masterpiece." 63

\footnotetext{
${ }^{59}$ Duke, Irony, 126-137. Duke notes that the highly ironically charged narrative in Chapter nine also breaks down into seven discrete scenes. As this contrasts the blind man's ascent to belief with the Jewish leader's decent into unbelief and blindness the comparison is apposite.

${ }^{60}$ Ibid., 127.

${ }^{61}$ Dodd, Historical Tradition, 96.

${ }^{62}$ E.g. Keener, John, 1097; John Whitacre, John, The IVP New Testament Commentary Series 4, (Downers Grove: IVP, 1999), 435; Brown, St John, 859; Moloney, Love, 29; Jo-Ann Brant, John, Paideia Commentaries on the New Testament, (Grand Rapids: Baker, 2011), 242.

${ }^{63}$ Grant Osborne, The Gospel of John, Cornerstone Biblical Commentary 13, (Carol Stream: Tyndale, 2007$)$, 262.
} 
A. “Outside; the Jews demand Jesus' death (18:28-32)

B. Inside: Pilate questions Jesus about his kingship (18:33-38a)

C. Outside: Pilate finds Jesus not guilty (18:38b-40)

D. Inside: The soldiers scourge Jesus (19:1-3)

$C^{1}$ Outside: Pilate finds Jesus not guilty (19:4-8)

$\mathrm{B}^{1}$. Inside: Pilate talks with Jesus about power (19:9-11)

$\mathrm{A}^{1}$. Outside: The Jews obtain Jesus' death (19:12-16a)",64

The climactic centre of this structure is at D. However, the description of "The soldiers scourge Jesus" does not accurately reflect the content of these verses. The literary and theological locus of this section is not the scourging in v. 1 but the ironic crowning, robing and proclamation of Jesus as king in vv.2-3. Furthermore, the soldiers, representatives of the wider unbelieving world, speak more than they know in v.3, when they say "Hail, King of the Jews!" They declare openly but ironically, what Pilate has questioned $(18: 33,37)$ and what the religious leaders will vehemently deny $(19: 12,15)$. Accordingly, the central section of this chiasm should be entitled, "Jesus is ironically proclaimed king."

This chiastic progression and regression from the central point accentuates the author's key concepts and locates irony at the heart of the inner structure. Irony is also at the centre of the outer structure. Moloney describes Act iii accordingly, "Ironically, the King of Truth overcomes the political powers of this world, Pilate presents Jesus to the people as their king, and they reject him. At the centre of 18:28-19:16, Jesus is, ironically, clothed and crowned as a king."65 Thus, both structures provide a framework for and highlight the irony that pervades the Passion Narrative. Conversely, an appreciation of how the author uses multiple layers to facilitate an ironic emphasis on his main points and thereby explicate his truth theme also explains the intricate structure.

\section{Plot and Characterisation}

A major contribution of narrative criticism is to remind us that while a text has structure and form these only exist to serve the story. Just as an overemphasis on source critical methods can diminish the text to an assembly of increasingly speculative sources, an overemphasis on

\footnotetext{
${ }^{64}$ Osborne, John, 262.

${ }^{65}$ Moloney, Love, 29.
} 
historical-grammatical exegesis can reduce the text to a mere collection of words and sentences, duly placed in their grammatical, syntactical, cultural and historical context but isolated from the plot of the narrative. Narrative criticism offers an opportunity to consider the story as a coherent entity, with an overarching plot, persistent themes and a message.

Another contribution of narrative criticism has been to provide a means for the analysis of the role of characters in developing a narrative's themes and plot. The last few decades have seen a surge of interest in Johannine characterisation. ${ }^{66}$ The interest may be because John's characters are more vividly drawn and have a greater depth than that those of the Synoptic Gospels. ${ }^{67}$ They "are in effect the prism which breaks up the pure light of Jesus' remote epiphany into colours the reader can see."68 The author amplifies and streamlines a reader's engagement with the story's characters through a theatrical strategy in which only the two currently active characters appear on stage at any one time. This is especially true in the trial narrative and helps to explain many of the plot elements, such as the movement back and forth by Pilate. Furthermore, since in characterisation terms "the Fourth Gospel prefers showing to telling, indirect presentation to direct presentation" the Gospel's characters are excellent vehicles for the delivery of irony. ${ }^{69}$

The plot of the Fourth Gospel has engendered much debate and little agreement. Segovia identifies a threefold biographical division of plot marked by a journey motif and repetitive patterns. $^{70}$ Stibbe classifies the overall plot as tending to the tragic and analyses it in terms of its causal, temporal and structural aspects. ${ }^{71}$ He proposes that the key structural elements are the notions of a sender/receiver and opponent/helper. There is a main plot with God as sender and a counterplot with the Devil as sender. There is an inherently ironic nature to the plot in that the opponent actually becomes the helper in the events of the Passion Narrative. ${ }^{72}$ Resseguie perceives the plots in terms of a U-shaped structure that moves from misfortune and misunderstanding to a happy conclusion with the plot therefore tending to the comedic. ${ }^{73}$

\footnotetext{
${ }^{66}$ For a summary of recent works, see R. Alan Culpepper, "The Weave of the Tapestry: Character and Theme in John," in Characters and Characterization in the Gospel of John, ed. Christopher W. Skinner (London: T\&T Clark, 2013), 19-23.

${ }^{67}$ They are more consistently "round" to use E. M. Forster's famous description, for an overview of round and flat characters see Resseguie, Narrative Criticism, 123-125.

${ }^{68}$ Culpepper, Anatomy, 104.

${ }^{69}$ James L. Resseguie, "A Narrative-Critical Approach to the Fourth Gospel," in Characters and Characterization in the Gospel of John, ed. Christopher W. Skinner (London: T\&T Clark, 2013), 11.

${ }^{70}$ Fernando Segovia, "The Journey(s) of the Word of God: A Reading of the Plot of the Fourth Gospel," in Culpepper, Semeia 53, 35-36.

${ }^{71}$ Stibbe, John's Gospel, 32-53.

72 Ibid., 46.

${ }^{73}$ Resseguie, The Strange Gospel, 169-196.
} 
Culpepper approaches the plot episodically, through the central features of sequence, causality, unity and affective power of a narrative. ${ }^{74}$ He cites with approval Sternberg's conclusion that the author "deprives most of these episodes of actional or propulsive value precisely in order to direct the reader to integrate them with the rest of the work not in terms of plot but of theme."75 Notably, this closely resembles Duke's conclusion in relation to Johannine irony that "form follows theme" ${ }^{, 76}$ Culpepper sees the plot repeatedly played out in each scene, since in all of Jesus' encounters with a new character he reveals something of his identity. The author advances the plot through a series of "attempted, failed and occasionally successful anagnoriseis (recognition scenes)", leading to the conclusion that "belief and unbelief, recognition or nonrecognition of Jesus as the Revealer, is the fundamental opposition on which the plot is developed." ${ }^{\text {77 }}$ Culpepper perceives a tragic plot and acknowledges the value of peripeteiai (twists and reversals) as well as anagnoriseis (which can also mean discovery) to the plot, both of which are also integral components of irony.

Lincoln employs a dual plot analysis. The first is a "basic" model utilising categories of commission, complication and resolution. ${ }^{78}$ The second, "advanced" model focuses on the action of the Gospel since "the action of the plot reveals the real nature and significance of Jesus' mission, reinforcing in the process his identity and relation to the world set out in the beginning of the narrative." 79 His advanced model uses actantial analysis, which designates six actants - Sender, Object, Receiver, Helper, Subject, and Opponent. These actants relate along three axes, those of communication, volition and power. ${ }^{80}$ The primary difference from Culpepper is that both of these models are set firmly in the context of an overarching cosmiclawsuit. Consequently, while Culpepper focuses on Jesus' role as revealer, Lincoln accentuates his role as witness and judge (cf. 18:37). Lincoln rejects Culpepper's description of Jesus' mission, ${ }^{81}$ but the two roles are not mutually exclusive and may even be indistinguishable.

\footnotetext{
${ }^{74}$ Culpepper, Anatomy, 80. See also Culpepper, Gospel and Letters, 67.

75 Meir Sternberg, Expositional Modes and Temporal Ordering in Fiction (Baltimore: John Hopkins University Press, 1978), 169.

${ }^{76}$ Duke, Irony, 92.

${ }_{77}^{7}$ Culpepper, Gospel and Letters, 71.

${ }^{78}$ Lincoln, Trial, 29-33.

${ }^{79}$ Ibid., 159.

${ }^{80}$ Ibid, 162-163.

${ }^{81} \mathrm{He}$ notes that while it has the advantage of "employing terminology from the prologue... it has the disadvantage that this terminology is hardly to the fore again in the narrative discourse." Lincoln, Trial, 162.
} 
Lincoln concludes that in relation to the Fourth Gospel's characters, the plot illuminates the narrative less than a consideration of its main themes, meaning that their function is ideological. "What is ultimately significant about them is whether they are witnesses to the truth or opponents to it, whether they receive the witness of Jesus or refuse it." 82 Lincoln therefore concurs with Culpepper that the advancement of the plot is secondary to the development of Johannine themes and that "plot development in John, then, is a matter of how Jesus' identity comes to be recognized and how it fails to be recognized." 83 The difference between Jesus as divine revealer or divine witness is primarily semantic. I remain unconvinced that there is a difference substantial enough to be problematic. Fittingly this terminology is reminiscent of O'Day and Duke's complementary descriptions of Johannine irony as "revelation" and "witness" respectively. ${ }^{84}$ This is significant because all the scholars mentioned above also agree that the author uses robust ironic elements to advance the plot of the Passion Narrative.

Just as literary motifs (e.g. light/dark, time, and festival markers) play symbolic roles, so do the main characters. For example, in the Prologue, the author first introduces Jesus symbolically as "the Word" (1:1-3). With respect to characters, it is important to recognise that symbolic expression does not mean they are fictional. ${ }^{85}$ Rather the author intentionally selects a cast of characters that are both real and representative. Collins first introduced this concept of representative roles in 1976 and it has received broad acceptance since. ${ }^{86}$ By the end of the Prologue, the reader is aware that Jesus represents the eternal Word (1:1-3), life (1:4), true light $(1: 4-5,9)$, glory $(1: 14)$, grace and truth $(1: 14,17)$, divine pre-eminence $(1: 2-3,10,15)$ and the revelation of God (1:18). The term "representative" helpfully avoids the notion of nonhistoricity that customarily follows the use of "symbolic" to describe individuals.

This use of representative roles also explains the uniqueness of Johannine characters, both in terms of characters that do not appear in the Synoptic Gospels and the idiosyncratic portrayal of characters that do. The author judiciously selects individuals to represent particular types of belief. ${ }^{87}$ For example, the author juxtaposes characters like Nicodemus (chapter three) and the Samaritan woman (chapter four), who are not found in the Synoptic tradition, to represent

\footnotetext{
${ }^{82}$ Lincoln, Trial, 166.

${ }^{83}$ Culpepper, Anatomy, 88.

${ }^{84}$ See Chapter 1: Survey of Literature.

85 "We will acknowledge that the persons depicted in John's Gospel can be both historical and symbolic without attempting to assess the extent to which the evangelist shaped the tradition he received." Koester, Symbolism, 3839.

${ }^{86}$ Collins, These Things, 1-45.

87 "In this way it is appropriate to look at the several individuals who appear in the Fourth Gospel as individuals who have been type-cast. In their individuality they represent a type of faith (or lack of faith).” Ibid., 7-8.
} 
different kinds of faith. One comes at night out of fear and unbelief and leaves in the dark, metaphorically and literally (3:9-10), with no record of confession. The other speaks plainly in the full light of day and leaves with Jesus' admission of Messiahship, leading to belief and testimony (4:39-42). ${ }^{88}$ It also explains the two Sabbath healings involving pools. ${ }^{89}$ One represents a negative reaction, with no response of belief and a betrayal of Jesus to his opponents $(5: 15)$ leading to the persecution of Jesus $(5: 16)$. The other represents a positive reaction, with a dynamic statement of belief together with an act of worship (9:38) and disdain for Jesus' opponents $(9: 25,27,30-33)$ leading to the persecution of the disciple $(9: 34) .{ }^{90}$ The similarities and differences encourage the reader to look beyond initial perceptions and to "not judge by appearances, but judge with right judgement" (7:24).

Notably, much of the ironic interplay stems directly from the characters' representative roles. The roles are not static and positions fluctuate and develop. The reader observes the characters' journeys as they descend to unbelief or ascend to belief. In the latter case, they may also move between passive and active faith. Just as things are frequently not what they seem, neither are people - often to the point that appearance and reality are ironically reversed. In the fine tradition of the alazōn a character will proclaim faith but act in diametric opposition or seek to mock, only to speak a better truth than they know. Thus the disciple who pledges the greatest faithfulness (13:37) lies and denies Jesus to underlings at the very the moment that Jesus speaks the truth in front of their masters $(18: 17,25-26)$. The religious leaders have boasted of their connection to God $(8: 39 ; 9: 28)$ yet deny it before Pilate to achieve their desired result $(19: 15)$. Nicodemus emerges from the shadows (19:39) to claim the body of the one he could not receive openly while living (3:2).

It is not coincidental that many of the ironic revelations of a character's true disposition occur during the Passion Narrative. It is the climactic moment when all journeys face resolution. ${ }^{91}$ Just as the various elements of the plot come together to emphasise the Gospel's central theme of Jesus' identity in the Passion Narrative so too do the Gospel's ironies. This confirms the view that both plot and Johannine irony are subservient to the Gospel's themes. These themes fully

\footnotetext{
${ }^{88}$ The author's ideal response of belief plus action - revelation and response - (cf. 20:31).

${ }^{89}$ The paralytic at the Pool of Bēthzatha (Chapter five) and the man born blind sent to the Pool of Siloam (Chapter nine).

90 "The representative figures in the Fourth Gospel help to maintain boundaries by showing readers the differences between belief and unbelief." Koester, Symbolism, 284.

${ }^{91}$ However, not all journeys end there. E.g. the informed reader is aware that Peter does believe but his faith was not active enough and was found wanting. However, due to his abiding belief there is a chance for post-Passion rehabilitation (21:15-19).
} 
revealed in the Passion Narrative as the antithetical norms that have clashed throughout the narrative finally collide and representative characters must choose a response. Consequently, irony comes to the fore because "the contrast between levels of meaning is sharpest in the Gospel's pervasive use of irony." 92 Irony is demonstrated to be the most effective manner of revealing the author's key truth themes at this crucial juncture. Furthermore, key characters whose representative faith positions signify them as alazōn or eirōn will convey this irony. Therefore, we now turn to consider several of these key characters in order to consider their representative roles and their ironic identity.

a) Jesus

For multiple reasons Jesus is an unlikely candidate for a character study. As Culpepper and Lincoln note, "Jesus is a static character. There is no change or development." 93 Furthermore, while he is the central protagonist his role in the action is remarkably restrained. All of Jesus' statements during the arrest and trials are either a response to a question, ${ }^{94}$ or a response to the actions of others. ${ }^{95}$ Moreover, the author places little significant irony in the mouth of Jesus, notwithstanding the fact that his comments elicit ironic responses or help the reader to identify situational ironies involving another character. ${ }^{96}$ Jesus is arguably the least ironic and least dynamic character in the Passion Narrative. However, non-dynamism and passivity are not the same things. Jesus is actively aloof and purposefully non-responsive. Consequently he answers questions with questions, or with silence, and with great tenacity does nothing that would further his ostensible cause. ${ }^{97}$

However, contra Culpepper and Lincoln, Jesus is not a static character. ${ }^{98}$ Within the Gospel narrative, he engages in not one but two journeys, albeit in a manner vastly dissimilar to the journeys of others. The other characters are on journeys towards or away from belief, which

\footnotetext{
${ }^{92}$ Koester, Symbolism, 31.

${ }^{93}$ Culpepper, Anatomy, 88; Lincoln, Trial, 18.

94 18:5, 8, 20, 23, 34, 36, 37: 19:11.

${ }^{95}$ I.e. the arrival of the arrestors 18:4; their falling back 18:7; Peter's sword attack 18:11.

96 "Jesus does not dominate the dialogue in the Passion Narrative, and when others get the chance to speak, feet end up in mouths." Brant, John, 233.

97 "Perhaps the most striking aspect of Jesus' characterization in act two is his elusiveness... This systematic absence of logic seems to suggest that Jesus is employing a strategy of deliberate transcendence in his interrogation, with the result that Pilate emerges as someone thinking entirely on the wrong plane." Stibbe, Storyteller, 112.

98 "All that is essential to his character is revealed to the reader before Jesus ever makes his appearance in the narrative." Culpepper, Anatomy, 88. On this level Culpepper and Lincoln are correct and in this one respect Jesus is unchanging, however, that does not necessarily make Jesus a static character.
} 
would be incongruous for Jesus. By contrast, Jesus' first journey is one of exploration as he searches for worthy interlocutors to whom he can reveal more of his identity. Since the reader knows Jesus' true identity from the start, they go with Jesus on this journey, sharing in his many frustrations and few triumphs. The author skilfully includes the reader with Jesus in a community of the knowing, thereby creating greater empathy for Jesus and building solidarity with the truths he represents.

The second journey is his inevitable progression towards death. This is presaged in the Prologue's central irony $(1: 10-11)$ and reinforced by numerous direct references. ${ }^{99}$ Repeated mentions of Jesus' hour remind the reader that a clock is ticking and when it strikes Jesus is destined to die a shameful, horrific death. ${ }^{100}$ Again, the author uses dramatic flair to cultivate compassion in the reader as Jesus increasingly cuts a heroic but doomed figure. Both of these journeys inexorably culminate in the Passion Narrative. Both are also ironically charged. As we have repeatedly observed, the revelation of Jesus' identity occasions the majority of Johannine ironies. Equally, the author presents Jesus' descent towards death ironically (and unlike the Synoptics) as an ascent to glorification and the triumphant success of his true mission. ${ }^{101}$

In the Passion Narrative, Jesus' representative character comes to the fore. Stibbe proposes that there are three important aspects of John's narrative Christology, which emerge in the Johannine Passion Narrative. All three represent interpretative understandings of the character of Jesus: “(i) Jesus as Judge, (ii) Jesus as King, (iii) Jesus as elusive God." ${ }^{102}$ Duke contrasts the double downward movement into unbelief of Pilate and "the Jews" with the ironic elevation of Jesus to the office of King, Judge, and Son of God. ${ }^{103}$ O'Day suggests a further role, that of Passover Lamb. ${ }^{104}$ However, the symbolism of the Passover lamb depends on disputed chronology and is found only in one verse (19:14). Therefore, it is at best a secondary role or theme. As an examination of the text demonstrates, the preeminent roles of King, Judge and Son of God do not preclude other representative roles, including Light of the World, the true High Priest, the

\footnotetext{
${ }^{99} 2: 19-21 ; 5: 18 ; 6: 51-56 ; 7: 19,33-34 ; 8: 21-22,28,40,59 ; 10: 11,17,31 ; 11: 50-53 ; 12: 7,10,24,32-33 ; 13: 33,36$; $14: 18,28-30 ; 16: 16,28$.

$1002: 4 ; 5: 25,28 ; 7: 6,8,30 ; 8: 20 ; 12: 23,27 ; 13: 31 ; 16 ; 21,25,32 ; 17: 1$.

101 "Gone is the horror of putting to death the Son of God (Matthew and Mark) or the death of the innocent, righteous martyr with its worshipful atmosphere (Luke). Instead, the cross is Jesus' exaltation, the culmination of his glory." Osborne, John, 252.

${ }^{102}$ Stibbe, Storyteller, 111.

${ }^{103}$ Duke, Irony, 127. The informed reader would recognise this dual but contrasting movement from the story of the man born blind in Chapter nine, where the man moves from blindness to true sight (9:37-38) while simultaneously the Pharisees move from sightedness to blindness (9:40-41).

104 "We note three such themes in particular that focus on Jesus' identity: he is the 'I AM,' king and judge, and the Passover lamb." O’Day, John, 169.
} 
Water of Life, the Truth and the Life. The role of Passover lamb corresponds with these secondary roles, all of which the author likewise expresses ironically.

An understanding of these three roles is important before encountering the text because they explain much of the content and composition of the Passion Narrative. For example, by mentioning Jesus' kingship eleven times, “John has with keen insight picked out the key of the passion narrative in the kingship of Jesus, and has made its meaning clearer, perhaps, than any other New Testament writer."105 Much of Jesus' behaviour, especially his puzzling detachment, is only explicable when viewed from the perspective of divine sovereignty. Accordingly, irony after irony follows the use of this term. Likewise, his role as judge subtly pervades the discourses and makes even his silences eloquent and weighty. ${ }^{106}$ The manifest absurdity of the true judge being examined by the accused provides yet more fertile ground for situational irony. The final role, of the Son of God, provides an extended irony drawing on the disclosures of the Prologue. The ultimate irony remains that Jesus is not just a king or judge, for which there are earthly equivalents, he is also "God the only Son" (1:18) rejected by those whom he created (1:3, $10)$.

b) Pilate

If Jesus is an unlikely candidate for a character study, Pilate is almost obligatory. He features predominantly in the Passion Narrative and is the only character in the inner structure that inhabits every scene as the narrative follows his movements. Consequently, Carter declares, "in each scene Pilate is the key figure."107 Conversely, he features nowhere else in the Gospel and the reader has no prior intimations as to his personality and likely responses. Pilate's sudden insertion into the narrative as a fresh character therefore underscores his representative role. The reader is immediately obligated to attempt to place him on the spectrum of belief-unbelief. However, this is not a straightforward exercise as Pilate is consistently hostile to Jesus'

\footnotetext{
${ }^{105}$ Barrett, St John, 443.

106 "As the Gospel has noted before $(3: 19 ; 8: 15)$, Jesus does not even need to act as judge. In his presence, the actions and words of the world are self-indicting." O'Day, John, 183.

107 Warren Carter, Pontius Pilate: Portraits of a Roman Governor (Collegeville: Liturgical Press, 2003$), 138$. Contra Köstenberger, who sees Pilate as "a comparatively minor character." Köstenberger is right that "Pilate only surfaces in John 18 and 19, and even there, he is continually shown to be torn in the clashing claims between the Jewish leaders and Jesus" however this unduly diminishes his impact on the narrative, the intensity of his dialogue and his representative role. Köstenberger, “'What is Truth?' Pilate's Question in its Johannine and Larger Biblical Context,” JETS 48/1 (March 2005), 59.
} 
opponents and often sympathetic to Jesus. Yet it is quickly apparent that earthly political considerations are his primary motivation. ${ }^{108}$

Furthermore, he is a historical anomaly. While he plays a pivotal role in central event of the Christian faith, in historical terms he is almost entirely unknown. What we know of his background predominantly comes from circumstantial inference, as "the only physical evidence is one inscribed stone and a few coins." ${ }^{109}$ From his name we can infer his ancestry; from his title "governor" we can discern his rank and career path. Pilate almost certainly held the rank of eques (which denoted an equestrian knight). Bond explains that "This was the middle rank of the Roman nobility, coming after senators but before curials. To possess the nomen or dignitas equestris a man needed free birth, certain moral standards and more importantly wealth." 110 Despite a measure of affluence, Pilate's social position was precarious and entirely dependent on the good graces of more powerful patrons. In order to receive his posting it is likely that Pilate was a protégé of Lucius Aelius Sejanus, the brutal commander of the Praetorian Guard who, from 23 to 31 C.E., held sway over the emperor's affections. ${ }^{111}$ The dignitas equestris necessitates military service and his promotion to governor suggests he may have distinguished himself. Therefore, in all probability Pilate was less the vacillating bureaucrat than a hardbitten, calculating military commander.

The only other contemporary sources on Pilate are the Jewish writers Philo and Josephus. ${ }^{112}$ Philo provides an entirely negative account of Pilate, recounting an incident involving the illadvised placing of votive shields in Jerusalem. The issue went before Emperor Tiberius who rebuked Pilate for his insensitivity and intransigence. Philo goes on to attribute to Pilate a litany of unscrupulous behaviour: "his corruption, and his acts of insolence, and his rapine, and his habit of insulting people, and his cruelty, and his continual murders of people untried and uncondemned, and his never ending, and gratuitous, and most grievous inhumanity." "113 Josephus' accounts are mixed. His Jewish Wars depicts Pilate as guilty of two instances of

\footnotetext{
${ }^{108}$ Rensberger useful reminds us of the oft-neglected political overtones present in the Passion Narrative: "I do not claim that John's interests here are exclusively political. The uppermost issues are certainly theological, and these of course have always been given close attention. Yet the title 'King of the Jews,' accorded such prominence in John, necessarily has political connotations, whatever its significance for Johannine Christology." David Rensberger, Johannine Faith and Liberating Community (Philadelphia: Westminster, 1988), 90.

${ }^{109}$ Ann Wroe, Pontius Pilate (New York: Random House, 2001), xii.

${ }^{110}$ Helen Bond, Pontius Pilate in History and Interpretation (Cambridge: Cambridge University Press, 1998$), 9$.

${ }^{111}$ Wroe, Pilate, 23.

112 As Jews, both Philo and Josephus are hardly objective critics and the extent to which this prejudices their accounts is much debated.

${ }^{113}$ Philo, "Embassy to Gaius," in The Works of Philo trans. C. D. Yonge, (Peabody: Hendrickson, 1993), 784.
} 
religious insensitivity but otherwise temperate in comparison with other governors. ${ }^{114}$ However, in his later Jewish Antiquities, Josephus portrays Pilate in a much harsher light and includes his actions amongst the factors that led to the Jewish revolt. ${ }^{115}$

In the Fourth Gospel, Pilate emerges as a complex and conflicted character. On the one hand, Pilate is patently the alazōn who represents himself in his verbal posturing as having power but his repeated toing and froing between Jesus and his opponents and his inability to follow through on his protestations of Jesus' innocence demonstrates that the opposite is true. ${ }^{116}$ On the other hand, the literary power of the trial narrative "consists of the way in which the evangelist suggests truths, particularly about Pilate, through artful reticence."117 Accordingly, the author could easily have presented Pilate as a buffoon or one-dimensional villain but refrains. Indeed Pilate makes ironic retorts at the expense of Jesus' opponents. The result is that Pilate is a complicated character who exhibits elements of the alazōn but also occasionally the eirōn. The reason is Pilate's role as 'a representative of the 'world,' essentially hostile to Jesus because he is not one of his followers." ${ }^{118}$ Nevertheless, his representative role is not of the open hostility of Jesus' direct opponents but rather the irresponsible indifference of "the world," which for the author is another, equally unacceptable, form of unbelief. ${ }^{119}$

This artful, complex characterisation of Pilate in which he can be sympathetic yet complicit, powerful and powerless, exonerating yet condemning, interrogating but unhearing, judging yet judged, mocking yet truthful, compliant and defiant, provide some of the Gospel's most powerful ironies. Just as the key Johannine themes culminate in the Passion Narrative, they have in Pilate's representative role a perfect ironic foil. As Carter summarises, "In not 'seeing' Jesus' identity and his God-given commission to reveal God's kingship or sovereignty Pilate, along with the empire he represents, belongs to 'the world.' Pilate thinks he asserts Rome's sovereignty and declares judgment on Jesus, but in effect Pilate is shown to be subject to God's sovereignty and to bring God's judgment on himself and the empire." ${ }^{120}$ Thus Pilate's journey to

\footnotetext{
114 Flavius Josephus, "The Wars of the Jews (2.169-177)." in The Works of Josephus trans. William Whiston (Peabody: Hendrickson, 1987), 608-609.

115 Josephus, “The Antiquities of the Jews (18.55-59)," Works, 479-480.

116 "His repeated movement through the door of the praetorium comes to signify vacillation and manipulation that is at odds with his claim to absolute power." Brant, John, 233.

${ }^{117}$ Stibbe, Storyteller, 113.

${ }^{118}$ Keener, John, 1097.

119 Thus the author omits the supposed absolution of Pilate washing his hands or his claims to innocence recorded in Matthew 27:24.

${ }^{120}$ Carter, Pilate, 127.
} 
unbelief, through a short but powerful narrative arc, is both representative and ironically charged.

\section{c) Religious Authorities}

In marked contrast, by the Passion Narrative the Jewish religious authorities are a known quantity to the reader. Their initial curiosity $(1: 19)$ quickly turns to antipathy. Their rejection is made complete by the verdict that for reasons of political expediency, Jesus must die (11:46-53). The term "religious authorities" includes the two main Jewish religious factions in the Gospel, the Pharisees and the chief priests (principally, but not exclusively, the Sadducees). ${ }^{121}$ While the two factions were frequently at odds politically and theologically, they were united in their opposition to Jesus, thus forming a unified representative character. ${ }^{122}$ The term can also encapsulate individuals such as Caiaphas and Annas but only because their conduct confirms they belong to this representative character. Conversely, while Nicodemus technically belongs to this group, his behaviour sets him apart. ${ }^{123}$

The two factions do engage with Jesus separately but in an identical manner. Furthermore, at every one of the crucial junctures the author explicitly places them together. It is "the chief priests and the Pharisees" who make the first abortive attempt to arrest Jesus (7:32), call the council that decides Jesus must die (11:46), proclaim the edict for a second attempt at arrest (11:57), and dispatch the soldiers and police with Judas to arrest Jesus at the start of the Passion Narrative (18:3). The religious authorities, whether mentioned together or separately, represent a single character: one who does not believe and expresses that unbelief in active opposition.

The religious authorities are frequently the subject of irony. Indeed, the author has them utter the Gospel's darkest and most tragic ironies. They are the Gospel's definitive alazōn, who reveal that they are not who they claim to be by the repeated deliver ironies of self-betrayal or by speaking better than they know. This explains why the author switches between characters on occasion. For example, in chapter 9 it is the Pharisees who first examine the man born blind

\footnotetext{
${ }^{121}$ In order to capture this wider meaning of the term "chief priests" in the Passion Narrative many commentators variously use synonyms like: "Jewish authorities" (Brown, Lincoln, Brant); "Jewish religious authorities" (O’Day); "Jewish judicial authority" (Schnackenburg); "Jerusalem's elite” (Carter); "religious leaders" (Morris); "Judean leaders" (Keener); or "Jewish leaders" (Köstenberger, Beasley-Murray, Osborne, Burge).

${ }^{122}$ Contra Sloyan, who presumes that the reference to the chief priests and officers in 19:6 is indicative that "the Pharisees of 18:3 have long since dropped out." Gerard Sloyan, John, Interpretation Commentary for Teaching and Preaching, (Atlanta: John Knox, 1988), 208

123 3:1-10; 7:50-51; 19:39-40.
} 
(9:13-17) and end up divided (9:16). "The Jews" then take over the interrogation and eventually drive the man out (9:18-34). However, the author unexpectedly reintroduces the Pharisees at the very end to quail under Jesus' withering denunciation of their spiritual blindness. During the Passion Narrative, "the Jews" contest with Pilate during the trial $(18: 31,36,38,40 ; 19: 7,12$, 14). However, in 19:6 and 19:15, the religious authorities ("the chief priests and the police") inexplicably appear instead of "the Jews." Consequently, they make the first call for crucifixion and blasphemously claim that they have no king but Caesar. Notably, in between these two statements "the Jews" return, revealing that the author intended the key repudiations of Jesus to come from the religious authorities. ${ }^{124}$

d) "The Jews"

The interplay between the religious authorities and "the Jews" identifies one of the Fourth Gospel's most intractable and controversial difficulties - determining what is meant by the term

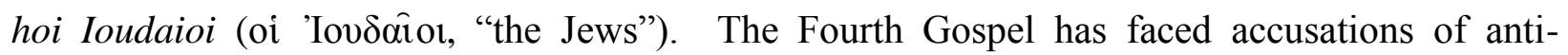
Judaism due to interpretations of the term as an ethnic identifier. Tragically, anti-Semites throughout history have made appeals to the language of all of the Gospels but most commonly the Fourth. ${ }^{125}$ However, scholars agree that whatever the term "the Jews" means, it is not a racial reference to the Jewish people. As Carson rightly observes "the New Testament dividing line is theological, spiritual, historical - not racial."126 Consequently, most scholars also dispute claims of anti-Judaism. $^{127}$

To determine the intended meaning of "the Jews" consideration must be given to "their apparently shifting identity within the Gospel." ${ }^{2128}$ There is often a pejorative element to the author's use of "the Jews"; ${ }^{129}$ however they are also portrayed as neutral, ${ }^{130}$ or even positive

\footnotetext{
124 "It can hardly be accidental that the Evangelist no longer speaks in general of 'the Jews' but of the 'chief priests,' who, along with 'the officers' under their command are the first to cry out , 'Crucify him!'” Ridderbos, John, 601. See also Morris, John, 702.

125 David Nirenberg, Anti-Judaism: The Western Tradition (New York: W.W. Norton, 2013), 78-83. "Some of Augustine's most virulently anti-Jewish language can be found in his sermons on the Gospel of John.” Ibid 505.

${ }^{126}$ Carson, John, 575.

127 "We would argue, with many others, that the anti-Judaic approach actually derives from reading the Gospel in a very different framework from that which it was composed.” Keener, John, 215.

128 Stephen Motyer, "Bridging the Gap: How Might the Fourth Gospel Help Us Cope with the Legacy of Christianity's Exclusive Claim over Against Judaism?” in Bauckham, Gospel of John, 150.

${ }^{129} 5: 16,18 ; 6: 41 ; 7: 1,11,13 ; 8: 48,52,57 ; 9: 18,22 ; 10: 31,33 ; 11: 8,54 ; 18: 14,31,36,38 ; 19: 7,12,14,31,38$; 20:19.

${ }^{130} 1: 19 ; 2: 13,18,20 ; 3: 1 ; 5: 1,10,15 ; 6: 4,52 ; 7: 15,35 ; 8: 22 ; 10: 19,24 ; 11: 19,31,33,55 ; 13: 33 ; 18: 20,33,39$; $19: 3,19,20,21,40$.
} 
towards Jesus. ${ }^{131}$ In analysing the usages of this term we find that $41 \%$ of uses have negative, $48 \%$ have neutral and $11 \%$ have positive connotations. In typical Johannine style classification is challenging, although less so with the negative connotations. ${ }^{132}$ For example, some of the neutral uses such as the third party references to Jesus as the king of the Jews $(18: 33,39: 19: 3$, $19,21)$ are arguably positive, since the author uses them ironically to develop his motif as Jesus as the true King. The positive uses of the term make up for their infrequency with their force. For example, Jesus allows himself to be identified as a Jew (4:9) and goes on to proclaim that "salvation is from the Jews" (4:22). There is sufficient diversity in the use of "the Jews" to suggest that a reading of this term as entirely negative, let alone anti-Jewish, is unjustifiable.

It is widely acknowledged that "the term the Jews seems instead to be a literary fiction, a composite group, drawn out of Judaism for sure, who oppose Jesus' ministry and his witness. In using this term, John has in essence created a character in the Gospel."133 Indeed, with the exception of Jesus, "the Jews" receive the most speaking lines in the narrative. ${ }^{134}$ It is therefore imperative to consider "the Jews" as "one of the characters in John's story, alongside other individual characters, like Nicodemus and the Samaritan woman, and other group characters like the Pharisees and the crowd." 135 Fortunately, despite the lack of clarity over the term's referent, it is possible to ascribe a representative character to "the Jews."

Since Bultmann it has been recognised that "the Jews" are "representatives of unbelief... and of the unbelieving world in particular." 136 However, because Bultmann eschewed any sense of historical particularity in the narrative, many scholars find his one-dimensional approach to "the Jews" as purely theological symbols to be unsatisfactory. Accordingly, Bennema points out that we must distinguish between the "referent" of the term (the identity of hoi Ioudaioi as real people in Jesus or John's time) and the "sense" of the term (the representative function of hoi Ioudaioi within the Johannine narrative). ${ }^{137}$ The sense of "the Jews" is relatively settled; they

\footnotetext{
$1314: 9,22 ; 8: 31 ; 11: 36,45 ; 12: 9,11$.

132 Many of which we will encounter in our consideration of "the Jews" in the Passion Narrative, since the pejorative use of the term increases as the Gospel progresses or where Jesus' identity is put on trial (e.g. chapter nine - the story of the man born blind).

${ }^{133}$ Mark Matson, John, Interpretation Bible Studies, (Louisville: John Knox, 2002), 111.

${ }^{134}$ Brant, Dialogue and Drama, 178.

${ }^{135}$ O’Day, John, 69-70.

${ }^{136}$ Bultmann, John, 86.

${ }^{137}$ Cornelis Bennema, "The Identity and Composition of OI IOUDAIOI in the Gospel of John," TynB 60.2 (2009), 240. Bennema follows and develops the work of Ashton. John Ashton, Studying John: Approaches to the Fourth Gospel (Oxford: Oxford University Press, 1994), 62.
} 
represent "the world that is being put on trial, the unbelieving world hostile to God's authorized agent and witness.",138

It is the historical identity of "the Jews" that engenders ongoing debate. Some believe that the term refers to Judeans (cf. 7:1; 11:7-8). However, "the Jews" are also found in Galilee $(6: 41$, 52). Others emphasise their connection with the religious authorities $(1: 19 ; 9: 22 ; 18: 14)$. But equally they are distinguished from these authorities in the narrative $(7: 32-35 ; 11: 45-46 ; 12: 9$ 11). Yet others posit a link with the Pharisees $(1: 24 ; 3: 1 ; 9: 13-18)$; however, the narrative also distinguishes them from the Pharisees (11:45-46). Likewise, the term is linked with "the crowd" in 12:9 but differentiated from them in $7: 1 .^{139}$ It is conceivable that a definitive identification is not possible; nonetheless many scholars remain undeterred. ${ }^{140}$ From a narrative critical perspective it is the "sense" of the term that is significant. Hence Bennema can conclude that "in John's dualistic world view, oi 'Iovdaion are of the realm 'below' (8:23) whereas those who belong to Jesus (including the Johannine believers) are of the realm 'above'. Hence, John's perspective on his non-believing compatriots was an outsider's (though still Jewish) perspective,

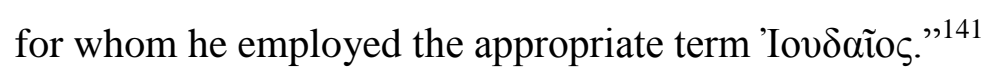

The difficulties in delineating the referent of "the Jews" may be because the author has chosen the term precisely since it resists easy identification, thereby accentuating its representative role. Not all characterisations support an equivalent sense and referent. For example, the term o коб́ $\mu \varsigma_{\varsigma}$ (the world) is used 78 times in the Fourth Gospel and while its sense is clear its referent is impossibly vague. ${ }^{142}$ Inasmuch as "the Jews" represents the unbelieving world perhaps it is not surprising its referent is likewise indeterminate. A correlation between the two concepts is established in the Prologue's meta-irony: "He was in the world, and the world came into being through him; yet the world did not know him. He came to what was his own, and his own people did not accept him" (1:10-11). The author establishes from the start that the responses of both the world and Jesus' own people were essentially identical. ${ }^{143}$ Thus the reader readily

\footnotetext{
${ }^{138}$ Lincoln, Trial, 126. See also Culpepper, Anatomy, 125-132.

${ }^{139}$ For a summary of these points see Motyer, Bridging, 150.

140 See Bennema, Identity. Daniel Boyarin, "What Kind of a Jew Is an Evangelist?" in Those Outside: Noncanonical Reading of Canonical Gospels eds. George Aichele and Richard Walsh, (New York: T\&T Clark, 2005). Motyer, Bridging. Reimund Bieringer, et al eds. Anti-Judaism and the Fourth Gospel (Louisville: John Knox), 2001.

${ }^{141}$ Bennema, Identity, 263.

${ }^{142}$ For example, at times it is used universally (i.e. of all humanity, $1: 29 ; 3: 16-17 ; 4: 42 ; 8: 12$ etc.) and at other times non-universally (some of humanity, 1:10; 7:7; 12:19;14:17, 22;15:18 etc.). Its universal application means that while hoi Ioudaioi is symbolical of ho kosmos, the reverse is not necessarily true. See Lars Kierspel, The Jews and the World in the Fourth Gospel (Tubingen: Mohr Siebeck, 2006), 153.

${ }^{143}$ Again the acceptance that they were Jesus" "own" show that any antipathy and rejection was one sided.
} 
apprehends that the phrase "the Jews" can approximate for the unbelieving world. Jesus reinforces this in 18:20, where he states before Annas that "I have spoken openly to the world; I have always taught in synagogues and in the temple, where all the Jews come together." Jesus equates speaking to "the world" with speaking to "the Jews."

Moreover, Jesus' revelation reached too few Gentiles to allow those it did to represent the wider world. It was therefore preferable for "the Jews" to take on this representative role in the narrative. As we have seen, Pilate likewise takes on this role but he does not appear until the Passion Narrative. The other non-Jews in the Gospel better serve other representative roles. For example, the Samaritan woman (4:7-42) represents correct belief and response. ${ }^{144}$ Whereas the Greeks (12:20-21) represent Jesus' paradoxical relationship with the world, namely that most will reject him (1:10-11) but some will receive him (1:12-13). To have laid the primary role of "the world" on the limited number of Gentile characters would have produced a Gospel pejorative to Gentiles. Instead the author draws from Jesus' primary audience to portray the world's reaction. The author artfully introduces Pilate to show that in the final rejection of Jesus both "the Jews" and the Gentile world respond identically and conjointly, thereby fulfilling the prophecy of 1:10-11. Indeed, as we will shortly see, the point that Pilate and "the Jews" are indistinguishable is driven home in one of the Gospel's most gratifying ironies.

The representative role of the "the Jews' also explains why their responses are mixed. Like most other characters, they too go on a journey. In the Passion Narrative, there are no positive references to "the Jews" and the reader is aware that the journey becomes a descent into unbelief. Those who earlier came to belief $(11: 45 ; 12: 11)$, while remaining ethnically Jewish, cease to be part of "the Jews" and become disciples. Those whose unbelief solidifies continue their downward trajectory. This journey of "the Jews" leads Brant to offer a characterisation of them as "the corporate voice of deliberation," who at times function like the chorus in a Greek tragedy. ${ }^{145}$ Brant adds that "focusing on the Jews or disciples as representatives of historical agents places emphasis upon the product of their deliberation - that is, their rejection of Jesus." If If "the Jews" are a synthesised group, sometimes the Pharisees and sometimes not, sometimes the Judean aristocracy and other times not, this emphasises the heterogeneous contributions to a collective voice of deliberation. Thus construction of "the Jews" as a composite, referentially ambiguous entity emphasises that anyone could be one of "the Jews,"

\footnotetext{
144 This is heightened by the response coming from an unlikely source; a non-Jewish woman with a past.

145 Brant, Dialogue and Drama, 178-187.

${ }^{146}$ Ibid., 181.
} 
since membership is based on belief (or lack thereof), not racial or theological affiliation. ${ }^{147}$ This also explains why the author is loath to put the worst repudiations in the mouth of "the Jews" and instead substitutes the religious authorities, who represent unbelief together with hostile action. ${ }^{148}$ The author preserves "the Jews" as a wider, constantly deliberating group who are, only ultimately, unbelieving. Hence, they talk of action but do not follow through. ${ }^{149}$ The religious authorities are a subset of wider unbelieving world but retain their own distinctive character, so they can act in their own right when the author requires it. ${ }^{150}$

The representative character of "the Jews" advances the ironic elements of the narrative in a different manner than the religious authorities and Pilate. They play less of the role of alazōn and develop subtler ironies, often indirectly. For example, they produce many ironies in the Book of Signs but they are typically ironies based on misunderstandings (e.g., 2:20; 6:52; 7:35; $8: 22,57)$ rather than ironies of self-betrayal. The latter do occur but mainly in the trial narrative when their unbelief reaches its apogee. For most of the narrative the ironies are built around the fact that they should know but do not (cf. 1:11). ${ }^{151}$ The irony is deepened by the reaction of nonJews like the Samaritan Woman, who resolves Jesus' identity without the cultural and theological advantages that Jesus' own people possessed. ${ }^{152}$

Keener proposes that "the Jews" is an ironic term and that "the Jews" denote the Jewish leaders who had implied that Jewish Christians were not true Jews. ${ }^{153}$ He proposes that "John's response is to ironically reverse this charge, thereby granting the authorities the very title they covet, while undermining their right to it." 154 Keener's conclusion as to referent would be vigorously disputed by others. ${ }^{155}$ However, there is value in his insight that "the Jews" is an

147 "Christian Jews "distinguished themselves from non-Christian Jews not theologically, but only in their association of various Jewish theologoumena and mythologoumena with this particular Jew, Jesus of Nazareth." Boyarin, Evangelist, 152.

148 "If the unbelief of the world is represented by the Jews, then in similar fashion the hostility of the Jews toward Jesus is concentrated in the Pharisees." Culpepper, Anatomy, 131.

${ }^{149}$ They want to forcibly make Jesus king $(6: 15)$, they want to arrest Jesus $(7: 30,44 ; 10: 39)$ and they take up stones to kill Jesus $(8: 59 ; 10: 31)$ but on each occasion inexplicably nothing happens. While Brant's statement that "the collective Jews never become actors" is incorrect, the comparative lack of action indicates that there is value in noting the similarities with a tragic chorus. Brant, Dialogue and Drama, 183.

${ }^{150}$ See Bennema, Identity, 260, for a useful Venn diagram.

151 "The descriptions of 'the Jews' are highly ironic, because the designation suggests that this group, of all people, should understand who Jesus is." O’Day, John, 70.

${ }^{152}$ This author only gently nudges the reader to this conclusion as all of the references to "the Jews" in chapter four, an irony rich environment, are positive.

${ }^{153}$ Keener, John, 214-228.

${ }^{154}$ Ibid., 227.

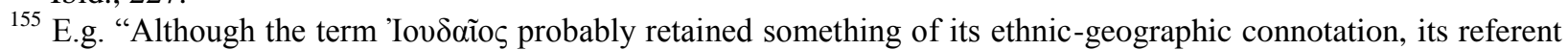
was extended to include any Jew who was loyal to the temple ideology or Judaean religion. It thus follows that the 
inherently ironic term. It is the reversal of those who should know but do not, who should believe but do not. This is significant for the readers as they have been provided with superior knowledge that now makes them the one who should know. Notably, 1:11 does not use the term "the Jews" but rather "his own people." This of course primarily refers to Jesus' Jewish compatriots. However, the Prologue reveals at 1:3 that all people "came into being through him" and so on another level everyone constitutes "his own people." Consequently, the Gospel invites the reader, regardless of ethnicity, to enquire whether he or she is one of "the Jews?"

Irony is therefore an interpretative key to the meaning of "the Jews." Bennema proposes that "in

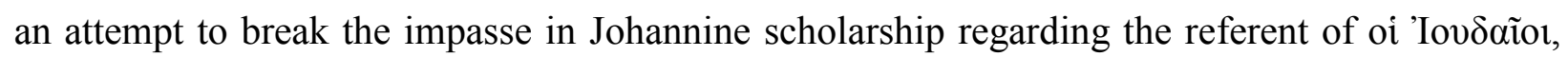
we suggest a combination of a historical and narratological approach."156 This is a useful methodology, which allows for recognition that "the term 'the Jews' seems rather intentionally unspecific." 157 If irony is allowed to inform the historical question, the possibility that the term is only fixed in sense but not as a referent becomes increasingly plausible. This approach breaks the impasse. The term "the Jews" can now accommodate all of the proposed referents, either concurrently or separately, just as we observe in the text. Not only does the term's shifting identity cease to be problematic, it becomes a positive feature underscoring the author's literary intention to produce a representative character whose historical particularity could not be fixed.

The advantage of a vague referent is threefold: first, it explains why there is broad consensus on the sense but none on the referent. ${ }^{158}$ Second, in disallowing association with any one group it prevents apportioning culpability for Jesus' death. Finally, it encourages identification and deliberation by readers as they come to realise that anyone, irrespective of ethnicity, theology, culture and historical setting could fall within the rubric of "the Jews." The use of this ironic term in the narrative therefore promotes the author's purposes by revealing that the question of Jesus' identity is universally pertinent and that a positive and active response is required to avoid becoming one of the "the Jews" and concomitantly the unbelieving world.

The other characters in the Passion Narrative will be considered as they arise in the analysis of the text. This is because they fall into one of three categories. First, their roles evoke no irony,

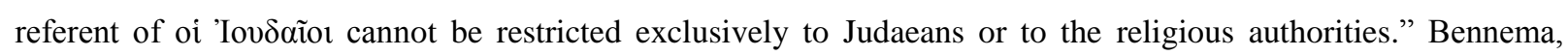
Identity, 245. See also Boyarin, Evangelist, 129-130.

${ }^{156}$ Bennema, Identity, 262. Although he then goes on to incongruously argue for a sole historical referent.

${ }^{157}$ Kierspel, The Jews, 18.

158 Those who do contest the representative meaning of the term have invariably failed to differentiate between referent and sense. 
such as Jesus' mother and the other faithful women, the Beloved Disciple and Nicodemus. Second, their roles are incorporated into other roles already discussed. Annas, Annas' servants, Caiaphas, the police, the chief priests and Pharisees come under the religious authorities. The soldiers are an extension of Pilate's role. Finally, their role and participation in the irony is limited and therefore better examined in the context of the particular verse. This applies to Judas, the disciples, Peter, Barabbas and Joseph of Arimathea.

\section{Conclusion}

Our consideration of the form, genre, structure, plot and characterisation of the Passion Narrative has revealed a well laid foundation for the expression of Johannine irony. The author presents historical figures and events but in a manner that maximises their theological potential. A remarkable textual construction creates multiple layers, with outer and inner structures and dual chiastic forms that facilitate parallelism and contrast. Stages are set which create movement in such a way that the movement itself becomes part of the Gospel's symbolism. The author skilfully uses the plot to illuminate the themes as well as the action. This imbues the character's utterances with deeper meaning as they connect with the refrains the author has been building throughout the entire narrative. As the trial reaches the most dramatic stages, the key characters are reduced to four representative roles. By the end of the trial that number will be reduced to three, as Pilate reveals his true colours. This mirrors the three roles revealed in the Prologue's meta-irony (1:10-11): Jesus, the world that do not know him and his own who do not accept him. It is therefore not surprising that the incidences of irony are more numerous in this part of the Gospel than any other section and, as we will soon see, that the ironies have a potency both in terms of their literary artistry and their theological import. Accordingly, there is no better place to test our hypothesis than by observing how the irony in the Passion account relates to the propositional statements of the narrative and in particular those that help to convey the author's truth theme. With this in mind, we now turn to a close reading of the ironies in the text. 


\section{Chapter 6}

\section{The Irony of the Passion Narrative}

The plot development of John 18 causes a discernible increase in the frequency and intensity of irony as the chapter progresses. The initial pericopae set the scene and orient the reader away from the primarily didactic elements in the Farewell Discourses. Notably they return the identity of Jesus as the central issue. The narrative pace builds inexorably to the dramatic and ironic climax at the end of chapter 18 and the start of chapter 19. Its counterpart in the concentric structure, the latter portion of chapter 19, features a corresponding abatement in irony. While we will use Moloney's structure while examining the text, it is beneficial to have a grasp of the underlying plot movement since the irony is not spread uniformly. The movement and pacing of the Passion Narrative's plot can be considered in three stages, which correspond to Moloney's five Acts. Each of these stages is of comparable length: stage one (Acts i and ii) comprises 27 verses, stage two (Act iii) 28 verses and stage three (Acts iv and v) 27 verses. ${ }^{1}$ However, the irony is not evenly distributed; stage one contains six ironies, stage two 24 and stage three seven.

Stage one moves upward with increasing dramatic force from an inept arrest and a farcical trial before those who have already rejected him (11:47-53), towards the main trial and decisive rejection. It commences with a notable reversal; the religious authorities and their agents successfully arrest Jesus despite the failure of all previous attempts. ${ }^{2}$ Act $\mathrm{i}$ uses irony to emphasise Jesus' identity and Act ii ironically expresses Jesus' relationship with his disciples. ${ }^{3}$ Both of these relate to major propositional statements (two of the seven "I am" claims) about Jesus and set the stage for the final determination of Jesus' identity. Stage two is the ironic peak both in terms of quantity and substance. Through sublimely iterated irony, the world (represented by Pilate and "the Jews") and more emphatically his own people (represented by the religious authorities) reject Jesus, as presaged in the Prologue (1:10-11). Stage three is a descent to the consequences of the denial of Jesus' identity. Accordingly, the dramatic tension

\footnotetext{
${ }^{1}$ The half-verse (16a and $\left.\mathrm{b}\right)$ is rounded up.

2 5:18; 7:1, 25, 30, 32, 45-46; 8:59; 10:31; 39; 11:53-54, 57; 12:19.

${ }^{3}$ The different themes mean that it is better to retain the five Act structure rather than the simpler three stages.
} 
wanes once the rejection is conclusive and the final steps to the cross are inevitable. The cross is also a reversal, which simultaneously represents Jesus' defeat at the hands of his enemies but also his triumphant lifting up $(3: 14 ; 8: 28 ; 12: 32)$. Mirroring the first two Acts, Act iv uses irony to emphasise Jesus' true identity and in Act $\mathrm{v}$ the irony relates to discipleship. For a summary, see Figure 5.

\begin{tabular}{|c|c|c|c|c|c|c|}
\hline & $\begin{array}{l}\text { Primary } \\
\text { Reversal }\end{array}$ & Verses & Structure & $\begin{array}{l}\text { Ironic } \\
\text { Verses }\end{array}$ & $\begin{array}{c}\text { Primary Ironic } \\
\text { Themes }\end{array}$ & $\begin{array}{l}\text { Meta- } \\
\text { Themes }\end{array}$ \\
\hline \multirow{2}{*}{ Stage One } & \multirow{2}{*}{$\begin{array}{l}\text { The opponents succeed } \\
\text { in arresting and trying } \\
\text { Jesus but he is in control }\end{array}$} & \multirow{2}{*}{$\begin{array}{c}18: 1-27 \\
(27 \text { verses })\end{array}$} & Act i & 2 & Jesus’ Identity & Revelation \\
\hline & & & Act ii & 4 & Discipleship & Response \\
\hline Stage Two & $\begin{array}{l}\text { Jesus is mocked as a } \\
\text { false king but is the true } \\
\text { king }\end{array}$ & $\begin{array}{c}18: 28- \\
19: 16 a \\
\text { (28 verses) }\end{array}$ & Act iii & 24 & Jesus is Sovereign & $\begin{array}{l}\text { Revelation } \\
\text { and } \\
\text { Response }\end{array}$ \\
\hline \multirow{2}{*}{ Stage Three } & \multirow{2}{*}{$\begin{array}{l}\text { The opponents succeed } \\
\text { in killing Jesus but this is } \\
\text { his triumph }\end{array}$} & \multirow{2}{*}{$\begin{array}{l}19: 16 b-42 \\
(27 \text { verses })\end{array}$} & Act iv & 5 & Jesus' Identity & Revelation \\
\hline & & & Act $v$ & 2 & Discipleship & Response \\
\hline
\end{tabular}

Figure 5.

In this chapter, I will provide a close reading of ironic utterances in the Passion Narrative. I will only discuss intervening text where it is relevant to the irony. For the crucial stages of the narrative the irony is so frequent that plot elaboration is unnecessary. Where applicable I will provide ratings for the irony from the assessments conducted in the survey. These will be in terms of attestation and the literary merits of the irony in accordance with the criteria set out in Chapter 1. Remembering that a robust attestation does not categorically prove the existence of irony and a limited attestation may only signify that the irony has gone unnoticed. Likewise, a stronger assessment does not make it good irony and weak irony is not necessarily bad. The survey's strength is in its ability to reveal patterns and provide start points for analysis, not in its ability to pronounce conclusively on individual ironies.

It is important to remember that for the reasons elaborated at length in Chapter 2, it is not possible to identify the presence of irony with certainty about irony, only to document perceptions of irony. Duke's warning over the pretentiousness of claiming to have grasped irony 
is also applicable to specific ironies. ${ }^{4}$ As irony is a surreptitious invitation to the reader, the result is never a forgone conclusion. The reader may miss or reject the invitation. Furthermore, even if an author's perspective is ironically proffered and received, the effect on the reader can be highly variable. This will be demonstrated in our consideration of the text, where it is evident that different interpreters highlight diverse aspects of the same irony. A large part of the appeal of irony is that it often allows the reader to explore differing facets or layers of a tendered truth. Consequently, it is sometimes difficult to determine if interpreters are seeing different sides of the same irony or different ironies altogether.

Moreover, irony is a creative and artistic form of expression, more so than other rhetorical devices. In many respects, it is like painting with words - at times using subtle tones and at others using vivid contrasts. In considering a painting, one observer may wonder at the whole composition (form and layout, subject matter) while another focuses on the technique (use of colour, brush strokes). Yet another may ignore these approaches and marvel at the emotional response the work evokes. The artistic appeal is notoriously idiosyncratic and defies easy articulation. Likewise, one does not simply explain the irony in a narrative, as if there is a formulaic approach that produces a single, correct solution. A reader may perceive and appreciate the irony in its wider context in the narrative, ${ }^{5}$ or due to the skilful ironic technique of the author. ${ }^{6}$ Another reader may enjoy the emotions derived from the thrill of discovery and inclusion in the author's community of the knowing. Ultimately, irony must speak for itself and each reader must make up his or her own mind. Accordingly, our consideration of the ironies in the Pasion Narrative draws on perceptions, not definitive conclusions. I will therefore engage with as many interlocutors as possible to consider multiple perceptions and allow the irony its fullest expression. Our first example, will demonstrate the value of this approach.

\section{Act i}

18:3 Judas leads a combined force of Roman soldiers and temple police, equipped "with lanterns and torches" to arrest Jesus. The irony in this verse is robustly attested to and strong. Notably it features paratactic style with four uses of $\alpha \alpha i$ as coordinating conjunctions. Interpreters see three ironies in this verse. The first relates to the arresting force, the second to Judas and the

\footnotetext{
${ }^{4}$ Duke, Irony, 4.

${ }^{5}$ Noting how it draws on earlier clues, reintroduces a familiar theme or emphasises a literary structure or pattern.

${ }^{6}$ Observing the skilful word play, how subtly it is adduced or the profundity of the point being made.
} 
third to the location. Furthermore, in the first, interpreters perceive three different ironic facets while in the second two are noted. These facets are of varying degrees of attestation and strength. The multiple interpretations of the irony in this verse amply demonstrate the fluidity of perceptions surrounding irony.

A majority of interpreters perceive an irony that draws on the prominent Johannine theme of

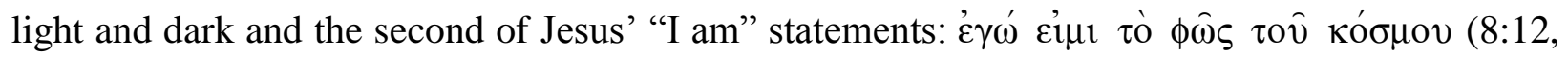
also 9:5). ${ }^{7}$ Judas, who was last seen going out into darkness (13:30), now returns, still in the dark, leading police and soldiers bearing lanterns and torches. Laden with artificial light sources, they come to arrest the "light of the world." The ironic inference is compelling as this theme of Jesus as the true light has been established since the opening verses of the Prologue $(1: 4-5,7-9){ }^{8}$ Furthermore, an informed reader is by now aware of the author's predilection for mentioning extraneous details that resonate with symbolic significance. ${ }^{9}$ Although the irony speaks to Jesus' identity, its rhetorical force derives from the symbolic light/dark motif.

Another feature deemed ironic is the size of the arresting party. Accordingly, the "forceful arrest initiated by Judas's leading a sizable number of soldiers and officials to Jesus stands in ironic contrast to Jesus' peaceful nature."10 The text is vague as to the exact composition and number of Romans. The term $\tau \dot{\eta} \nu$ $\sigma \pi \varepsilon i p \alpha \nu$ would usually denote an unfeasibly large cohort of 6001,000 men. However, the noun $\sigma \pi \varepsilon i p \alpha$ can refer to a "maniple" of 200 men, and it is not necessary to assume that an entire unit was present. ${ }^{11}$ The author may have intentionally used ambiguous language that implies a large number to increase the ironic potential. ${ }^{12}$ O'Day proposes that the mention of weaponry provides a third ironic aspect. ${ }^{13}$ Jesus' arrestors come armed but his determination to carry out the Father's will $(4: 34 ; 5: 30 ; 6: 38-40)$ renders them redundant, just as Peter's use of the sword is uncalled for (18:11). This last ironic aspect is weaker and would not function independently. However, it works well as one of three aspects creating a weighty situational irony.

\footnotetext{
${ }^{7}$ Zumstein, Saint Jean, 199; Ellis, Genius, 248; Keener, John, 1078; Duke, Irony, 114; Köstenberger, John, 505; Culpepper, Anatomy, 174, 177; Lincoln, Saint John, 444; Hamed-Khani, Revelation, 82; O’Day, John, 170.

${ }^{8}$ I.e. five of the first nine verses refer to Jesus in terms of light.

${ }^{9}$ Duke refers to such instances as "hyperbolizing imagery." Duke, Irony, 110, 114.

${ }^{10}$ Gerald Borchert, John, New American Commentary 25A/B, (Nashville: Broadman \& Holman, 2002), 2.219

${ }^{11}$ Carson, John, 577.

${ }^{12}$ The author also uses similarly ambiguous language to make an ironic point at 19:13.

${ }^{13}$ O'Day, John, 170.
} 
Keener sees another situational irony in the mention of Judas leading the way. He notes that the betrayal tradition is undoubtedly historical but the author carefully recasts it so that it reminds the reader that the extreme betrayal may come from those once considered disciples. ${ }^{14}$ This irony involves a strong reversal of expectation and the imminent progression of the text to the denial of Peter (18:15-17) provides further support. The author often juxtaposes similar events, in this case dual betrayals, with contrasting results. ${ }^{15}$ Keener proposes a second ironic aspect of Judas' role, predicated on ambiguous language. The text states that Judas led $(\lambda \alpha \beta \omega v)$ the detachment, with the principal meaning being that he directed the soldiers/police to Jesus. However, while historically implausible, it is grammatically possible to render this as Judas led, in the sense of "commanded," the detachment. Keener proposes that the author uses $\lambda \alpha \beta \omega$ ' to do "double duty" in that "the strength of John's expression makes more sense as graphic Johannine irony: those who betray God's servants are as responsible for their executions as if they had killed them themselves (16:2)."16 This aspect is less persuasive than the first, but since both aspects express notions of rejection they are thematically consistent and correlate to existing patterns in the narrative. Again, the author creates multiple ironic layers that accentuate one another.

The final proposed irony alludes to the Old Testament. Wright proposes a dramatic reversal in that the author produces a "new Genesis" and that "the story of Adam in the garden, in Genesis 2 and 3, stands behind the garden of betrayal in this chapter."17 This interpretation constitutes a noteworthy dramatic irony: whereas in Genesis God came looking for sinful humanity in a garden, in the Passion Narrative the roles are reversed and sinful humanity comes looking for God in a garden. He adds, "Like all humans they are looking for God, but they don't know that's what they are doing" proving an ironic element of the alazōn. ${ }^{18}$ If this is an allusion to the Garden of Eden, then the irony is compelling. Furthermore, it provides symbolic meaning to the specific mention of the garden in 18:1, which otherwise serves little purpose in the narrative other than acting as an inclusio.

18:6 Jesus confronts his arrestors and asks who it is they seek. They name Jesus and he responds with $\varepsilon \gamma \omega \dot{~ \varepsilon i \mu l ~(18: 5) . ~ A t ~ t h i s ~ h i s ~ a r r e s t o r s ~ s t e p ~ b a c k ~ a n d ~ f a l l ~ t o ~ t h e ~ g r o u n d ~(18: 6) . ~ T h e ~}$ prostration of the arrestors has potent theophanic symbolism. Some, like Lindars, argue that "it

\footnotetext{
${ }^{14}$ Keener, John, 1076.

${ }^{15}$ For example, Nicodemus/Samaritan Women, the lame man/the man born blind.

${ }^{16}$ Keener, John, 1081.

${ }^{17}$ Tom Wright, John for Everyone 2 vols. (Westminster: John Knox, 2002), 2.102.

18 Ibid., 2.102.
} 
can scarcely be regarded as an historically reliable detail, however awe-inspiring and majestic Jesus was on this occasion."19 Others have argued for a literal interpretation and proffered multiple explanations, none of which are entirely convincing. ${ }^{20}$ However, the author has previously noted the powerful sway Jesus' words have had on those who had come to arrest him (7:45-46). As Carson observes, if they were in awe of Jesus before, "in the light of day and in the precincts of the temple where they most feel at home, it is not hard to believe that they are staggered by his open disclosure on a sloping mountainside in the middle of the night." 21

Other scholars suggest an implicit theophanic connotation means that the falling back was an ironic response. $^{22}$ Repetition is an indicator of Johannine irony and notably the author gratuitously repeats the theologically loaded ' $\gamma^{\prime} \omega^{\prime} \varepsilon \dot{\imath} \mu \mathrm{u}$ in vv.5, 6 and 8. This indicates that at the very least, the author desired to accentuate the term. O'Day suggests that in order that the reader does not miss the import of these words the response of the soldiers, a conventional response of people in the presence of God, ironically confirms Jesus' identity. ${ }^{23}$ Carson adds that even if this was not a direct theophany it could still constitute an unconscious one. ${ }^{24}$ Accordingly, this would still constitute an ironic response, albeit one of unknowing self-betrayal. This irony has only limited support but is worthy of a medium assessment. It relates directly to the ironic theme of Jesus' identity with an intensity that immediately calls to the reader's mind the language of the Prologue. The ironic powerlessness of Jesus' arrestors may be a reminder of 1:5: "The light shines in the darkness, and the darkness did not overcome it." Their response demonstrates that Jesus retains sovereign control and gives himself up willingly.

Lindars sees an ironic connection between the $\varepsilon \gamma \omega$ ' $\varepsilon \dot{\imath} \mu \mathrm{r}$ of v.6 and the reference to "Judas, who betrayed him, was standing with them" in the preceding verse. The last time Judas and Jesus were together, Jesus predicted his betrayal and Judas departing into the darkness (13:30). At 13:18, Jesus makes first reference to his betrayal and concludes with the portentous statement, "I tell you this now, before it occurs, so that when it does occur, you might believe that $\varepsilon \gamma \omega \dot{\omega} \varepsilon \dot{\varepsilon} \mu$ " (13:19). Consequently, "the ego eimi here can be taken as a cross-reference to this verse in the Last Supper account, intended to call to mind the tragic irony of the situation." 25 Lindars'

\footnotetext{
${ }^{19}$ Lindars, John, 541.

${ }^{20}$ For example, "It was possible that given their suspicion that Jesus was a magician $(7: 20 ; 8: 48,52 ; 10: 20)$, they might have fallen back in terror when he pronounced the divine name." Keener, John, 1082.

${ }^{21}$ Carson, John, 578.

${ }^{22}$ Anderson, Graduations, 185.

${ }^{23}$ O'Day, John, 171.

${ }^{24}$ Carson, John, 579.

${ }^{25}$ Lindars, John, 541.
} 
linking of 18:6 and 13:19 is astute and credible. However, since neither Judas' presence in 3:1819 or $18: 5$ generates irony it is less certain what he means by "the situation." If we speculate that he is referring to Jesus' closest followers only being able to receive the revelation of his divine identity subsequent to an act of betrayal by one of them, then this is indeed a tragic situational irony. Despite the poor attestation of this irony, it is of medium strength and speaks to the key theme of Jesus' identity once again.

\section{Act ii}

18:12 The soldiers and temple police bind Jesus before delivering him to Annas. Lincoln suggests that the reference to the binding of Jesus creates an ironic contrast between Jesus' physical constraints and his sovereign control. ${ }^{26}$ However, while there is contrast there is no reversal sufficient to generate irony. It is not a reversal of expectation for a prisoner to be bound, nor is it unexpected that Jesus would allow them to bind him if he was in control and determined to drink the cup that the Father has given him (18:11). Otherwise, everything negative that occurred to Jesus would be ironic, since it would be incongruent with his sovereignty. Lincoln misconstrues the author's theme that Jesus is sovereign not despite what is happening to him but because of it. Jesus' chastening is part of the cup he must drink before he is lifted up and glorified $(3: 14 ; 8: 28 ; 12: 32 ; 17: 1,5,19)$. This is therefore a disputed irony.

18:14 The narrator intrudes into the narrative to explain that Annas was the father-in-law of Caiaphas, the current high priest (18:13). ${ }^{27}$ The narrator also reiterates that it was Caiaphas "who had advised the Jews that it was better to have one person die for the people" (18:14). This reminds the reader, with uncharacteristic directness, of one of the Gospel's most poignant ironic utterances. The author intends readers to progress into the rest of the Passion Narrative with these words resounding in their ears. Accordingly, the repetition of this irony has less to do with identifying Caiaphas than with reminding "the reader of the full and tragic run of ironies" that unfold in the Passion Narrative. ${ }^{28}$ This reinforces in the reader's mind the role of the religious authorities as alazōn and the idea that Jesus' death is for the people, in ways greater

\footnotetext{
${ }^{26}$ Lincoln, Saint John, 451.

27 “'P]reservation of Annas's name and relation to Caiaphas probably suggests that the event itself, while capable of serving John's purposes, also reflects historical tradition.” Keener, John, 1090.

${ }^{28}$ Carson, John, 581.
} 
than those calling for his death can even begin to imagine. The author therefore sets the tone for the ironic unfolding of the divine plan of salvation for all people.

Annas had been high priest from 6 to $15 \mathrm{CE}$ and five of his sons were later to hold the position. Brown observes that many Jews still considered Annas the legitimate high priest because the high priesthood was a lifetime office (Numbers 35:25) and "perhaps in the de facto situation the shrewd, old Annas was the effective high priest wielding the power behind the scenes while his relatives held the title." 29 Consequently, Witherington notes deliberate irony in the use of "that year" in this verse and in 11:49. ${ }^{30}$ The repetition of the phrase points to possible irony and serves to cement in the reader's mind the link with the earlier prophecy. However, this is a sarcastic remark that borders on irony but is weak at best. Nonetheless, it is worth noting that this highlighting of the dubious and highly politicised nature of the incumbents may play into later ironies that hint at Jesus as the true high priest and the true prophet. ${ }^{31}$

18:19 Immediately following Peter's first denial the scene reverts to the interrogation inside where the high priest questions Jesus about his disciples and his teaching. The author, in another difference to the Synoptic tradition, divides Peter's denials into two accounts, separated by Jesus' response to his interrogators. Stibbe proposes that "this creates a highly ironic scene in which Jesus calls forth his disciples as witnesses at the same time as Peter is denying any knowledge of him." 32 He describes the scenario in terms of dual trials, one of Jesus inside the house and another of Peter outside the house. Stibbe is broadly correct, as witness is a prevalent theme. Nevertheless, Jesus does not call his disciples as witnesses but rather refers to his having "spoken openly to the world" (18:20). Culpepper captures the irony better. Peter's denials, given at precisely the moment when Jesus is interrogated about his disciples, allow the reader to see "what the chief priest cannot: in their present condition the disciples pose no threat to anyone." 33 This irony serves the rejection theme and demonstrates that the phrase "his own people" (1:11) can apply, albeit temporarily, to even his closest followers.

In the following verses, Jesus prevaricates when questioned about his disciples (18:19-20) and is struck in exasperation by a member of the police. His protective manner is reminiscent of how he earlier acquiesced with his arrest to secure the freedom of his disciples (18:8). In doing so,

\footnotetext{
${ }^{29}$ Brown, St John, 2.820.

${ }^{30}$ Witherington, John's Wisdom, 287.

${ }^{31}$ Ellis, Genius, 254.

${ }^{32}$ Stibbe, Storyteller, 97.

${ }^{33}$ Culpepper, Anatomy, 175.
} 
Jesus practically demonstrates another of his major propositional statements: 'E $\gamma \omega \dot{\omega}$ cंuı ó

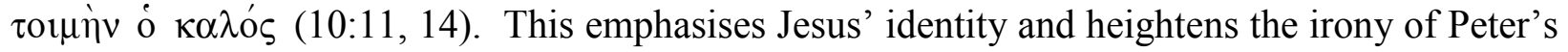
denial. The reaction of the high priest and his retainers will feature later as "the slap is one of two found in the story (see also 19:3); both take place as the truth has been proclaimed but rejected by this gesture." 34 While there is potential for a minor irony in Jesus being punished for telling the truth, this is dissipated by Jesus overtly making this point in v.23. The author removes the irony here so that it can set the stage for deeper irony when he uses repetition of this act later in the narrative.

18:26 Peter's last denial is made to one of the high priest's slaves. However, with Johannine exactitude, the author notes that this slave was a relative of Malchus, whose ear Peter had removed in the garden. Lincoln discerns dramatic irony in that "with reckless boldness Peter had attempted to defend Jesus by using the sword against Malchus in the garden, but now he denies being there and the person before whom he does so is a relative of the same Malchus." 35 This is a weak situational irony.

The greater ironic association to Peter's denials is his precipitous statement that he would die for Jesus in 13:37. However, the locus of the irony is in the statement not the denials. Brant offers a different perspective on the denials by proposing that Peter is not acting as an alazōn. Instead, "Peter manifests traits of the mōros, who is deficient in intellect or understanding and so commits rash and impulsive or absurd acts. In Greco-Roman theatre, the morros is the secondary character who imitates the actions of the principal character and misunderstands or reacts inappropriately." 36 Unlike the alazōn and eirōn, the mōros ( $\mu \omega \rho$ ó $_{-}$" "fool") is not primarily an ironic figure because there is no incongruity between who he or she is and who they claim to be. This does not affect the ironies proposed above, which are dependent on the juxtaposition of Jesus' response and the identity of the servant, not Peter's status as alazōn. Instead, this observation may explain why Peter's betrayal is distinguishable from that of Judas. However, Brant does not fully make the case for Peter as a mōros. It is conceivable that as an historical individual, his character was too mercurial and complex to fit such a stock characterisation.

\footnotetext{
${ }^{34}$ Moloney, Resurrection, 103.

${ }^{35}$ Lincoln, Saint John, 455.

${ }^{36}$ Brant, John, 233-234. Brant is undoubtedly correct that Peter is not an alazōn. At times he incongruously boasts like an alazōn, but in the end he is what he claims to be: a disciple (albeit, not always a successful one). Notably, his mistakes such as those at 13:8-9 are based on over-enthusiasm resulting from a genuine understanding of Jesus' identity (6:69). Furthermore, his brief forays into hubris do not warrant punishment in the narrative. The author does not mention Peter's bitter tears (Luke 22:68) and he is fully restored in 21:15-19.
} 
There is a further irony in 18:26 that many comment on in general terms but surprisingly do not identify as ironic. There is at least a medium irony in the fact that although Jesus could not be justly convicted for a crime, Peter could be. ${ }^{37}$ Furthermore, "the charge that Peter had drawn a weapon and injured a servant of the high priest was, in fact, more serious than his being a disciple of Jesus." 38 Thus there is a situational irony in that the innocent is unjustly convicted inside whilst the guilty escapes justice outside.

\section{Act iii}

a) Scene 1

18:28 The formal trial before Pilate opens with a well-attested irony that has been described as "formidable," “weighty," “terrible," and “characteristically Johannine.,"39 Jesus' Jewish opponents take him from Caiaphas to Pilate's headquarters but refuse to enter to avoid ritual defilement. This necessitates Pilate coming out to them. Morris labels the irony that they are scrupulous about a ritual defilement that would prevent them from keeping a feast on the due date but not at all concerned about taking part in an act of judicial murder, "a curious commentary on human nature". ${ }^{40} \mathrm{He}$ adds that it is characteristic of Johannine irony that the author simply mentions the fact without stopping to draw out its implications. Brown notes a secondary ironic element in that they will make use of a Gentile to destroy their adversary, but they will not deign to enter the Gentile's house. ${ }^{41}$ He continues with a third aspect that is more speculative. "Implicitly there may be another element of irony: they fear that ritual impurity will prevent their eating the Passover lamb, but unwittingly they are delivering up to death him who is the Lamb of God $(1: 29,36)$ and thus making possible the true Passover."42 The author accordingly demonstrates that a rejection of Jesus inevitably results in ironically incongruent behaviour.

\footnotetext{
${ }^{37}$ Keener, John, 1096.

${ }^{38}$ Moloney, John, 491.

${ }^{39}$ Carson, John, 589; Duke, Irony, 127-128; Kruse, John, 358; Barrett, St. John, 532-533, respectively.

${ }^{40}$ Morris, John, 675-676. See also Bultmann, John, 633; Lincoln, Saint John, 460; Sloyan, John, 204; Moloney, John, 494, 497; Zumstein, Saint Jean, 221; Köstenberger, John, 524; Culpepper, Anatomy, 177; Brant, John, 242; Ellis, Genius, 261; F. F. Bruce, The Gospel and Epistles of John (Grand Rapids: Eerdmans, 1983), 349; Klaus Wengst, Das Johannes-evangelium, Theologischer Kommentar zum Neuen Testament 4.1-2. (Stuttgart: Kohlhammer, 2000), 2.235.

${ }^{41}$ Brown, St John, 2.866.

${ }^{42}$ Ibid. Whitacre concurs and adds, "Perhaps most ironic is the fact that their very act is a sin that defiles in this deep sense yet contributes to the cleansing of their sin and the sin of the whole world." Whitacre, John, 438.
} 
The refusal to enter the Praetorium starts the toing and froing that marks the inner structure of the Passion Narrative. The drama now operates on two stages, front and back. The result of the theatrical staging is threefold. First, it enhances the dramatic quality of the narrative. Second, it excludes the opponents from the revelation of truth to Pilate. Finally, and perhaps most significantly, the reader begins to comprehend that as Pilate moves back and forth the author vividly portrays the human predicament in which one must definitively choose between Jesus and the world. ${ }^{43}$ Fittingly, the category of the irony in this verse is misplaced belief and a consequence of their inconsistent scruples is that they will metaphorically remain in the dark, playing the blustering alazōn. The increasingly absurd results of the Jewish opponents' unbelief will be a predominant theme for the formal trial.

18:29 Pilate demands to know what accusation Jesus' opponents bring against him. This request is consistent with Roman judicial practice, which requires a specific charge. ${ }^{44}$ However, since the Roman soldiers could not have been present at the arrest without the express orders of Pilate, it seems unlikely that this is the first Pilate has heard of the matter. There must have been a previous meeting or meetings for the religious authorities to apprise Pilate of their concerns about Jesus as a dangerous subversive and a threat to public order, sufficient to warrant the use of Roman troops. ${ }^{45}$ Accordingly, his request for an accusation catches them off guard and explains their petulant response in 18:30. The formal trial is off to a rocky start and the author will exploit the burgeoning antipathy for multiple ironies.

Keener proposes that an informed audience may "find it ironic that the accusers bring a $\kappa \alpha \tau \eta \gamma о \rho i \alpha \nu$ against Jesus (18:29) yet encounter Moses' law, which they are violating (pace

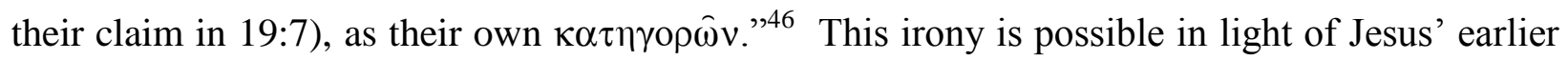
claim that his opponents stand accused by Moses (5:45). However, this requires a percipient reading of the narrative and in the absence of other signals in the text or any of the usual indicators of irony it is difficult to be certain if this irony was intended by the author. Prima facie, Pilate's request is a reasonable and appropriate judicial protocol. The author's intent may therefore be a simple contrast with the subsequent truculent response. Rather than a multi-

\footnotetext{
${ }^{43}$ Duke, Irony, 127. See also Beasley-Murray, John, 327-328.

${ }^{44}$ Lindars, John, 555. Merrill C. Tenney, John, The Expositors Bible Commentary 9, (Grand Rapids: Zondervan, 1981), 174. Keener provides a useful summary of the requirement for a delatores or accuser to bring a charge. Keener, John, 1103-1104.

${ }^{45}$ The consensus is that Pilate was already aware of the issue: Carter, Pilate, 140-141; Beasley-Murray, John, 328; Carson, John, 590; Michaels, John, 313; Ridderbos, John, 589; Thomas Brodie, The Gospel According to John: A Literary and Theological Commentary (Oxford: Oxford University Press, 1993), 532. Contra Schnackenburg, who suggests that Pilate "could hear of it for the first time now." Schnackenburg, St. John, 3.244.

${ }^{46}$ Keener, John, 1104.
} 
layered approach yielding irony, it may be a straightforward signal of the simmering antagonism between Pilate and "the Jews" that will be played out during the rest of the trial. Accordingly, despite this irony's subtle appeal, it is rated as weak.

18:30 Jesus' opponents respond vaguely, with discernible irritation, that Jesus is a criminal. It appears they were expecting Pilate to rubber-stamp their decision. Pilate's previous acquiescence presumably led them to believe that he would ratify the findings of the Sanhedrin and move on to finding a suitable punishment. Pilate's intention to fulfil his legal obligations and hear the facts for himself precipitates a sullen response. Their reply also demonstrates their inability to bring an evidentially sustainable charge against Jesus. Accordingly, the nebulous accusation of criminality rebounds to reflect prejudicially on them rather than Jesus. The reader already knows that Jesus is innocent of their allegations (8:48), and furthermore he is not culpable because he is who they accuse him of pretending to be (10:33).

Moreover, as Duke observes, the author handles this theme of Jesus' relation to sin with consistent irony. Consequently, "the accusers are not only fantastically wrong about Jesus, but are remarkably guilty themselves of the very faults they find in him. ${ }^{, 47}$ It is possible to perceive their allegation as a straightforward lie rather than an ironic reversal, which would result in a low rating in terms of the strength of the irony. This interpretation depends on the intentionality of the speaker; if they are deceitful and therefore consciously wrong this reduces the ironic potential. However, if they believe themselves to be justified and are unconsciously wrong, then the likelihood of irony increases. The presence of the derogatory demonstrative pronoun and the negative participle $m \bar{e}$, which are regular signifiers of irony, supports the latter conclusion. The author's literary wink to the reader suggests once again the unconscious self-betrayal of the alazōn. This irony serves the identity theme, in this case who Jesus is not.

18:31 Pilate instructs the opponents to try Jesus according to their own laws to which they reply they cannot put anyone to death. ${ }^{48}$ Both Pilate's dismissal and their reply feature irony. Duke notes their previous and embarrassing failures to judge Jesus: "The Law of Moses simply will not condemn him. So Pilate's words mock their impotence to kill Jesus; and they themselves are

\footnotetext{
${ }^{47}$ Duke, Irony, 79. Gary Burge, John, The NIV Application Commentary, (Grand Rapids: Zondervan, 2000), 499.

48 "The Romans had deprived the Sanhedrin of all such power. No one knew this better than Annas himself. He knew it to his cost, for he had been deposed by the procurator Valerius Gratus, in A.D. 14, for carrying out capital sentences." Septimus Buss, The Trial of Jesus: Illustrated From Talmud and Roman Law (London: William Clowes, 1906), 100.
} 
more correct than they know in confessing they have no legal ground for the deed."49 This exchange advances the author's ironic purposes in two ways. First, it makes Pilate the unexpected voice of reason. Since Pilate is the only character present in each scene, the author requires him to be able to act in opposition to Jesus and his opponents. Pilate's response shows that he is not unthinking or blind to the intentions of the opponents and thereby encourages the reader to consider carefully his words and their implications. This is not to say that the exchange reflects well on Pilate, whose ulterior motive for his sarcastic reply was undoubtedly to humiliate the Jewish leaders. ${ }^{50}$ However compared to the murderous intent of the opponents, now laid bare, he appears, at least provisionally, judicious. The second purpose is that the author wishes to demonstrate how unbelief and hatred has blinded Jesus' opponents (9:41) and just how far this will eventually drive them (cf. 19:15). ${ }^{51}$ The irony of this verse reflects the ongoing misunderstandings but more importantly establishes the representative characteristics of two of the key players in the trial narrative.

18:32 The narrator intervenes once again to note that the response of the opponents is a fulfilment of Jesus' prophecy as to the type of death he would die. Rather than being stoned at the hands of his compatriots $(10: 31 ; 11: 8)$ he would face a Roman crucifixion. The narrator

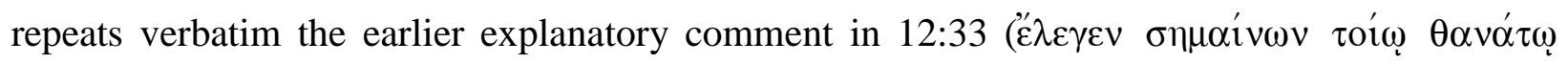
$\dddot{\eta} \mu \varepsilon \lambda \lambda \varepsilon v \alpha \dot{\alpha} \pi \mathrm{o} \theta v \eta \underline{\sigma} \sigma \kappa \varepsilon \imath v)$ in response to Jesus' prediction that when he was lifted up he would draw all people to himself (12:32). By making this connection "the author presents the larger irony of his Gospel" in that Jesus' opponents will have him shamefully crucified to prevent the world from going after him, while conversely he long ago had chosen just such a means of gathering the world unto himself. ${ }^{52}$ The author continues the theme that the divine plan was always that Jesus be lifted up $(3: 14 ; 8: 28 ; 12: 32)$, and accordingly, it is through his death that "the life" will be "the light of all people" and overcome the darkness (cf. 1:4-5). The author demonstrates in the previous sentence that the opponents are acting in bad faith and with malicious intent. In this aside, he shows their actions are ultimately and ironically counterproductive.

b) Scene 2

\footnotetext{
${ }^{49}$ Duke, Irony, 128.

50 "The Pilate disclosed in the historical documents almost certainly acted like this not so much out of any passion for justice as out of the ego-building satisfaction he gained from making the Jewish authorities jump through legal hoops and recognize his authority." Carson, John, 591

${ }^{51}$ Schnackenburg, St. John, 3.245.

${ }^{52}$ Duke, Irony, 128-129. See also, Brown, St John, 2.867.
} 
18:33 Pilate returns to the back stage and Jesus. In accordance with Roman judicial procedure, he must make enquiry of the accused directly. ${ }^{53}$ However, the first words that Pilate addresses to Jesus are highly unconventional. Senior rightly suggests that "as for most of the narrative, only irony provides the key to this scene." ${ }^{, 54}$ Without introduction and unprompted, Pilate poses the question, "Are you the King of the Jews?" The reader is aware that the trial's central issue will be not be Jesus' alleged criminality (18:39) but his claim to kingship. Thus, the narrative abruptly and with archetypal irony progresses from establishing the key characters to the heart of the issue: Jesus' identity. The irony is underscored by Pilate's use of the emphatic personal pronoun $\sigma \dot{v}$. The author juxtaposes the opponent's descent with Jesus' sudden elevation. Despite Nathaniel's proclamation of Jesus as "the King of Israel" (1:49) and the abortive attempt by the crowd "to make him king" (6:15), this is the Gospel's first use of the term "king of the Jews." 55 This sudden development, and the distinctiveness of the expression, has a dramatic effect on the narrative. Culpepper observes that not only is Jesus greater than the Patriarchs, ${ }^{56}$ he is the king of the Jews and "the trial before Pilate spins this irony into a fine and intricate tapestry." 57 Pilate's motives are unresolved at this stage of the narrative and his flat delivery of the question heightens the theological, dramatic and ironic implications. ${ }^{58}$

18:34 Jesus does not answer the question and responds with a question of his own, probing as to whether Pilate's question is his own or one he has heard from others. Through Jesus' question, the author deftly introduces the meta-theme of response. Jesus' first words before Pilate demonstrate that he cares little for the accusations but is intrigued as to what Pilate makes of the situation he now finds himself embroiled in. While some interpreters take the question at face value as a request for information, ${ }^{59}$ Duke proposes that it is better to hear Jesus, who "knew

\footnotetext{
${ }^{53}$ Keener, John, 1109-1110.

${ }^{54}$ Senior, Passion, 152. See also Duke, Irony, 129; Köstenberger, Theology, 155; Zumstein, Saint Jean, 224.

55 But as in many other cases in the Gospel, John is preaching from genuine tradition rather than creating it wholesale for his purposes. The charge, 'King of the Jews' (18:33) is undoubtedly historical." Keener, John, 1111 .

${ }^{56}$ Moses: 1:17; 5:46; Jacob: 4:12; Abraham: 8:56-58.

${ }^{57}$ Culpepper, Anatomy, 172.

${ }^{58}$ Contra Michaels who proposes that "All that happens... is the product of Pilate's sick and anti-Semitic sense of humor. He seems obsessed throughout with the grim joke that Jesus is the Jew's king." Michaels, John, 317. Since this is addressed to Jesus alone at this point it seems unlikely to be an anti-Jewish sentiment. Pilate seems to have had a genuine interest in the details of the case; if only in an official capacity to ascertain political motivation. It is only later that he doggedly continues this point to irritate "the Jews."

${ }^{59}$ Carter thinks that "Jesus' question draws attention to Pilate's alliance with the Jerusalem leaders. Pilate feigns ignorance of and tries to hide the alliance, but the narrative has already uncovered it." Carter, Pilate, 142. This is possible but hardly the question's primary purpose.
} 
what was in man" $(2: 25)$, as speaking ironically. ${ }^{60}$ In a deft reversal, similar to the blind man who asked "the Jews" if they too wanted to become disciples (9:27), Jesus turns the trial on Pilate from the outset. Accordingly, the issue for Pilate is not what the world thinks of Jesus, but what he thinks. Keener takes the irony a stage further and suggests that Jesus may be implying that Pilate's charge is divinely inspired, and he speaks contrary to his own knowledge. ${ }^{61}$

The author's trial motif provides a secondary component of this irony. Jesus' first words to Pilate belong to a pattern by now familiar to a reader, in which the accused becomes the accuser and the one on trial is seen as the judge. ${ }^{62}$ It is possible to interpret Jesus' response as a subdued Johannine equivalent of the Synoptic question: "But who do you say that I am?" (Mark 8:29; Matthew 16:15; Luke 9:20). This fits the prevailing motifs of Jesus' identity and the reverse trial in which questions rebound on the interrogator. However, such an interpretation is uncertain. Most commentators simply observe that Jesus cannot properly answer Pilate's question without understanding the basis upon which Pilate is enquiring. ${ }^{63}$ Furthermore, Jesus' composed manner actively attests his divine sovereignty, to which Pilate has just alluded.

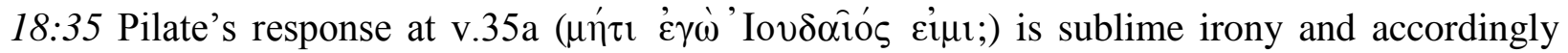
robustly attested. ${ }^{64}$ The author frames Pilate's response as a simple rhetorical question but it resonates with deeper connotations. The obvious meaning is a verbal shrug, a throwaway line designed to distance himself from Jesus and his Jewish opponents. However, the reader is cognisant that the interrogative particle $\mu \eta^{\prime} \imath$, used here to signal that a negative answer is expected, is a frequent indicator of irony, especially when teamed with a rhetorical question. Moreover, as discussed in the previous chapter, the term "the Jews" is an ironic designation, representing the unbelieving world. Consequently, the attentive reader hears: "I am not part of the unbelieving world that rejects you, am I?" The answer to this question is less obvious but will be definitively resolved by the end of the Passion Narrative. Pilate's comment seeks to dissociate him ethnically from the Jewish opponents but the reader recognises that symbolically and ironically he is indistinguishable from them because they represent the world in the dispute between God and the world. Jesus has turned the tables and now Pilate's identity is under question.

\footnotetext{
${ }^{60}$ Duke, Irony, 129.

${ }^{61}$ Keener, John, 1111.

${ }^{62}$ Lincoln, Saint John, 461; Culpepper, Anatomy, C172.

${ }^{63}$ E.g. Köstenberger, John, 528; Carson, John, 593.

${ }^{64}$ See Lincoln, Saint John, 461-462; Köstenberger, John, 528; Brodie, John, 534; Carson, John, 593; Duke, Irony, 129-130.
} 
Pilate's ironic assimilation into the designation "the Jews" is nothing short of dramatic genius. The Passion Narrative is the thematic climax of the characterisation of "the Jews" and this verse can be considered as its ironic punch line. ${ }^{65}$ This enigmatic group that has drifted in and out of the narrative, sometimes positively but frequently negatively, will conclude its journey in a final and firm rejection of Jesus. Just as their response becomes increasingly clear so does their composition. Their embodiment of the unbelieving world, presaged in 1:10-11, is made certain by counting Pilate amongst their numbers. Notably, since Jesus was taken to the Praetorium his opponents have remained anonymous behind plural pronouns, but from this juncture, they are openly named as "the Jews." 66 Furthermore, as we observed in Chapter 2, a key component of irony is the conscious pleasure of awareness of the contrast between appearance and reality. ${ }^{67}$ For the reader these resolutions are a satisfying reward for paying attention to the author's multilayered narrative. Enjoyment is subjective, but it is hard to imagine a reader not finding pleasure in the adroit unveiling of Pilate as a brash alazōn, in reality no different from the Jewish opponents he is condescendingly taunting. This revelation of Pilate's true identity equips the reader with the interpretive keys to make sense of the trial's upcoming ironies and resolves some of the narrative's hitherto unanswered questions as to the nature and composition of "the Jews."

In typical Johannine fashion, there are layers within the layers. Duke suggests that "given Pilate's designation of Jesus as 'King of the Jews,' the question 'Am I a Jew?' hints at the deeper question, 'Are you my king?",68 This ironic reinterpretation of the king motif will continue as Pilate returns to this term repeatedly. Additionally, while Pilate and "the Jews" are identical in representative terms they continue to spar acrimoniously during the trial. Although Pilate is ostensibly the one with all the authority, his true allegiances will undermine all his efforts to resist until he is forced, incrementally and ironically, to carry out the will of "the Jews." During the course of the trial, the distance between Pilate and the Jews diminishes, both physically and ideologically. ${ }^{69}$ Primarily, this is because both groups place political interests before all else, including the truth. Their differing political agendas mean that while they are united in their rejection of Jesus, they also reject each other. ${ }^{70}$

\footnotetext{
${ }^{65}$ Notably the expression "the Jews" will not be used again after the Passion Narrative; with the exception of a minor, generic use at 20:19.

${ }^{66}$ At least, until the crux of the trial when the religious authorities are reintroduced.

${ }^{67}$ Muecke, Irony, 33-54.

${ }^{68}$ Duke, Irony, 129-130.

${ }^{69}$ O’Day, John, 175.

70 This distinction is another reason why the narrator reminds the reader of the political agenda of the religious authorities at 18:14 (cf. 11:48-53).
} 
18:37 Jesus responds with his first substantive answer. He affirms that that he is a king but that his "kingdom is not from here" (18:36). Pilate retorts but his words are indistinct. A reader may perceive them as: a statement, "If you have a kingdom you are a king"; or as a question, "So you are a king then?"; or alternatively as irony (with more than a hint of sarcasm), "So then, it is a king that you are!" Morris suggests that the retort is most likely a question but even so, it is more than a simple request for information and therefore contains a note of irony. ${ }^{71}$ Very few scholars comment on this irony, though it features numerous ironic indicators. It contains the emphatic use of the pronoun su ("So YOU are a king?"), an unanswered question, upper and lower concepts of kingdom (similar to dialogue with Nicodemus), misunderstanding (emphasised by next verse), repetition of a previous phrase in Jesus' rejoinder, and the use of oun to link. If the phrase is an ironic question then over-confidence is also present. Pilate's words also speaks powerfully to the Gospel's core question - who is Jesus really? Although poorly attested to, this has all the features of classic Johannine irony.

Jesus' surprisingly fulsome response includes the only reference to his birth in the Gospel. The author draws a direct connection between Jesus' origin and his mission "to testify to the truth." Furthermore, the author also explicitly links this to his kingship, to the point that they are indistinguishable. Thus, Carson notes that for John truth is understood in more than an intellectual sense; "it is nothing less than the self-disclosure of God in his Son, who is the truth (14:6)." ${ }^{, 72}$ He surmises that disclosing the truth of God is Jesus' principal way of making subjects and exercising his saving kingship. This explains why the Johannine truth theme is so pervasive and important to the narrative. The profundity of Jesus' response cannot be overemphasised, as it is the only example in the Gospel where all three aspects of the truth theme occur simultaneously. It contains explicit truth statements (twice), the use of an implicit truth statement (i.e. witness language, $\mu \alpha \rho \tau \nu \rho \eta \dot{\sigma} \sigma \omega),{ }^{73}$ and propositional statements (regarding revelation, identity and response). ${ }^{74}$ As noted in Chapter 3, this sets up the dialogue for one of the defining ironies of the Fourth Gospel, the only place in the narrative where a direct truth statement and irony coexist.

\footnotetext{
${ }^{71}$ Morris, John, 680-681.

${ }^{72}$ Carson, John, 594-595.

73 "Its distinctiveness is shown in that no other mission statement in the narrative is given such emphasis (cf. e.g. $6.38 ; 10.10 ; 12.46)$. Jesus' mission in this world can be summed up in terms of witness and truth." Lincoln, Saint John, 463.

${ }^{74}$ Furthermore, the propositional truths here are not peripheral; they encompass Painter's two meta-themes and the Gospel's most prevalent ironic theme.
} 
18:38 Pilate responds to Jesus' forthright and weighty revelation with an indecipherable $\tau$ ' $\hat{\varepsilon} \sigma \tau \iota v$ $\dot{\alpha} \lambda \eta^{\prime} \theta \varepsilon 1 \alpha$; in one of the Gospel's most important and commonly remarked on ironies. ${ }^{75}$ The author leaves the reader to ponder what Pilate meant by this. Is it dismissive: "Who knows?" Sarcastic: "As if you would know the truth." Engaging: "Tell me more about truth?" Alternatively, is it philosophical: "Is truth even knowable?" Each option has proponents. However, the fact that Pilate does not stay for an answer militates against the latter two. Accordingly, most commentators see the question as flippant rather than sincere. The potency of this irony is not dependent on which interpretation is favoured. The irony of this scene is that Pilate asks this question of the incarnate Truth (14:6). Witherington observes, "Pilate is shown not to be a real truth seeker; indeed, the real irony is that he does not perceive truth with a capital $\mathrm{T}$ when he is standing right before him in the flesh." "76 The author has prepared the reader from the Prologue to know that the real question is not "What is truth?" but "Who is truth?" This question, following on from v.35, reveals that not only does Pilate not know who he is; he has no comprehension of who Jesus is. Accordingly, this irony is a potent pronouncement on the identity theme.

A case can be made that a significant part of the narrative has been heading to this central ironic question. $^{77}$ The rejection of Jesus has been the subject of the Prologue's chiastic heart and metairony (1:10-11) and this is the moment in which the world's rejection is fully made manifest. Pilate looks Jesus in the face, receives divine revelation and turns away with a flippant remark. The reader is aware that no matter how sympathetic Pilate is to Jesus, and indeed the next sentence is Pilate's first proclamation of Jesus' innocence, it will make no difference. ${ }^{78}$ Pilate has decisively rejected the truth. Tragically, not just $a$ truth, but a rejection of the very embodiment of truth. Consequently, the truth will not make him free (cf. 8:31-32). Pilate's rejection of Jesus now shackles him to the inevitable consequences. As the narrative will show, he becomes increasingly powerless and progressively more aligned to the very Jewish opponents

\footnotetext{
75 "It is hard to imagine a more profound question with more momentous consequences." Köstenberger, Truth, 33. See also Culpepper, Anatomy, 172, 176; Hamid-Khani, Revelation, 82, 216; Ellis, Genius, 9, 248; Duke Irony, 130-131; Lincoln, Saint John, 463; Köstenberger, Theology, 155; Keener, John, 1114; Scott M. Lewis, The Gospel According to John, New Collegeville Bible Commentary, (Collegeville: Liturgical Press, 2005), 91; Matthew L. Skinner, The Trial Narratives (Louisville: John Knox, 2010), 103.

${ }^{76}$ Witherington, John's Wisdom, 292.

77 "The instances of alêtheia in 18:37-38, then, provide some closure to the presentation of truth in the Johannine narrative... Quite likely, the three references to truth in 18:36-38 constitute an inclusio with the three references to grace and truth in 1:14-17." Köstenberger, Truth, 45.

78 "As in the Synoptic Gospels, Pilate is represented as not unfriendly to Jesus; he does not wish to put him to death, and he sees that he is the victim if a Jewish plot. Yet sympathy is, in John's mind, a quite inadequate attitude to Jesus; like Nicodemus (7.50f.), Pilate for all his fair play and open-mindedness is not of the truth; he is of this world." Barrett, St John, 538.
} 
that he so despises. The crucial moment of decision has now passed and the rest of the Passion Narrative involves the characters playing out their representative roles to their fateful conclusion.

The reader is aware, however, that this outcome is nevertheless part of the divine plan. In order for Jesus to be glorified he must first be lifted up (3:14, 8:28, 12:32-34) and, as the Prologue foreshadowed, Jesus' glory is the revelation of grace and truth (1:14). This means that Jesus' interaction with Pilate was part of his ordained path. Pilate, in representing the world, had to look truth in the face and walk away from it for the plan to succeed. Pilate obliges in a manner that is not just uncomprehending but ironically over-confident and arrogant. He becomes an alazōn of the first order. The reader can now render judgment in the reverse trial; Pilate has been examined and found wanting. Conversely, Jesus is found faithful, and the outcome will be that for the disciples of Jesus "pain will turn to joy" $(16: 20,22)$ and the world gains the chance for "eternal life" $(3: 15,16,36 ; 4: 14 ; 5: 24 ; 6: 27,40,47 ; 10: 28 ; 17: 2-3)$.

Whether Pilate affords Jesus no opportunity to reply or Jesus chooses to remain silent, the narrative will nonetheless provide a reply to Pilate's question. The author "records no answer in words, but the whole of the following narrative of the death and resurrection of Jesus is John's answer in action."79 The narrative reveals that it is on the cross and at the empty tomb that we learn what God's truth is. The author therefore connects his ongoing truth theme to the cross, in terms of revealing both its soteriological and Christological functions. "What is truth?" ranks only behind "Who is Jesus?" as the Gospel's most important questions. From the Prologue, these questions have been linked, and it is in the Passion Narrative that they find their ultimate expression.

Throughout the wider narrative, but more so in the Passion Narrative, the author demonstrates that truth is a personal matter, for Jesus and for the reader. The author makes it apparent that "it is Jesus who represents the truth in his very own person, and it is he who calls people to respond to him in faith. People's rejection of the truth, likewise, manifests itself in their rejection, not of a set of abstract propositions, but of Jesus." 80 The author skilfully develops this theme in the narrative and then explicitly states it in 20:31. Through Pilate's example, the author warns the reader of the consequences of compromise in relation to Jesus' identity. Culpepper notes that "the reader who tries to temporize or escape through the gate of indecision will find Pilate as his

\footnotetext{
${ }^{79}$ Morris, John, 682.

${ }^{80}$ Köstenberger, Truth, 59.
} 
companion along that path." 81 Pilate's question therefore "remains open-ended, and still rings through the ages, calling for an answer from every reader of the Gospel." 82

Pilate's first of three exonerations of Jesus creates a secondary irony. Pilate explicitly states, "I find no case against him" (v.38b). Pilate is, ostensibly, the judge and so this should be the end of the matter. However, just as the rejection of Jesus by the Jewish opponents leads to their incongruent behaviour, Pilate now finds himself hamstrung. The Johannine motif of the inevitable descent of Jesus' opponents again comes to the fore in Pilate's descent into deeper complicity in Jesus' execution while simultaneously and steadfastly protesting his innocence. The ironic inconsistency between his view of Jesus' innocence and the outcome that he presides over, reminds the reader that while the truth may set you free (8:31-32), the rejection of the truth binds an individual to increasingly inappropriate responses.

Köstenberger, following Miroslav Volf, perceives "an even more striking irony” predicated on notions of truth in the trial. ${ }^{83}$ Trials are usually about determining facts and dispensing justice; however, in this trial both the accusers and now the judge have demonstrated that they have no respect for the truth. Volf notes that for Jesus' opponents and Pilate the truth is irrelevant because it works at cross-purposes to their hold on power. ${ }^{84}$ Ironically, it fell to the accused to remind the judge of the importance of truth to the proceedings. This is indeed a fine situational irony, but it is subordinate in both quality and thematic significance to the central irony. Nonetheless, Köstenberger adds value in drawing out the author's implicit commentary on the power of truth: "Truth has a power of its own, a power that in the long run proves stronger than the usurped authority of institutional power. Jesus embodies this hope, the hope of the ultimate triumph of truth in the reign of his kingdom." ${ }^{85}$ This emphasises how the Johannine notion of truth is personal and heuristic rather than impersonal and deterministic.

\footnotetext{
${ }^{81}$ Culpepper, Anatomy, 143.

${ }^{82}$ Köstenberger, Truth, 45.

${ }^{83}$ Köstenberger, Truth, 58.

${ }^{84}$ Miroslav Volf, Exclusion and Embrace: A Theological Exploration of Identity, Otherness, and Reconciliation (Nashville: Abingdon, 1996), 266. "Volf's entire discussion of Jesus' trial before Pilate (entitled "Jesus Before Pilate: Truth Against Power") on pp. 264-71 repays careful reading.” Köstenberger, Truth, 58.

${ }^{85}$ Köstenberger, Truth, 62.
} 
18:39 Pilate moves to the outer stage and offers to release a prisoner at the Passover, presenting Jesus as a candidate. He again uses the title "king of the Jews," but on this occasion, it is in front of "the Jews" for the first time. This causes some to place the locus of the title's irony in this verse. ${ }^{86}$ Since the term is not only true but also an underestimation of Jesus' kingship, it is an ironic expression. However, Pilate's decision to use it here also creates a situational irony. Pilate's motive is once again difficult to interpret. It is unlikely he is insulting Jesus, whom he has just declared innocent and by raising the amnesty is seeking to free. However, if he intends it as an insult to "the Jews," he is hardly helping Jesus' cause, thereby demonstrating ambivalence towards a just outcome for Jesus. Duke notes that "Dramatically, the phrase does force 'the Jews' to make their choice about Jesus with the sound of his rightful title over them ringing in their ears." ${ }^{\circ 7}$ While there is no historical evidence for a Passover amnesty (as described in all the Gospels), Blinzer notes that Roman law permitted two kinds of amnesty: abolitio (acquitting a prisoner before trial) and indulgentia (pardoning a convicted criminal). ${ }^{88}$ Furthermore, historical accounts record that Governors like Pilate had the delegated authority to issue amnesties and regularly freed prisoners (often en masse) on local feasts. ${ }^{89}$

18:40 "The Jews" spurn Pilate's offer to release Jesus and they demand the release of Barabbas, a bandit. The irony in this scene is captivating, multi-layered and well supported. ${ }^{90}$ Since Pilate has just accorded Jesus the title "king of the Jews," in the first instance this is an ironic rejection of their true king. Moreover, in asking for Barabbas "the Jews" reveal their own ambivalence to the truth in that immediately after falsely denouncing Jesus as a criminal they ask for the release of a real criminal. The narrator's description of Barabbas as a bandit ( $\lambda \eta \sigma \eta \dot{\eta} \varsigma)$ recalls the Gospel's earlier use of the term, in 10:1, 8, where Jesus contrasts the bandit to the good shepherd. Now "the Jews" prefer the bandit who enters the sheepfold surreptitiously "to steal and kill" to the good shepherd who came "that they may have life, and have it abundantly" (10:10). Accordingly, this is also a rejection of one of Jesus' "I am" propositional statements, for which his credentials were established earlier in the Passion account (18:19).

\footnotetext{
${ }^{86}$ E.g. Burge, John, 501; Zumstein, Saint Jean, 229.

${ }^{87}$ Duke, Irony, 131.

${ }^{88}$ Josef Blinzer, The Trial of Jesus trans. Isabel and Florence McHugh, (Westminster: Newman, 1959), $207-208$.

${ }^{89}$ For a good summary of these historical accounts see, Keener, John, 1116-1117.

90 See Bultmann, John, 657-658; Kruse; John, 361; Köstenberger, John, 530; Culpepper, Anatomy, 172, 177; Keener, John, 1118; Duke, Irony, 131; Lincoln, Saint John, 464-465; Zumstein, Saint Jean, 228, 229; Burge, John, 502; Carson, John, 596; Beasley-Murray, John, 333; Brown, John, 872; Brant, John, 245.
} 
Others perceive a further irony in Barabbas' name, which means "son of the father." The reader is used to Jesus constantly being referred to as "the Son"91 and the incongruity of the "the Jews" rejecting the true Son of the Father for this other "son" is tragically ironic. ${ }^{92}$ Finally, Carter proposes that in preferring Barabbas, "the Jews" hold an impromptu referendum on their preferred means of opposition to the Roman Empire. He describes their options as violence against it or its demise at Jesus' return. Ironically, “they opt for violence, a form of resistance that Rome has shown it can overcome!"93 This verse resonates with strong, multifaceted irony relating to the identity of Jesus and the misplaced beliefs of his Jewish opponents.

d) Scene 4

19:1-3 Pilate, having failed to gain abolitio for Jesus, changes tack. He has Jesus flogged. During this process, the soldiers place a crown of thorns on his head, dress him in a purple robe and whilst striking him, hail him as "King of the Jews" (19:3). This sadistic and sarcastic treatment of a prisoner has historical precedence in the Roman soldier's game of "mock king."94 The situational ironies of this tableau were obvious as early as the patristic era, even if not addressed in rhetorical terms. Cyril states that "they dressed him in purple, partly in mockery, partly prophetically, for he was a king. Though they were acting mainly for their own amusement, still they did it, and it was a sign of his royal dignity." 95 Contemporary scholars concur and this irony is robustly attested. ${ }^{96}$

Apart from the slap by the police at $18: 22$, this is the only moment of degradation prior to the cross. It is significant that the author places this event at the chiastic heart of the narrative. This is in contrast to Mark 15:16-20 and Matthew 27:27-31, where this scene is last in sequence before the crucifixion. Notably, the Johannine account avoids the Synoptic description of the

\footnotetext{
${ }^{91}$ Son of God: $1: 14,18,34,45 ; 3: 16-18,35-36 ; 5: 19-23,25-26 ; 6: 40 ; 8: 36 ; 10: 36 ; 11: 4,27 ; 14: 13 ; 17: 1$. Son of Man: $1: 51 ; 3: 13-14 ; 5: 27 ; 6: 27,53,62 ; 8: 28 ; 9: 35 ; 12: 23,34 ; 13: 31$

${ }^{92}$ Ellis, Genius, 263.

${ }^{93}$ Carter, Pilate, 145.

94 "Many scholars make allusion to the game of 'mock king' played by soldiers during the Roman Saturnalia, and it is interesting that on the stone pavement of the fortress Antonia (Note on xix 13) there are scratching pertinent to this game made by Roman legionnaires quartered there. None of these parallels is perfect but they do indicate that the mockery described in the Gospels would not have been strange.” Brown, St. John, 2.888-889.

${ }^{95}$ Cyril, "Homily on the Paralytic by the Pool," in Cyril of Jerusalem trans. Edward Yarnold, ed. Carol Harrison (London: Routledge, 2000), 75.

${ }^{96}$ Moloney, John, 495, 499; Carson, John, 598; George W. MacRae, Invitation to John (New York: Doubleday, 1978), 208; Keener, John, 1118-1123; Lincoln, Saint John, 458, 465; Morris, John, 700-701; Neyrey, John, 306; Brown, John, 889; Duke, Irony, 131-132; Adeline Fehribach The Women in the Life of the Bridegroom: A Feminist Historical-Literary Analysis of the Female Characters in the Fourth Gospel (Collegeville: Liturgical Press, 1998), 123-124; Kanagaraj, John, 25; Ellis, Genius, 9.
} 
soldiers' actions as "mockery." 97 The author perpetuates the emphasis on Jesus' sovereignty and continues to downplay the shameful elements of the Passion Narrative. ${ }^{98}$ Moreover, unlike the Synoptic tradition John's account makes no specific mention of the removal of the symbols of kingship, ${ }^{99}$ which means that in the Johannine narrative Jesus proceeds to the cross still dressed and crowned as a king. ${ }^{100}$ This scene reminds the readers that in the Prologue the authoritative voice of the narrator both proclaims Jesus and prophesies his rejection. In the Prologue's chiastic centrepiece (and meta-irony), the rejection is by the world and his own people (1:1011). ${ }^{101}$ In the chiastic centrepiece of the Passion Narrative, the world violently rejects Jesus, at the instigation of his own people, while ironically proclaiming his rightful title. The author's skilful handling of this event achieves the difficult task of simultaneously acknowledging the shameful rejection of the world while also reinforcing Jesus' kingship.

The crux of the irony is that the soldiers speak better than they know. Irony of self-betrayal is one of the author's favourite rhetorical stratagems; however, this scenario is slightly different in that this irony inverts the soldiers' own irony. ${ }^{102}$ The dual ironies may be another reason why the author may have chosen to emphasise this scene. Many scholars have commented on the similarities between this incident and the formal elements of a king's consecration. Malina and Rohrbaugh list the crowning and homage (19:1-3); the proclamation (19:4-5); the acclamation (19:6-7); the enthronement (19:13-16); the naming and title (19:19-22) and eventually a royal burial (19:38-42). ${ }^{103}$ That the author intended this scene as an ironic status-elevation ceremony is persuasive, irrespective of the doubts of some scholars whether all six elements are present. ${ }^{104}$ As Duke suggests, the key components are present; Pilate provides the proclamation of the king to his people and then the soldiers brutally conduct the enthroning and investiture. ${ }^{105}$ After the scourging the narrative tone changes and the emphasis falls less on Jesus' reign and more on the rejection of that reign, which further underscores the centrality of this ironic crowning to the narrative. ${ }^{106}$

\footnotetext{
${ }^{97}$ Mark 15:20; Matthew 27:29, 31; Luke 22:63, 23:11.

98 The shame is downplayed but not eradicated. "Especially it is noteworthy that, for all his emphasis on Jesus' honor, John mostly reinterprets rather than removes symbols of shame in the tradition." Keener, John, 1073.

${ }^{99}$ Mark 15:20; Matthew 27:31.

${ }^{100}$ See Moloney, Resurrection, 104.

101 The second part of the Prologues centrepiece, the positive response has no counterpart in the trial narrative, which focuses only on rejection.

${ }^{102}$ Keener, John, 1123.

${ }^{103}$ Malina, Social-Science, 249.

${ }^{104}$ Keener is not entirely convinced by elements 4 and 6 but comments that all are ironic. Keener, John, 1120 .

105 Duke, Irony, 132.

${ }^{106}$ Brodie, John, 536.
} 
There is a subsidiary situational irony in the mention of the soldiers striking Jesus on the face (19:3). The repetition of the noun $\rho \alpha \pi t \sigma \mu \alpha$ ("a blow or slap to the face") connects this verse with the Gospel's only other use of the term in 18:22. In both scenarios, at the same time the truth is pronounced, an underling strikes Jesus on the face. In 18:22, Jesus speaks the truth whereas in 19:3 the soldiers ironically proclaim his true title. The irony, that they will punish Jesus for falsely claiming what the reader knows to be true, mirrors the overarching irony that the punishment of the cross will fall on the only person who does not deserve it. Truth personified (14:6) and the one who came into the world to testify to the truth (18:37) will be put to death by the lies of the world he did not come to condemn but to save (3:17). ${ }^{107}$

\section{e) Scene 5}

19:5 Pilate proclaims Jesus' innocence for a second time (19:4) and then produces Jesus, who the narrator notes "came out, wearing the crown of thorns and the purple robe" (91:5). This reinforces and continues the irony of 19:3. Pilate then presents the scourged Jesus with the

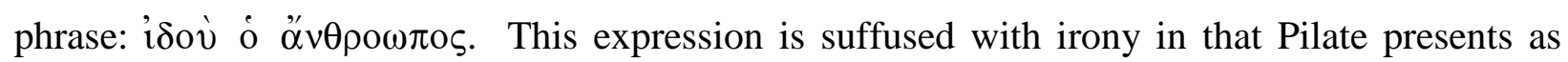
harmless and somewhat ridiculous the man that "the Jews" and religious authorities have described as dangerous and threatening. ${ }^{108}$ This is the culmination of the Gospel's theme of unintentional depreciation associated with descriptions of Jesus as "a man," which, as Culpepper notes, invariably signals irony. ${ }^{109}$ By use of this term, Pilate mocks Jesus, possibly with the intention of evoking sympathy and securing his release. However, the term also mocks the opponents - this mere man, bedraggled and bleeding, a pitiful sight is by Pilate's constant assertion their king.

The reader could perceive a deeper level of irony here in that the "Son of Man" is a term that Jesus has consistently used to refer to himself $(1: 51 ; 3: 13-14 ; 5: 27 ; 6: 27 ; 53,62 ; 8: 28 ; 9: 35$; 12:23, 13:31). The designation here calls to mind the narrator's description of Jesus as the "the Word made flesh" (1:14). Duke's analysis is insightful:

\footnotetext{
${ }^{107}$ The corollary to v.17 that those who reject Jesus' identity (i.e. "have not believed in in the name of the only Son of God," cf. v.18) are "condemned already," presages the forensic theme that those who presume to judge Jesus bring judgment upon themselves.

108 Carson describes the phrase as "dripping irony." Carson, John, 598. See also Keener, John, 1123-1124; MacRae, Theology and Irony, 92; Köstenberger, John, 533; Duke, Irony, 106-107; Culpepper, Anatomy, 171-172, 177; Neyrey, John, 14; Lincoln, Saint John, 466; Hamid-Khani, Revelation, 75; Kanagaraj, John, 25; Zumstein, Saint Jean, 231; Brown, John, 890; Ellis, Genius, 248; Johnston, Ecce Homo, 126.

${ }^{109}$ Culpepper, Anatomy, 171.
} 
There is more at work here than Pilate's intended sarcasm or appeal for pity: the author permits Pilate to say more than he knows. Such a conclusion seems obvious in view of the heavily ironic context of the trial, the statement's parallel structure and proximity to $18: 39$ ("King of the Jews"), and its parallel to 19:14 ("Behold your King!"). As we will see, the whole trial might be viewed as an ironic enactment of a king's enthronement. In this scheme of things, the proclamation, "Behold the man!" becomes "a title, a throne-name given to the "King of the Jews." . ...that evokes for the reader a vision of "heaven opened, and the angels of God ascending and descending upon the Son of man" (1:51). Thus in three devastating words the author has crystallized a great depth of ironic truth which no direct utterance could convey. ${ }^{110}$

Other commentators note possible Old Testament allusions. ${ }^{111}$ The most commonly attested reference is to Samuel's introduction of Saul. In the Septuagint this is translated as, "Here is the

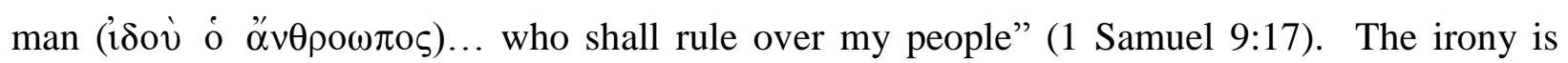
striking, in that Pilate's mockery of Jesus and of Jewish notions of kingship employs the words used of Israel's first king, thereby reinforcing Jesus' identity as "King of the Jews." "112 While the tone of the main narrative changes to emphasise the rejection of Jesus, the ironic undertone proclaiming Jesus' true identity continues unabated. Notably, Pilate will not describe Jesus as a "man" again; instead he will return to addressing Jesus as "the King of the Jews" $(19: 14,15,19)$.

19:6 It is at this juncture that the identity of the opponents switches from that of "the Jews" to the chief priests and their functionaries, the police. Their response to Pilate is an unequivocal and repeated demand to "crucify him," a call the author did not want to come from "the Jews" due to their representative character. Pilate's response is to pronounce Jesus' innocence again and to refuse the demand of the Jews with "wrathful irony."113 The repetition of the phrase "I find no case against him" $(18: 38,19: 4,6)$ signals ironically that Pilate's attempts to release Jesus are not as benevolent as they appear. As the judge in the case, he could simply discharge Jesus based on his findings of Jesus' innocence, which he repeats here for the third and final time. Instead, he is playing a political game with his opponents. However, by allowing himself to be drawn into a discussion and by appealing to their sympathy, he has already lost. In addition to

\footnotetext{
${ }^{110}$ Duke, Irony, 106-107.

${ }^{111}$ E.g. Daniel 7:13-14; Zechariah 6:11 (cf. Barrett, St John, 541).

112 See Lincoln, Saint John, 466.

113 Bultmann, John, 659. See also Hamid-Khani, Revelation, 216; Duke Irony, 132-133; Keener, John, 1133; Westcott, St. John, 269.
} 
the irony of Pilate's sarcastic reply, which he knows full well they are not capable of, there is also the continuing irony of Jesus' imminent conviction and execution despite continual proclamations of his innocence by no less than the judge in the case. Jesus will go to the cross despite consistent and repeated statements providing the truth concerning his identity and lack of guilt.

19:7 With the pejorative cry of "crucify him" out of the way the author immediately switches back to "the Jews." Perceiving that they have angered Pilate they drop the pretence that Jesus is a political criminal and reveal that their charges are grounded in religious concerns. Jesus must die because he has claimed to be "the Son of God." As Keener observes, "The greatest irony, however, is the claim that the law demands Jesus' execution for claiming to be God's Son (19:7) when in fact the rest of the Gospel demonstrates that Jesus provided ample evidence that he was God's Son (10:34-38) and that the law supported his claims against theirs (e.g., 5:45-47)."114 The reader is aware that while all the other charges were false this one, the one upon which he will be convicted and executed, is ironically true.

The use of the disputed designation "Son of God," for the first time in the Gospel by Jesus' opponents, completes a reversal of the titles accorded Jesus at the end the first chapter, where in a "crescendo of belief," Jesus is referred to as the "Son of God" $(1: 34,49)$, "King of Israel" (1:49), and "Son of Man" (1:51). ${ }^{115}$ The Passion Narrative returns to these titles and within seven sentences he is called the "King of the Jews" (19:3), "the man" (19:5), and "the Son of God" (19:7). However, this time the titles are reapplied either to mock or to deny their validity. The reader cannot fail but notice the irony as the trial turns into a crescendo of disbelief.

\section{f) Scene 6}

19:8-9 Pilate's reaction to the description of Jesus as "the Son of God" is to recoil in superstitious fear. Sons of the gods were something the Roman world understood, divine men who acted as messengers for the gods. ${ }^{116}$ It was not wise to get on the wrong side of them and certainly not to have just flogged one! Pilate's fear prompts him to ask the question that he should have asked first, "Where are you from?" Jesus' provenance continues to be one of the

\footnotetext{
${ }^{114}$ Keener, John, 1123. See also Moloney, John, 499; Culpepper, Anatomy, 177.

115 Duke, Irony, 133. See also, Brown, St. John, 2.891.

${ }^{116}$ Witherington, John's Wisdom, 293.
} 
"ironically ambiguous themes" in the narrative. ${ }^{117}$ Conditioned by the revelations of the Prologue and the use of $\pi$ ó $\theta \varepsilon v$ ("from where") in 7:27-8, 8:14, and 9:29-30, the reader knows by now that the appropriate answer is "from God." The use of the term $\alpha \nu \omega \theta \varepsilon v$, ("from above"), in the ensuing dialogue in v.11 would further refresh their memory. There is also significant irony in that Pilate, the judge, is afraid of Jesus, the accused. This reinforces the notion that in dramatic reversal it is both Pilate and Jesus' opponents that are on trial. There is also further irony in that a pagan Roman proves more willing to believe that there is something divine about Jesus than are his own people. ${ }^{118}$

19:10-11 Jesus provides no answer ${ }^{19}$ and an exasperated Pilate attempts to lecture him on worldly power structures. Jesus explains that real power can only come $\alpha^{\prime} v \omega \theta \varepsilon v(19: 11)$. The situational irony is that while Pilate claims the power to release Jesus, the reader has come to realise that he does not. The truth is that while theoretically he has such power, practically he is "bound by his own sins and by the political commitments he had made."120 Pilate is above all a political beast, which binds him to the local authorities and ultimately to the capricious will of Caesar who could take away all his power, as indeed occurred a few years later. ${ }^{121}$ Ironically, everything Pilate says is correct (when seen from below) but also entirely wrong (when seen from above). ${ }^{122}$ Pilate's impotence will be demonstrated in the next few verses when he tries to release Jesus but fails utterly. The farcical nature of the trial continues as it becomes clear that "having been arrested by those less powerful than he, Jesus is tried by those with less authority than himself." 123 The reader is prompted by the author to ponder where the real power lies and will likely connect these events with Jesus earlier comment: "I have the power to lay [my life] down and I have the power to take it up again" (10:18).

\section{g) Scene 7}

19:12 Pilate's mind is set on releasing Jesus but "the Jews" out-manoeuvre him. Just as Pilate offered them a choice of Jesus or Barabbas, "the Jews" now offer Pilate a choice of Jesus or

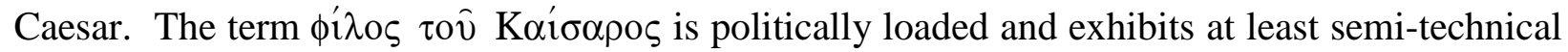

\footnotetext{
${ }^{117}$ Lincoln, Saint John, 467.

${ }^{118}$ Keener, John, 1125.

119 "Roman law did not interpret silence as a confession of guilt." Keener, John, 1125.

${ }^{120}$ Merrill Tenney, John: An Analytical Study of the Text (Grand Rapids: Eerdmans, 1976), 264.

${ }^{121}$ Köstenberger, Truth, 61-62.

122 "The dichotomous Johannine language of above/below corresponds with Johannine cosmology in which the dualistic language of above/below, heavenly/earthly, ascend/descend expresses the theologoumenon that truth is from above and error is from below." Aune, Literature and Rhetoric, 248.

${ }^{123}$ Culpepper, Anatomy, 174.
} 
force for a distinguished person in good favour with Rome. ${ }^{124}$ Many commentators note that Pilate's presumed patron, Aelius Sejanus, had fallen from power in $31 \mathrm{CE}$. This would have left Pilate in a precarious political position. The last thing he needed was any hint reaching Rome that he was not a "friend of Caesar." Accordingly, it is likely that these words were meant or received as a veiled threat. $^{125}$ In any case, the verse contains strong irony, which is well attested. $^{126}$ In order to achieve Jesus's death, his opponents make themselves out to be more loyal subjects of Caesar than Pilate. They thereby demonstrate that despite their earlier denials, they are slaves politically (8:33) and slaves to sin (8:34). Once again, the author ironically portrays Pilate as a study in the impossibility of compromise within a Johannine belief structure. Pilate desires to release Jesus but cannot do so because it would make him politically vulnerable. An innocent man's life counts for little in Pilate's estimation of priorities, which, like those of the religious authorities are all about self-preservation (cf. 11:47-53).

19:13 Pilate knows now that there is nothing to be done and brings Jesus out to the $\beta \hat{\eta} \mu \alpha$ ("judge's bench"). However, the wording is ambiguous as to who actually sits in the judgment seat. If the verb $\varepsilon \kappa \alpha \dot{\theta} \theta \imath \varepsilon v$ is intransitive then Pilate sat, as would be expected. Conversely, if it is transitive then Pilate caused Jesus to sit, presumably to irk "the Jews." If the latter interpretation is correct this would constitute the culmination of the reverse trial motif and represent a profound ironic reversal. There are arguments for and against the notion that Jesus was seated on the bema, ${ }^{127}$ but Beasley-Murray speaks for most; "one must admit that all this is possible, but on balance doubtful." 128

It is not necessary for Jesus to assume the judge's position for irony to exist in this situation. This is likely to be another example of the author using ambiguous language to create ironic potentiality. ${ }^{129}$ A narrative critical approach allows us to contemplate "both the historical

\footnotetext{
${ }^{124}$ Carson, John, 607.

${ }^{125}$ Contra Moloney who argues that no Jewish crowd would thus threaten the procurator, concluding that "dramatic irony, not history, is the major feature of the episode." Moloney, John, 500. Moloney underestimates mob dynamics and the false courage of the crowd; while overstating the threat, which is indirect at best. The opponents have already shown a surprising degree of insolence and at this stage are gaining the ascendency and growing in confidence.

${ }^{126}$ Duke, Irony, 134-136; Culpepper, Anatomy, 143; Beasley-Murray, John, 340; Moloney, John, 496, 500; Carson, John, 602-603; Morris, John, 706.

${ }^{127}$ For an overview see Barrett, St John, 544, who provides four arguments for the transitive and three for the intransitive. See also, Carson, John, 607-608; Hamid-Kani, Revelation, 81; Lincoln, Saint John, 469-470; Stibbe, Storyteller, 142.

${ }^{128}$ Beasley-Murray, John, 342.

${ }^{129}$ See comments on 18:3.
} 
probability that Pilate sat and the suggestive possibility for perceptive readers that Jesus sat." Duke also observes that even if we accept only the intransitive sense, we can still see Pilate's presence on the bèma as ironic. Pilate assumes the position of the judge but his vaunted power has all but dissipated and since he forces the real judge (5:27) to stand he demonstrates his complete inability to "judge with right judgment" (7:24). The author skilfully maintains the extended irony of reversed roles in the trial.

19:14a The narrator provides temporal coordinates, placing the events at noon on the day of preparation for the Passover. For the purposes of this study, we do not need to rehearse the arguments surrounding Johannine versus Synoptic timing. It is sufficient to note that the author has previously been fastidious with timing markers and these have frequently had ironic implications. Thus, whether the timing is historical or theological the informed reader will perceive rhetorical significance. Noon is the hour in which the priests begin to slaughter the paschal lambs. The author potentially introduces a powerful irony in that "the Jews" deliver Jesus, "God, the only Son" (1:18), for death at the very moment when their priests are beginning the preparations for the feast that annually recalls God's deliverance of his people. ${ }^{131}$

This recalls the only optimistic title bestowed on Jesus at the beginning of the Gospel that has so far not been reproduced in the Passion Narrative: "the Lamb of God" (1:29, 36). Now, if only through ironic association, Jesus becomes the Paschal lamb. O'Day suggests that this dual presentation of Jesus as both the Passover offering and as king is John's unique contribution to a deeper appreciation of Jesus' death. ${ }^{132}$ The Paschal lamb symbolism is striking but almost too blatant for gratifying irony. As Duke rightly points out, there is superior irony located in notions of faithfulness to the covenant rather than in sacrificial imagery. ${ }^{133}$ Jesus' opponents are faithless to the existing covenant while at the same time Jesus faithfully ushers in a new covenant by becoming "the Lamb of God who takes away the sins of the world" (1:29). The author ironically grounds the truth of Jesus' identity in covenantal terms. The reader is becoming aware that Jesus' credentials as Messiah are unassailable on every level.

19:14b Pilate proclaims, "here is your King", returning to the title he has doggedly and perversely maintained throughout the trial. This continues the extended irony of Pilate, like

\footnotetext{
${ }^{130}$ Duke, Irony, 135.

${ }^{131}$ See Brown, St John, 2.895; Duke, Irony, 135; Kanagaraj, John, 25; Köstenberger, Theology, 155.

132 O’Day, John, 183.

${ }^{133}$ Duke, Irony, 135.
} 
Caiaphas before him (11:49-52), speaking better than he knows. ${ }^{134}$ Caiaphas, through ironic and unconscious prophecy, had succinctly proclaimed Jesus' mission and Pilate has consistently proclaimed his identity. However, in this verse, Pilate's use of the term subtly changes; he moves from the third to the second person. He is aware that their pious observations on loyalty to Caesar are nothing more than hypocrisy, born of political expediency, to secure the death of Jesus. By proclaiming Jesus as "your King", with a further "bitter irony" he throws the spurious charge of sedition back in their face and mocks their vassal status by implying that this bloodied and helpless prisoner is the only king they are likely to have. ${ }^{135}$ The author's prefacing of the title with ide continues its prominent role as an indicator of irony. ${ }^{136}$

19:15 "The Jews" reply to Pilate with a cry of "away with him, crucify him", repeating the demand of the religious authorities in v.6. Pilate again asks, "Shall I crucify your king?" "The Jews" fade from the narrative in the middle of the debate with Pilate, to be replaced once again by the chief priests. ${ }^{137}$ They utter the words the author clearly did not want to put in the mouths of "the Jews." 138 Appallingly they announce, "we have no king but Caesar." This is another bitter irony in which the final rejection of Jesus is simultaneously a denial of their allegiance to God and their theocratic heritage. ${ }^{139}$ As Culpepper observes, "the implied author does not wink or smile. Is that grim satisfaction or tears in his eyes?"140 The response of the chief priests is unthinkable on two levels. Firstly, it is not just a specific rejection of Jesus as the Messiah but of the hope for a messiah per se. Secondly, it also constitutes a profession of fidelity to their Roman oppressors and therefore a denunciation of their covenantal responsibilities to God. Accordingly, the author demonstrates that to reject Jesus is invariably to reject the Father who sent him (5:37-38).

The irony extends even deeper for readers familiar with the Haggadah, which sets out the order of the Passover Seder and is to be recited to remind all generations of the Passover events (cf.

\footnotetext{
${ }^{134}$ Moloney, John, 496; Zumstein, Saint Jean, 236; Barrett, St. John, 545-546; Köstenberger, John, 538; Culpepper, Anatomy, 177; Carson, John, 605; Morris, John, 709; Neyrey, John, 14; Hamid-Khani, Revelation, 75; O’Day, John, 182; John A. Beck, God as Storyteller: Seeking Meaning in Biblical Narrative (St. Louis: Chalice Press, 2008), 92.

${ }^{135}$ Carson, John, 605.

${ }^{136}$ Duke notes that the author uses ide with increasing irony "as the Passion approaches.” Duke, Irony, 86.

${ }^{137}$ They will not return as a character until after Jesus is dead (19:31).

138 "There is singular force in the exact definition of the speakers here... The official organs of the theocracy themselves proclaim that they have abandoned the faith by which the nation had lived." Westcott, St John, 272.

${ }^{139}$ This is a particularly strong and well-attested situational irony. See, Köstenberger, John, 539; Schnackenburg, St. John, 2.348; Lincoln, Saint John, 470-471; Barrett, St. John, 546; Moloney, John, 17; Culpepper, Anatomy, 169, 177; Morris, John, 709-710; Duke, Irony, 135-136; Lindars, John, 572; Hamid-Khani, Revelation, 248; Anderson, The Having-Sent-Me Father, 40; Neyrey, John, 301.

${ }^{140}$ Culpepper, Anatomy, 169.
} 
Exodus 13:8-10). It includes the line: "From the beginning to the end of the world You are Almighty G-d; and other than You we have no King, Redeemer and Saviour who delivers, rescues, sustains, answers and is merciful in every time of trouble and distress; we have no King but You." 141 The irony is tragic and deep. It exacerbates the ironic incongruity of the earlier concerns of Jesus' opponents to remain ritually clean so that they could celebrate the Passover. The chief priest's blasphemy is the decisive fulfilment of the Prologue's prophecy in 1:10-11. The rejection of Jesus is complete.

\section{Act iv}

19:16 The enormity of the preceding irony hangs heavy as the author abruptly states, "Then he handed him over to them to be crucified." The phraseology contains another irony in that $\pi \alpha \rho \alpha \delta i \delta \omega \mu$ เ meaning "to hand over" (used here in the aorist) has repeatedly been used to signify betrayal, first by Judas $(6: 64,71 ; 12: 4 ; 13: 2,11,21 ; 18: 2,5)$, then by Jesus' opponents $(18: 30$, $35 ; 19: 11)$. The term has a consistently negative connotation and if the reader has observed the pattern, the meaning is palpable. Pilate has tried to distance himself from the Jewish leaders and shown enmity towards them throughout the trial scene. He has claimed that he is not a Jew (18:35), but by "handing over" Jesus just as "the Jews" did to him $(18: 30,35)$ he shows how similar he really is. ${ }^{142}$ A postscript to the "handing over" motif is that in 19:30 Jesus will $\pi \alpha \rho \varepsilon \delta \omega \kappa \varepsilon v$ iò $\pi v \varepsilon \hat{v} \mu \alpha$ and thus have the last say. ${ }^{143}$ Finally, the reference $\alpha \dot{\tau} \tau o i \varsigma$ ("to them") does not signify that Pilate handed Jesus back to the religious authorities to crucify. Rather it serves a literary purpose of completing an inclusio that reverses their delivery of Jesus to him and in doing so further demonstrates Pilate's complicity in what transpires.

19:19-20 Pilate's fascination with naming Jesus "the King of the Jews" finds its final iteration on the titulus attached to the cross for all to see. The inscription continues the extended irony that Jesus went to his death bearing a title that was, unintentionally but profoundly, true. ${ }^{144}$ This is one of the Gospel's most noted ironies. ${ }^{145}$ Most scholars agree that Pilate's continuation with

\footnotetext{
${ }^{141}$ Nosson Scherman and Meir Zlotowitz, eds. The Family Haggadah (New York: Mesorah, 2004), 73. See also Duke, Irony, 135; O’Day, John, 182; Lincoln, Saint John, 470-471.

${ }^{142}$ O'Day, John, 183.

${ }^{143}$ The author thus clarifies that while they had the power to hand him back and forth they did not have the power to take his life, only he had the power to lay it down and take it up again (10:18).

${ }^{144}$ Barrett, St John, 550.

145 Duke, Irony, 89, 136; Schnackenburg, St. John, 2.400; Brown, John, 901; Keener, John, 1136-1137; Bultmann, John, 633, 669; Lincoln, Saint John, 74; Moloney, John, 502; Culpepper, Anatomy, 172, 177; Beasley-Murray,
} 
his grim jest once Jesus' fate is decided is solely intended to vex "the Jews" and the religious authorities. However, it may also reflect Pilate's personal feelings of disquiet over Jesus' innocence. Culpepper suggests that "in characteristic Johannine irony it is also his half-believed testimony which simultaneously betrays Pilate's duplicity in condemning an innocent man and proclaims Jesus' kingship to all the world."146 That the titulus was polyglot (Hebrew, Latin and Greek) underscores the irony and indicates the universality of Jesus' reign. ${ }^{147}$

19:21-22 Not surprisingly the chief priests object and proffer an alternative wording which would clarify that this is not a title but a claim. Pilate tersely dismisses them. The articulation by the chief priests of the irony contained in the preceding verses further highlights it. However, emphasising an irony is often counterproductive since as it becomes more blatant its allure is diminished. The author presumably deemed the centrality of theme to be worthy of the risk of diluting the ironic appeal. He returns to ironic form in Pilate's use of the perfect form of $\gamma \rho \alpha \dot{\phi} \omega$ ( $\gamma^{\prime} \gamma \rho \rho \phi \alpha$ "I have written") in response, which conveys finality ${ }^{148}$ and implies that the title for Jesus is true and unalterable, ${ }^{149}$ rather than the anticipated aorist form. ${ }^{150}$ Furthermore, the irrevocability of the phrase reminds astute readers that every other use of this term in the Gospel has referred to scripture $(2: 17 ; 6: 31,45 ; 8: 17 ; 10: 34 ; 12: 14,16 ; 15: 25)$ which "cannot be annulled" (10:35). ${ }^{151}$ Keener sees further irony in that "John may ironically suggest that Pilate, as God's unwitting agent (19:11), may carry out God's will in the scriptures." 152 This latter ironic aspect is much weaker than the central irony. There is a final situational irony in that Pilate's firm resolve at this juncture stands in stark contrast with his previous inability to refuse the religious authorities' demands despite his vaunted claims to power.

19:23-24 The soldiers gamble for Jesus' clothes but do not divide his seamless tunic. Some scholars see symbolic import in the seamless tunic, which is taken as a reference to the high priest's garment. The decision of the soldiers not to tear it further supports this interpretation (cf. Lev 21:10). Heil makes an appealing case that the author intends an ironic portrayal of Jesus

John, 346; Neyrey, John, 14, 307; Zumstein, Saint Jean, 243; Wright, John, 2.215; Hamid-Khani, Revelation, 75, 81-82; Stibbe, Storyteller, 120; Kanagaraj, John, 25; Carson, John, 611; Borchert, John, 2.264; Ellis, Genius, 269.

${ }^{146}$ Culpepper, Anatomy, 172.

${ }^{147}$ Lincoln, Saint John, 74.

148 Köstenberger, John, 545.

${ }^{149}$ Lincoln, Saint John, 475.

${ }^{150}$ The perfect $\gamma^{\prime} \varepsilon_{\rho} \alpha \phi \alpha$ emphasises a completed action whose affects continue to be felt ("I have written it, and I am its author) as opposed to the aorist " $\gamma^{\prime} \rho \alpha \phi 0 v$ ("what I wrote, I wrote).

151 'In addition, there is the emphasis on the word 'write' (graphein), which is repeated five times and which is regularly used for the scripture i.e., the writings.” Ellis, Genius, 269.

${ }^{152}$ Keener, John, 1138. 
as high priest. A reader will perceive that Jesus' high priesthood is new and different, as Jesus sacrifices himself rather than an animal; and it is unique, since Jesus is the one and only true high priest in contrast to the plurality of Jewish high priests that the author artfully featured at the commencement of the Passion Narrative. ${ }^{153}$ However, others such as Carson and Keener wisely caution that such allusions are far from certain. ${ }^{154}$ As the irony depends on the existence of unsubstantiated symbolism, it is rated as weak. Keener suggests that "John leaves unstated the irony of a soldier afterward wearing (or perhaps selling) the very tunic Jesus has worn." "155 However, while some may possibly find this notion incongruous, a soldier wearing or selling Jesus' garment does not create dual levels of meaning and consequently there is no ironic reversal.

19:28 Jesus' cry of thirst from the cross is a rare admission of frailty that the author has presumably taken from either the Synoptic or a parallel tradition. He tempers it, however, by stating that Jesus utters the cry "in order to fulfil the scripture" (19:28). ${ }^{156}$ The cry of thirst inevitably brings to mind the Gospel's significant water motif, which until this point has been uplifting. Jesus has created a miracle from water (2:1-11), offered living water (4:7-15; 7:38), walked on water (6:16-21) and washed his disciple's feet with water (13:5-12). The irony of the man who bid the thirsty to come to him (7:37) dying in thirst is poignant and "strikes with more horror than humor." "157 The pathos continues, as the final mention of water is the blood and water from his side (19:34).

19:31 "The Jews" ask Pilate to have the legs of those crucified broken so that they will die more expeditiously and therefore not desecrate the Sabbath. This is a continuation of the theme of the incongruous and ironic religious sensibilities of "the Jews", which began in 18:28. They are zealous to ensure no desecration of the land, in accordance with the Law, but are oblivious to the fact that they are desecrating themselves by rejecting their true Messiah and desecrating the law by putting to death an innocent man. ${ }^{158}$ The narrator adds the parenthetical comment that they acted "especially because that Sabbath was a day of great solemnity." The reference to the Sabbath reminds the reader of Jesus' various Sabbath disputes with his opponents. Jesus has

\footnotetext{
153 John Heil, “Jesus as the Unique High Priest in the Gospel of John,” Catholic Biblical Quarterly 57 (1995), 730. Heil puts forward 3 reasons: Caiaphas' advice to Sanhedrin in 11:45-53, the arrest and trial of Jesus before high priests, thirdly the Roman soldier's decision not to divide the seamless tunic.

${ }^{154}$ Carson, John, 614; Keener, John, 1140.

${ }^{155}$ Keener, John, 1140 fn.641.

${ }^{156}$ Presumably Psalm 69:21; see Carson, John, 619.

${ }^{157}$ Culpepper, Anatomy, 171. See also Duke, Irony, 113; Brown, John, 930; Tenney, John, 54.

${ }^{158}$ Kruse, John, 371; Neyrey, John, 313; Brant, John, 254; Keener, John, 1151; Moloney, John, 505.
} 
previously pointed out the irony of them persecuting him for doing good on the Sabbath (5:16; $7: 22-23 ; 9: 14-16)$. Now they seek to inflict further harm on Jesus to satisfy piety concerns over the Sabbath. The reference to the solemnity of the day is classic ironic understatement as they are oblivious to the true significance of the day's events - a day that their esteemed ancestor Abraham "rejoiced that he would see" (8:56).

\section{Act $v$}

19:38 Joseph of Arimathea, who features in all four Gospels, approaches Pilate and asks for Jesus' body. He was a secret disciple due to his fear of the "the Jews." That Pilate acquiesces is perhaps another indication that he truly believed Jesus to be innocent or alternatively relished yet another opportunity to irk the religious authorities. There is moderate situational irony in that Joseph has more reason to fear his own people than the Romans. Keener proposes that this may also be reflective of the ironic situation of the early Christians. ${ }^{159}$ Like their master and just as he predicted, they are rejected by their own (cf. 15:20). The fact that the family did not try to claim the body reinforces Jesus' status as a criminal, since in such circumstances the Romans would not permit family to honour their dead. Therefore, Brant perceives irony in Pilate releasing of the body to two delegates of the authorities who are actually covert allies of Jesus. ${ }^{160}$ This irony is possible but is weakened by the presumption of detailed knowledge of Hebrew and Roman burial customs by the reader.

19:41-42 The narrator notes that there was a garden in the place where Jesus was crucified. Joseph, joined by an emboldened Nicodemus (19:39), lays Jesus in a new tomb. As noted, these verses form an inclusio with 18:1 and therefore conclude the Passion Narrative. Some see a weak situational irony in that scripture normally records gardens as pleasant places (e.g. Eccl 2:5; Song $4: 12,15-16 ; 6: 2,11)$ but in the Johannine narrative Jesus is unjustly arrested in one and then, after his unjust execution has his body deposited in another. ${ }^{161}$ This does not advance any key Johannine narrative theme, as there is no extended garden motif beyond the inclusio. ${ }^{162}$ However, given that the only reference to gardens feature arrest $(18: 1-3)$, violence $(18: 10 ; 26)$ and burial (19:41-42) irony is possible. Moreover, the narrator's parenthetical comment, "there

\footnotetext{
${ }^{159}$ Keener, John, 1160.

${ }^{160}$ Brant, John, 255.

${ }^{161}$ Keener, John, 1165.

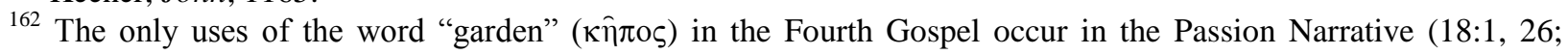
19:41).
} 
was a garden in the place where he was crucified" (19:41) specifically adds death to the litany of unfortunate things that happen in the author's gardens.

\section{Analysis}

If the Prologue was instructive in terms of irony's function within the text, the Passion Narrative proves to be more conclusive. Although we must remain cognisant of the difficulties of connecting inherently covert irony to overt elements of the narrative, John's account of the Passion does allow us to make some definitive observations. At no other juncture of the narrative does the irony come so close to the surface level. ${ }^{163}$ Accordingly, the author often trades subtlety for power, as the ironies draw the main threads of the narrative together and dramatically conclude them. ${ }^{164}$ On occasion, the directness of the irony threatens to destabilise the duality of appearance and reality (e.g. 18:14; 19:14, 21-22). The author deliberately risks repetition of the ironic point, explanation or other means of emphasising the irony because he is less concerned with maintaining the ironic veil than he is with ensuring that the reader does not miss the underlying point. The sheer number of ironies and their significance to the narrative allow for the following observations:

(i) The incidence of ironies follows the structure of the Passion Narrative. This is particularly noticeable when the chiastic interpretations are considered. Irony comes to the fore at the chiastic heart of both the outer and inner structures (Figures 3 and 4) in a manner reminiscent of the meta-irony in the chiastic centre of the Prologue. This demonstrates authorial intentionality in that the irony is interwoven into the fabric of the narrative consistent with the author's overarching literary schema. The irony is not haphazard or coincidental but consonant with the sections of the narrative that the author intends to highlight.

(ii) The frequency and substance of the ironies closely follows the dramatic movement of the plot. ${ }^{165}$ This demonstrates that the author is increasingly incorporating the ironies into the primary subject matter of the text. Irony usually provides secondary meaning to the overt

\footnotetext{
${ }^{163}$ Tovey explains the surface level of a text the level at which the narrative transaction takes place and accordingly is directly evident to the reader. This is creates explicit commentary, which he distinguishes from deeper, implicit commentary where irony and other rhetorical device function. Tovey, Narrative Art, 48.

${ }^{164}$ The comparative lack of irony in the following chapters evidences that the Passion Narrative concludes many of the Gospel's ironies. The ironies are also of an inferior quality with only one strong and two medium ironies out of a total of 11. In contrast, the Passion Narrative contains 37 ironies, with 17 rated as strong and 14 medium.

${ }^{165}$ Figure 5 illustrates this point.
} 
subject matter of a text, functioning as an aside for astute readers. ${ }^{166}$ However, all of the Passion Narrative's key moments of plot progression $(18: 2,19,25-26,28,33-38 ; 19: 1-3,8-9,13-16,23$, $28,31,38$ ), with the singular exception of 19:25-27 (which deals with Jesus' mother), contain robust irony. ${ }^{167}$ This occurs to the extent that the irony no longer passively follows the subject matter, adding peripheral layers of meaning, but is actively assisting in conveying it. The ironic meaning comes closer to the surface of the text and plays a greater role in advancing the plot. ${ }^{168}$ As scholars have noted in the Passion Narrative irony becomes an essential interpretive key. ${ }^{169}$ This supports my hypothesis that Johannine irony will serve an integrating theme. It also confirms MacRae, Duke and O'Day's proposal that any clues to rationale will be found in the text itself.

(iii) The theme of the ironies in the Passion Narrative follows the patterns we identified in the Prologue. This supports our initial conclusion that there is a quantitative link between Johannine irony and the Gospel's key themes. We identified in Chapter 4 that the identity (including the origins and rejection) of Jesus is a key component of the truth theme (cf. 20:31). Notably, the proportion of ironies concerning the identity of Jesus increases from 56\% in the wider Gospel to $73 \%$ in the Passion Narrative! $!^{170}$ The ironies of the Passion Narrative provide the denouement of a majority of the Gospel's key themes and recurring questions. In a degree second only to the Prologue, Jesus' true identity is established. However, this time it is the not the reliable voice of the narrator providing insight into Jesus' provenance and significance but the ironic voice of his opponents. Moreover, the same ironic voices finally reveal their own true identities. Through irony, the opponents ("the Jews", Pilate and the religious authorities) reveal themselves to be the world that does not know Jesus (1:10) and his own that did not accept him (1:11). Accordingly, the Passion Narrative answers all identity issues raised in the Prologue.

\footnotetext{
${ }^{166}$ For example, ironies that draw on reoccurring motifs often have little to add to the main plot. Thus, in 2:9-10 the comments of the steward to the bridegroom advances the plot and satisfactorily concludes the miracle story. The fact that there are two ironies relating to Jesus as the true bridegroom and the "good wine" relating to the ongoing water/thirst motif is entirely secondary and peripheral to the main plot. These ironies repay an attentive reader but are not essential.

167 The exception of 19:25-27 supports my conclusion in demonstrating that where irony is not used is often as illustrative as where it is. The placing of Jesus' mother in to the care of the Beloved Disciple is not a central truth claim and the fact that irony ceases at this point supports the notion that the irony is targeted at key truth claims only.

${ }^{168}$ Several key moments in the trial, such as Pilate's rhetorical questions, hinder the flow of the plot as they leave the reader with multiple options and no obvious means of resolution. Irony alone can allow the reader to interpret these developments in a manner that draws upon the author's carefully cultivated themes in the wider Gospel, and reveals how they seamlessly fit into and advance the plot of the trial narrative. Of course, most readers would do this intuitively without necessarily labelling it as irony.

169 Senior, Passion, 152; O’Day, Revelation, 112-113; See also Duke who demonstrates that the entire inner structure functions as an extended irony. Duke, Irony, 126-137.

${ }^{170}$ The full figures are Identity 73\% (up 17\%); Misunderstanding 13\% (down 9\%); Signs 8\% (down 1\%); Death 3\% (down 5\%); and Miscellaneous 3\% (down 2\%).
} 
(iv) Just as in the Prologue, the connection between irony and the truth theme is not only quantitative but also qualitative. In our exegesis of the ironies of the Passion Narrative an array of descriptors accumulated from commentators: "potent," "striking," "wrathful," "formidable," “terrible," “sublime," “bitter," “captivating," “tragic," “strong," “significant," "powerful," "poignant," and "weighty." Many of the ironies are remarkable in both literary and theological terms and have normally undemonstrative scholars reaching for superlatives. Like the Prologue, but again on a greater scale, there is a qualitative link with the key concepts of the truth theme. Through these potently iterated ironies, the author subtly reminds the reader of and reinforces key propositional statements previously developed in the narrative. For example, Jesus' use of

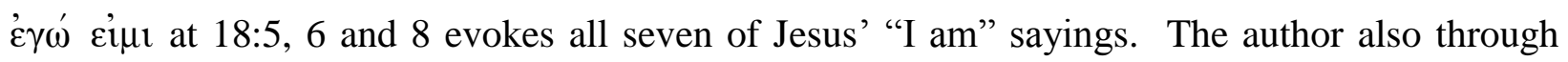
irony reminds the reader specifically of Jesus' sayings, "I am the Light of the World" (8:12), "I am the Good Shepherd" $(10: 11,14)$, and "I am the Way, the Truth and the Life" (14:6). Other ironies evoke the author's descriptions of Jesus as "the Word" $(1: 1,14)$ and the provider of "living water" (4:10; 7:37). Others address important titles that Jesus has been granted or used in relation to himself. Yet other ironies draw upon the meta-irony of the Prologue and demonstrate the true identity of those who either passively (Pilate, "the Jews") or actively (the religious authorities) refuse to accept Jesus' identity. In the author's estimation both become indistinguishable. Through skilfully iterated ironies, the author draws these thematic threads together and produces a definitive portrait of Jesus' correct identity and that of those who oppose him. As the account progresses, the reader is continually confronted with the reality of who Jesus is and the resultant incongruity of the trial's proceedings. At every key point in the Passion Narrative, the reader perceives that reality and appearance are ironically at odds and accordingly they must resolve the conundrum for himself or herself, just as the author intended.

\section{Conclusion}

The extent to which irony is interwoven with the author's key themes, the plot development and previously iterated propositional statements means that in Kierkegaardian terminology, irony is providing the "truth, actuality, [and] content" of the Passion Narrative. ${ }^{171}$ Irony serves as both the revelation of and the witness to the author's fundamental truths about Jesus, his opponents and the cross. Irony also makes these truths appealing to the reader as they are revealed by an

\footnotetext{
${ }^{171}$ Kierkegaard, Concept of Irony, 326.
} 
author who draws them into his community of the informed, while simultaneously demonstrating that those who reject these truths are reduced to incongruous, deceitful and eventually self-destructive behaviour. This provides the confirmation we sought at the end of Chapter 3 and further substantiation of our hypothesis that the rationale for Johannine irony is in its service of the Gospel's truth theme. 


\section{Chapter 7}

\section{Conclusion}

The aim of this study has been to provide an analysis and rationale for the pervasive use of irony in the Fourth Gospel. To this end, it began with an examination of the concept of irony. Immediately, we encountered the caveats that scholars frequently apply to this most elusive of rhetorical devices, from its designation as the "mother of all confusions," to its colourful description as akin to trying to gather the mist. In the exegesis of selected passages, we saw that even when irony is widely perceived in a text, observers regularly identify differing shades or facets of meaning. Irony's stubborn refusal to be fixed with specificity, either as a term or in a text, led Kierkegaard to warn that it is possible for the ironist to become "intoxicated, so to speak, in the infinity of possibilities." ${ }^{1}$ Suitably cautioned, we developed a working knowledge of this rhetorical device through an examination of its formal elements, a classification of its types and a survey of its historical development.

After examining several hypotheses for the "why" of Johannine irony, the Gospel's truth theme was identified as the most compelling explanation. However, while numerous truth statements clearly demonstrate that John's concept of truth has a richer texture than in the Synoptics, ${ }^{2}$ his explicit use of truth terminology nonetheless leaves the content of the truth unspecified. The reader is expected to scrutinise the narrative's propositional statements to discover the author's key truth claims. The author provides direct guidance to some of these pivotal truths in his purpose statement (20:31). However, his predominantly elusive use of the term "truth" allows multiple understandings to emerge from its semantic surplus. ${ }^{3}$ Accordingly, the exact content of the author's conception of truth is open to interpretation, while some elements are certain (cf. 20:31) interpreters may dispute others. An analysis of the Johannine truth theme would be

\footnotetext{
${ }^{1}$ Kierkegaard, Concept of Irony, 261-262.

${ }^{2}$ That is not so say that the Synoptic Gospels do not communicate truth. Rather they focus on presenting an orderly and detailed account of Jesus' ministry, whereas John focuses on presenting certain theological truths as revealed by aspects of the ministry of Jesus (which also explains the Gospel's unique content).

${ }^{3}$ Tenney's observation which is directed at truth and the use of imagery in the Fourth Gospel is also applicable to other rhetorical devices: "The exact expression of truth in intelligible fashion is always difficult. General truth is best formulated in abstractions which will encompass any given situation, but abstractions are not comprehensible to the uninitiated." Tenney, Literary Keys, 13.
} 
worthy of its own comprehensive study to determine, amongst other things, which propositional elements fall within its purview. ${ }^{4}$

Early in this study, I described testing of this hypothesis as being an attempt to identify a connection between the indefinable and the unspecified. However, while both irony and the truth theme are inherently opaque, the author of the Fourth Gospel skilfully presents both device and theme in a manner not intended to obscure understanding but to further his clearly articulated aims. This means that patterns are readily discernible, especially through a detailed exegesis of the text. Accordingly, not too much should be made of both device and theme being ambiguous and indirect forms of communicating, except to note that this similarity between them further evidences their compatibility. It is time now to draw together the conceptual threads and determine what we can conclude with a degree of certainty. In particular, does the evidence support our preferred hypothesis that the rationale for the form, function and pervasiveness of Johannine irony is in service to the Gospel's truth theme? For a number of substantive reasons, the answer to this question is affirmative.

The proposal that Johannine irony serves the truth theme starts from a position of strength due to the well-documented philosophical link between irony and truth. In particular, our survey of historical shifts in the denotation of irony in Chapter 2 reveals that while the manner of interaction has varied considerably over time, every iteration of thought concerning irony is always expressed relative to notions of truth. Furthermore, prior to conducting our own analysis, we encountered significant circumstantial evidence from prominent commentators on irony in the form of obiter dicta. These comments drew a connection between irony and truth at a conceptual level, such as Feagin's observation that "irony functions basically as an instrument of truth." ${ }^{, 5}$ Moreover, with specific reference to the Fourth Gospel, Duke notes a substantive link in observing that "Irony is a device; and irony is the truth." 6 Others, such as O'Day, identify how Johannine irony serves the author's purposes. "It reveals by asking the reader to make judgements and decisions about the relative value of stated and intended meanings, drawing the reader into its vision of the truth." 7 Such remarks suggest that our hypothesis is consistent with the broader, scholarly consensus on Johannine irony.

\footnotetext{
${ }^{4}$ In my opinion such themes include, in relation to Jesus (his identity, mission, origins (o $\check{\alpha}^{\prime} v \omega \theta \varepsilon v$ ), glory, sovereignty, sonship, role as judge and role as the Word/fulfilment of scripture) and in a general sense (John's concepts of active belief, life, light, witness and genuine discipleship).

${ }^{5}$ Feagin, Irony, 27.

${ }^{6}$ Duke, Irony, 41.

${ }^{7}$ O'Day, Revelation, 31.
} 
Arguably the most compelling evidence that irony serves the truth theme is how impeccably it conforms to and facilitates the author's stated purpose: "But these are written so that you may come to believe that Jesus is the Messiah, the Son of God, and that through believing you may have life in his name" (20:31). This purpose can be paraphrased as comprising revelation (31a) and response (31b), which corresponds with Painter's two proposed meta-themes. As we observed in Chapters 2 and 3, "ce soit le mot alētheia qui exprime avec le plus de plénitude le thème johannique fondamental de la revelation." 8 The author uses irony to create and recreate the dynamics of revelation in the narrative. ${ }^{9}$ Furthermore, we have found that irony is able to challenge a reader's false assumptions and present challenging truths in an indirect way that encourages a favourable response. Accordingly, the truth theme and use of irony as rhetorical device are not just idiosyncratic examples of Johannine literary style but rather part of a well thought out and astute literary strategy. The author's decision to use irony to reveal difficult theological propositional truths about Jesus, and to engage with readers in a way that draws them into an inclusive community of those who know the truth, ${ }^{10}$ is an inspired choice that dramatically improves his chance of fulfilling his purposes.

In turning to the text itself, we found that patterns do emerge which substantiate our hypothesis. First, we identified a quantitative correlation between what is undoubtedly the principal tenet of the truth theme (the identity of Jesus, cf. 20:31a) and a categorisation of the subject matter of the plot's ironies. We observed that across the whole narrative an ironic treatment of the identity of Jesus is the leading category of irony, to the extent that it is more common than the other four categories combined and over two and a half times as prevalent as the next category. When we focused on an exegetical consideration of the ironies of the Passion Narrative, which is the dramatic and ironic climax of the Gospel, this number increased from 56\% to 73\%, which is just under six times more prevalent than the next category. This numerical correlation, in which the predominant topic of Johannine irony follows the predominant topic of the truth theme reinforces Duke's conclusion that in terms of irony in the Fourth Gospel, "form follows theme." 11 The author shapes the composition of his ironic expression to serve his major themes.

\footnotetext{
${ }^{8}$ Ignace de la Potterie, La Vérité, 1.3.

${ }^{9}$ O'Day, Revelation, 10.

${ }^{10}$ Not just any truth, but the key truths that Jesus epitomises and in which belief and adherence will set an individual free.

${ }^{11}$ Duke, Irony, 92.
} 
A close reading of the ironic texts also produces another form of validation of our hypothesis. A consideration of the specific ironies, their relative strength, and the degree to which they influence the story, reveals that certain ironies have a special relationship with the composition of the narrative. We saw that an ironic expression of the rejection of Jesus' identity, which I have labelled a "meta-irony", sits at the chiastic centre of the Prologue, thereby making it the dominant idea. This is doubly significant given that the Prologue plays an important role in arming readers with inside knowledge to inform their journey through the rest of the narrative, including the identification of subsequent ironies. In the Passion Narrative too, we found at its chiastic core an ironic affirmation of Jesus' real identity, which at the same time is the practical manifestation of the rejection foreshadowed in the Prologue's meta-irony. The co-location of irony and significant expressions of the truth theme at crucial junctures in the narrative, reveal a qualitative link between them. This suggests that just as irony delivers important features of the truth theme, so too the truth theme renders several key ironies central to the plot. In my view, this creates several meta-ironies in the text that are pivotal to the plot of the Fourth Gospel or that present an ironic subplot, which mirrors the key points of the substantive plot. A full consideration of this topic is beyond the scope of this study, but I suggest there are several candidates for consideration as meta-ironies: $1: 10-11 ; 2: 19 ; 9: 39-41 ; 11: 49-50 ; 18: 35,38 ; 19: 1$ $3,15$.

Our examination of the text would not be complete without a consideration of where irony is not utilised by the author. That irony is thematically selective is equally evident in acts of omission. If irony is the primary vehicle for the delivery of the truth theme, then when certain truths are not being actively adduced irony should also abate. Our exegesis has confirmed this in two ways. First, in the irony-intensive Passion Narrative, irony is constantly implicated when the primary themes of Jesus' identity and the identity of those who reject him are treated. However, as soon at the narrative's focus shifts to other topics irony abruptly ceases. Irony is not found, for example, during Peter's assault on Malchus (18:10-11), Peter's denials (18:15-18, 25-27), the crucifixion (19:16b-18), the entrusting of Jesus' mother (19:25-27), Jesus' final cry and death (19:30), the post-mortem actions of the soldiers, including the spear in the side (19:32-37), and the burial of Jesus (19:19:39-42). ${ }^{12}$ The juxtaposition of ironic and non-ironic passages along thematic lines is distinct and compelling.

\footnotetext{
12 There are two minor ironies proposed at 18:26 and 19:38, which would appear to be exceptions but are not. The first is an irony based on contrast and so relates to the identity of Jesus not Peter's denial and likewise, the second is an ironic reflection on the identity of Jesus opponents and not Joseph of Arimathea, the ostensible subject of the sentence.
} 
Second, when the narrative as a whole is considered it is notable that incidences of irony decrease significantly in the Farewell Discourses and Epilogue. ${ }^{13}$ The reduction in the Farewell Discourse is explicable by the move from a primarily polemical interaction with "the Jews" and the religious authorities in relation to their misgivings over Jesus' identity (both through his selfrevelation and his signs), to a didactic exposition on matters other than Jesus' identity. ${ }^{14}$ The didactic nature of the Farewell Discourse means that it contains many propositional truths but few that contribute to the truth theme. ${ }^{15}$ The Epilogue sees a similar abatement in irony because the majority of issues pertaining to identity (both of Jesus and of the world that rejects him, cf. 1:10-11) have been resolved during the trial account. If we discount ironies related to the resurrection (an extended irony and the plot's greatest reversal), Mary's misidentification and Thomas' refusal to accept Jesus' post-resurrection identity without proof, then irony almost ceases altogether. ${ }^{16}$ Consequently, not only is there a quantitative and qualitative connection with the truth theme, there is a discernible disconnection with topics not related to the theme.

To summarise, at each turn, the evidence confirms our central hypothesis. This conclusion is consistent with the prevailing philosophical view of irony. It supports the view that John's concept of irony corresponds to the Socratic model of irony as truth telling, which we know formed the literary and philosophical milieu of the author. Our exegetical treatment of the text, despite the elusive nature of both device and theme, returns remarkably congruent and conclusive results. The evidence establishes that the author has intensified the innate relationship between truth and irony with direct truth terminology but in a way that obligates each reader to resolve the content of the truth for himself or herself. Then, in a mutually reinforcing manner, he thematically integrates truth and irony to produce a subtle and engaging presentation of his primary theological concerns. The result is a narrative that takes the reader on a journey of discovery, one that is masterfully crafted to accentuate revelation and response.

\footnotetext{
${ }^{13}$ Refer to Figure 2.

14 The primary emphasis changes to teachings on the identity of the Holy Spirit and God the Father. The other teachings relate to discipleship, Accordingly, Jesus' teachings on his role as "the true vine" (15:1) is predominantly about true discipleship (abiding in the vine 15:4-7,9-10) and the Father ("the vinegrower" 1:1). Notably this is the only "I am" statement not to attract irony.

${ }^{15}$ See Chapter 2 for comments on the didactic sections of the Gospel. However, Tenney's comment on the author's means of expressing truth through the rhetorical device of imagery is equally applicable to irony, "they are illustrative rather than didactic." Tenney, Literary Keys, 14. As Ressiguie notes the author prefers "showing to telling, indirect presentation to direct presentation." Resseguie, Fourth Gospel, 11.

${ }^{16}$ E.g. 20:19, 21:7, 22, 24 - all are rated as poorly attested and rated as weak.
} 
Elucidation of the interplay between irony and the truth theme can also enhance our appreciation of other features of the Fourth Gospel, such as characterisation. This study has demonstrated how on occasions only irony fully conveys the true nature of a character and the theological connotations of their representative role. We have observed, for example, how because of the author's literary choices the character of Pilate cannot be fully appreciated without recourse to irony. Ironic characterisation is also sometimes determinative of the author's portrayal of propositional truth. Frequently a character's attempts to dispute the truth will ironically provide its clearest articulation. ${ }^{17}$ As we noted in Chapter 5, the author's use of the term "the Jews" is predominantly ironic. Similarly, in this study we have perceived how irony is more integrated into the theme and plot of the narrative, than had previously been realised. ${ }^{18}$ There is room for further investigation of the role of irony in the construction of the plot as well as the possible existence of an ironic subplot or implicit ironic commentary on the main plot. ${ }^{19}$ Viewing plot, theme and characters through the lens of irony therefore offers intriguing insights into the artistry of the Fourth evangelist.

Perhaps the most fertile ground for additional research is how our conclusions illuminate the relationship between the author and reader. This study has made much of the author's use of irony with the intention of evoking response. Accordingly, consideration may be given to how the reader experiences irony on an emotive level and how this may conform to or differ from the author's expectations. Both the thrill of discovery and the emotional connection established between the author and reader are large parts of the appeal of irony, more so than most other rhetorical devices. McDaniel has recently produced an exposition of the reader's experience of irony in the Gospel of Matthew, looking at aspects such as suspense, surprise and curiosity. ${ }^{20}$ The Fourth Gospel would be an ideal candidate for a similar treatment.

The implications of our finding that Johannine irony serves the truth theme are theological as well as literary because, as MacRae has observed, it is through the author's "ironic vision that the contact with Johannine theology is made." 21 Any clarification of the form and function of Johannine irony will therefore help to define the theological underpinnings of the author's

\footnotetext{
${ }^{17}$ The religious authorities in the Passion Narrative provide a salient example: "Through their attempts to suppress the truth, the authorities actually declare and affirm it. They play a part in making it visible." Skinner, The Trial Narratives, 103.

${ }^{18}$ Particularly in light of irony's presence in significant structural elements such as the chiasms in the Prologue and Passion Narrative.

${ }^{19}$ To use Culpepper's terminology. Culpepper, Anatomy, 149.

${ }^{20} \mathrm{Karl}$ McDaniel, Experiencing Irony in the First Gospel (London: T\&T Clark, 2013).

21 MacRae, Theology and Irony, 94. O'Day also observes "the intrinsic relationship of narrative mode and theological claim.” O’Day, Revelation, 114.
} 
persistent presentation to the reader of duality, that is, of repeated discrepancies between appearance and reality. For John, the truths that count and that reveal his primary theological concerns are discovered in the resolution of these incongruities. Irony is only one of the tools that he uses to create multiple layers of meaning in the narrative; however, given its prominence at crucial points in the narrative, it is surely his preferred device. More often than not, the reader finds the resolution of contrasting appearance and reality and the bridge to John's truth in the witness and revelation of Johannine irony.

However, as this study has shown, Johannine irony is more than the isolated uses of a favoured rhetorical device. There is ironic coherence throughout the narrative, which is shaped by, and in turn shapes, the truth theme. Accordingly, the author's ironic flourishes do not merely aid in the telling of the story; the story itself - who Jesus was, how others received him, how he undertook his mission and how he brought eternal life through death on the cross - is deeply ironic. This integration of device and theme turns Johannine irony into the ideal midwife of truth. The truths that it delivers, in a manner utterly unique to the Fourth Gospel, are both profound and beguiling. $^{22}$ These truths are never academic but rather a personal and experiential revelation of Jesus. Johannine irony is therefore the perfect midwife for the truth that Jesus is the Messiah, the Son of God and that through believing in him there is eternal life in his name.

\footnotetext{
22 "The Gospel of John contains some of the profoundest truth in the New Testament, but there are no other writings which express it more simply." Tenney, Literary Keys, 13.
} 


\section{Bibliography}

Abbott, Edwin A. Johannine Vocabulary. London: Adam and Charles Black, 1905.

. Johannine Grammar. London: Adam and Charles Black, 1906.

Aichele, George and Walsh, Richard, eds. Those Outside: Noncanonical Reading of Canonical Gospels. New York: T\&T Clark, 2005.

Alter, Robert. The Art of Biblical Narrative. New York: Basic Books, 2011.

Anderson, Paul N. The Riddles of the Fourth Gospel. Minneapolis: Fortress, 2011. . The Fourth Gospel and the Quest for Jesus. London: T\&T Clark, 2007. . The Christology of the Fourth Gospel. Tübingen: Mohr Siebeck, 1996.

. "Graduations of Symbolization in the Johannine Passion Narrative." In Imagery in the Gospel of John, edited by Jörg Frey et al. Tübingen: Mohr Siebeck, 2006, 157-194.

. "The Having-Sent-Me Father: Aspects of Agency, Encounter, and Irony in the Johannine Father-Son Relationship.” Semeia 85, (1999), 33-57.

Anderson, P. Just, F. Thatcher, T. eds. John, Jesus and History: Volume 1. Atlanta: SBL, 2007. . John, Jesus and History: Volume 2. Atlanta: SBL, 2009.

Aquinas, Thomas. Commentary on the Gospel of St. John. Translated by James A. Weisheipal. Albany: Magi, 1998.

Aristophanes. Lysistrata/The Acharnians/The Clouds. New York: Penguin, 1973.

Aristotle. The Nicomachean Ethics. New York: Penguin, 1976. . Poetics. New York: Norton \& Company, 1982.

Ashton, John ed. The Interpretation of John. 2nd ed. Edinburgh: T \& T Clark, 1997.

. Studying John: Approaches to the Fourth Gospel. Oxford: Oxford University Press, 1994.

. Understanding the Fourth Gospel. Oxford: Oxford University Press, 1991.

Attridge, Harold W. "Genre Bending in the Fourth Gospel.” JBL 121 (2002), 3-21.

Aune, David E. The Westminster Dictionary of New Testament and Early Christian Literature and Rhetoric. Louisville: John Knox, 2003.

. The New Testament in Its Literary Environment. Philadelphia: Westminster, 1987.

Bailey, Kenneth E. Poet and Peasant: A Literary Cultural approach to the Parables in Luke.

Grand Rapids: Eerdmans, 1976.

Balfour, Glenn. “Is John’s Gospel Anti-Semitic?” TynB 48.2, (1997), 369-372.

Bammel, Ernst; Moule, Charles F. D. eds. Jesus and the Politics of His Day. Cambridge: Cambridge University Press, 1985. 
Barclay, M. Newman and Nida, Eugene A. A Handbook on the Gospel of John. New York: UBS, 1980.

Barnett, Paul. John: The Shepherd King. Sydney: Aquila, 2005.

Barrett, C. K. The Gospel According to St John. 2nd ed. Cambridge: University Press, 1978.

Barton, John. ed. The Cambridge Campanion to Biblical Interpretation. Cambridge: Cambridge University Press, 1998.

Bauckham, Richard. Jesus and the Eyewitnesses: the Gospels as Eyewitness Testimony. Grand Rapids: Eerdmans, 2006.

. The Testimony of the Beloved Disciple. Grand Rapids: Baker, 2007. . Gospel Women. Grand Rapids: Eerdmans, 2002.

Bauckman, Richard and Mosser, Carl eds. The Gospel of John and Christian Theology. Grand Rapids: Eerdmans, 2008.

Bauer, Walter. A Greek-English Lexicon of the New Testament and Other Early Christian Literature. Edited by F. W. Danker, 3rd ed. Chicago: Chicago University Press, 2000. . Orthodoxy and Heresy in Earliest Christianity. Edited by Robert A. Kraft and Gerhard Krodel. Philadelphia: Fortress, 1971.

Beasley-Murray, George R. John. Word Biblical Commentary 36. 2nd ed. Nashville: Thomas Nelson, 1999.

Beck, John A. God as Storyteller: Seeking Meaning in Biblical Narrative. St. Louis: Chalice, 2008 .

Becker, Jürgen. Das Evangelium Nach Johannes. Ökumenisscher Taschenbuch-Kommentar Zum Neuen Testament 4/1-2. 2 vols. Wursburg: Gütersloher Verlagshaus Gerd Mohn, 1991.

Behler, Ernst. Irony and the Discourse of Modernity. Washington: University of Washington Press, 1990.

Beirne, Margaret. Women and Men in the Fourth Gospel. London: T\&T Clark, 2003.

Bennema, Cornelis. "The Identity and Composition of OI IOY $\triangle A I O I$ in the Gospel of John." TynB 60.2, (2009), 239-263.

. "A Theory of Character in the Fourth Gospel with Reference to Ancient and Modern Literature." Biblical Interpretation 17.4, (2009), 375-421.

. The Power of Saving Wisdom. Tübingen: Mohr Siebeck, 2002. . "The Character of John in the Fourth Gospel.” JETS 52/2, (June 2009), 271-284.

Berger, Klaus. Identity and Experience in the New Testament. Translated by Charles Muenchow. Minneapolis: Fortress, 2003. 
Bernard, J. H. A Critical and Exegetical Commentary on the Gospel According to St. John. 2 vols. Edinburgh: T\&T Clark, 1929.

Bieringer, Reimund et al eds. Anti-Judaism and the Fourth Gospel. Louisville: Westminster John Knox, 2001.

Blinzer, Josef. The Trial of Jesus. Translated by Isabel and Florence McHugh. Westminster: Newman, 1959.

Blomberg, Craig L. The Historical Reliability of John's Gospel. Downers Grove: Intervarsity Press, 2001.

Bond, Helen K. Pontius Pilate in History and Interpretation. Cambridge: Cambridge University Press, 1998.

Booth, Wayne C. A Rhetoric of Irony. Chicago: University of Chicago Press, 1974.

Borchert, Gerald. John. New American Commentary 25A/B. 2 Vols. Nashville: Broadman \& Holman, 1996, 2002.

Borge, Jorge Luis. Ficciones. New York: Grove, 1962.

Botha, Eugene. "The Case of Johannine Irony Reopened I: The Problematic Current Situation." Neotestamentica 25 (1991), 209-220.

. "The Case of Johannine Irony Reopened II: Suggestions, Alternative Approaches." Neotestamentica 25 (1991), 221-232.

Boyarin, Daniel. "What Kind of a Jew Is an Evangelist?" In Those Outside: Noncanonical Reading of Canonical Gospels, edited by George Aichele and Richard Walsh. New York: T\&T Clark, 2005, 149-219.

Brant, Jo-Ann A. Dialogue and Drama: Elements of Greek Tragedy in the Fourth Gospel. Peabody: Hendrickson, 2004.

. John. Paideia Commentaries on the New Testament. Grand Rapids: Baker Academic, 2011.

Brodie, Thomas L. The Gospel According to John: A Literary and Theological Commentary. Oxford: Oxford University Press, 1993.

Brown, Colin. ed. The New International Dictionary of New Testament Theology. 4 Vols. Grand Rapids: Zondervan, 1978.

Brown, Raymond E. The Gospel According to St John. Anchor Bible Commentary 29/29A. 2 vols. New York: Doubleday, 1966. . An Introduction to the Gospel of John. New York: Doubleday, 2003. . The Community of the Beloved Disciple. New York: Paulist Press, 1979. . The Epistles of John. Anchor Bible Commentary 30. New York: Doubleday, 1982. 
. The Death of the Messiah: A Commentary on the Passion Narratives in the Four Gospels. 2 vols. New York: Doubleday, 1994.

Bruce F. F. The Gospel and Epistles of John. Grand Rapids: Eerdmans, 1983.

Bryan, Steven M. "Power in the Pool: The Healing of the Man at Bethesda and Jesus' Violation of the Sabbath (jn. 5:1-18)." TynB 54.2, (2003), 7-22.

Büchner, Wilhelm. "Über den Begriff der Eironeia." Hermes: Zeitschrift für klassische Philologie-einzelschriften 4, (1941), 339-358.

Bultmann, Rudolf. The Gospel of John: A Commentary. Philadelphia: Westminster, 1964.

Burge, Gary M. Interpreting the Gospel of John. Grand Rapids: Baker, 2002. . John. The NIV Application Commentary. Grand Rapids: Zondervan, 2000. . Letters of John. The NIV Application Commentary. Grand Rapids: Zondervan, 1996.

Burridge, Richard A. What Are the Gospels?: A Comparison with Graeco-Roman Biography. 2nd ed. Cambridge: Cambridge University Press, 1992.

Buss, Septimus. The Trial of Jesus: Illustrated From Talmud and Roman Law. London: William Clowes and Sons, 1906.

Callahan, Allen D. A Love Supreme: A History of the Johannine Tradition. Minneapolis: Fortress, 2005.

Camery-Hoggatt, Jerry. Irony in Mark's Gospel. Cambridge: Cambridge University Press, 1992.

Carson, D. A. The Gospel According to John. Pillar New Testament Commentary. Leicester: IVP, 1991.

. "The Purpose of the Fourth Gospel: John 20:31 Reconsidered.” JBL 106/4, (1987), 639651.

. "Syntactical and Text-critical Observations on John 20:30-31: One More Round on the Purpose of the Fourth Gospel.” JBL124/4, (2005), 693-714.

. "Current Source Criticism of the Fourth Gospel: Some Methodological Questions.” JBL 97/3, (1978), 411-429.

. "Understanding Misunderstandings in the Fourth Gospel." TynB 33, (1982), 59-89.

Carter, Warren. Pontius Pilate: Portraits of a Roman Governor. Collegeville: Liturgical Press, 2003.

Carter, T. L. “The Irony of Romans 13.” Novum Testamentum 46, no.3 (2004), 209-228.

Catchpole, David R. The Trial of Jesus. Leiden: Brill, 1971.

. "You Have Heard His Blasphemy." Tyndale Bulletin 16, (October 1965), 10-18.

Chennattu, Rekha M. Johannine Discipleship as a Covenant Relationship. Peabody: Hendrickson, 2006. 
Cicero, Marcus Tullius. On Oratory and Orators. Translated by John Selby Watson. Carbondale: Southern Illinois University Press, 1986.

Clavier, Henri. “L’ironie dans L’enseignement de Jésus.” Novum Testamentum 1, (Jan. 1956), 320.

Cohen, Shaye J. D. The Beginning of Jewishness: Boundaries, Varieties, Uncertainties. Los Angeles: University of California Press, 1999.

Colebrook, Claire. Irony: The New Critical Idiom. London: Routledge, 2004. . Irony in the Work of Philosophy. Lincoln: University of Nebraska Press, 2002.

Collins, Raymond F. These Things Have Been Written: Studies in the Fourth Gospel. Louvain: Peeters, 1990.

Coloe, Mary. "The Structure of the Johannine Prologue and Genesis 1." Australian Bible Review 45, (1997), 40-55.

. God Dwells with Us: Temple Symbolism in the Fourth Gospel. Minnesota: Liturgical Press, 2001.

. "Raising the Johannine Temple (John 19:19-37)." Australian Biblical Review 48, (2000), $47-58$.

. Dwelling in the Household of God: Johannine Ecclesiology and Spirituality. Collegeville: Liturgical Press, 2007.

Connick, Milo. “The Dramatic Character of the Fourth Gospel.” JBL 67, no.2 (1948), 159-169.

Conway, Daniel W. “Taking Irony Seriously: Rorty's Postmetaphysical Liberalism.” American Literary History vol. 3, no.1 (1991), 198-208.

Cornell, Drucilla et al. eds. Deconstruction and the Possibility of Justice, New York: Routledge, 1992.

Counet, Patrick Chatelion. John, a Postmodern Gospel: Introduction to Deconstructive Exegesis Applied to the Fourth Gospel. Leiden: Brill, 2000.

Countryman, William L. The Mystical Way in the Fourth Gospel. Harrisburg: Trinity, 1994.

Cox, Stephen. The New Testament and Literature: a Guide to Literary Patterns. Chicago: Open Court, 2006.

Crump, David M. "Truth.” In Dictionary of Jesus and the Gospels, edited by Joel Green, et al. Downers Grove: IVP, 1992, 859-862.

Culpepper, Alan R. Anatomy of the Fourth Gospel: A Study in Literary Design. Philadelphia: Fortress, 1983.

. "Reading Johannine Irony." In Exploring the Gospel of John. Edited by Alan R. Culpepper, Clifton C. Black. Louisville: John Knox, 1996, 193-207. 
. "The Plot of John's Story of Jesus." Interpretation 49, (1995), 347-358.

. ed. Critical Readings of John Six. Leiden: Brill, 1997.

. The Gospel and Letters of John. Nashville: Abingdon, 1998.

. “The Pivot of John's Prologue.” NTS 27, (1980), 1-31.

. "The Weave of the Tapestry: Character and Theme in John." in Characters and

Characterization in the Gospel of John, edited by Christopher W. Skinner (London: T\&T

Clark, 2013), 18-35.

Culpepper, Alan R., Segovia, Fernando F. eds. Semeia 53: The Fourth Gospel From A Literary Perspective. Atlanta: SBL, 1991.

Culpepper, Alan R., Black, Clifton C. Eds. Exploring the Gospel of John. Louisville: John Knox, 1996.

Cyril, "Homily on the Paralytic by the Pool." In Cyril of Jerusalem. Translated by Edward Yarnold. Edited by Carol Harrison. London: Routledge, 2000.

Dane, Joseph A. The Critical Mythology of Irony. Athens: University of Georgia Press, 1991.

Dapaah, Daniel S. The Relationship Between John the Baptist and Jesus of Nazareth. Lanham: University Press of America, 2005.

Davies, Margaret. Rhetoric and Reference in the Fourth Gospel. Sheffied: JSOT Press, 1992.

De La Potterie, Ignace. "Structure du Prologue de Saint Jean.” NTS 30/03, (July 1984), 354-381. . La Vérité dans Saint John. 2 Vols. Rome: Biblical Institute Press, 1977.

. "L'arrière-fond du theme johannique de vérité." In Studia Evangelica: Papers Presented to the International Congress on 'The Four Gospels in 1957' Held at Christ Church, Oxford 1957, edited by Kurt Aland, et al. Berlin: Akademie-Verlag, 1959, 227-294.

. "The Truth in Saint John." In The Interpretation of John, edited by John Ashton. Edinburgh: T \& T Clark, 1997, 53-66.

De Jonge, Marinus. "The Gospel and Epistles of John Read Against the Background of the History of the Johannine Communities." In What We Have Heard From the Beginning: The Past, Present, And Future of Johannine Studies, edited by Tom Thatcher. Waco: Baylor University Press, 2007, 127-144.

Derrett, J. Duncan M. “John 9:6 Read with Isaiah 6:10; 20:9.” EQ 66:3, (1994), 251-254.

Derrida, Jacques. Writing and Difference. Translated by Alan Bass. Chicago: The University of Chicago Press, 1978.

. "Force of Law: The Mystical Foundation of Authority." Deconstruction and the Possibility of Justice, edited by Drucilla Cornell et al., New York: Routledge, 1992, 3-67. 
Dietzfelbinger, Christian. Das Evangelium nach Johannes. Zürcher Bibelkommentare 4.1-2. Zürich: Theologischer Verlag, 2004.

Dodd, C. H. The Interpretation of the Fourth Gospel. Cambridge: Cambridge University Press, 1953.

. Historical Tradition in the Fourth Gospel. Cambridge: Cambridge University Press, 1963.

Dokka, Trond Skard. "Irony and Sectarianism in the Gospel of John." New Readings in John: Literary and Theological Perspectives, edited by Nissen, Johanes and Pedersen, Sigfred. Sheffield: Sheffield Academic Press, 1999, 83-107.

Donahue, John R. ed. Life in Abundance: Studies of John's Gospel in Tribute to Raymond E. Brown. Collegeville: Liturgical Press, 2005.

Drane, John. ed. The Gospel of St John. New York: St. Martin's Griffin, 1999.

Duke, Paul D. Irony in the Fourth Gospel. Atlanta: John Knox, 1985.

Dumbrell, William J. John: Gospel of the New Creation. Caringbah: New Covenant Press, 2006.

Dumm, Demetrius R. A Mystical Portrait of Jesus: New Perspectives on John's Gospel. Minnesota: Liturgical Press, 2001.

Dyck, Elmer. ed. The Act of Bible Reading: A Multi-disciplinary Approach to Biblical Interpretation. Downers Grove: IVP, 1996.

Ellis, Peter F. The Genius of John: A Composition-Critical Commentary on the Fourth Gospel. Collegeville: Liturgical Press, 1984.

Erickson, Millard. Truth or Consequences: The Promise and Perils of Postmodernism. Downers Grove: IVP, 2001.

Esolen, Anthony. Ironies of Faith: The Laughter at the Heart of Christian Literature. Wilmington: ISI Books, 2007.

Estes, Douglas. The Questions of Jesus in John. Leiden: Brill, 2013.

Euripides. Medea and Other Plays. New York: Penguin, 1963.

Evans, Craig A. "The Passion of Jesus: History Remembered or Prophesy Historicized?" Bulletin for Biblical Research 6, (1996), 159-165.

Farelly, Nicholas. The Disciples in the Fourth Gospel. Tübingen: Mohr Siebeck, 2010.

Feagin, Glyndle M. Irony and the Kingdom in Mark. Lewiston: Mellen Biblical, 1997.

Fee, Gordon. "On the Text and Meaning of John 20:30-31." To What end Exegesis: Essays; Textual, Exegetical and Theological. Grand Rapids: Eerdmans, 2001, 29-42. 
Fehribach, Adeline. The Women in the Life of the Bridegroom: A Feminist Historical-Literary Analysis of the Female Characters in the Fourth Gospel. Collegeville: Liturgical Press, 1998.

Fish, Stanley. Doing What Comes Naturally: Change, Rhetoric, and the Practice of Theory in Literary and Legal Studies. Durham: Duke University Press, 1989.

Fortuna, Robert, Thatcher, Tom. eds. Jesus in Johannine Tradition. Louisville: John Knox, 2001.

Frazier, Brad. Rorty and Kierkegaard on Irony and Moral Commitment. New York: Palgrave MacMillan, 2006.

Frey, Jörg, et al. eds. Imagery in the Gospel of John. Tübingen: Mohr Siebeck, 2006.

Frommel, Thomas J. Tempelaktion und Tempelwort Jesu in Joh 2, 13-22. Norderstedt: Druck und Bindung, 2006.

Gabel, John B., et al. eds. The Bible as Literature. 4th ed. Oxford: Oxford University Press, 2000.

Gench, Frances Taylor. Encounters with Jesus. Louisville: John Knox, 2007.

Gerson, Lloyd. "Philosophy, Literature and Truth." University of Toronto Quarterly 59, (1990), 449-451.

Gibbs, Raymond W. Jr., Herbert L. Colston. eds. Irony in Language and Thought. New York: Lawrence Erlbaum, 2007.

Giblin, Charles Homer. "Two Complimentary Literary Structures in John 1:1-18.” JBL 104/1, (1985), 87-103.

Good, Edwin M. Irony in the Old Testament. 2nd ed. Sheffield: Almond, 1981.

Gordley, Matthew. "The Johannine Prologue and Jewish Didactic Hymn Traditions: A New Case for Reading the Prologue as a Hymn.” JBL 128, (2009), 781-802.

Grayston, Kenneth. The Gospel of John. Epworth Commentaries. London: Epworth, 1990.

Green, Humphrey C. “The Composition of St. John’s Prologue.” Expository Times 66, (19541955), 291-294.

Green, Joel B., McKnight, Scot, Marshall, I. Howard. eds. Dictionary of Jesus and the Gospels. Downers Grove: IVP, 1992.

Grosjean, Jean. L'ironie Christique: Commentaire de L'Évangile selon Jean. Paris: Gallimard, 1991.

Haenchen, Ernst. A Commentary on the Gospel of John. Hermeneia. Edited by Robert W. Funk and Ulrich Busse. Translated by Robert W. Funk. 2 vols. Philadelphia: Fortress, 1984. 
Hahn, Scott. "Temple, Sign, and Sacrament: Towards a New Perspective on the Gospel of John.” Letter \& Spirit 4, (2008), 107-143.

Hamid-Khani, Saeed. Revelation and Concealment of Christ: A Theological Inquiry into the Elusive Language of the Fourth Gospel. Tübingen: Mohrs Siebeck, 2000.

Hardee, A. Maynor. Irony and Satire in French Literature. New York: Rodopi, 1987.

Hawkin, David J. "The Johannine Concept of Truth and its Implications for a Technological Society." EQ 59-1, (1987), 3-13.

Hegel, Georg Wilhelm Friedrich. Hegel's Philosophy of Right. Translated by Thomas Malcolm Knox. London: Oxford University Press, 1967.

Heil, John Paul. "Jesus as the Unique High Priest in the Gospel of John." Catholic Biblical Quarterly 57, (1995), 729-745.

Hengel, Martin. The Johannine Question. John Bowden Trans. London: SCM Press, 1989.

. "The Prologue of the Gospel of John as the Gateway to Christological Truth." In The Gospel of John and Christian Theology, edited by Richard Bauckman and Carl Mosser. Grand Rapids: Eerdmans, 2008, 265-294.

Hill, Charles E. The Johannine Corpus in the Early Church. Oxford; Oxford University Press, 2004.

Holland, Glenn S. Divine Irony. London: Associated University Press, 2000.

Hollenbach, Bruce. "Lest They Should Turn and Be Forgiven: Irony." Bible Translator 34.3, (July 1983), 312-321.

Homer. The Odyssey. Ware: Wordsworth, 1992.

Hoskyns, Edwyn C. The Fourth Gospel. 2 vols. London: Faber, 1940.

Houghton, Hugh. Augustine's Text of John. Oxford: Oxford University Press, 2008.

Hunter A. M. The Gospel According to John. The Cambridge Bible Commentary. Cambridge: Cambridge University Press, 1965. . According to John. London: SCM Press, 1968.

Hurtado, Larry W. “Gospel (Genre).” In Dictionary of Jesus and the Gospels, edited by Joel Green, et al. Downers Grove: IVP, 1992, 276-282.

Hutcheon, Linda. Irony's Edge: The Theory and Politics of Irony. New York: Routledge, 1995. . "The Complex Functions of Irony.” Revista Canadiense de Estudios Hispánicos. Vol. 16, No. 2, (1992), 219-234.

Ironside, H. A. John. An Ironside Expository Commentary. Grand Rapids, Kregel, 1920. 
Johnston, George. "Ecce Homo! Irony in the Christology of the Fourth Evangelist." In The Glory of Christ in the New Testament: Studies in Christology, edited by L. D. Hurst, and N. T. Wright Eugene: Wipf and Stock, 1987, 125-138.

Jonsson, Jakob. Humour and Irony in the New Testament. Reykajavík: Bókaútgáfa Menningarsjóos, 1965.

Josephus, Flavius. The Works of Josephus. Translated by William Whiston. Peabody: Hendrickson, 1987.

Kanagaraj Jey J. and Kemp Ian S. The Gospel According to John. Asia Bible Commentary Series. Singapore: Asia Theological Association, 2002.

Kant, Immanuel. Critique of the Power of Judgment. Translated by Paul Guyer and Eric Matthews. Cambridge: Cambridge University Press, 2000.

Keener, Craig S. The Gospel of John. 2 vols. Peabody: Hendrickson, 2003.

Keddie, Gordon J. A Study Commentary on John. 2 vols. Auburn: Evangelical, 2001.

Kelly Anthony J. and Moloney Francis J. Experiencing God in the Gospel of John. New York: Paulist Press, 2003.

Kermode, Frank. "St John as Poet.” JSNT 28, (1986), 3-16.

Kierkegaard, Søren. The Concept of Irony with Continual Reference to Socrates. Translated by Howard V. Hong. Princeton: Princeton University Press, 1989.

Kierspel, Lars. The Jews and the World in the Fourth Gospel. Tubingen: Mohr Siebeck, 2006.

Kim, Stephen S. "The Literary and Theological Significance of the Johannine Prologue." Bibliotheca Sacra 166, (October-December 2009), 421-35.

Kinman, Brent. "Pilate's Assize and the Timing of Jesus' Trial." Tyndale Bulletin 42.2, (1991), 282-295.

Kittredge, Cynthia Briggs. The Gospel of John. New York: Morehouse, 2007.

Klein, Lillian R. The Triumph of Irony in the Book of Judges. Sheffield: Sheffield Academic, 1989.

Klein, William, et al. eds. Introduction to Biblical Interpretation. Nashville: Thomas Nelson, 2004.

Klink, Edward W. III. ed. The Audience of the Gospels. London: T\&T Clark, 2010.

Koester, Craig R. Symbolism in the Fourth Gospel. 2nd ed. Minneapolis: Fortress, 2003. . The Word of Life: A Theology of John's Gospel. Grand Rapids: Eerdmans, 2008. . "Rethinking the Ethics of John." JSNT 36, (July, 2013), 85-98.

Köstenberger, Andreas J. Encountering John: The Gospel in Historical, Literary and Theological Perspective. Grand Rapids: Baker Academic, 1999. 
. John. Baker Exegetical Commentary on the New Testament. Grand Rapids: Baker Academic, 2004.

. ed. A Theology of John's Gospel and Letters. Grand Rapids: Zondervan, 2009.

. The Missions of Jesus and the Disciples According to the Fourth Gospel. Grand Rapids:

Eerdmans, 1998.

. "What is Truth?” Pilate's Question in its Johannine and Larger Biblical Context. JETS 48/1, (March 2005), 33-62.

Kotze, Pieter P. A. “John and Reader's Response.” Neotestamentica 19, (1987), 50-63.

Kruse, Colin G. John. Tyndale New Testament Commentaries 4. Leicester: IVP, 2003.

. The Letters of John. The Pillar New Testament Commentary. Grand Rapids: Eerdmans, 2000 .

Kuyper, Lester J. "Grace and Truth: An Old Testament Description of God, and Its Use in the Johannine Gospel.” Interpretation 18.1, (January 1964), 3-19.

Kysar, Robert John. The Maverick Gospel. Louisville: John Knox, 1993. . Voyages with John: Charting the Fourth Gospel. Waco: Baylor University Press, 2005.

Lanham, Richard A. A Handbook of Rhetorical Terms. 2nd ed. Berkley: University of California Press, 1991.

Larson, Casper Bro. Recognizing the Stranger: Recognition Scenes in the Gospel of John. Leiden: Brill, 2008.

Lee, Dorothy A. Flesh and Glory: Symbolism, Gender and Theology in the Gospel of John. New York: Crossroad, 2002.

. The Symbolic Narratives of the Fourth Gospel. Sheffield: JSOT Press, 1994.

. Hallowed in Truth and Love: Spirituality in the Johannine Literature. Preston: Mosaic, 2011.

Leroy, Herbert. Rätsel und Missverständnis: Ein Beitrag zur Formgeschichte des Johannesevangeliums. Bonn: Hanstein, 1968.

Leung, Mavis M. "The Narrative Function and Verbal Aspect of the Historical Present in the Fourth Gospel.” JETS 51/4, (December 2008), 703-720.

Lewis, Scott M. The Gospel According to John. New Collegeville Bible Commentary. Collegeville: Liturgical Press, 2005.

Lieu, Judith M. "Blindness in the Johannine Tradition.” NTS 34, (1988), 83-95.

Lightfoot, R. H. St John's Gospel: A Commentary. Oxford: Oxford University Press, 1960.

Lincoln, Andrew T. Truth on Trial: The Lawsuit Motif in the Fourth Gospel. Peabody: Hendrickson, 2000. 
. The Gospel According to Saint John. Black's New Testament Commentary IV. New York: Hendrickson, 2005.

. "We Know That His Testimony is True': Johannine Truth Claims and Historicity.” In

John, Jesus and History: Volume 1, Edited by Paul Anderson, et al. Atlanta: SBL, 2007, 179-197.

Lindars, Barnabas, et al. The Johannine Literature. Sheffield: Sheffield Academic, 2000.

. The Gospel of John. The New Century Bible Commentary. Grand Rapids: Eerdmans, 1972.

. Essays on John. Leuven: Leuven University Press, 1994.

. Behind the Fourth Gospel. Saffron Walden: Talbot, 1971.

Lioy, Dan. "The Biblical Concept of Truth in the Fourth Gospel." Conspectus 6, (Sept. 2007), 67-119.

Lücke, Friedrich. Commentar Über Das Evangelium Des Johannes. Bonn: Eduard Weber, 1840.

MacComb, Samuel. “The Irony of Christ.” The Biblical World vol.23, no.2 (1904), 104-109.

MacGregor, G. H. C. The Gospel of John. Moffat New Testament Commentary. London: Hodder and Stoughton, 1953.

MacKay Ian D. John's Relationship with Mark. Tübingen: Mohrs Siebeck, 2004.

MacRae, George W. Invitation to John. New York: Doubleday, 1978.

. "Theology and Irony in the Fourth Gospel." In The Gospel of John as Literature: An Anthology of Twentieth Century Perspectives, edited by Mark Stibbe, Leiden: Brill, 1993, 83-96.

Madou, Jean-Pol. "Ironie Socratique, Ironie Romanesque, Ironie Poetique.” In Irony and Satire in French Literature Vol. 16, edited by Maynor Hardee. New York: Rodopi, 1987, 62-73.

Malina, Bruce J., Rohrbaugh, Richard L. Social-Science Commentary on the Gospel of John. Minneapolis: Fortress, 1998.

Marsh, John. The Gospel of Saint John. Pelican New Testament Commentaries. Harmondsworth: Penguin, 1968.

Marshall, I. Howard. The Epistles of John. The New International Commentary on the New Testament. Grand Rapids: Eerdmans, 1978.

Martin, J. Louis. History and Theology in the Fourth Gospel. 3rd ed. Louisville: John Knox, 2003.

Martinez, Roy. Kierkegaard and the Art of Irony. Amherst: Humanity Books, 2001.

Matson, Mark A. John. Interpretation Bible Studies. Louisville: John Knox, 2002.

McDaniel, Karl. Experiencing Irony in the First Gospel. London: T\&T Clark, 2013. 
Meeks, Wayne. The Prophet-King: Moses Traditions and the Johannine Christology. Leiden: Brill, 1967.

Menke, Cristoph. Tragic Play: Irony and Theatre from Sophocles to Beckett. Translated by James Phillips. New York: Columbia University Press, 2009.

Metzger, Bruce M. A Textual Commentary on the Greek New Testament. 2nd ed. Stuttgart: Deutsche Bibelgesellschaft, 1994.

Metzger, Paul Louis. The Gospel of John. Downers Grove: IVP, 2010.

Muecke, Douglas. C. The Compass of Irony. London: Methuen, 1969. . Irony: The Critical Idiom. London: Methuen, 1970. . Irony and the Ironic. 2nd ed. London: Methuen, 1982.

Michaels, J. Ramsey. The Gospel of John. The New International Commentary on the New Testament. Grand Rapids: Eerdmans, 2010. . John. New International Biblical Commentary. Peabody: Hendrickson, 1989.

Moloney, Francis J. The Gospel of John. Sacra Pagina 4. Collegeville: Liturgical Press, 1998. . Belief in the Word: Reading John 1-4. Eugene: Wipf \& Stock, 1993. . Signs and Shadows: Reading John 5-12. Eugene: Wipf \& Stock, 1996. . Glory Not Dishonor: Reading John 13-21. Eugene: Wipf \& Stock, 1998. . "Johannine Studies in the Australia-Pacific Region." Australian eJournal of Theology 19.1, (April, 2012).

. "Recent Johannine Studies: Commentaries." The Expository Times 123 vol. 7, (2012), 313-322.

. "Recent Johannine Studies: Monographs." The Expository Times 123 vol. 9, (2012), 417428.

. "Who is 'the Reader' in/of the Fourth Gospel?" Australian Biblical Review 40, (1992), 20-33.

. The Resurrection of the Messiah. Mahwah: Paulist Press, 2013.

. Love in the Gospel of John. Grand Rapids: Baker, 2013.

Moody-Adams, Michele. "Theory, Practice, and the Contingency of Rorty's Irony." Journal of Social Philosophy 25, (1994), 209-227.

Morgan, G. Campbell. The Gospel According to John. London: Marshall, Morgan and Scott, 1933.

Morris, Leon. The Gospel According to John. The New International Commentary on the New Testament: 2nd ed. Grand Rapids: Eerdmans, 1995.

. Studies in the Fourth Gospel. Grand Rapids: Eerdmans, 1969. 
Motyer, Stephen. "The Fourth Gospel - An Appeal to Jews.” TynB 45.1, (1994), 201-205. . "Bridging the Gap: How Might the Fourth Gospel Help Us Cope with the Legacy of Christianity's Exclusive Claim over Against Judaism?" In The Gospel of John and Christian Theology, edited by Richard Bauckman and Carl Mosser. Grand Rapids: Eerdmans, 2008, 143-167.

Moule, Charles F. D. Essays in New Testament Interpretation. Cambridge: Cambridge University Press, 1982.

Myers, Doris. "Irony and Humor in the Gospel of John." Occasional Papers in Translation and Textlinguistics 2, (1988), 1-13.

Nagel, Titus. Die Rezeption des Johannesevangeliums im 2. Jahrhundert. Leipzig: Evangelische Verlagsanstalt, 2000.

Nanos, Mark D. The Irony of Galatians: Paul's Letter in First-Century Context. Minneapolis: Augsburg, 2002.

Neeb, Corinna. Exegese von Johannes 2, 1-11 "Die Hochzeit zu Kana" - Das erste Zeichen Jesu. Norderstedt: Druck und Bindung, 2007.

Newheart, Michael Willett. Word and Soul: A Psychological, literary, and Cultural Reading of the Fourth Gospel. Collegeville: Liturgical Press, 2001.

Newman, Barclay, Nida, Eugene. A Handbook on the Gospel of John. New York: UBS, 1980.

Neyrey, Jerome H. The Gospel of John in Cultural and Rhetorical Perspective. Grand Rapids: Eerdmans, 2009. . The Gospel of John. Cambridge: Cambridge University Press, 2007.

- "Despising the Shame of the Cross: Honor and Shame in the Johannine Passion Narrative." Semeia 69, (1996), 113-137.

. "The Trials (Forensic) and Tribulations (Honor Challenges) of Jesus: John 7 in Social Science Perspective.” Biblical Theology Bulletin 26, (1996), 107-124.

. “Jesus the Judge: Forensic Process in John 8:21-59.” Biblica 68, (1987), 509-541. . "'My Lord and My God': the Divinity of Jesus in John's Gospel." SBL Seminar Papers, (1986), 152-171.

. "What's Wrong With This Picture? John 4, Cultural Stereotypes of Women, and Public and Private Space.” Biblical Theology Bulletin 24, (1994), 77-91.

. "Encomium versus Vituperation: Contrasting Portraits of Jesus in the Fourth Gospel." JBL 126, (2007), 529-552.

Niall, Lucy, Postmodern Literary Theory. Oxford: Blackwell, 1997.

Nietzsche, Friedrich. Human All-Too-Human. New York: Dover, 1880. 
. Beyond Good and Evil. Translated by R. J. Hollingdale. London: Penguin, 1990.

Nirenberg, David. Anti-Judaism: The Western Tradition. NewYork: W. W. Norton, 2013.

Nissen, Johanes and Pedersen, Sigfred. eds. New Readings in John: Literary and Theological Perspectives. Sheffield: Sheffield Academic Press, 1999.

O’Day, Gail R. Revelation in the Fourth Gospel. Philadelphia: Fortress, 1986.

. "Narrative Mode and Theological Claim: A Study in the Fourth Gospel." JBL 105/4, (1986), 657-668.

O’Day, Gail R. and Hylen, S. E. John. Westminster Bible Companion. Louisville: Westminster John Knox, 2006.

Okure, Teresa. The Johannine Approach to Mission. Tübingen: Mohr, 1988.

O’Neil, J. C. “The Prologue to St. John's Gospel,” JTS NS 20, (1969), 41-52.

Orton, David E. The Composition of John's Gospel: Selected Studies from Novum Testamentum. Leiden: Brill, 1999.

Osborne, Grant R. The Gospel of John. Cornerstone Biblical Commentary 13. Carol Stream: Tyndale, 2007.

Painter, R. Jackson. The Gospel of John: A Thematic Approach. Eugene: Wipf and Stock, 2011.

Painter, John. The Quest for the Messiah: The History, Literature and Theology of the Johannine Community. Edinburgh: T\&T Clark, 1991.

Parsenios, George L. Departure and Consolation: The Johannine Farewell Discourses in Light of Greco-Roman Literature. Leiden: Brill, 2005.

. Rhetoric and Drama in the Johannine Lawsuit Motif. Tubingen: Mohrs Siebeck, 2010.

Perkins, Robert L. Ed. The Concept of Irony. International Kierkegaard Commentary 2. Macon: Mercer University Press, 2001.

Phillips, John. Exploring the Gospel of John: An Expository Commentary. Grand Rapids: Kregel, 1989.

Philo. The Works of Philo. Translated by C. D. Yonge. Peabody: Hendrickson, 1993.

Poirier, John C. "DDay and Night' and the Sabbath Controversy of John 9." Filologia Neotestamentaria 19, (2006), 113-119.

Poythress, Vern S. "The Use of the Intersentence Conjunctions De, Oun, Kai, And Asyndeton in the Gospel of John.” Novum Testamentum 26/4, (1984), 312-340.

Pratt, D. Butler. "The Gospel of John from the Standpoint of Greek Tragedy." The Biblical World, 30.6, (1907), 448-459. 
Prince, Gerald. "Introduction to the Study of the Narratee." In Reader-Response Criticism:

From Formalism to Post-Structuralism, edited by Jane Tompkins. Baltimore: John Hopkins University Press, 1980, 7-25.

Purdy, Jedediah. For Common Things: Irony, Trust, and Commitment in America Today. New York: Vintage Books, 2000.

Quintilian, Marcus F. Quintilian: The Orator's Education. Edited and translated by Donald A. Russell. 5 vols. Cambridge: Harvard University Press, 2001.

Reardon B. P. ed. Collected Ancient Greek Novels. Berkeley: University of California Press, 2008.

Rein, Matthias. Die Heilung des Blindgeborenen. Tübingen: Mohr, 1995.

Reinhartz, Adele. Befriending the Beloved Disciple: A Jewish Reading of the Gospel of John. New York: Continuum International, 2001.

Rensberger, David K. Johannine Faith and Liberating Community. Philadelphia: Westminster, 1988.

Resseguie, James L. Narrative Criticism of the New Testament. Grand Rapids: Baker, 2005. . The Strange Gospel: Narrative Design and Point of View in John. Leiden: Brill, 2001.

. "A Narrative-Critical Approach to the Fourth Gospel." In Characters and Characterization in the Gospel of John, edited by Christopher W. Skinner (London: T\&T Clark, 2013), 3-17.

Ridderbos, Herman. The Gospel of John: A Theological Commentary. Grand Rapids: Eerdmans, 1997.

Rissi, Mathias. "Jn 1:1-18 (the Eternal Word)." Interpretation 31, (1977), 394-401.

Robbins, Vernon K. "Writing as a Rhetorical Act in Plutarch and the Gospels." In Persuasive Artistry: Studies in New Testament Rhetoric in Honour of George A, Kennedy, edited by D. F. Watson. Sheffield, Sheffield Academic Press, 1991, 142-168.

Robinson John A.T. “The Destination and Purpose of St. John's Gospel.” Twelve New Testament Studies. London: SCM Press, 1962, 117-131.

Ronning, John. The Jewish Targums and John's Logos Theology. Peabody: Hendrickson, 2010.

Rorty, Richard. Contingency, Irony and Solidarity. Cambridge: Cambridge University Press, 1989.

Ruckstuhl, Eugen. Die Literarische Einheit des Johannesevangeliums: der Gegenwärtige Stand der Einschlägigen Forschung. Freiburg: Paulus, 1951.

Ruprecht, Louis A. This Tragic Gospel: How John Corrupted the Heart of Christianity. San Fransico: Jossey-Bass, 2008. 
Sadananda, Daniel Rathnakara. The Johannine Exegesis of God: An Exploration into the Johannine Understanding of God. Berlin: Walter de Grutyer, 2004.

Salmon, George. A Historical Introduction to the Study of the Books of the New Testament. 7th ed. Dublin: University Press, 1894.

Sanders E. P. Judaism: Practice and Belief 63 BCE-66 CE. London: SCM, 1992.

Sanders, Joseph N. The Fourth Gospel in the Early Church: Its Origin and Influence on Christian Theology Up to Irenaeus. Cambridge: Cambridge University Press, 1943.

Schaan, Philipp. Die Heilung eines Blindgeborenen (Joh 9). Norderstedt: Druck und Bindung, 2012.

Scherman, Nosson and Zlotowitz, Meir. eds. The Family Haggadah. Translated by Nosson Scherman. New York: Mesorah, 2004.

Schnackenburg, Rudolf. The Gospel According to St John. 3 vols. New York: Crossroad, 1968.

Schneiders, Sandra M. Written That You May Believe: Encountering Jesus in the Fourth Gospel. New York: Crossroad, 2003.

Schnelle, Udo. "Recent Views of John's Gospel." Word \& World, Vol. 21.4, (Fall 2001), 352359.

Searle, John. "Literary Theory and its Discontents," New Literary History 25, (1994), 637-667.

- Speech Acts: An Essay in the Philosophy of Language. Cambridge: Cambridge University Press, 1969.

Sedgewick, G. G. Of Irony: Especially in Drama. Vancouver: Ronsdale, 2003.

Segovia, Fernando F. ed. "What is John?” Readers and Readings of the Fourth Gospel. 2 vols. Atlanta: SBL, 1996, 1998.

. "The Journey(s) of the Word of God: A Reading of the Plot of the Fourth Gospel." In Semeia 53: The Fourth Gospel From A Literary Perspective, edited by Alan Culpepper and Fernando Segovia. Atlanta: SBL, 1991, 23-54.

Senior, Donald. The Passion of Jesus in the Gospel of John. Collegeville: Liturgical Press, 1991.

Sharp, Carolyn J. Irony and Meaning in the Hebrew Bible. Bloomington: Indiana University Press, 2009.

Skinner, Christopher W. Ed. Characters and Characterization in the Gospel of John. London: T\&T Clark, 2013.

Skinner, Matthew L. The Trial Narratives. Louisville: Westminster John Knox, 2010.

Sloyan, Gerard S. Jesus on Trial: A Study of the Gospels. 2nd ed. Minneapolis: Fortress, 2006. . John. Interpretation Commentary for Teaching and Preaching. Atlanta: John Knox, 1988.

Smalley, Stephen S. John: Evangelist and Interpreter. 2nd ed. Downers Grove: IVP, 1998. 
. 1, 2, 3 John. Word Biblical Commentary 51. Nashville, Thomas Nelson, 2007.

Smith, Kym. The Amazing Structure of the Gospel of John. Blackwood: Sherwood, 2005.

Smith, Moody D. The Fourth Gospel in Four Dimensions. Columbia, University of South Carolina Press, 2008.

Søltof, Pia. "Ethics and Irony," In The Concept of Irony. International Kierkegaard Commentary

2. edited by Robert L. Perkins. Macon: Mercer University Press, 2001, 265-288.

Sophocles, The Theban Plays. New York: Penguin, 1984.

Staley, Jeffrey Lloyd. The Print's First Kiss: A Investigation of the Implied Reader in the Fourth Gospel. Atlanta: Scholars Press, 1988.

. Reading with a Passion: Rhetoric, Autobiography, and the American West in the Gospel of John. New York: Continuum, 1995.

Sternberg, Meir. Expositional Modes and Temporal Ordering in Fiction. Baltimore: John Hopkins University Press, 1978.

Stevick, Daniel B. Jesus and His own: A Commentary on John 13-17. Grand Rapids: Eerdmans, 2011.

Stewart, Roy A. "Judicial Procedure in New Testament Times." Evangelical Quarterly 47.2, (1975), 94-109.

Stibbe, Mark W. G. John as Storyteller: Narrative Criticism and the Fourth Gospel. Cambridge: Cambridge University Press, 1992.

. The Gospel of John as Literature: An Anthology of Twentieth Century Perspectives. Leiden: Brill, 1993. . John's Gospel: New Testament Readings. New York: Routledge, 1994.

Stovell, Beth M. Mapping Metaphorical Discourse in the Fourth Gospel. Leiden: Brill, 2012.

Strecker, Georg. Literaturgeschichte des Neuen Testaments. Göttingen: Vandenhoeck \& Ruprecht, 1992.

Stott, John R. W. The Letters of John. Grand Rapids: Eerdmans, 1988.

Strohschneider-Kohrs, Ingrid. Die Romantische Ironie in Theorie und Gestaltung. Tübingen: Niemeyer, 2002.

Talbert, Charles H. Reading John: A Literary and Theological Commentary on the Fourth Gospel and the Johannine Epistles. Macon: Smyth \& Helwys, 2005. . What is a Gospel?: The Genre of the Canonical Gospels. Philadelphia: Fortress, 1977.

Tasker, R. V. G. John. Tyndale New Testament Commentaries 4. Leicester: IVP, 1960.

Tenney, Merrill C. John: An Analytical Study of the Text. Grand Rapids: Eerdmans, 1976. . John. The Expositors Bible Commentary 9. Grand Rapids: Zondervan, 1981. 
. “The Meaning of 'Witness' in John.” Bibliotheca Sacra 132, (July 1975), 229-241.

. "Literary Keys to the Fourth Gospel: The Imagery of John.” Bibliotheca Sacra 121, (Jan. 1964), 13-21.

Thatcher, Tom. "The Sabbath Trick: Unstable Irony in the Fourth Gospel." JSNT 76, (1999), 53-77.

. ed. What We Have Heard From the Beginning: The Past, Present and Future of Johannine Studies. Waco: Baylor University Press, 2007.

. ed. Jesus the Voice, and the Text: Beyond the Oral and Written Gospel. Waco: Baylor University Press, 2008.

. Jesus the Riddler: The Power of Ambiguity in the Gospels. Louisville: John Knox, 2006.

. Greater Than Caesar: Christology and Empire in the Fourth Gospel. Minneapolis:

Fortress, 2009.

. Why John Wrote a Gospel. Louisville: John Knox, 2006.

Thatcher, Tom and Moore Stephen D. eds. Anatomies of Narrative Criticism: The Past, Present, and Future of the Fourth Gospel as Literature. Atlanta: SBL, 2008.

Thayse, André. Jean L'évangile Revisité. Paris: Le Cerf, 2001.

Theodore of Mopsuestia. Commentary on the Gospel of John. Ancient Christian Text. Translated by Marco Conti, Edited by Thomas C. Oden and Gerald L. Bray. Downers Grove: IVP, 2010.

Theissen, Gerd. The Gospels in Context. London: T\&T Clark, 1992.

Thiselton, Anthony C. "Truth," In The New International Dictionary of New Testament Theology, edited by Colin Brown. 4 vols. Grand Rapids: Zondervan, 1978, 3.874-902.

Thomson, James A. K. Irony: A Historical Introduction. London: Allen \& Unwin, 1926.

Thompson, Marianne Meye. The God of the Gospel of John. Grand Rapids: Eerdmans, 2001. . "Signs and Faith in the Fourth Gospel." Bulletin for Biblical Research 1, (1991), 89-108.

Thyen, Hartwig. Das Johannes-evangelium. Handbuch zum Neuen Testament 6. Tübingen: Mohrs Siebeck, 2005.

Tolbert, Mary A. “A Response from a Literary Perspective," In Semeia 53: The Fourth Gospel from a Literary Perspective, edited by Alan Culpepper and Fernando Segovia. Atlanta: SBL, 1991, 203-211.

Tompkins, Jane P. (Ed.) Reader-Response Criticism: From Formalism to Post-Structuralism. Baltimore: John Hopkins University Press, 1980.

Tovey, Derek. Narrative Art and Act in the Fourth Gospel. Sheffield: Sheffield Academic, 1997. 
. "Narrative Strategies in the Prologue and the Metaphor of ò $\lambda$ ó $\gamma \circ \varsigma$ in John's Gospel", Pacifica 15/2, (2002), 138-153.

. Jesus, Story of God: God's Story of Jesus. Hindmarsh: ATF Press, 2007.

Trites, Alison A. The New Testament Concept of Witness. Cambridge: Cambridge University Press, 1977.

Tsutserov, Alexander. Glory, Grace and Truth: Ratification of the Sinaitic Covenant According to the Gospel of John. Eugene: Pickwick, 2009.

Twelftree. Graham H. Jesus the Miracle Worker: A Historical and Theological Study. Downers Grove: IVP, 1999.

Twomey, Jay. “Reading Derrida's New Testament: A Critical Appraisal.” Biblical Interpretation 13.4 (2005), 374-403.

Um, Stephen T. The Theme of Temple Christology in John's Gospel. London: T\&T Clark, 1988.

Vasiliou, Iakovos. "Conditional Irony in the Socratic Dialogues.” The Classical Quarterly vol.49 no.2 (1999), 456.

Volf, Miroslav. Exclusion and Embrace: A Theological Exploration of Identity, Otherness, and Reconciliation. Nashville: Abingdon, 1996.

Von Wahlde, Urban C. The Gospel and Letters of John. Eerdmans Critical Commentary. 3 Vols. Grand Rapids: Eerdmans, 2010.

Vos, Geerhardus. "True and Truth in Johannine Writings.” The Biblical Review 12, (1927), 507520.

Vouga, Francois. Le Cadre Historique et L'intention Théologique de Jean. Paris: Éditions Beauchese, 1977.

Wead, David W. "Johannine Irony as a Key to the Author-Audience Relationship in John's Gospel." In American Academy of Religion Biblical Literature: 1974, edited by Fred O. Francis. Missoula: Scholars Press, 1974, 33-50.

Wengst, Klaus. Das Johannes-evangelium. Theologischer Kommentar zum Neuen Testament 4.1-2. 2 vols. Stuttgart: Kohlhammer, 2000.

Westcott, B. F. The Gospel According to St John. London: John Murray, 1882.

Westermann, Claus. The Gospel of John: In the Light of the Old Testament. Peabody: Hendrickson, 1998.

Whitacre, John A. John. The IVP New Testament Commentary Series 4. Downers Grove: IVP, 1999.

Wiarda, Timothy. Peter in the Gospels: Pattern, Personality and Relationship. Tübingen: Mohr Siebeck, 2000. 
Wilckens, Ulrich. Das Evangelium nach Johannes. Das Neue Testament Deutsch 4. Göttingen: Vandenhoeck \& Ruprecht, 2000.

Wiles, Maurice F. The Spiritual Gospel: The Interpretation of the Fourth Gospel in the Early Church. Cambridge: Cambridge University Press, 1960.

Wilkinson, Loren. "Hermeneutics and the Postmodern Reaction Against 'Truth'," The Act of Bible Reading: A Multi-disciplinary Approach to Biblical Interpretation, edited by Elmer Dyck. Downers Grove: IVP, 1996, 114-147.

Winokur, Jon. The Big Book of Irony. New York: St. Martin's, 2007.

Winter, Dorian. Das Verhältnis zwischen der Gestalt Mose und Jesus im Johannesevangelium. Norderstedt: Druck und Bindung, 2013.

Winter, Paul. On the Trial of Jesus. 2nd ed. Berlin: Walter de Gruyter, 1974.

Witherington, Ben. John's Wisdom: A Commentary on the Fourth Gospel. Louisville: Westminster John Knox, 1995.

Wolfsdorf, David. "The Irony of Socrates." The Journal of Aesthetics and Art Criticism. 65.2 (2007), 175-187.

Wright, Tom. John for Everyone. 2 vols. Westminster: John Knox, 2002.

Wroe, Ann. Pontius Pilate. New York: Random House, 2001.

Yak-Hwee, Tan. Re-Presenting the Johannine Community: A Postcolonial Perspective. New York: Peter Lang, 2008.

Yarbrough Robert W. 1-3 John. Baker Exegetical Commentary on the New Testament. Grand Rapids: Baker Academic, 2008.

Yarnold, Edward. Cyril of Jerusalem. London: Routledge, 2000.

Zimmermann, Ruben. Christologie der Bilder im Johannesevangelium. Tübingen: Mohrs Siebeck, 2004.

Zumstein, Jean. L'évangile Selon Saint Jean (13-21). Geneva: Labor et Fides, 2007. 